\title{
Using Structural Geology and Cosmogenic Nuclide Dating to Infer the Slip Rate and Frictional Strength of the Active Mai'iu Low-Angle Normal Fault, Eastern Papua New Guinea
}

\author{
By \\ Samuel McKeever Webber
}

\begin{abstract}
A thesis
submitted to Victoria University of Wellington

in partial fulfilment of the requirements for the degree of

Master of Science

in Geology
\end{abstract}

School of Geography, Environment and Earth Sciences

Victoria University of Wellington

2017 


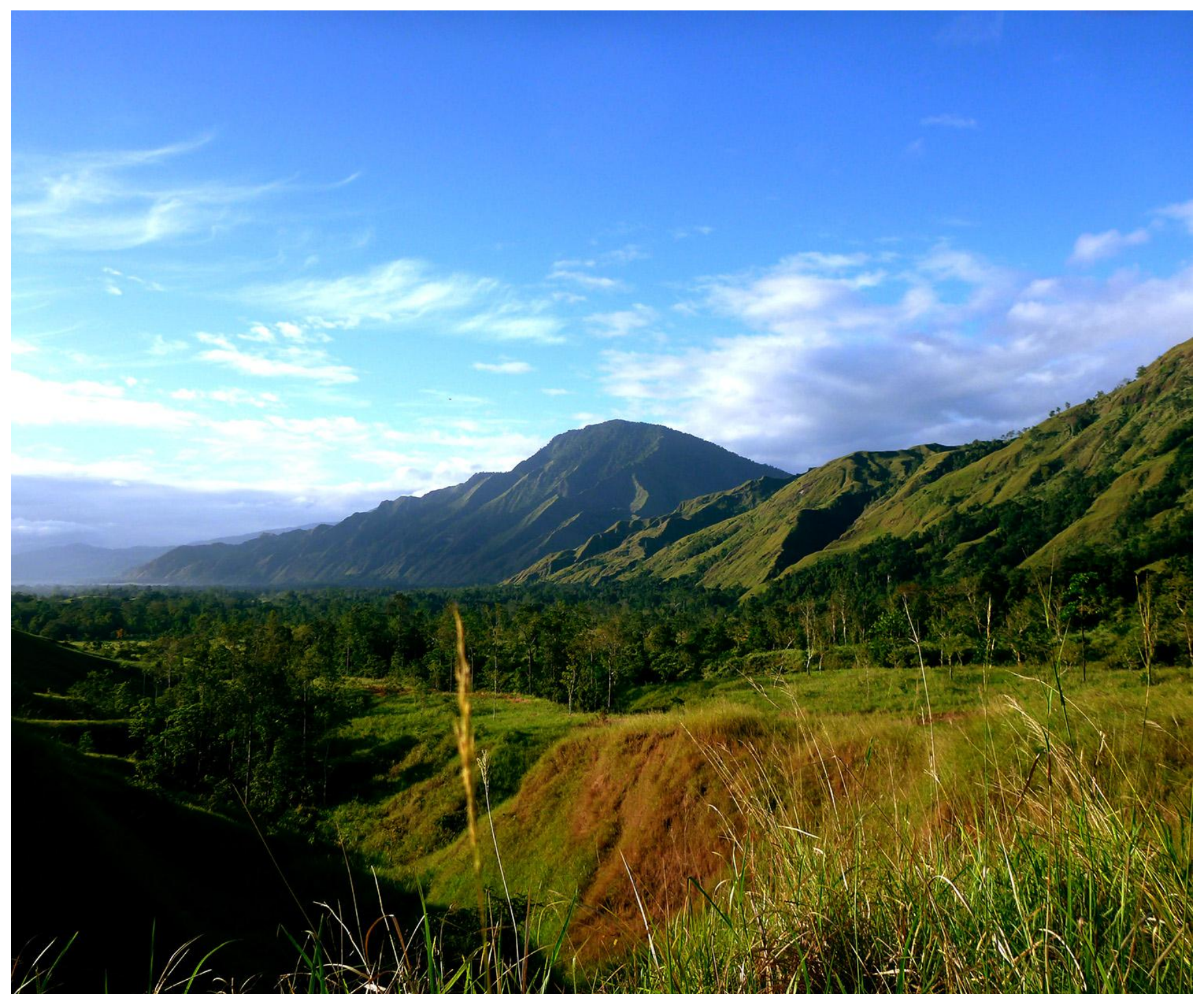

Frontispiece: $\quad$ East-facing view of the Gwoira Fault, an active detachment and splay of the Mai'iu Fault, Eastern Papua New Guinea. 


\section{Abstract}

Low-angle normal faults (LANFs) have induced debate due to their apparent non-Andersonian behaviour and lack of significant seismicity associated with slip. Dipping $21^{\circ} / \mathrm{N}$, the Mai'iu Fault, located in the Woodlark Rift, Eastern Papua New Guinea is an active LANF that occupies a position at the transition between continental extension and seafloor spreading. Surface geomorphology indicates that the Mai'iu Fault scarp is not significantly eroded despite high rainfall and $\sim 2900 \mathrm{~m}$ of relief. Based on modelling of regional campaign GPS data (Wallace et al., 2014) the Mai'iu Fault is thought to accommodate rapid (7-9 $\mathrm{mm} / \mathrm{yr}$ ) horizontal extension; however the slip rate of the Mai'iu Fault has not been directly validated. I use a range of methodologies, including field mapping, cosmogenic exposure dating, cosmogenic burial dating, and Mohr-Coulomb modelling, in order to provide new constraints on LANF strength and slip behaviour.

I analyse the structure of conglomeratic strata within a back-rotated rider block atop the Mai'iu Fault surface. The Gwoira rider block is a large fault-bounded sedimentary rock slice comprising the Gwoira Conglomerate, located within a large synformal megamullion in the Mai'iu Fault surface. The Gwoira Conglomerate was originally deposited on the Mai'iu Fault hanging wall concurrent with extension, and has since been buried to a maximum depth of $\sim 2 \mathrm{~km}$ (evidenced by modelling of vitrinite reflectance data, and structural analysis), back-tilted, and synformally folded.

The Mai'iu Fault is also overlain by a large fault slice (the Gwoira rider block), that has been transferred from the previous LANF hanging wall to the current footwall by the initiation of the younger Gwoira Fault. Both the Gwoira Conglomerate (former hanging wall) and mylonitic foliation (footwall) of the Mai'iu Fault have been shortened $\sim \mathrm{E}-\mathrm{W}$, perpendicular to the extension direction. I show that N-S trending synformal folding of the Gwoira Conglomerate was concurrent with on-going sedimentation and extension on the Mai'iu Fault. Structurally shallower Gwoira Conglomerate strata are folded less than deeper strata, indicating that folding was progressively accrued concurrent with $\sim \mathrm{N}-\mathrm{S}$ extension. I also show that abandonment of the inactive strand of the Mai'iu Fault in favour of the Gwoira Fault, which resulted in formation of the Gwoira rider block, occurred in response to progressive megamullion amplification and resultant misorientation of the inactive strand of the Mai'iu Fault. I attribute N-S trending synformal folding to extension-perpendicular constriction. This is consistent with numerous observations of outcropscale conjugate strike-slip faults that deform the footwall and hanging wall of the Mai'iu Fault (Little et al., 2015), and accommodate E-W shortening. Constrictional folding remains active in the near-surface as evidenced by synformal tilting of inferred Late Quaternary fluvial terraces atop the Gwoira rider block. In order to date this sequence of progressive constrictional folding, I have processed ten ${ }^{26} \mathrm{Al} /{ }^{10} \mathrm{Be}$ terrestrial 
cosmogenic nuclide burial samples obtained from the Gwoira Conglomerate; unfortunately these data were not yet available at the time of printing, due to reasons outside of my control.

I also present terrestrial cosmogenic nuclide (TCN) exposure ages for ten rock samples obtained from the lowermost Mai'iu Fault scarp at Biniguni Falls, in order to determine the Holocene slip-rate and style using cosmogenic ${ }^{10} \mathrm{Be}$ in quartz. I model exposure age data after the approach of Schlagenhauf et al. (2011), using a Monte-Carlo simulation in which fault slip rate, the period of last slip on the fault, and local erosion rate are allowed to vary. Modelling evidences that the Mai'iu Fault at Biniguni Falls is active and slipping at $13.9 \pm 4.0 \mathrm{~mm} / \mathrm{yr}(1 \sigma)$, resolved over the last $13.2 \pm 2.7 \mathrm{ka}(1 \sigma)$. Modelling constrains the time of last slip to $2.9 \pm 1.4 \mathrm{ka}(1 \sigma)$; this is consistent with a seismic event at that time, followed by non-slip on the Mai'iu Fault until the present day.

Finally, because rider block formation records abandonment of the uppermost part of a LANF, Coulomb fault mechanical analysis can be applied to field observations to provide an upper limit on LANF frictional strength $\left(\mu_{\mathrm{f}}\right)$. Calculations are made in terms of Mohr-Coulomb mechanics, after the framework of Choi and Buck (2012). The lock-up (abandonment) orientation at any particular position on the Mai'iu Fault is principally a function of fault friction $\left(\mu_{f}\right)$, crustal friction $\left(\mu_{c}\right)$, fault cohesion $\left(C_{f}\right)$, crustal cohesion $\left(C_{c}\right)$, depth, fault orientation, fluid pressure, and the orientation of the greatest principle stress. Model results suggest that fault friction for the active Gwoira-Mai'iu Fault surface is $0.128 \leq \mu_{\mathrm{f}} \leq 0.265$ for $\mathrm{C}_{\mathrm{f}}<1.8 \mathrm{MPa}$, and $0.2 \leq \mu_{\mathrm{f}} \leq 0.265$ for $\mathrm{C}_{\mathrm{f}} \leq 0.5 \mathrm{MPa}$. Modelling of abandonment of the inactive Mai'iu Fault suggests that $0.26 \leq \mu_{\mathrm{f}} \leq 0.309$ for $\mathrm{C}_{\mathrm{f}}<1.8 \mathrm{MPa}$. This suggests that past slip on the inactive Mai'iu Fault, and continued slip on the active Gwoira-Mai'iu Fault, were enabled by low fault frictional strength. I also model the strength of the active Mai'iu Fault at Biniguni Falls; results suggest greater LANF friction $\left(\mu_{\mathrm{f}} \geq 0.32\right)$ than the GwoiraMai'iu Fault surface, and inactive Mai'iu Fault. In order to explain active slip on the LANF at Biniguni Falls concurrent with widespread field observations of outcrop-scale faulting of the LANF footwall, I suggest a process whereby overall the LANF remains viable and active, but locally stress conditions exceed the LANF abandonment criteria; this results in highly localised and temporary 'footwall damage' where the LANF footwall is locally dissected by outcrop-scale faulting. 


\section{Acknowledgements}

I have been supported in my studies by a big team of awesome people! So many people have helped me and provided input to my work, and I will do my best to acknowledge you all.

My sincere thanks go to my two co-supervisors, Tim Little and Kevin Norton. Tim's office door is always open, and he has given up a huge amount of time to support this study. Tim also personally organised the vast majority of the logistics involved with organising the three field seasons (2014-2016). Kevin has also lent a great deal of support, having spent many hours guiding me with lab work, aiding in the processing and interpretation of data, and answering my many, many questions. Kevin also developed the program for modelling fault slip rates, and performed structure-from-motion analysis of the Mai'iu Fault scarp at Biniguni Falls.

It is important to note that this thesis is part of a much larger project, led by Tim Little, Diane Seward, and Kevin Norton, and involving a wide range of New Zealand and overseas collaborators. This work was funded by Marsden Grant VUW1310. I was also supported by Marsden Grant VUW1310, and by an RSNZ Student Travel Grant, to present at the AGU 2015 Fall Meeting (presentation T43C-3022).

Two PhD students also working on the Mai'iu Fault, Marcel Mizera and Jürgen Öesterle, have contributed much to this project, from hard work in the field over two seasons, to late nights throwing ideas around. Cheers guys!

A huge thanks go to all my field buddies! I was accompanied in the field at various times over two separate field seasons by Tim Little, Kevin Norton, Marcel Mizera, Jürgen Öesterle, Susan Ellis, Laura Wallace, James Biemiller, and Danny Stockli. Diane Seward also contributed to the planning of field logistics and sampling. These guys were awesome, and showed their mettle on many an occasion.

I am grateful to Nathan Daczko and Peter Caffi for allowing me to use their field observations; Nathan was extremely forthcoming with advice regarding their structural data and field observations. I appreciate help provided by lan Smith and Hugh Davies, who provided copies of their unpublished field notes. I appreciate the help of Paul Mann and Fred Taylor, who provided unpublished uplift rates from exposed corals from along the coast of Goodenough Bay. Thanks go to David Lindley for his help acquiring several reports, and for his advice regarding field logistics. Additional thanks go to Susan Ellis for answering various modellingrelated questions. Thanks a bunch to Jane Newman for being kind enough to measure vitrinite reflectance free of charge, and for providing helpful advice regarding its interpretation. Thanks also to David Bennett for his advice regarding coal sample processing and data analysis. Thanks to Brian Anderson and Kevin Norton for generating the Structure-From-Motion models and DEMs. 
I want to thank all the friendly people we met in Papua New Guinea, who were so kind and generous to us. Unfortunately there are far too many to list in full. I particularly want to thank Colin for accommodating us in Biniguni, accompanying us, helping with our political negotiations, and for being so supportive of our work. Thank you Paul and Ethyl for accommodating us at Rakau and for cooking such amazing food. Thank you to James Benson Aniton for accommodating us at his house in Pumani, and for accompanying us in the field. Thanks to our other hosts who accommodated us at various times, and thank you to all the landowners who allowed us to work on their land. My sincere thanks go to all our PNG carriers without whose help our work could not have happened. A big thank you to my 2015 carriers, Windom, Stanley and Steven; and to all our 2016 carriers Andrew, Jerome, Harold, Gabriel, Mark, Judah, Steven, Danziel, Tennyson, Phineas, Amos, Derek, James, Vera, Livingston, Jamie, McLaren, Gabriel, Vincent, and one other whose name I do not have recorded (sorry!). You guys were awesome.

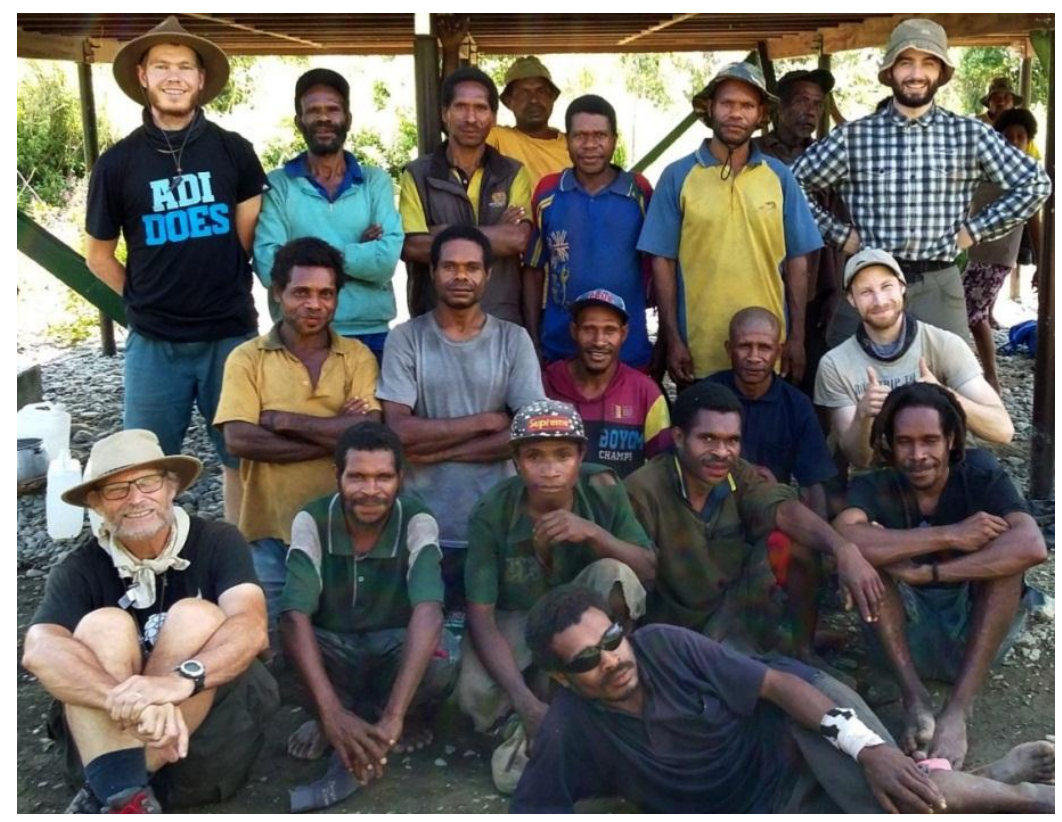

Photo: The team from our June 2016 Bonenau-Biniguni traverse.

I want to thank my family and friends who have supported me through this thesis - my love to you all! This fantastic, expansive team has helped me through two hip operations, and have helped in so many tangible and intangible ways. Cheers to all the postgrads, staff and undergrads around the department for keeping me (mostly) sane. Thanks to all my kind hosts who accommodated me while on the road. Thank you to my proof-readers Emily and Hamish - I really appreciate the help, and I owe you big time! Mum and Dad have offered so much love and support, which I cannot hope to sum up. Finally, Emily, who is the greatest. She has been so, so supportive of my work, and has worked so hard to allow me to focus on this stack of words, for which I am eternally grateful. 


\section{Dedication}

To my parents, who are so awesome, and who have stuck by me through and through. 


\section{Table of Contents}

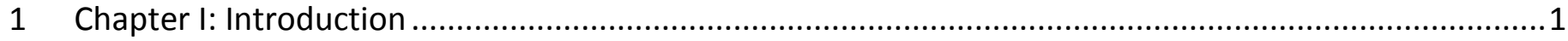

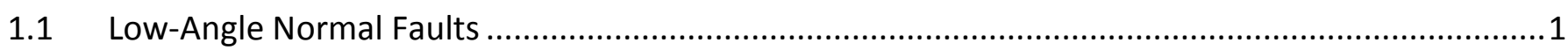

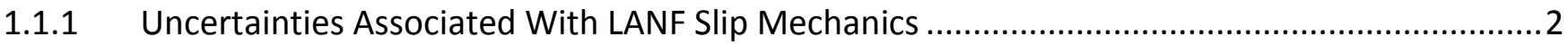

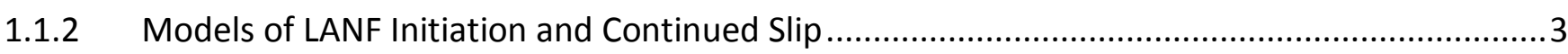

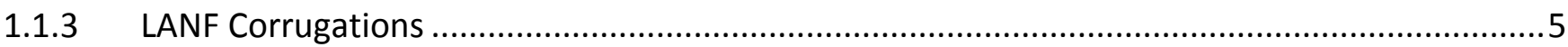

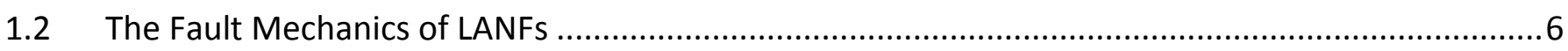

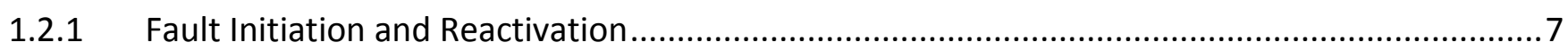

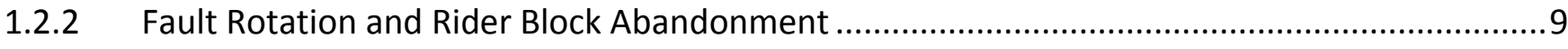

1.3 Cosmogenic Nuclides and Dating Methodology .................................................................... 11

1.3.1 Overview of Cosmic Radiation and Cosmogenic Nuclides...................................................11

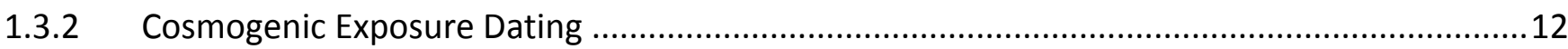

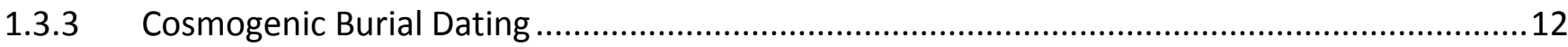

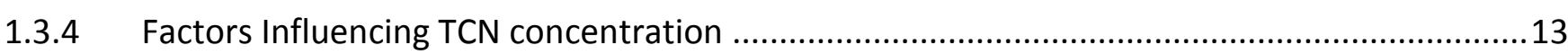

1.4 Motivation and Research Objectives of This Thesis.................................................................14

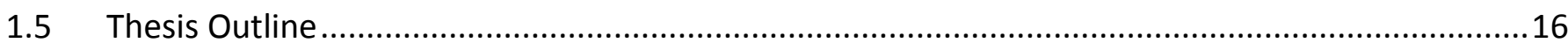

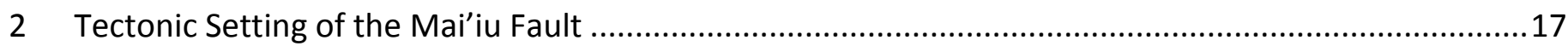

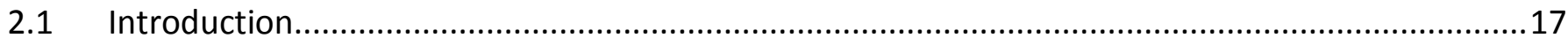

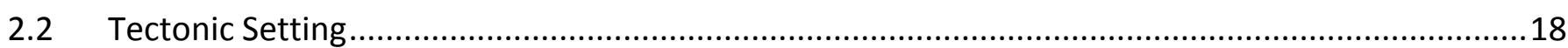

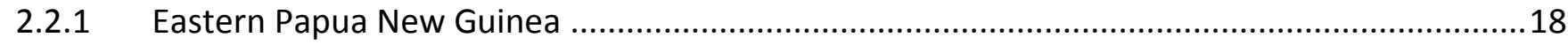

2.2.2 The Papuan Peninsula and the Woodlark Rift ....................................................................19

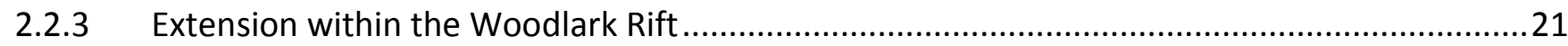

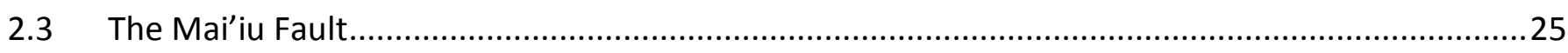

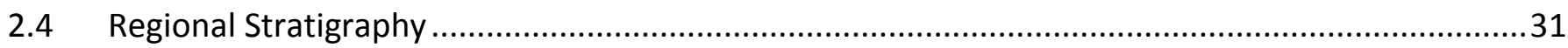

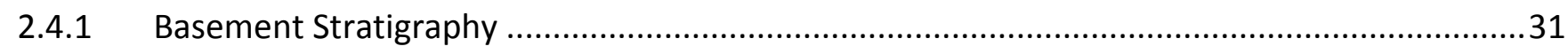

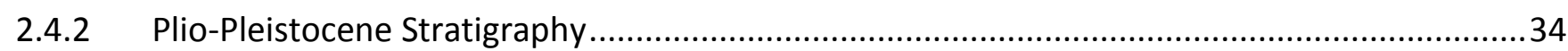

2.5 Cenozoic Tectonic Evolution of the Papuan Peninsula .............................................................36

2.5.1 Early Paleocene-Early Eocene Coral Sea Rifting................................................................36

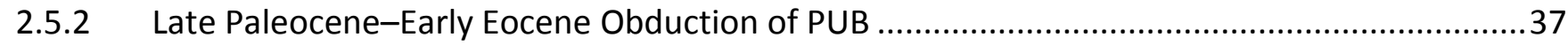

2.5.3 Eocene-Present (?) North Solomon Trench Subduction .........................................................38

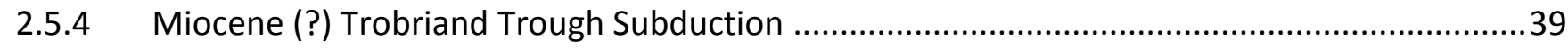

2.5.5 Middle Miocene (?) Subduction at Pocklington Trough .....................................................40

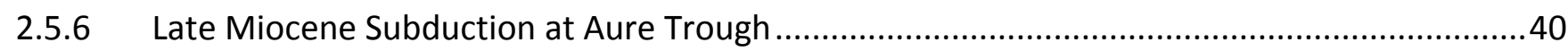

2.5.7 Middle Miocene (?) Obduction of the Kutu Volcanics........................................................40

2.5.8 Middle Miocene-Present Subduction at the New Britain and San Cristobal Trenches ............42

2.5.9 Late Miocene-Recent Oceanic Spreading and Rifting....................................................42

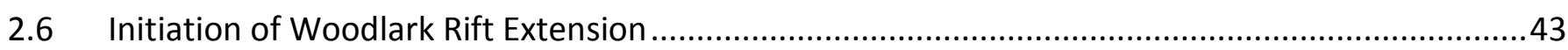

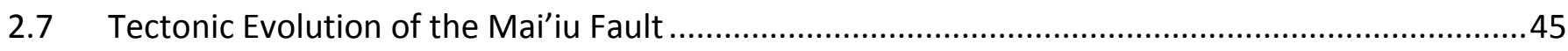

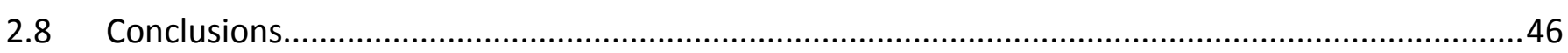

3 Chapter 3: Stratigraphy and Structure of the Gwoira Embayment.....................................................48

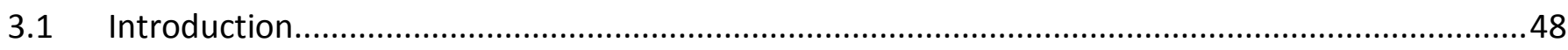

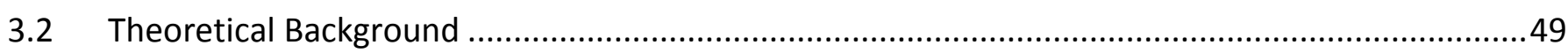

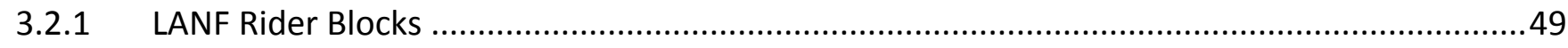




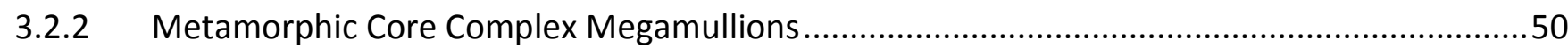

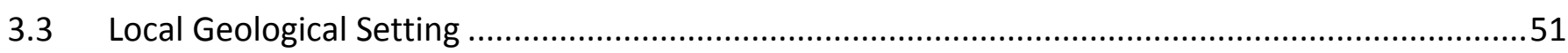

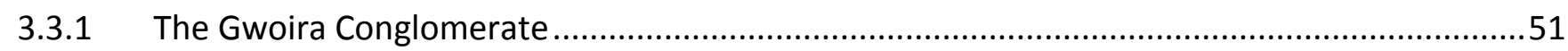

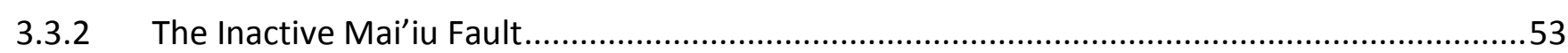

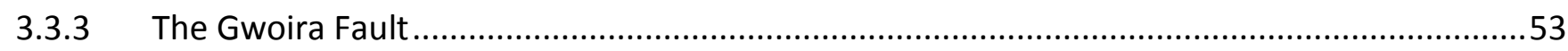

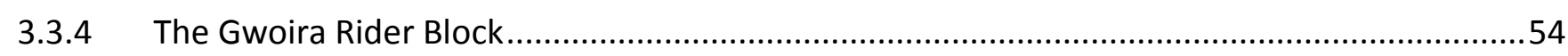

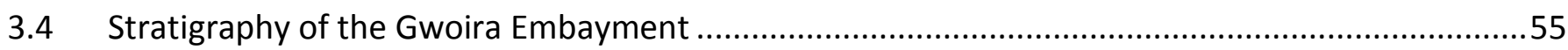

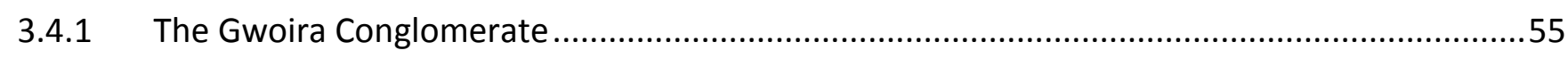

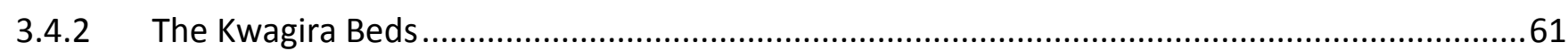

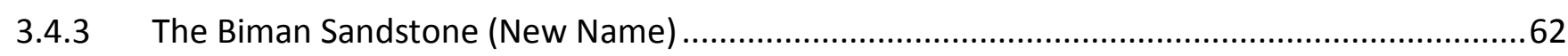

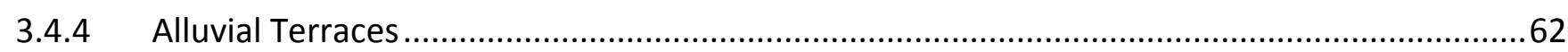

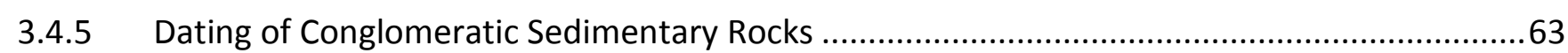

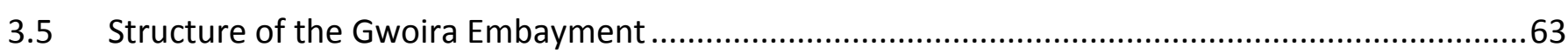

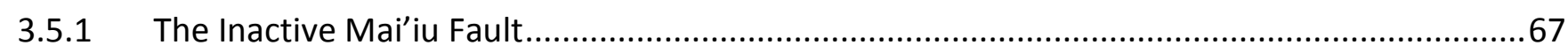

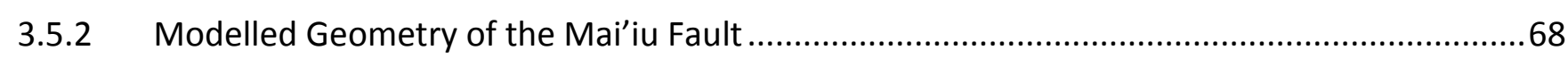

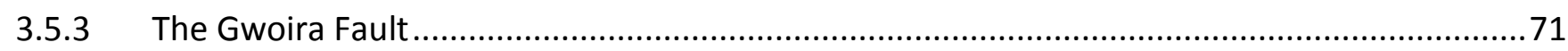

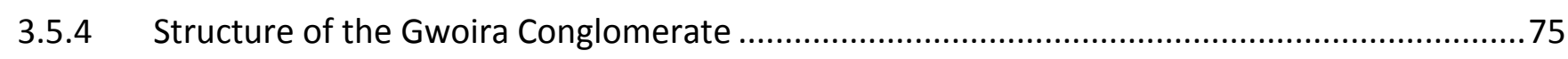

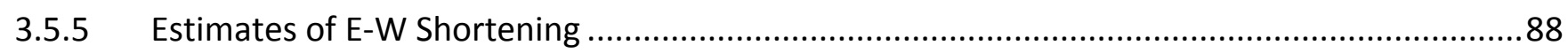

3.5.6 Maximum Burial Depth of the Gwoira Conglomerate.........................................................91

3.5.7 Structure of Late Quaternary (?) Deposits atop the Gwoira Rider Block .................................95

3.5.8 Fluvial Geomorphology of the Gwoira Embayment and Inactive Mai'iu Fault Footwall ..........99

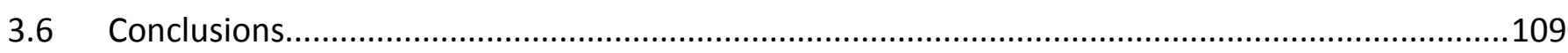

4 Chapter 4: The Pliocene to Recent Tectonic Evolution of the Gwoira Embayment ...........................112

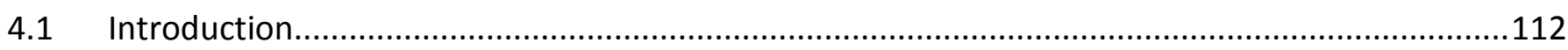

4.2 Theories of MCC Megamullion Formation and Amplification ...................................................113

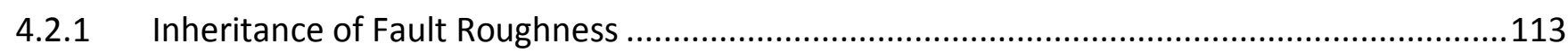

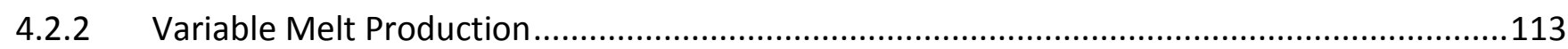

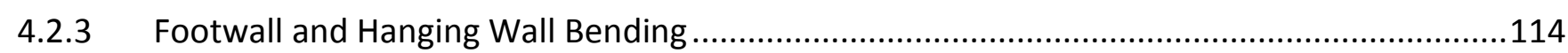

4.2.4 Buckle Folding and Amplification within a Constrictive Stress Regime..............................114

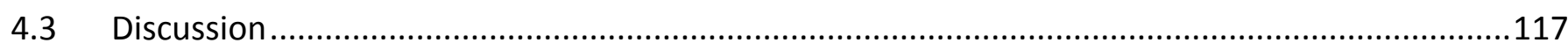

4.3.1 Synclinal Folding of the Gwoira Embayment ................................................................117

4.3.2 The Timing of Onset of Motion on the Mai'iu Fault .............................................................119

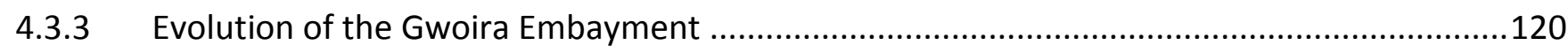

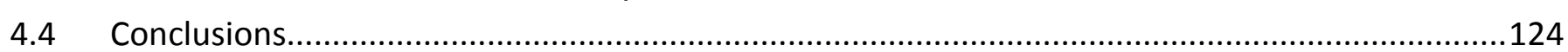

5 Chapter 5 - Slip Rate and Style of the Active Mai'iu Fault West of Pumani ......................................125

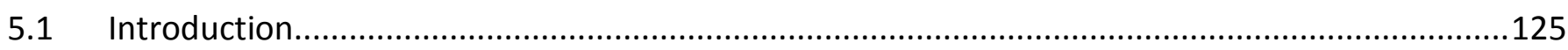

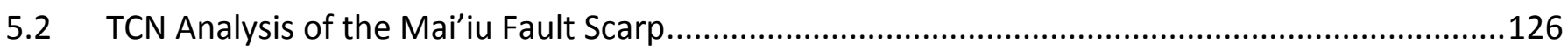

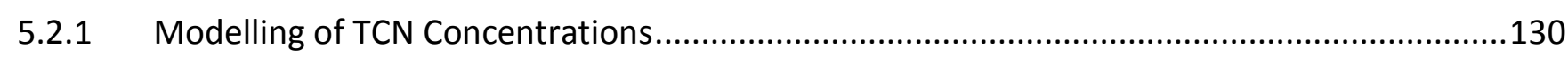

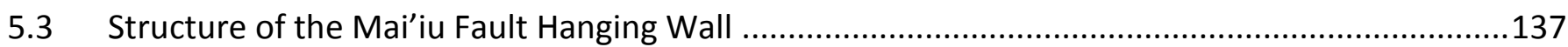

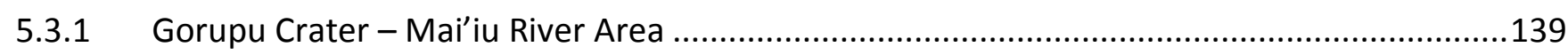

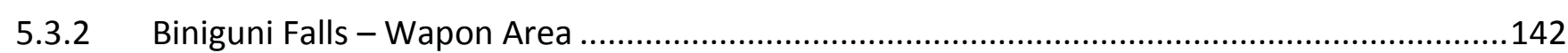

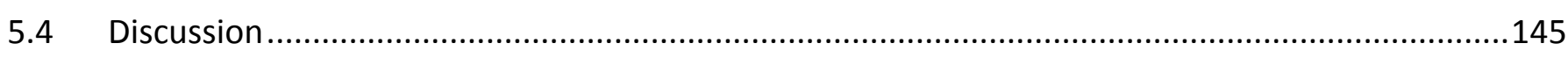

5.4.1 Slip Rate of the Mai'iu Fault at Biniguni Falls .................................................................. 145

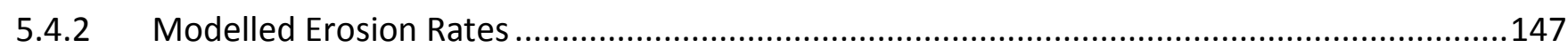




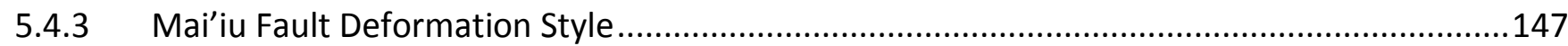

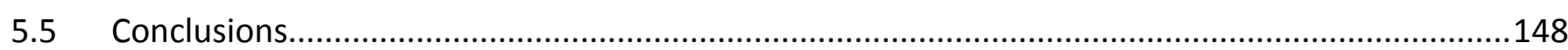

6 Chapter 6: Mohr-Coulomb Modelling of the Mai'iu and Gwoira Faults ............................................149

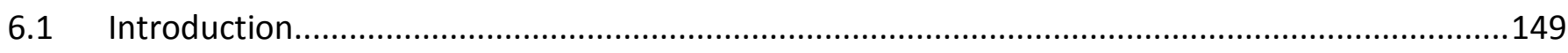

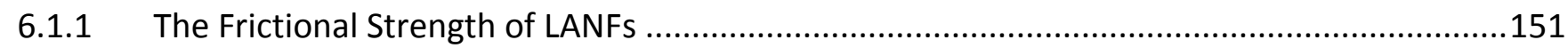

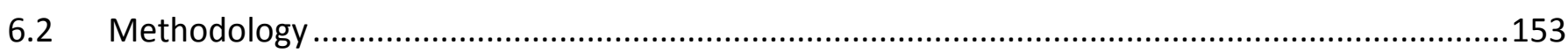

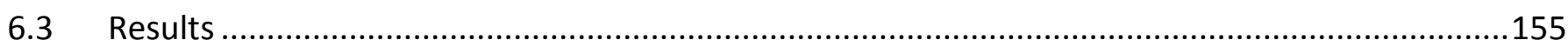

6.3.1 Strength of the Active Gwoira-Mai'iu Fault Surface .......................................................... 155

6.3.2 Strength of the Inactive Mai'iu Fault Surface ................................................................... 156

6.3.3 Strength of the Active Mai'iu Fault at Biniguni Falls............................................................159

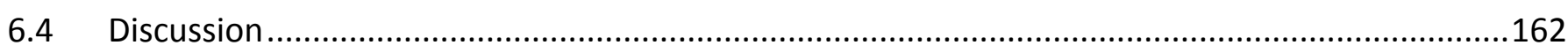

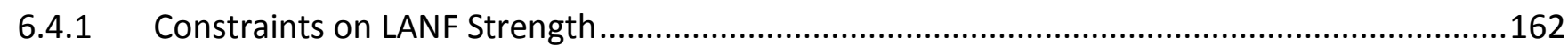

6.4.2 Deformational Style of the Active Mai'iu Fault at Biniguni Falls .......................................163

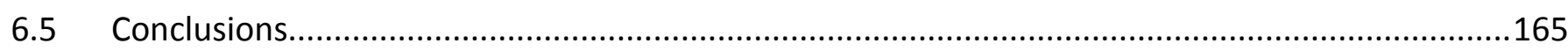

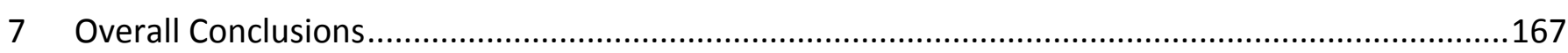

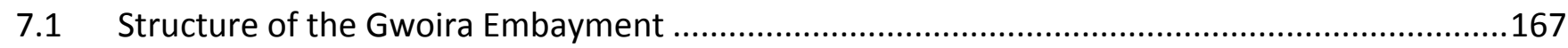

7.2 Pliocene-Recent Evolution of the Gwoira Embayment .......................................................169

7.3 Slip Rate and Deformational Style of the Active Mai'iu Fault at Biniguni Falls ..........................169

$7.4 \quad$ Frictional Strength of the Mai'iu Fault .............................................................................170

7.5 Unanswered Questions and Directions for Future Research ..................................................171

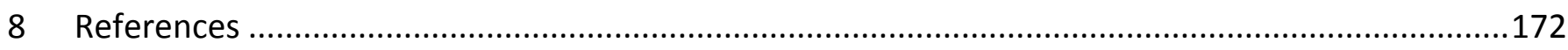

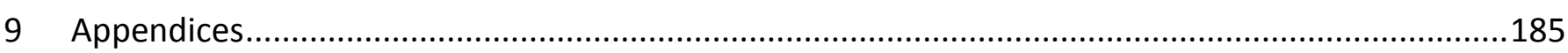

9.1 Appendix A - Quartz Preparation and Separation of Cosmogenic Beryllium and Aluminium ....185

9.2 Appendix B - Modelling of the Active Mai'iu Fault at Biniguni Falls ......................................189

9.3 Appendix C-Mohr-Coulomb Modelling..........................................................................190

9.4 Appendix D - Structural Data and Samples Used within this Thesis - See Attached CD-ROM

\section{List of Figures}

Fig. 1 - Schematic cross-sections illustrating the evolution of a LANF according to the rolling-hinge model..

Fig. 2 - Schematic cross-sections contrasting the two prominent models of LANF development: the rolling-hinge model; and the original low-angle normal fault model.

Fig. 3 - SRTM elevation model illustrating first order fault corrugations on the Suckling-Dayman Metamorphic Core Complex, Eastern Papua New Guinea.

Fig. 4 - Diagram illustrating shear stress and normal stress resolved on a potential fault plane oriented at angle $\theta$ to the greatest principle stress.

Fig. 5 - Mohr Circle diagram used to illustrate fault activation for a range of fault orientations and frictional failure criterion...

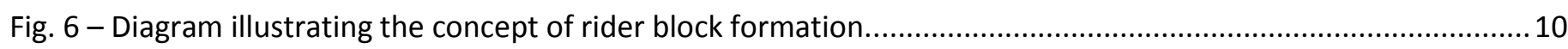

Fig. 7 - West-facing view of the Mai'iu Fault taken from near Pumani Village......................................................... 18

Fig. 8 - Tectonic setting of the Papuan Peninsula and the Mai'iu Fault.................................................................. 19

Fig. 9 - Campaign GPS data and modelling results of Wallace et al. (2014)..........................................................20

Fig. 10 - Spatial P-wave velocity variation within the Woodlark Rift of Eilon et al. (2015).........................................22 
Fig. 11 - Geological Map illustrating showing the Suckling-Dayman massif, which I define as comprising Dayman Dome, Suckling Dome, and Mt Masasoru.

Fig. 12 - Interpretative cross-section of crustal structure beneath the Papuan Peninsula.

Fig. 13 - Simplified, pseudo-spatially resolved diagram illustrating stratigraphic relationships between basement formations, and Late Miocene-recent sedimentary rocks exposed on Cape Vogel Peninsula.

Fig. 14 - Detailed tectonic configuration of SE Papua New Guinea and the Woodlark Plate.

Fig. 15 - Cartoon cross-sections illustrating a model for the successive emplacement of the PUB and Emo

Metamorphics.

Fig. 16 - Cartoon cross-sections illustrating my interpretation of the Cenozoic tectonic evolution of the Eastern

Papuan Peninsula and the Mai'iu Fault.

Fig. 17 - East-facing view of Dayman Dome and the Gwoira Rider Block.

Fig. 18 - Map excerpt showing the Gwoira Conglomerate as mapped by Davies and Smith (1974)............................52

Fig. 19 - East-facing photo of the Gwoira rider block, taken from the NE flank of Dayman Dome.............................54

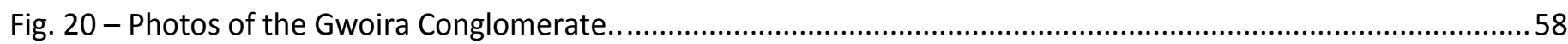

Fig. 21 - Photos illustrating the angular unconformity within the Gwoira Conglomerate..........................................61

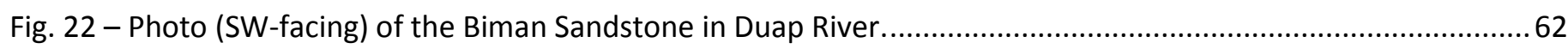

Fig. 23 - Northeast-facing photo showing fluvial terraces north of Biman................................................................63

Fig. 24 - Geological map depicting the structure of the Gwoira rider block and Gwoira Fault hanging wall. ...............65

Fig. 25 - Geologic cross-sections (A, B, C, C2) through the Gwoira rider block......................................................67

Fig. 26 - Photographs illustrating the outcrop and landscape-scale morphology of the inactive Mai'iu Fault. ............67

Fig. 27 - Modelled geometry of the OFZ, generated based on a depth-migrated seismic reflection section (MCS line 1190) using 2d-Move by Fitz (2011).

Fig. 28 - The modelled Mai'iu Fault surface generated in Leapfrog Geo through linear interpolation of preserved dip

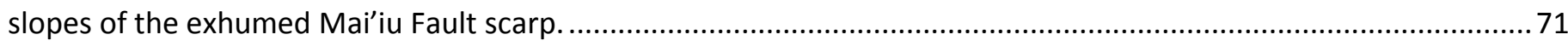

Fig. 29 - Photographs illustrating the outcrop and landscape-scale morphology of the active Gwoira Fault...............73

Fig. 30 - Lower-hemisphere stereograms illustrating bedding orientations for the Gwoira Conglomerate..................75

Fig. 31 - Cartoon illustrating the progressive back-rotation of the Gwoira embayment............................................ 81

Fig. 32 - Comparison of sedimentary dip-fanning within the Gwoira Conglomerate with strata south of the Cape Vogel structural high, and with experimental results of (McClay 1989).

Fig. 33 - Lower-hemisphere stereograms showing faulting within the Gwoira Embayment and the Gwoira Fault

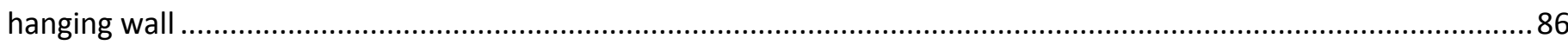

Fig. 34 - WNW-ESE non-vertical cross-section drawn through the Gwoira Gonglomerate.......................................89

Fig. 35 - Calculation of horizontal shortening accommodated by the Owen Stanley Fault, Uga Fault, Mai'iu Fault, and

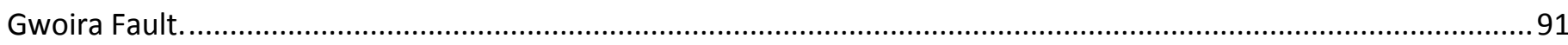

Fig. 36 - Plot of modelled maximum burial depth for sample PNG-15-20...........................................................94

Fig. 37 - Plots illustrating the variability in the weighted mean azimuth with the choice of maximum slope for

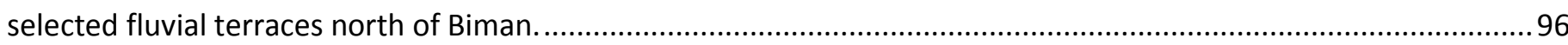

Fig. 38 - Maps depicting Late Quaternary (?) terraces located near Biman at the southern extremity of the Gwoira rider block, based on the analysis of aerial photography and the $4.5 \mathrm{~m}$ FUGRO DEM. ...........................................98

Fig. 39 - Comparison of models of the development of drainages in the footwall of the Mai'iu Fault....................... 101 Fig. 40 - Map illustrating the location of k1 knickpoints (here reinterpreted as k1 apices) identified by Miller et al. (2012).

Fig. 41 - Stream profiles drawn through the Yau-Bonenau and Ruaba Rivers, modelled relative (non-quantitative) uplift rate distribution used to generate modelled longitudinal stream profiles, and unexaggerated profiles illustrating the original, uneroded domal geometry of the inactive Mai'iu Fault footwall south of the Gwoira embayment. 105

Fig. 42 - Modelled long-term uplift rates for the Yau-Ruaba River at the Gwoira Fault trace. 107 
Fig. 43 - Conceptual model illustrating the possible evolution of a stream capture event within the Gwoira embayment.

Fig. 44 - Conceptual model illustrating the development of LANF corrugations due to a constrictional stress field.. 115 Fig. 45 - Schematic N-S cross-sections drawn through the Gwoira rider block, illustrating the Pliocene to recent evolution of the Gwoira embayment......

Fig. 46 - Orthorectified $0.1 \mathrm{~m}$ horizontal resolution Structure-From-Motion model of the lowermost Mai'iu Fault scarp at Biniguni Falls.

Fig. 47 - Sample 10Be concentrations, plotted against scarp-parallel distance Mai'iu Fault trace.

Fig. 48 - Example of modelled 10Be concentrations, in which I randomly vary erosion rate, fault slip rate, and the time of last slip, plotted against sample 10Be concentrations.

Fig. 49 - Plot of modelled erosion rates for the Mai'iu Fault scarp at Biniguni Falls.

Fig. 50 - Plot showing modelled time of last slip on the Mai'iu Fault at Biniguni Falls ...........................................135

Fig. 51 - Plot of modelled fault slip rates for the Mai'iu Fault at Biniguni Falls. ................................................... 136

Fig. 52 - Geological map detailing the Mai'iu Fault between Gorupu Crater and Wapon....................................... 138

Fig. 53 - Geologic cross-sections west of Gorupu Crater Lake (D), and through the upper Mai'iu River (E).............. 141

Fig. 54 - Cartoon illustrating LANF abandonment in the near-surface in favour of high-angle normal faulting.........142

Fig. 55 - Geologic cross-sections through Biniguni Falls (F), and Maneyao (G). ................................................... 144

Fig. 56 - Interpretive evolution of the Mai'iu Fault, illustrating the formation of a thrust duplex in the hanging wall of

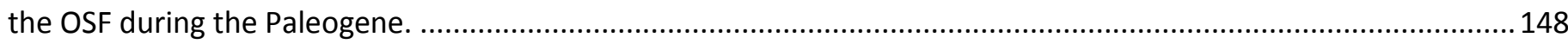

Fig. 57 - The results of extensional wedge modelling of Mai'iu Fault of Spencer (2011) .......................................153

Fig. 58 - Cartoon illustrating the differential stress resolved on a LANF at the time of near-surface abandonment..154

Fig. 59 - Plot of modelled fault cohesion and fault friction for the active Gwoira-Mai'iu Fault surface. 156

Fig. 60 - Modelled geometry of the inactive Mai'iu Fault at the present day, and a range of possible modelled retro-

deformed fault geometries for the inactive Mai'iu Fault at the time of abandonment. 158

Fig. 61 - Plot of critical fault abandonment conditions for the inactive Mai'iu Fault. 159

Fig. 62 - The results of Mohr-Coulomb modelling of the active Mai'iu Fault at Biniguni Falls. 160

Fig. 63 - Illustrations showing the physical manifestation of the mechanical conditions stipulated by modelling of the

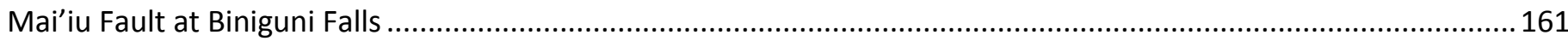

Fig. 64 - Illustration of a moddelled LANF of constant curvature. 189

Fig. 65 - Mohr Circle diagram illustrating of the relationship between maximum LANF rotation and other quantities.

\section{List of Tables}

Table 1 - Table of quantities for modelling of maximum burial depth from coal vitrinite reflectance data............... 92

Table 2 - Summary of results of modelling of maximum burial depth for sample PNG-14-20................................ 94

Table 3 - Summary of results of modelling of uplift rates at the Gwoira Fault trace, based on modelling of the Yau-

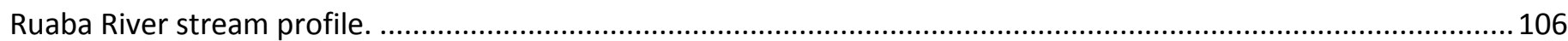

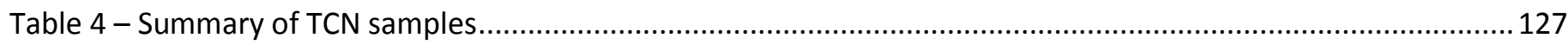

Table 5 - Summary of sample TCN concentrations. ................................................................................. 129

Table 6 - Table of quantities used in the calculation of synthetic TCN concentrations..........................................130

Table 7 - Summary of modelled erosion rates for the Mai'iu Fault scarp at Biniguni Falls....................................134

Table 8 - Summary of results of modelling of the time of last slip on the Mai'iu Fault at Biniguni Falls .................... 135

Table 9 - Summary of results of modelling of dip-slip rate for the Mai'iu Fault scarp at Biniguni Falls...................... 136

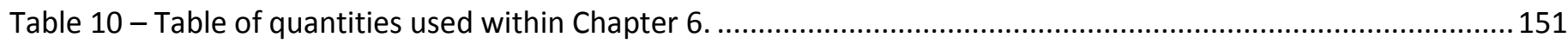

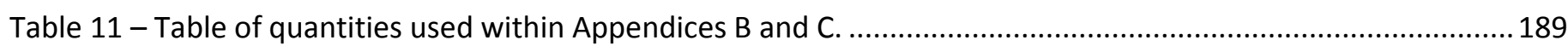




\section{List of Equations}

Equation 1 - Calculation of maximum burial depth

Equation 2 - The equation for detachment-limited streams.

Equation 3 - Equations used to describe the exponential downstream variation in uplift rate.....

Equation 4 - Calculation of scarp exposure age at each scarp-parallel position on the Mai'iu Fault scarp at Biniguni

Falls

Equation 5 - Calculation of post-exposure TCN accumulation, and soil scaling factor ...........................................132

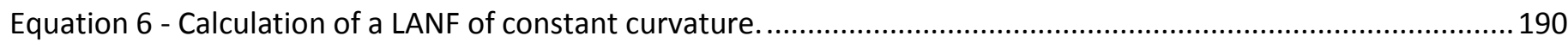

Equation 7 - Calculation of maximum LANF rotation prior to abandonment ......................................................... 191

Equation 8 - Calculation of differential stress required to cut intact crust. ............................................................191

Equation 9 - Calculation differential stress required to slip on the LANF...........................................................191 


\section{Chapter I: Introduction}

\subsection{Low-Angle Normal Faults}

Low-angle normal faults (LANFs) are normal faults that slip at extremely shallow angles $\left(<30^{\circ}\right)$. They are relatively rare, major geological structures that have been the subject of debate for more than three decades, due to their seemingly infeasible geometries that are highly misoriented for slip and the lack of significant seismicity attributable to slip on such structures (Collettini, 2011). LANFs are enigmatic because slip initiation and continued slip on faults that dip shallower than $30^{\circ}$ are mechanically unviable for standard experimentally determined values of rock friction. LANFs are also inexplicable because there is little evidence that they slip during large earthquakes (Abers et al., 1997; Axen, 2004; Collettini, 2011; Jackson and White, 1989; Styron and Hetland, 2014). The Mai'iu Fault, Eastern Papua New Guinea, is a rare example of an exposed, active LANF. In order to clarify outstanding questions regarding their slip mechanics, in this thesis I investigate deformation within the hanging wall of the Mai'iu Fault, investigate active LANF slip rate, and model LANF frictional strength.

Studies of active and inactive LANFs suggest that they are capable of accommodating slip of tens of kilometres (Collettini, 2011). LANFs are shallow dipping normal faults that commonly accrued large-offsets (up to $50 \mathrm{~km}$ slip), characteristically juxtaposing rocks of widely varying structural depth (Axen, 2004). Given sufficient slip, a LANF may evolve into a domed detachment fault that exhumes mid to lower crustal metamorphic rocks in its footwall. The resultant domal structures are metamorphic core complexes (MCCs). MCCs can form in continental crust, or near the axes of mid-ocean spreading ridges to form oceanic core complexes (OCCS). The processes thought to govern the formation and continued slippage of continental MCCs and OCCS are broadly similar, but vary in detail - the former may reactivate older, shallow-dipping faults or fabrics (e.g., Corinth Rift; Jolivet et al., 2010), while OCCs generally form in mechanically homogeneous rock (Whitney et al., 2013).

Research to date has failed to ascertain whether slip on LANFs is accompanied by significant seismicity, and whether active LANFs indeed slip at frictionally implausible angles (and if so how this is accomplished), (Collettini, 2011). Studies of LANFs have generally focused on inactive detachment faults, largely because of the rarity of active, sub-aerially exposed LANFs (Whitney et al., 2013). Because detachment faults may have been active at steeper dips than are currently 
preserved, these studies remain inconclusive, particularly as not all detachment faults were necessarily LANFs at the time of their activity.

\subsubsection{Uncertainties Associated With LANF Slip Mechanics}

Understanding the slip mechanics and seismic expression of LANFs is crucial to understanding extensional tectonic settings. It is unknown whether slip on such structures is enabled by the presence of an intrinsically weak fault zone that can slide at low shear stresses, or whether fluid overpressures may enable slip through reduction of the effective normal stress on the fault (Axen, 2004). For most LANFs, the fault friction coefficient $\left(\mu_{f}\right)$ and fault cohesion $\left(C_{f}\right)$ are poorly constrained, although it has been suggested that these values must be relatively low (possibly $\mu_{\mathrm{f}}<0.4$ ) in order to explain their activity at seemingly unfeasibly shallow dips (Collettini, 2011). In OCCS, LANF slip may also be aided by progressive strain softening as a consequence of mantle serpentinisation (Tucholke et al., 1998).

Whether LANFs are seismic or aseismic is a topic of contention. While large $M_{w}>6.0$ earthquakes have been attributed to LANFs within the Woodlark Rift (Abers, 1991; Abers et al., 1997) and within the Corinth Rift (Rigo et al., 1996), a global absence of significant LANF seismicity is notable (Collettini, 2011). Between 1967 and 1992, nine $M_{w}>5.0$ extensional earthquakes were documented in the vicinity of the Mai'iu LANF, Eastern Papua New Guinea, including two $M_{w}>6.0$ events; however, none of these events were located on the surface of the Mai'iu Fault, and so more likely represent slip on high-angle $43-54 \% \mathrm{~N}$ dipping faults in the hanging wall and footwall of the Mai'iu Fault (Abers et al., 1997). Collettini (2011) hypothesises that LANFs may move principally through aseismic creep. This hypothesis may be supported by the observation that the total rate of seismic moment release on some LANFs is only attributable to $5-20 \%$ of local extension, suggesting significant aseismic creep (Abers et al., 1997; Collettini, 2011). Because faults may act periodically as preferential conduits for fluid flow (Sibson, 2001), LANFs may develop fluid overpressure between slip events, promoting frictional failure at which point the fluid overpressure is relieved (Collettini, 2011). Fluid circulation and mineral reactions may favour the formation of weak phyllosilicate minerals (friction less than 0.4), which are also characterised by velocity-strengthening behaviour (Collettini, 2011). This may promote aseismic slip at shallow dips; however, these minerals are not always observed in exposed LANFs (Collettini, 2011). 


\subsubsection{Models of LANF Initiation and Continued Slip}

Debate exists as to the origin and mechanics of LANFs, and how the exhumation of MCCs is accomplished (e.g., Collettini, 2011; Jackson and White, 1989; Lavier et al., 1999; Tirel et al., 2008; Wernicke, 1981; Wernicke and Axen, 1988). If LANFs are indeed able to slip at dips of $<30^{\circ}$, then a mechanism by which they continue to slip must be identified. More difficult than explaining slip on a misoriented fault is the initiation of LANFs at low dip angles in settings where the greatest principle stress $\left(\sigma_{1}\right)$ is vertical. Most geomechanical models follow Mohr-Coulomb theory (with Byerlee friction) and assume that LANFs initiate at $\sim 60^{\circ}$ dips (Lavier et al., 1999; Tirel et al., 2008), and that once initiated, faults are later rotated to shallower dips due to progressive isostatic uplift and back-rotation of the exhumed footwall according to the rolling-hinge model of Buck (1988), (Fig. 1, Fig. 2a). This model has recently been confirmed in the case of OCCs through demonstration of progressive rotation of the orientation of footwall thermo-remnant paleomagnetisation (Garcés and Gee, 2007; Morris et al., 2009; Reston and Ranero, 2011).

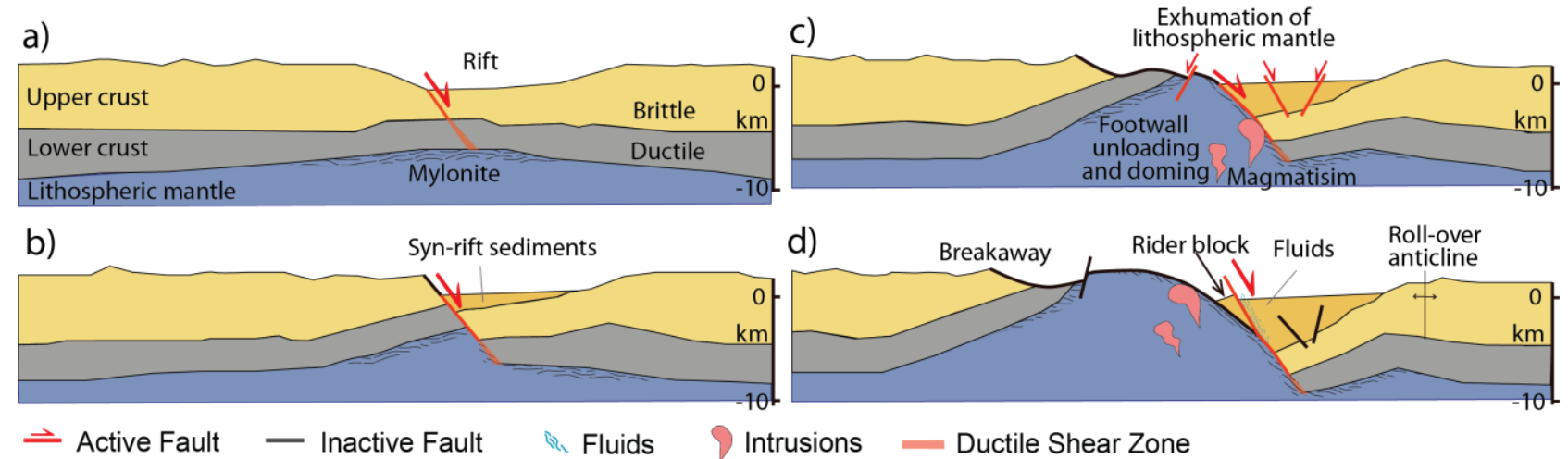

Fig. 1 - Schematic cross-sections illustrating the evolution of a LANF within oceanic crust, according to the rolling-hinge model. a) A high-angle normal fault cuts the crust in response to rifting. b) Continued fault offset provides accommodation space on the hanging wall, in which sediments are deposited. c) Lithospheric mantle is eventually exhumed in the fault footwall, forming a MCC. The footwall begins to unload as it uplifts isostatically. Doming occurs as the footwall back-rotates forming a LANF. Exhumation decompression gives rise to magmatism in the footwall. The hanging wall begins to deform. d) A roll-over anticline forms as the hanging wall deforms and sediments are deposited against the LANF. If the LANF is sufficiently back-rotated, fault abandonment may occur over some depth interval, where a new high-angle normal fault cuts the hanging wall forming a rider block. Modified after Tucholke et al. (1998).

Other models have been proposed to explain LANF initiation and continued slip. In some situations once steeply-dipping normal faults may have been rotated into shallow orientations by the domino rotation model of Proffett (1977). Spencer and Chase (1989) suggest that normal faults may initially form at low-angles due to pre-existing flexural stresses in the crust, as might be the case where there is Moho relief that is not isostatically compensated. Such a non-Andersonian 
scenario (Anderson, 1905) would be characterised by a non-vertical greatest principle stress and shallowly dipping shear stresses, that might be conducive to the nucleation of a LANF in an isotropic crust. Other models also explain the initiation of LANFs in a non-Andersonian stress field using other boundary conditions (e.g., Chéry, 2001; Westaway, 2002, 2005). Yet evidence for these scenarios is tenuous (Collettini, 2011), and these non-Andersonian mechanisms do not adequately explain the formation and operation of many active and inactive LANFs observed world-wide (Collettini, 2011). A simpler theory posits that LANFs may reactivate pre-existing shallow-dipping surfaces (Fig. 2b), especially thrust faults and nappe boundaries (e.g., Corinth Rift; Jolivet et al., 2010; Lecomte et al., 2010). LANFs might conceivably cut the entire lithosphere (the simple shear model of Wernicke (1981)), or may root into a rheologically-controlled subhorizontal ductile shear zone in the middle-lower crust (Behr and Platt, 2011; Collettini, 2011; Lister and Davis, 1989).

Thus there are two dominant models that appear to explain many of the characteristics of LANFs both the rolling-hinge model and the original low-angle normal fault model (Fig. 2) predict that isostatic rebound of the unloaded footwall will accompany sustained slip, resulting in the progressive back-tilting of the exhumed footwall and MCC (Wernicke and Axen, 1988). It is important to find additional criteria with which to discriminate between these models in the context of MCCs.

a) Rolling hinge model: back-tilted high-angle normal fault

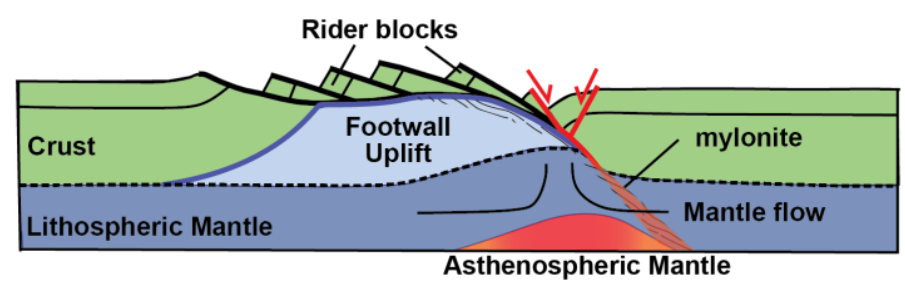

b) Original low-angle normal fault model

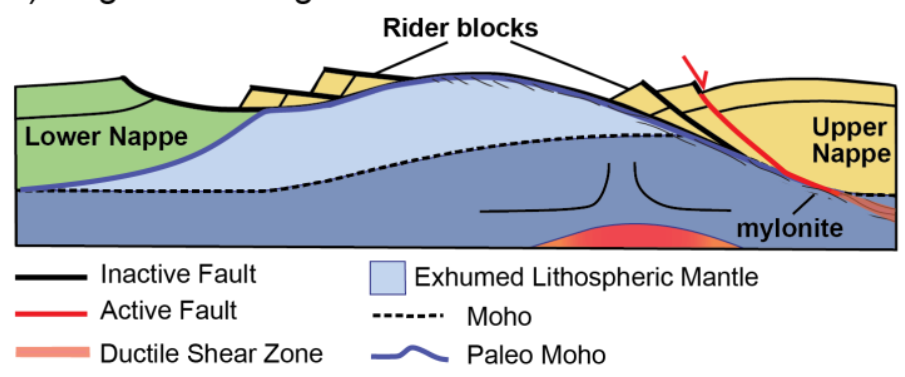

Fig. 2 - Schematic cross-sections contrasting the two prominent models of LANF development. a) The rolling-hinge model. In this model the LANF initiates as a high-angle normal fault at depth, and a LANF forms at shallow depths as the footwall is back-rotated. After Wernicke and Axen (1988). b) The original low-angle normal fault model. In this model a LANF initiates through reactivation of a nappe boundary, and cuts the entire crust at shallow angles (after Lister and Davis, 1989). Note both models account for the formation of rider blocks, the ultimate exhumation of mantle lithosphere to form a MCC, and for observed isostatic uplift and doming of the LANF footwall in response to unloading. 


\subsubsection{LANF Corrugations}

Continental MCCS and OCCs commonly exhibit a first order domal structure (megamullion), with a superimposed second order corrugated structure (mullions). The latter have corrugation axes that are oriented parallel to the extension direction (e.g., Fig. 3), (Whitney et al., 2013). These largescale features are marked by elevated residual gravity anomalies (Cannat et al., 2009; Tucholke et al., 1998). The origin of corrugations in MCCs and OCCs is strongly debated (Cannat et al., 2009; Singleton, 2013; Spencer, 2000). MCCs must have a very low flexural rigidity in order to develop corrugations, although it is unclear whether this is due to elevated temperatures or weakening of the footwall due to internal deformation (Cannat et al., 2009). For OCCs, many invoke elevated magmatism and a variable along-strike BDT depth to form the corrugations by a casting process (Tucholke et al., 2008). This model appears less applicable to continental MCCs due to reduced amount of available melt in such MCCs, and many corrugated MCCs lack associated magmatism.

Singleton (2013) has argued that continental MCC corrugations are folds in the fault surface in response to horizontal shortening perpendicular to the extension direction, which is itself the consequence of a constrictive stress regime. However it may be that corrugations are at least partially inherited structures that reflect primary fault roughness (e.g., Navarro and Manapla, 2002).

While it is important to acknowledge that many processes governing the evolution of OCCs differ from those controlling continental MCCs (i.e., overlying water column; largely uniform, homogeneous rock strength and composition; young, hot rock; extremely shallow Moho; large melt production and hydrothermal activity), it is useful to compare their features, particularly because OCC corrugations tend to be very well preserved (Reston and Ranero, 2011). In the case of OCCs, it has been argued that corrugations may arise due to spatial variability in melt production (Lin et al., 1990; Whitney et al., 2013). Corrugated OCCs have also been inferred to develop in settings characterised by intermediate rates of magma generation, forming on average at mid ocean ridges with melt supplies of $\sim 50 \%$ of the global average (Cannat et al., 2009; Whitney et al., 2013). Additionally, in the case of OCCs, the steeper dip of terminal fault scarps compared to younger fault scarps demonstrates that plate flexural rigidity increases during the terminal stages of OCC evolution (Cannat et al., 2009). 


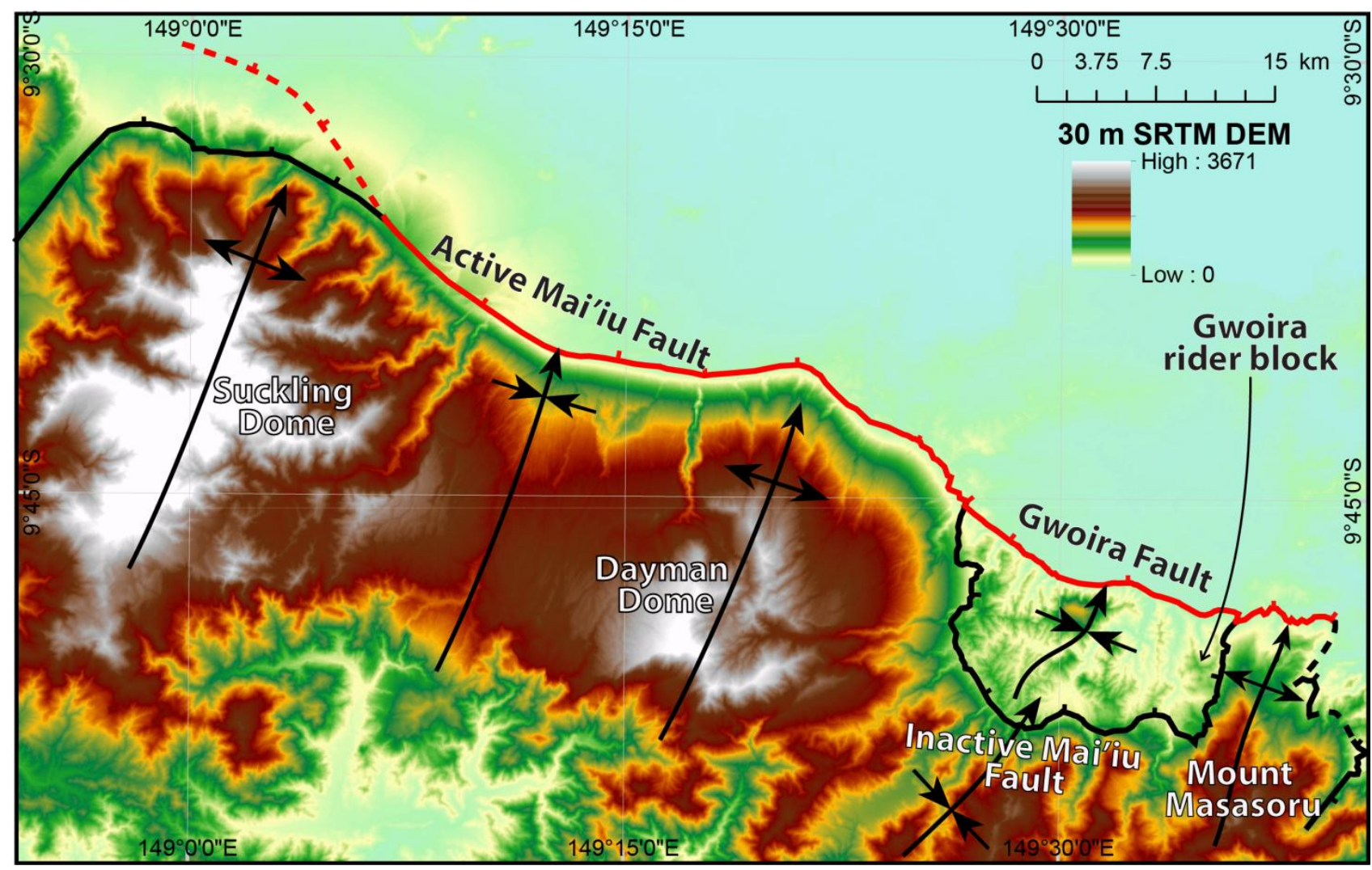

Fig. 3 - SRTM elevation model illustrating first order fault corrugations on the Suckling-Dayman continental MCC, Eastern Papua New Guinea. Note corrugation hingelines, which trend NNE and run parallel to stream drainages and the LANF slip direction inferred from campaign GPS studies (Wallace et al., 2014). Note the locations of the active Mai'iu Fault (including the active Gwoira Fault), inactive Mai'iu Fault, the Gwoira Fault, Gwoira rider block, Biniguni Falls, and Pumani Village.

\subsection{The Fault Mechanics of LANFs}

Traditional Andersonian fault mechanics (Anderson, 1905) requires that normal faults initiate oriented at $\sim 30^{\circ}$ to the greatest principle stress, (assumed to be vertical in regions dominated by extensional tectonics) within Byerlee crust (crustal friction $\mu c^{\sim 0.65 ;}$ Byerlee, 1978; Sibson, 1985) implying $\sim 60^{\circ}$ dips, and frictional locking when the fault dip approaches $30^{\circ}$ (Sibson, 2001). However abundant field evidence suggests that LANFs may dip at angles as low as $\sim 20^{\circ}$ (Collettini, 2011), and fault plane solutions are indicative of shallow-dipping structures in several active extensional tectonic settings (e.g., Chéry, 2001; Jolivet et al., 2010; Lambotte et al., 2014).

Reconciliation of LANFs with Mohr-Coulomb mechanics requires at least one of several possibilities. It may be that the coefficient of friction of the fault $\left(\mu_{f}\right)$ is significantly lower than laboratory-determined Byerlee values, perhaps due to the presence of geometrically interconnected weak phyllosilicate minerals (Byerlee, 1978; Collettini, 2011; Sibson, 1985). Hydrothermal fluid flow and abundant nutrient supply may also favour the formation of weak 
phyllosilicate minerals $(\mu<0.4)$, which would allow slip at low angles - however weak phyllosilicates such as smectite and talc are not present within all previously investigated LANFs (Collettini, 2011). Slip on LANFs may instead be enabled by a reduction in effective normal stress resolved on the LANF surface, due to elevated pore fluid pressure $\left(P_{f}\right)$, maintained by impermeable phyllosilicate minerals and perhaps modulated by fault-valve action (Collettini, 2011; Sibson, 2001). Because active faults in general act periodically as preferential conduits, and subsequently barriers, to fluid flow (Sibson, 2001), LANFs may promote fluid overpressure between slip events, allowing slip at low angles which would release the fluid overpressure (Collettini, 2011). Alternatively we may invoke a non-Andersonian stress field in order to explain fault initiation and continued slip at shallow angles (e.g., Chéry, 2001; Westaway, 2002, 2005).

\subsubsection{Fault Initiation and Reactivation}

Fault slip rate and style is controlled by the orientations and magnitudes of the minimum $\left(\sigma_{3}\right)$, intermediate $\left(\sigma_{2}\right)$, and maximum $\left(\sigma_{1}\right)$ principal stresses (Fig. 4), (Altmann, 2010; Çiftçi, 2013; Sibson, 2001; Wiprut and Zoback, 2002). $S_{1}, S_{2}$, and $S_{3}$ are unit vectors describing the stress orientations (Célérier, 1988). Ideal extensional tectonic regimes are characterised by a vertical $\sigma_{1}$ $\left(S_{v}\right)$, and a horizontal $\sigma_{2}\left(S_{H \max }\right)$ and $\sigma_{3}\left(S_{H \min }\right)$, with optimal fault surfaces oriented at $\sim 30^{\circ}$ to $\sigma_{1}$ (Çiftçi, 2013). Faults are traditionally modelled as frictional planar surfaces using Mohr-Coulomb mechanics. Faults are assumed to form by cutting homogeneous, unfaulted rock at an angle $\theta$ (ideally $\sim 30^{\circ}$ ) to the principle stress $\sigma_{1}$, according to Andersonian theory (Fig. 4), (Sibson, 1985). Fault slip occurs when stress conditions resolved on the fault surface meet a failure criterion (Altmann, 2010). This failure criterion is defined by the equation $\tau=C+\mu_{f} \cdot \sigma^{\prime} n$, where $\mu_{f}$ represents the slope of the Mohr-Coulomb failure criterion, $\sigma_{n}^{\prime}$ is the effective normal stress $\left(\sigma_{n}^{\prime}=\right.$ $\sigma_{n}-P_{f}$ ), and $C$ is fault cohesion (often assumed to be negligible), (Altmann, 2010; Ikari et al., 2007).

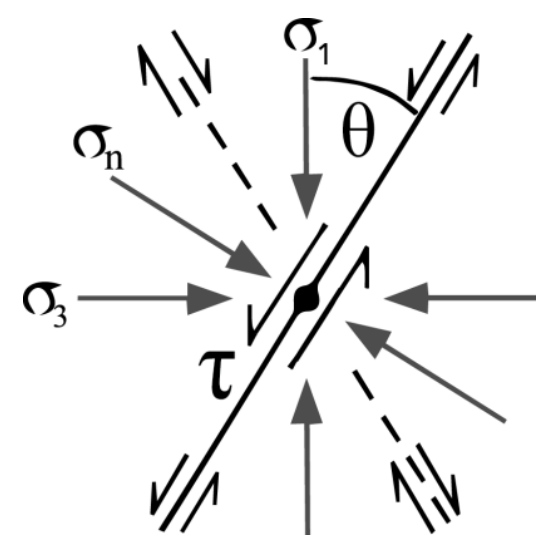

Fig. 4 - Diagram illustrating shear stress $(\tau)$ and normal stress $\sigma_{n}$ resolved on a potential fault plane oriented at angle $\theta$ to the greatest principle stress $\left(\sigma_{1}\right) . \sigma_{3}$ represents the least principle stress. This diagram implicitly assumes $\sigma_{1}=\sigma_{\mathrm{v}}$. Normal fault dip is equal to $90^{\circ}-\theta$. Sibson (2001). 
Continued LANF slip may be assessed through consideration of fault reactivation. An optimally oriented fault, with orientation $\theta=\theta^{*}=0.5 \tan ^{-1}(1 / \mu)$, (where $\theta^{*}$ is the optimum angle for reactivation; see Fig. 4) may be reactivated given differential stress $\left(\sigma_{\text {diff }}=\sigma_{1}^{\prime}{ }_{1}-\sigma_{3}^{\prime}\right)$ of sufficient magnitude (Sibson, 2001). However, the reactivation of severely misoriented faults $\left(\theta>2 \theta^{*}=\right.$ $\tan ^{-1}(1 / \mu)$ requires special conditions (Collettini, 2011; Sibson, 2001). Reactivation of a severely misoriented Byerlee fault $\left(0.65 \leq \mu_{f} \leq 0.8\right)$ requires $P_{f}>\sigma_{3}$, such that the effective least principle stress $\left(\sigma^{\prime}{ }_{3}\right)$ is negative. This is problematic because negative $\sigma_{3}^{\prime}$ may trigger hydraulic fracturing, which tends to increase permeability and thus reduce $P_{f}$, increasing $\sigma_{3}^{\prime}$ (Sibson, 2001). To avoid hydrofracturing, a very small differential stress is required for shear reactivation to occur, without shear fracturing wall rocks. This raises issues for explaining LANFs, which are severely misoriented faults, in terms of Mohr Coulomb mechanics. However it is possible that LANFs are characterised by non-Byerlee $\left(\mu_{\mathrm{f}}<0.65\right)$ friction. Non-Byerlee faults may be reactivated for $\theta>2 \theta^{*}$ (see Fig. 5), and severely misoriented non-Byerlee faults may intersect the reactivation criterion for positive values of $\sigma_{n}^{\prime}$ (Axen, 1992; Behr and Platt, 2011). Low fault cohesion is also conducive to fault reactivation at non-optimal orientations (Fig. 5).

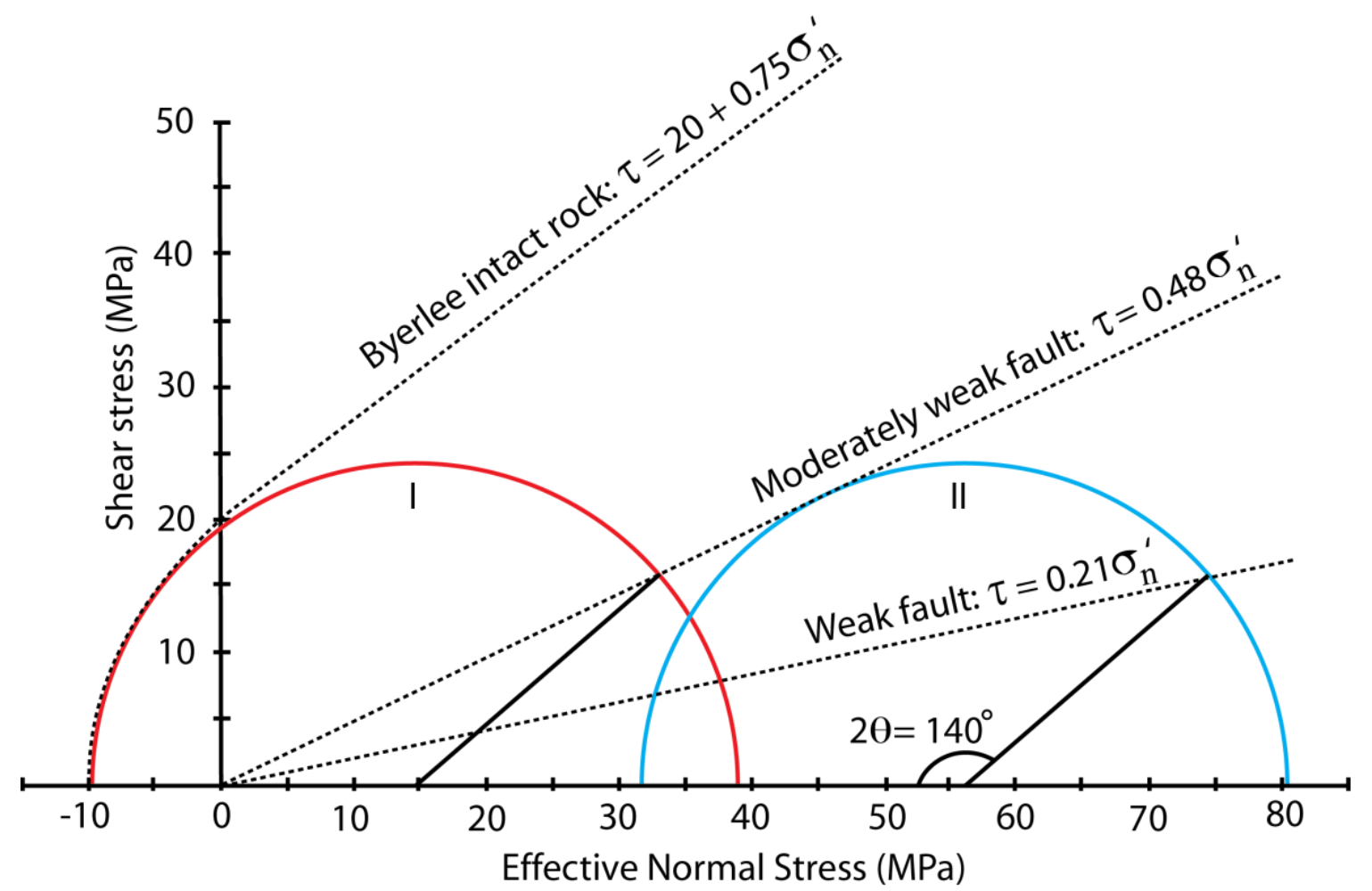

Fig. 5 - Mohr circle diagram used to illustrate fault activation for a range of fault orientations and frictional failure criterion (dashed black lines). Failure occurs when a Mohr circle meets a failure criterion. Circle I (red): illustration of how the activation of a LANF of moderately weak $\mu_{\mathrm{f}}$ is limited by the failure of intact Byerlee rock. Circle II (blue): illustration of how a LANF of very weak $\mu_{f}$ may be reactivated at unfavourable fault orientations $\left(20^{\circ}\right.$ in this example), as the failure criterion for intact rock is unattainable. Çiftçi (2013). 


\subsubsection{Fault Rotation and Rider Block Abandonment}

As illustrated by Fig. 5, frictionally weak faults may remain active despite severe misorientation (Choi and Buck, 2012). An infinitely weak fault $\left(\mu_{\mathrm{f}}=0\right)$ will remain active at any angle $\theta$. However, a fault of some strength will be expected to lock at some critical angle $(\Delta \theta)$, at which point a new, optimally oriented fault will splay through intact rock. If this new fault forms as a new splay cutting the hanging wall, it is termed a rider block (Choi et al., 2013). In general rider blocks are inferred to form in response to the abandonment of shallow, highly misoriented portions of a LANF. This splaying process may be aided by the presence of hanging wall sedimentary rocks that are weaker $(\mathrm{C}<5 \mathrm{MPa})$ than footwall metamorphic rocks ( $\sim 20 \mathrm{MPa})$. Because LANFs need to lock before forming a rider block, the presence of rider blocks places a minimum constraint upon fault friction and cohesion (Lavier et al., 2000). This is a useful tool that may be used to constrain the frictional and cohesive strength, and mechanics of LANFs.

Rider blocks are common features of LANFs (Anders and Schlische, 1994; Choi and Buck, 2012; Choi et al., 2013; Jolivet et al., 2010; Reston and Ranero, 2011). They are fault slices of the former hanging wall that are formed due to the progressive back-rotation and abandonment of LANFs with increasing offset. An initial, back-rotated LANF may become increasingly misoriented and is ultimately replaced by a new, more steeply dipping fault. These two faults bound the rider block, which is then uplifted along with the footwall.

The geometry of a rider block may be able to be related to fault frictional properties at the time of its formation. Choi and Buck (2012), based on the framework of Nur et al. (1986), define a method for predicting the maximum rotation $(\Delta \theta)$ that part of a LANF may undergo prior to lock up. Calculations are made in terms of Mohr-Coulomb mechanics, such that lock-up orientation is a function of fault and crustal friction and cohesion, $P_{f}$ and depth (Choi and Buck, 2012; Choi et al., 2013). The differential stress required to slip on a fault of orientation $\theta$ is compared with the differential stress required to form a rider block by cutting homogeneous crust. LANF abandonment is controlled by the difference between $\sigma_{\text {diff }}$ required for continued LANF slip, and that required for shear fracture of intact rock $\left(\Delta \sigma_{\text {diff }}\right)$, above the cross-over depth $\left(d_{c} ;\right.$ Fig. 6$)$. If this value is positive, then the LANF is abandoned and a new ideally oriented fault forms at depth $d_{c}$, forming a rider block. Additionally, because the cross-sectional area of a rider block is a function of LANF lock-up depth, which occurs at depth $d_{c}$, LANF cohesion and friction can be related to rider block geometry. This methodology requires an assumption regarding the orientation of $\sigma_{1}-$ 
generally it is assumed that $\sigma_{1}=\sigma_{v}$ (Choi and Buck, 2012). In this thesis, I aim to apply this model to the Mai'iu Fault, in order to place constraints upon fault strength.

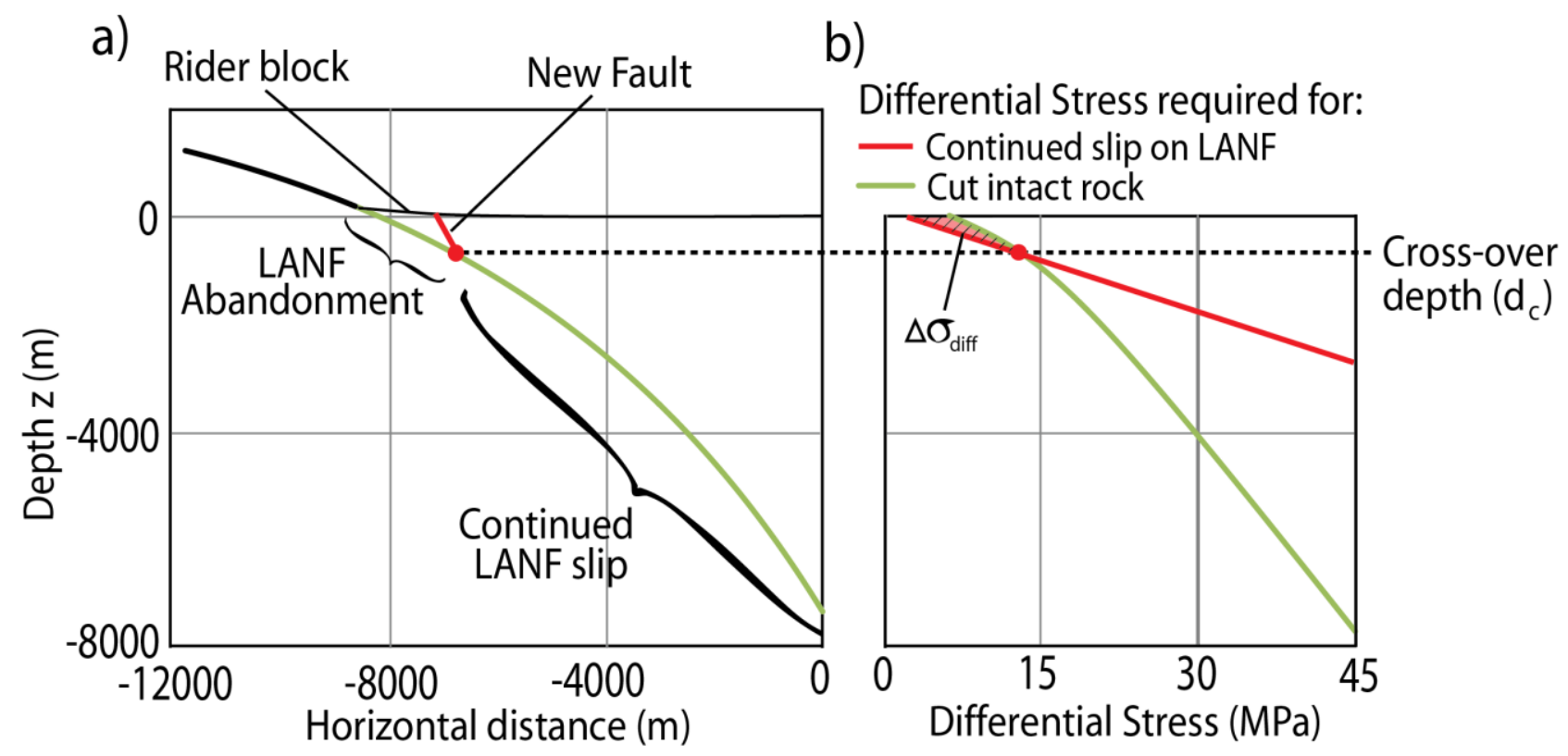

Fig. 6 - Diagram illustrating the concept of rider block formation. a) Geometry of rolling hinge style LANF. Note rider block formation at cross-over depth $\left(d_{c}\right)$. b) Plot of differential stress ( $\sigma_{\text {diff }}$ ) required for continued slip on LANF, and to cut intact rock. Since the sign of the difference between $\sigma_{\text {diff }}$ required for continued slip, and that required to cut intact rock $\left(\Delta \sigma_{\text {diff }}\right)$ above $d_{c}$ is positive, the LANF is abandoned and a new ideally oriented fault forms at depth $d_{c}$.

\subsection{Cosmogenic Nuclides and Dating Methodology}

\subsubsection{Overview of Cosmic Radiation and Cosmogenic Nuclides}

Primary cosmic rays are derived from supernovae, and interact with Earth's atmosphere to produce rare radioactive isotopes. Galactic cosmic radiation (GCR) principally originates from within the Milky Way galaxy, and comprises high energy nucleons (Gosse and Phillips, 2001; Lingenfelter and Flamm, 1964). Such radiation typically has energies ranging from $1 \mathrm{MeV}-1020 \mathrm{eV}$ (Dunai, 2010; Lingenfelter and Flamm, 1964). Solar cosmic radiation (energies between 1-100 $\mathrm{MeV}$ ) provides only a small contribution to Earth's incident radiation flux within the atmosphere, because cut-off energies are too high (Cerling and Craig, 1994). Together, these sources of primary cosmogenic radiation principally comprise protons, alpha particles, with some small amount of heavier particles (Masarik and Reedy, 1995). These particles are funnelled through Earth's geomagnetic field and interact with Earth's atmosphere, particularly nitrogen and oxygen, to form a reaction cascade of secondary radiation, comprising nucleons (protons and neutrons) and mesons (kaons and muons; Gosse and Phillips, 2001). After this initial increase, particle flux then decays in a near-exponential fashion with increased proximity to Earth's surface, owing to energy 
loss with successive particle collisions (Rossi, 1964). Particles cascade through Earth's atmosphere, in the fashion frequently illustrated by the archetypal secondary cosmogenic cascade diagram (e.g., Dunai and Lifton, 2014).

In situ Terrestrial Cosmogenic Nuclides (TCN), such as ${ }^{10} \mathrm{Be}$ and ${ }^{26} \mathrm{Al}$, are produced by the reaction of secondary cosmogenic particles with the nuclei of atoms in crystalline materials exposed at the Earth's surface. In situ TCNs may be generated via high energy spallation reactions due to the impact of nucleons; thermal (slow) neutron capture reactions; or via nuclear disintegrations induced by muons (Lal, 1988). Fast neutrons are the most significant source of cosmogenic nuclide production at low elevations, while protons and alpha particles only represent $<10 \%$ of TCN atmospheric flux (Lal, 1988). Similarly, meteoric TCN are produced in Earth's atmosphere through the reaction of primary radiation, (especially ${ }^{40} \mathrm{Ar}$, oxygen, and nitrogen). Following formation, meteoric TCN are adsorbed onto dust and incorporated into precipitation within the atmosphere, and then percolate through the Earth's surface and become incorporated into minerals (Middleton et al., 1987). Due to their much higher production rates, this meteoric TCN contribution confounds the analysis of in situ produced cosmogenic nuclides, and must be subtracted from measured in situ concentrations (Lal, 1988).

\subsubsection{Cosmogenic Exposure Dating}

Cosmogenic nuclide surface exposure dating employs an in situ produced cosmogenic isotope, commonly ${ }^{10} \mathrm{Be}$ in quartz, in order to determine the duration over which the host rock has remained exposed to cosmogenic radiation. Because in situ TCN production rapidly attenuates with depth, and because erosion tends to remove the material nearest the Earth's surface, it is important that surface erosion rates be determined, or that erosion rates are very slow, such that the erosion timescale approaches the exposure age. If erosion can be quantified, TCN exposure dating may be used to determine the length of time the rock has remained at the surface (assuming zero nuclide inheritance). Nuclide concentration is a positive function of the duration of surface exposure, and is inversely proportional to local erosion rate (Dunai, 2010).

\subsubsection{Cosmogenic Burial Dating}

Cosmogenic nuclide burial dating utilises pairs of in situ TCN to determine the time at which the rock was last buried (Balco and Shuster, 2009; Granger, 2006; Granger and Muzikar, 2001). In situations where the rock has not undergone repeated burial and exposure, this is equivalent to a 
sediment depositional age. A commonly used isotopic pair is ${ }^{26} \mathrm{Al}$ and ${ }^{10} \mathrm{Be}$, which are both produced in quartz. The ratio of isotopic production for these nuclides $\left({ }^{26} \mathrm{Al}:{ }^{10} \mathrm{Be}\right.$ ) is $\sim 6.75: 1$ (Balco and Shuster, 2009). TCN burial dating typically relies on the assumption that rock follows a simple burial and exhumation pattern, whereby the sediment is initially deposited and exposed to cosmogenic rays which produce in situ ${ }^{26} \mathrm{Al}$ and ${ }^{10} \mathrm{Be}$. When these sediments is subsequently buried and shielded from cosmogenic rays, both isotopes then decay at well determined, characteristic rates.

The half-lives of ${ }^{26} \mathrm{Al}$ (0.705 Myr; Norris et al., 1983) and ${ }^{10} \mathrm{Be}$ (1.39 Myr; Korschinek et al., 2010) are sufficiently different that the isotopic ratio decreases exponentially as both isotopes decay with increasing burial time (Balco and Shuster, 2009). Therefore the burial age can be determined from a measured isotopic ratio. For the isotopic pair ${ }^{10} \mathrm{Al} /{ }^{10} \mathrm{Be}$, this methodology is sensitive up to a burial age of ca. $6 \mathrm{Myr}$, limited largely by the half-life of ${ }^{26} \mathrm{Al}$ - for greater burial ages the uncertainty asymptotically increases to $>100 \%$ (Balco and Shuster, 2009).

\subsubsection{Factors Influencing TCN concentration}

Both TCN exposure ages and burial ages are a function of TCN concentration. TCN concentration in general increases with time exposed at Earth's surface, although concentrations will eventually plateau due to TCN radioactive decay for radioactive nuclides. Therefore specific nuclides are sensitive to specific timescales, dependent on their half-lives - for example the ${ }^{26} \mathrm{Al}-{ }^{10} \mathrm{Be}$ isotopic pair is only useful for burial dating of sedimentary rocks of age between ca. 0.5-6 Ma (Balco and Shuster, 2009).

In situ TCN concentration is a function of the duration of exposure and local TCN production rate. Because production rates vary both temporally and spatially, the TCN production rate is calibrated using a sample whose age is independently known, and production rates are scaled to sea level and high latitude (Balco et al., 2008). Production rate is a function of altitude, as a consequence of variations in atmospheric depth ('atmospheric shielding'; Stone, 2000). Production rates also vary spatially due to the geometry of Earth's geomagnetic field, which controls the flux of primary cosmogenic radiation (Bierman, 1994). Charged primary cosmogenic radiation may be deflected by Earth's magnetic field, or funnelled to higher latitudes (Gosse and Phillips, 2001). As a consequence, the production rate of in situ (produced) cosmogenic nuclides varies with altitude and latitude (Lal and Peters, 1967). Production rate also decays exponentially with depth. Cosmogenic nuclides are produced in situ in appreciable quantities up to a depth characteristic of 
the material density. This depth is referred to as the attenuation depth. The attenuation depth for neutrons is equal to $106 \mathrm{~g} \mathrm{~cm}^{-2}$ (Lal, 1988).

Measured TCN concentrations are also controlled by several other factors. The half-lives of ${ }^{10} \mathrm{Be}$ (1.39 Myr) and ${ }^{26} \mathrm{Al}(0.705 \mathrm{Myr})$ means that in most instances the possibility of TCN inheritance must be considered (Balco and Shuster, 2009) - however because previous episodes of surface exposure are difficult to ascertain, generally it is necessary to assume zero inheritance. TCN concentrations are also a function of local erosion rates, which must be independently determined or estimated (Balco et al., 2008). Erosion will tend to remove the highest nuclide concentrations in the near-surface, which will lead to erroneously young apparent exposure ages. TCN concentrations are also controlled by shielding due to vegetation, soil, or colluvial cover, and topographic shielding, which must each be accounted for (Dunne et al., 1999).

In the case of a progressively exhumed fault scarp, TCN exposure dating enables the derivation of a slip chronology from an exposed, minimally eroded, normal fault scarp. Applied to LANFs, this may indicate whether the LANF is actively slipping or instead no longer active, and thus shed light on LANF slip rate, slip style, and mechanical evolution. Additionally, TCN burial dating using multiple TCNs may be used to date syn-tectonic quartz-bearing strata derived from the exhumation of a MCC along a LANF.

I will first provide a concise background on terrestrial cosmogenic nuclides, followed by a cursory explanation of the principles of TCN exposure dating and TCN burial dating. I will then expound briefly on various factors influencing in situ TCN concentrations. These subjects will be explained in more detail in chapters 3 and 4, and within Appendix A.

\subsection{Motivation and Research Objectives of This Thesis}

LANFs are poorly understood as geological structures (Collettini, 2011), and the active Mai'iu Fault presents a unique opportunity to study LANF seismicity (or aseismicity), fault strength, and corrugation and rider block development, within a sub-aerial environment. This thesis intends to address the following research objectives:

\section{Constrain the Quaternary Slip-Rate and Slip-Style of the Mai'iu Fault}

The Mai'iu Fault, Woodlark Rift (Fig. 3) is only one of a handful of actively slipping, sub-aerially exposed LANFS, and hence represents an ideal case study for the mechanics of actively slipping LANFs. The slip rate of the Mai'iu Fault is unknown (Daczko et al., 2011), although regional 
campaign GPS studies suggest that the Papuan Peninsula is undergoing rapid $\sim \mathrm{N}-\mathrm{S}$ horizontal extension (7-9 mm/yr; Wallace et al., 2014). Using TCN exposure dating of the fault scarp, I aim to determine whether the Mai'iu Fault is actively slipping in the near-surface, and if so use a MonteCarlo simulation to model recent fault slip rate.

Additionally, if the Mai'iu Fault is active in the near-surface then it may be possible to confirm whether it slips during large earthquakes, or whether slip is mostly aseismic (as is suggested by the lack of observed seismicity), through modelling gradients in TCN concentration with fault offset (e.g., Schlagenhauf et al., 2010; Schlagenhauf et al., 2011). However this objective may be limited by our low sampling resolution ( $5 \mathrm{~m}$ horizontal sample spacing; Schlagenhauf et al., 2011).

\section{Place Constraints on the Initiation of Rifting in the Woodlark Rift Through Cosmogenic Burial Dating of the Syn-Tectonic Gwoira Conglomerate}

The Plio-Pleistocene (?) Gwoira Conglomerate lies in the immediate hanging wall of an inactive part of the Mai'iu Fault (further explained in Chapter 2). This formation was deposited synextensionally, and is dominated by clasts eroded from the uplifting footwall of the Mai'iu Fault. The Gwoira Conglomerate forms the fault-bounded Gwoira rider block (Fig. 3), and while its petrography and clast provenance are broadly understood, its depositional age is poorly known (Caffi, 2008; Davies, 1980a; Smith and Davies, 1976). Through determination of depositional ages using TCN burial dating, it may be possible to determine a minimum age for onset of motion on the Mai'iu Fault. This may help to constrain the evolution of rifting on a larger, regional scale within the Woodlark Rift, which is tectonically complex and not fully understood.

\section{Produce a Model for the Amplification of LANF Megamullions, and Formation of the Gwoira Rider Block}

The structural evolution of the Gwoira embayment may also potentially record deformation that may be linked to the progressive evolution of the Mai'iu Fault. The Gwoira rider block is the sole known rider block atop the otherwise barren exhumed Mai'iu Fault surface (Fig. 3), and so presents an opportunity to study along-strike variability in LANF slip behaviour. The Gwoira rider block's location within a large corrugation (megamullion) in the inactive Mai'iu Fault (Fig. 3) suggests that the formation of long wavelength $(\sim 25 \mathrm{~km})$ corrugations is somehow related to the process of rider block formation. Thus I will investigate the timing of rider block formation, and investigate whether the Gwoira Conglomerate preserves a record of megamullion amplification. 


\section{Place constraints on LANF strength, and characterise the mode of exhumation of Dayman Dome}

The strength characteristics of LANFs is poorly known (Collettini, 2011). I aim to model the frictional and cohesive strength of the Mai'iu Fault using simple Mohr-Coulomb mechanics, in order to test recent experimental friction data (Little et al., 2015) that have been produced for gouge samples obtained from the inactive Mai'iu Fault. In this way it may be possible to determine whether these values are representative of the Mai'iu Fault as a whole, and whether fault strength varies along strike. The abandonment of the inactive Mai'iu fault strand in favour of the more steeply dipping Gwoira Fault has implications for LANF evolution and fault strength (Choi and Buck, 2012). Thus it may be possible to use Mohr-Coulomb modelling to constrain the strength of: the Gwoira-Mai'iu Fault surface; the inactive Mai'iu Fault; and the active Mai'iu Fault.

\subsection{Thesis Outline}

This thesis is divided into 7 chapters. Chapter 1 has provided an overview of low-angle normal faulting, fault frictional mechanics, and cosmogenic nuclides, and has stipulated the motivation for study and my research objectives. Chapter 2 will outline the regional tectonic setting for the Mai'iu Fault, and discuss the Cenozoic tectonic evolution of Eastern Papua New Guinea.

Chapter 3 describes the stratigraphy of the Gwoira Conglomerate and details the structure of the Gwoira embayment. This chapter presents: modelling of the geometry of the inactive part of the Mai'iu Fault; progressive syn-tectonic folding and back-rotation of the Gwoira Conglomerate; estimates of shortening; constraints on maximum burial depth of the Gwoira Conglomerate using vitrinite reflectance data; modelling of local uplift rates using stream profile geometry; and evidence for progressive tilting of Late Quaternary (?) terraces. ${ }^{26} \mathrm{Al} /{ }^{10} \mathrm{Be} \mathrm{TCN}$ burial age data for the Gwoira Conglomerate were not yet available at the time of thesis presentation. In Chapter 4, these observations and results are synthesised in order to interpret the structural evolution of the Gwoira embayment. In this chapter syn-tectonic folding of the Gwoira embayment is rationalised in terms of a constrictive stress field.

Chapter 5 presents the results of ${ }^{10} \mathrm{Be}$ TCN exposure dating of the lowermost Mai'iu Fault scarp. Quaternary LANF dip-slip rate, erosion rates, and the time of last slip on the Mai'iu Fault are each modelled using our own Monte-Carlo simulation simplified after the methodology of Schlagenhauf et al. (2011). Model results are then placed in the context of the local geology in order to determine the slip-style of the Mai'iu Fault along the northern range-front of the SDM. 
In Chapter 6, geological observations and interpretations previously described in Chapters 3-5 are integrated in order to inform Mohr-Coulomb modelling of the Mai'iu and Gwoira Faults. The frictional strength of these faults is modelled, and results are rationalised in terms of the deformation style of the Mai'iu Fault.

Finally, Chapter 7 outlines overall conclusions drawn from this study. 


\section{Tectonic Setting of the Mai'iu Fault}

\subsection{Introduction}

This thesis is concerned with the Mai'iu Fault, an active and rapidly slipping LANF located in Eastern Papua New Guinea. This chapter introduces the Mai'iu Fault, and outlines its tectonic setting, relevant regional stratigraphy, and Cenozoic tectonic evolution. Dipping $21^{\circ} / \mathrm{N}$ at the surface, the exhumed Mai'iu Fault footwall forms a mega-corrugated Metamorphic Core Complex (MCC), located in the western Woodlark Rift $\sim 220 \mathrm{~km}$ east of the transition between continental extension and seafloor spreading. Based on modelling of campaign GPS data (Wallace et al., 2014) the Mai'iu Fault is thought to accommodate $7-9 \mathrm{~mm} / \mathrm{yr}$ of approximately $\mathrm{N}-\mathrm{S}$ horizontal extension, accommodating a large fraction of total extension within the Woodlark Rift, although it is uncertain whether slip on this fault, like that of other global LANFs, is principally seismic or aseismic. Surface geomorphology indicates that the lower most Mai'iu Fault scarp is not significantly eroded, despite high rainfall and $\sim 2900 \mathrm{~m}$ relief. This presents a unique opportunity to study an active, sub-aerially exposed LANF. The exhumed Mai'iu Fault scarp bounds the SucklingDayman massif (SDM), including Dayman Dome (Fig. 7) for much of its length. This exhumed fault surface is more than $25 \mathrm{~km}$ wide (parallel to the slip direction), is smooth and corrugated, and is mostly devoid of rider blocks. However the Gwoira rider block is the single exception to this statement. Its local presence provides an opportunity to study along-strike variability in LANF partial abandonment within the near-surface.

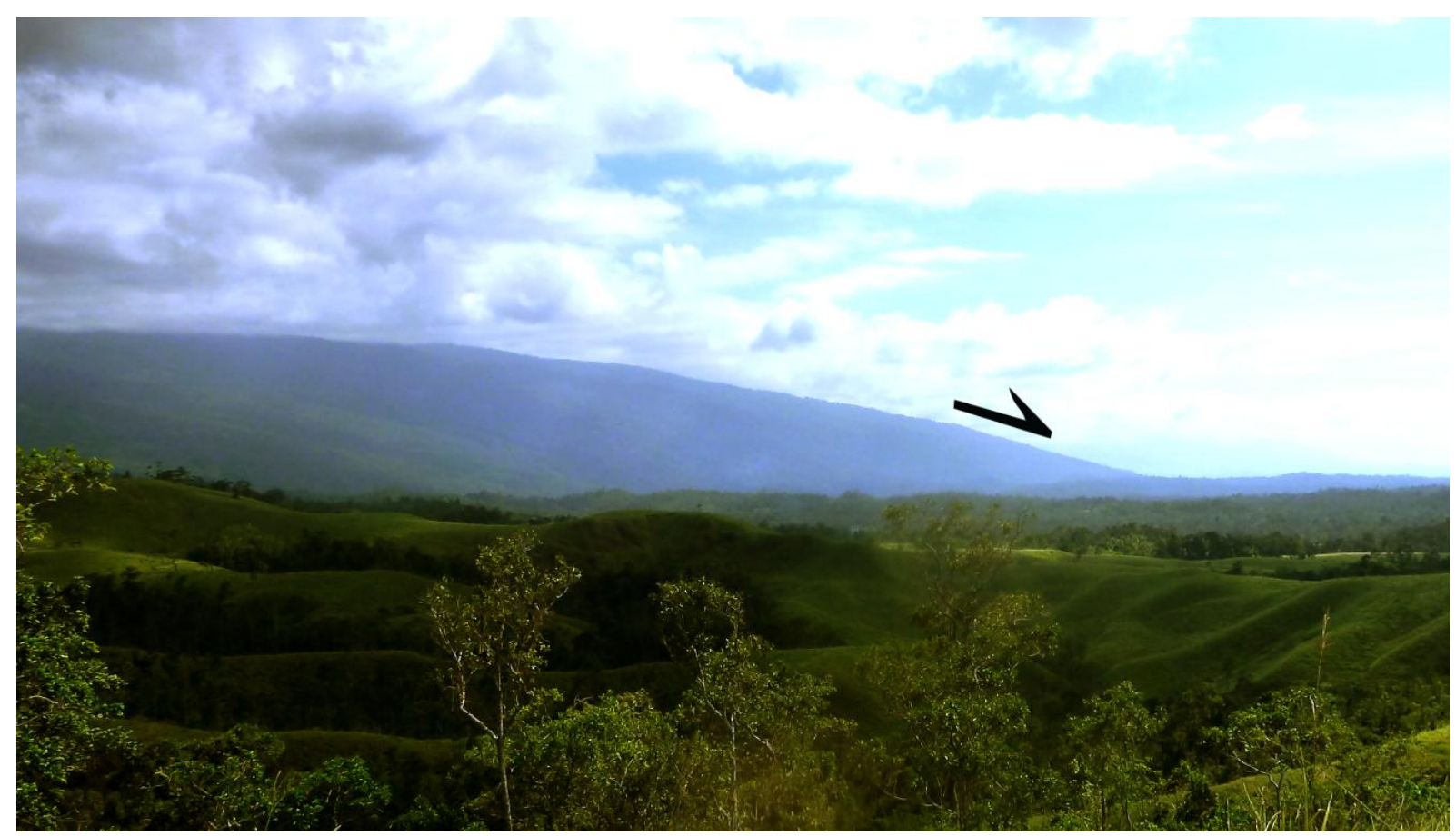

Fig. 7 - West-facing view of the Mai'iu Fault taken from near Pumani Village. Here the exhumed Mai'iu Fault surface forms the smooth surface of Dayman Dome. This section of the exhumed fault is barren (i.e., devoid of rider blocks), and is probably active. 


\subsection{Tectonic Setting}

\subsubsection{Eastern Papua New Guinea}

The Mai'iu Fault is located in Eastern Papua New Guinea, a tectonically complex region, presently dominated by oblique NE-SW convergence (10-11 cm/yr; Fig. 8) between the Australian and Pacific plates (Holm et al., 2016). Convergence between the Australian and Pacific Plates is currently accommodated at the San Cristobal and New Britain Trenches (Holm et al., 2016). A mosaic of microplates enclosed between the Pacific and Australian Plates is rapidly evolving, and exhibits a diverse range of plate boundary types and tectonic regimes, including oceanic spreading and microplate rotation, that vary considerably along the length of Pacific-Australian plate interface.

SE Papua New Guinea itself comprises a collage of up to six rotating microplates, including the Woodlark Plate, as defined by geological relationships and campaign GPS observations (Wallace et al., 2014; Wallace et al., 2004). The northern edge of the Woodlark Plate is being subducted beneath the South and North Bismarck Plates at the New Britain and San Cristobal Trenches (Ott and Mann, 2015). From the Late Miocene, slab pull at this subduction interface is thought to have instigated oceanic spreading in Woodlark Basin, and extension in the Woodlark Rift, which together separate the Woodlark Plate from the Australian Plate (Taylor et al., 1999). 


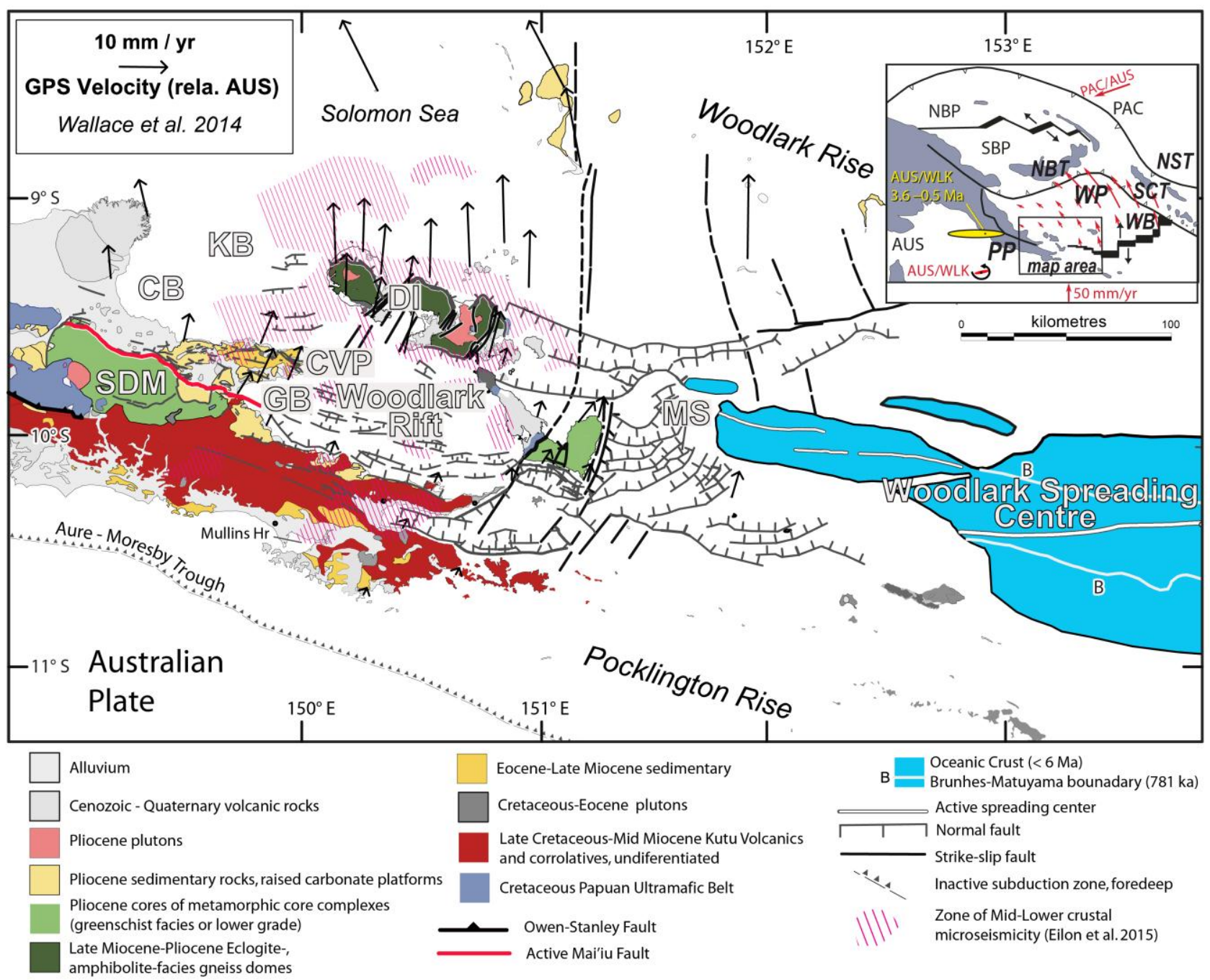

Fig. 8 - Map inset: Tectonic setting of Papuan New Guinea. Australian Plate (AUS); Moresby Seamount (MS); North Bismarck Plate (NBP); New Britain Trench (NBT); North Solomon Trench (NST); Owen Stanley Fault Zone (OSFZ); Pacific Plate (PAC); Papuan Peninsula (PP); South Bismarck Plate (SBP); San Cristobal Trench (SCT); Woodlark Basin (WB); Woodlark Plate (WP). Note Euler poles for rotation of WP with respect to AUS, from seafloor magnetic anomalies (yellow), and from campaign GPS (red; Wallace et al., 2014) Modified after (Webb et al., 2008). Main map: Tectonic setting of the Papuan Peninsula and the Mai'iu Fault. Collingwood Bay (CB); Cape Vogel Peninsula (CVP); D'Entrecasteaux Islands (DI); Goodenough Bay (GB); Kiribisi Basin (KB); Suckling-Dayman massif (SDM). Note GPS velocities with respect to the Australian Plate (Wallace et al., 2014). Geology after Little et al. (2007), Smith and Davies (1976); magnetic anomalies after Taylor et al. (1999). Modified after a map prepared by Tim Little (2016).

\subsubsection{The Papuan Peninsula and the Woodlark Rift}

The Papuan Peninsula lies on the northern edge of the Australian Plate, and is separated from the Woodlark Plate to the north by the Owen Stanley Fault Zone, and by the Woodlark Rift east of $\sim 149^{\circ} \mathrm{E}$ (Fig. 7). Seafloor spreading is presently occurring in the Woodlark Basin, which transitions to the west into continental rifting in the Woodlark Rift (Fig. 7). The 3.5-0.5 Ma Euler pole of rotation for the Woodlark Plate with respect to the Australian Plate, defined by oceanic spreading 
in Woodlark Basin, is located south of the Papuan Peninsula (Goodliffe et al., 1997; Taylor et al., 1999). These data suggest that the Woodlark Rift may be extending at $15-35 \mathrm{~mm} \mathrm{yr}^{-1}$ near Cape Vogel Peninsula (Abers et al., 2016; Goodliffe et al., 1997; Taylor et al., 1999). However Wallace et al. (2014) calculate $20-40 \%$ slower extension rates from campaign GPS results, and infer a small amount of interseismic strain throughout SE Papua New Guinea based on the similar statistical fit between models including, and models excluding, fault locking (Fig. 9). Wallace et al. (2014) also define several (up to six) rotating blocks, suggesting the Woodlark Plate may be further subdivided (Fig. 9).

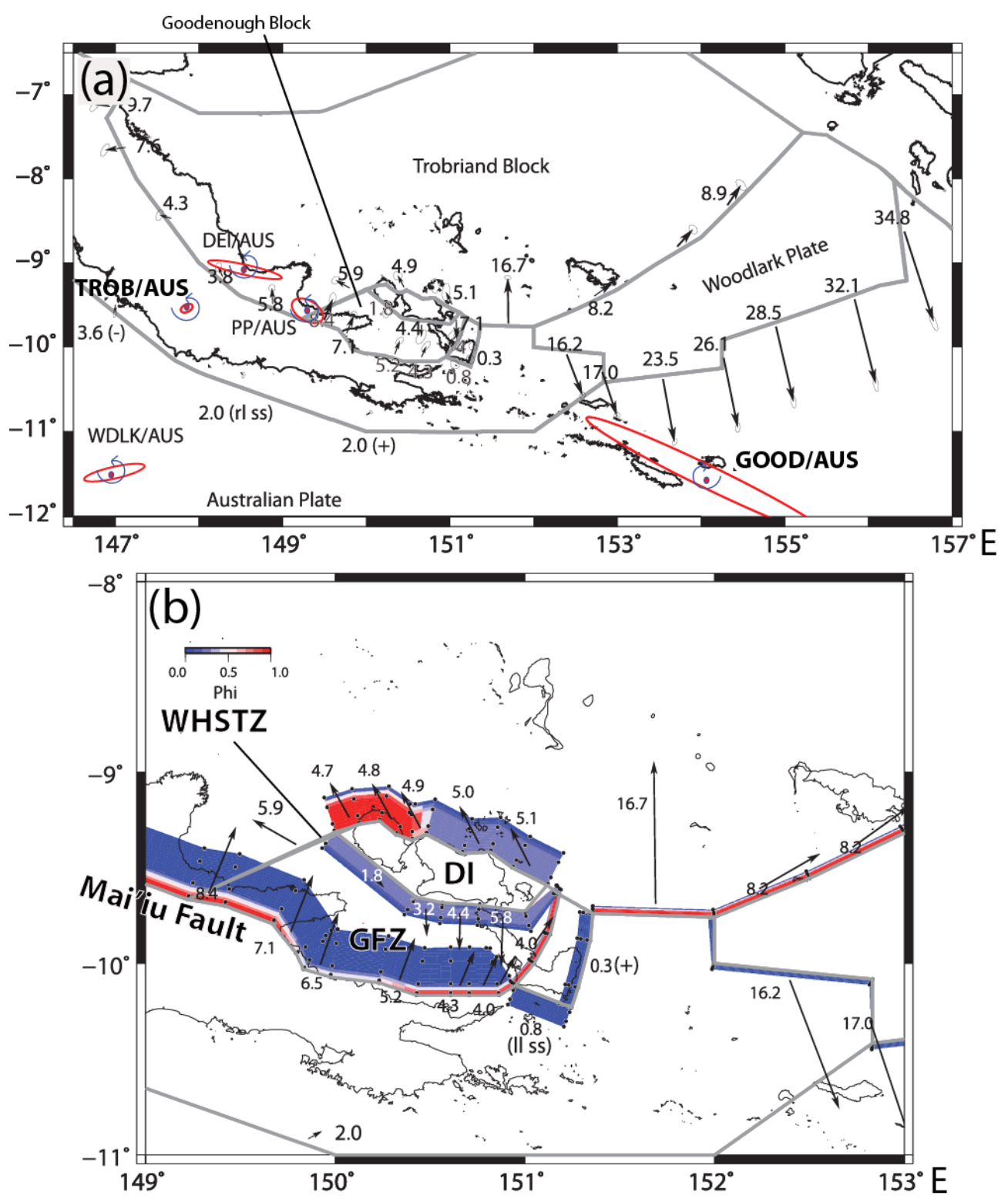

Fig. 9 - Campaign GPS data and modelling results of Wallace et al. (2014). a) Poles of rotation (red dots) calculated from GPS data, with and fault slip rates in $\mathrm{mm} \mathrm{yr}^{-1}$. Note that the Trobriand block is anticlockwise, while the rotation of the Goodenough Block in clockwise. b) Modelled fault slip rates $(\mathrm{mm} / \mathrm{yr}$ ), and fault locking: phi=1.0 (red) corresponds to a fully locked fault; phi=0.0 (blue) represents $100 \%$ active creep. Note that the Mai'iu Fault is aseismic at depth, and is slipping at 7.1-8.4 mm/yr. Note positions of the D'Entrecasteaux Islands (DI), Goshen Fault Zone (GFZ), Mai'iu Fault, Ward Hunt Strait Fault Zone (WHSTZ). 
The Papuan Peninsula comprises thick Australian continental crust overlain by a younger ophiolitic slab (Davies, 1980a). Receiver function analyses suggesting Moho depths of 28-32 km beneath the SDM, with crustal thicknesses increasing to $38 \mathrm{~km}$ west of Cape Vogel Peninsula (Abers et al., 2012; Jin et al., 2015). The presence of continental crust beneath the ophiolitic rocks exposed on Papuan Peninsula is implied by the presence of undeformed Pliocene felsic intrusives (Mai'iu Monzonite, Suckling Granite, Bonua Porphyry; Daczko et al., 2011; Davies and Smith, 1974). Additionally, Davies and Warren (1988) describe a gravity low beneath the Suckling-Dayman massif, which they ascribe to underlying felsic rocks and intrusions. However these observations apparently conflict with widespread surface exposures of oceanic basalts and ultramafic rocks exposed on the Papuan Peninsula (Davies, 1980b; Smith and Davies, 1976) - this discrepancy will be addressed below.

\subsubsection{Extension within the Woodlark Rift}

Within the Woodlark Rift, extension is principally taken up by normal faults bounding the D’Entrecasteaux Islands and on the Papuan Peninsula by the Mai'iu Fault (Fig. 7), as indicated by regional campaign GPS observations of Wallace et al. (2014). 3D phase-velocity inversions of ambient noise and teleseismic earthquakes suggest that extension within the mantle is broadly distributed (up to $\sim 70 \mathrm{~km}$ wide) than upper crustal extension (Fig. 10), and takes place along an axis extending $<20 \mathrm{~km}$ north of the D'Entrecasteaux Islands, and encompassing most of the area beneath Collingwood Bay (Abers et al., 2016; Eilon et al., 2015; Eilon et al., 2014; Jin et al., 2013). The north-dipping Mai'iu Fault defines the southern rift axis margin, which is displaced from the zone of north-dipping normal faults which bound the D'Entrecasteaux Islands to the north (Fig. 8). These two rift zones are linked by the Ward Hunt Strait Transfer Zone (Fig. 9, Fig. 10), which is marked by NE-trending band of microseismicity (Abers et al., 2016). Block subrotations (Fig. 9) have been confirmed by campaign GPS data of Wallace et al. (2014), and by demonstration of vertical-axis rotations using characteristic remnant magnetization (Cairns et al., 2015). The former study suggests that the Trobriand block is rotating anticlockwise, while the Goodenough Block, including Cape Vogel Peninsula is rotating clockwise (Fig. 9), perhaps due to an E-W gradient in slip rate on the Mai'iu Fault (Wallace et al., 2014). The latter study suggests that the entire Papuan Peninsula was undergoing anticlockwise rotation until the Late Miocene (Cairns et al., 2015). 
a)

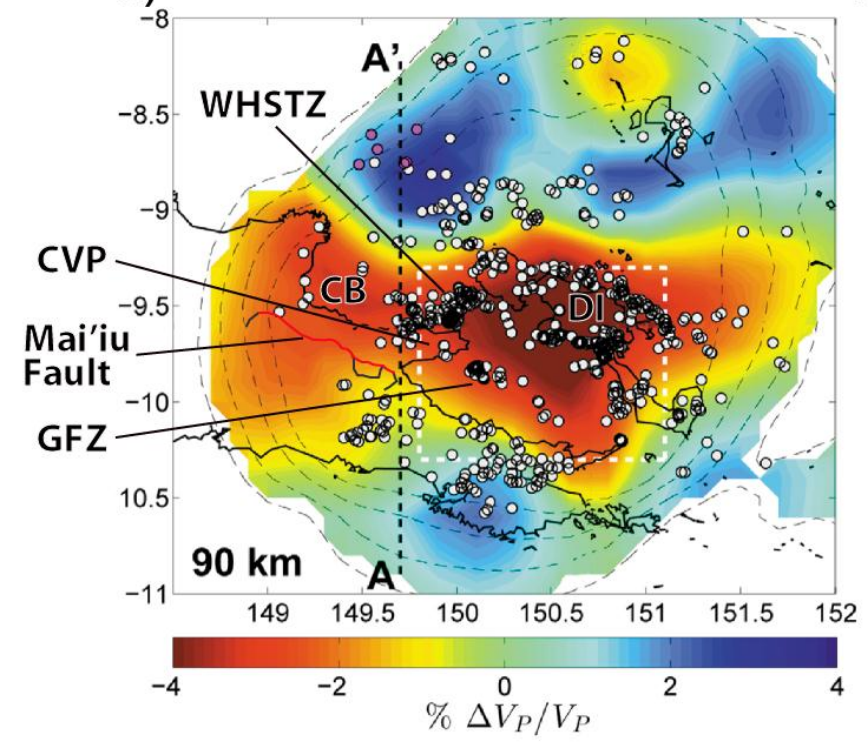

b)

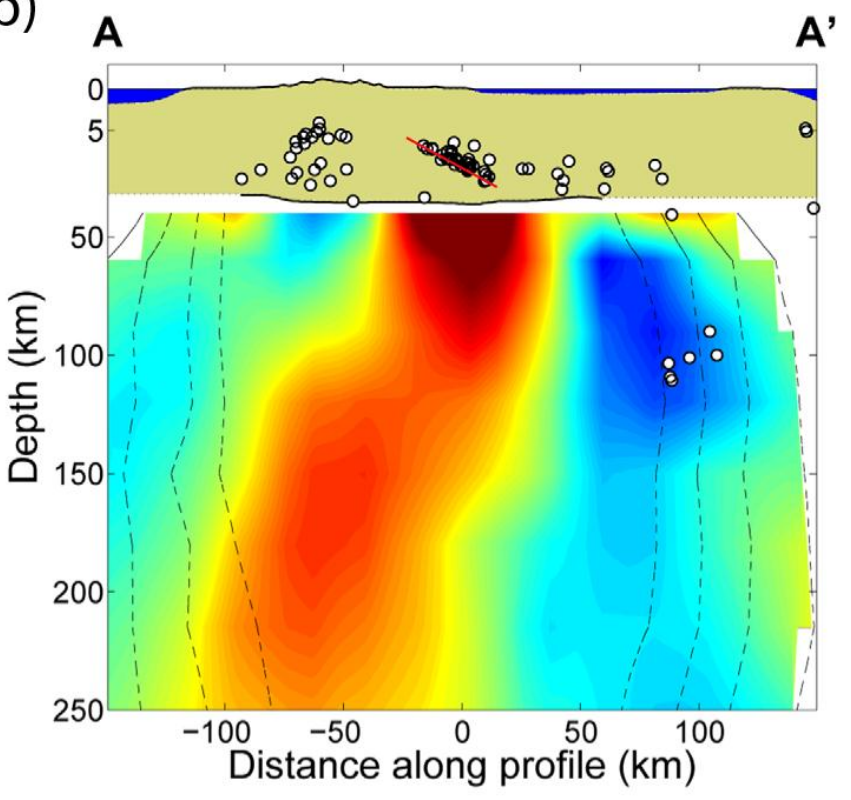

Fig. 10 - Spatial P-wave velocity variation within the Woodlark Rift. a) Map showing $90 \mathrm{~km}$ depth. Note the positions of Collingwood Bay (CB), Cape Vogel Peninsula (CVP), the D'Entrecasteaux Islands (DI), Goshen Fault Zone (GFZ), and Mai'iu Fault (see text for definitions). Parts of the Mai'iu Fault inferred to be active (inactive) are coloured red (grey). b) N-S cross-section - note variable vertical scale. Moho Depth is generated using receiver functions. Note the slow anomaly beneath the D'Entrecasteaux Islands and north of Cape Vogel Peninsula, indicating mantle extension and shallow asthenospheric mantle. Also note the linear, $31^{\circ}$ dipping band of microseismicity (red line) north of Cape Vogel Peninsula. From Eilon et al. (2015).

While the onset and evolution of oceanic spreading within Woodlark Basin is well constrained by seafloor fabric and seafloor magnetisation, the onset and evolution of continental rifting within the Woodlark Rift is not well known (Taylor et al., 1999); however there is abundant evidence for extension in the Woodlark Basin. At the broadest scale, continental rifting is suggested by N-S separation of the Pocklington Rise from the Woodlark Rise (Petersen and Buck, 2015). However, in contrast to high geothermal gradients expected for active rifts (Biswas, 1982), the Woodlark Rift is characterised by very low geothermal gradients of $18.2^{\circ} \mathrm{C} \mathrm{km}^{-1}$ (Martinez et al., 2001; Tjhin, 1976). The implications of this are unknown. Microplate subrotations and resultant extension within the Woodlark Rift have been demonstrated through campaign GPS studies (Wallace et al., 2014; Wallace et al., 2004). Both onshore (e.g., Bickel, 1974; Davies and Smith, 1974; Little et al., 2007; Smith and Davies, 1976) and offshore (Fitz and Mann, 2013b) extensional geological structures within the Woodlark Rift have been mapped, though detailed studies have concentrated on northdipping normal faults bounding the D’Entrecasteaux Islands. 
The D'Entrecasteaux Islands contain ultra high-pressure (UHP) rocks, which have been exhumed and sub-aerially exposed, which were metamorphosed at eclogite-coesite facies (up to $26 \mathrm{kbar}$ ) and crystallised between ca. 8-2 Ma (Baldwin et al., 2004; Baldwin et al., 2008; Gordon et al., 2012; Little et al., 2013; Little et al., 2011; Monteleone et al., 2007). Exhumation of the D'Entrecasteaux Islands has been ascribed to trans-crustal diapirism (Ellis et al., 2011), or extensional reactivation of an inherited subduction zone (Petersen and Buck, 2015). The SDM MCC on the Papuan Peninsula is thought to have been exhumed since the Pliocene (Smith and Davies, 1976). Rapid deposition of Pliocene sedimentary formations on the Papuan Peninsula is inferred to have been driven by subaerial exhumation and erosion of the SDM (Davies, 1980a; Smith and Davies, 1976). Such deposition occurred in the context of the Cape Vogel Peninsula structural high, formed from the Dabi Volcanics and overlying onlapping Ruaba Sandstone (Bickel, 1974). Raised Pliocene-Holocene coral reefs exposed in coastal areas on the Papuan Peninsula and the D'Entrecasteaux Islands provide evidence for uplift associated with slip on the Mai'iu Fault, resulting in footwall uplift (Little et al., 2007; Mann et al., 2009; Mann and Taylor, 2002; Smith and Davies, 1976).

Extension in the Woodlark Rift is expressed within the upper brittle crust as normal faulting, MCC (Fig. 8), and microseismicity (Fig. 10) concentrated along mapped normal faults (Eilon et al., 2015). West-propagating oceanic spreading of the Woodlark Basin (Fig. 8) presently terminates at Moresby Seamount OCC (Taylor et al., 1995), and transitions to the west into the Woodlark Rift (Taylor et al., 1995). ${ }^{206} \mathrm{~Pb}^{*} /{ }^{238} \mathrm{U}$ ages $(1.98 \mathrm{Ma})$ of zircons from granitoids, that were synkinematically emplaced into UHP meta domes, place a minimum constraint on the exhumation of gneiss domes of the D'Entrecasteaux Islands from mantle depths (Baldwin and Ireland, 1995). This age is bracketed by the ca. 8-1.5 Ma age of Kwinimage Formation conglomerates encountered in the Goodenough-1 well (Garside I.E., 1973; Taylor and Huchon, 2002), which are derived from the erosion of the D'Entrecasteaux Islands domes (Baldwin and Ireland, 1995). Some ascribe the exhumation of gneiss domes of the D'Entrecasteaux Islands to the buoyant ascent of Rayleigh-

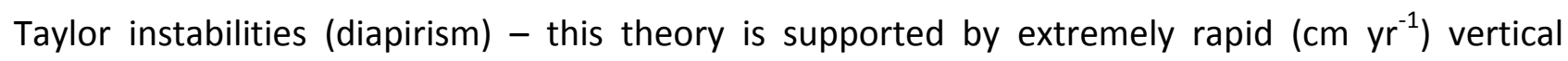
ascent rates, peak metamorphism during the Miocene-Pliocene, and westward younging of the timing of peak metamorphism (parallel to the propagation direction of the Woodlark Rift; Ellis et al., 2011; Little et al., 2011). Alternatively, domes of the D'Entrecasteaux Islands may have been exhumed along a reactivated subduction zone (eduction; Petersen and Buck, 2015). This model is reminiscent of the SDM, which is thought to have been exhumed through extensional reactivation of part of the Owen Stanley Fault, a Paleocene subduction thrust (Davies, 1980a). 
The Woodlark Rift upper mantle beneath the D'Entrecasteaux Islands and Collingwood Bay (Fig. 10; 50-250 km depth) displays a strong N-S P-wave velocity anisotropy, suggestive of mantle extension, in contrast to the dominantly E-W mantle anisotropy of nearby unrifted continental lithosphere (Eilon et al., 2016; Eilon et al., 2015). Lithospheric mantle is almost entirely absent beneath the Woodlark Rift, being replaced by buoyant asthenospheric mantle (Eilon et al., 2015), in contrast to a more moderate amount (Fitz and Mann, 2013b) of upper crustal extension, calculated from the summation of fault offsets. This is suggestive of depth-dependent rifting (Eilon et al., 2015; Fitz and Mann, 2013b).

It is unclear how much extension has been accomplished within the Woodlark Basin. Total continental extension accommodated within the Woodlark Rift, inferred from the 6-3.6 Ma Woodlark basin Euler rotation pole calculated from Woodlark Basin seafloor spreading data, is predicted to be $\sim 95 \mathrm{~km}$ at $149^{\circ} \mathrm{E}$, increasing to $220 \mathrm{~km}$ at $151^{\circ} 6^{\prime} \mathrm{E}$ (near Moresby Seamount; Fang, 2000; Taylor et al., 1999). However the Euler pole describing extension within the Woodlark Rift differs from that describing extension within Woodlark Basin, as evidenced by campaign GPS studies (Wallace et al., 2014; Wallace et al., 2004).

Seismic reflection studies employing sedimentary backstripping and summing of fault heaves measure more moderate extension magnitudes (Fitz and Mann, 2013a). Fitz and Mann (2013b) calculate $2.3 \mathrm{~km}$ extension over a $100 \mathrm{~km} \mathrm{~N}$-S profile in Kiribisi Basin (Fig. 8), north of Cape Vogel Peninsula $(\beta=1.02)$. South of this profile, the Mai'iu Fault has accommodated at least $25 \mathrm{~km}$ of horizontal extension, as evidenced by the drainage-parallel length of its exhumed, domed footwall scarp. Extension accommodated by smaller onshore faults has not been estimated. Within Goodenough Basin (Fig. 8), Fitz and Mann (2013b) calculate 9.1 km of extension accommodated within the Goshen Fault Zone over a $72 \mathrm{~km} \mathrm{~N}-\mathrm{S}$ profile immediately east of Cape Vogel Peninsula $(\beta=1.21)$, and $>5.9 \mathrm{~km}$ extension over a $75 \mathrm{~km} \mathrm{~N}-\mathrm{S}$ profile south of Goodenough Island $(\beta=1.1)$. However these estimates ignore extension associated with faults bounding MCC of the D'Entrecasteaux Islands (Little et al., 2013; Little et al., 2011). Using the seismic interpretation of Fitz and Mann (2013b), Petersen and Buck (2015) calculate extension at Fergusson Island to be $<100$ $\mathrm{km}$, assuming extensional reactivation of some as yet unidentified, inherited subduction thrust, and applying the 3.6-0.5 Ma Euler Pole of Taylor et al. (1999) over the entire period. Middle and lower crustal extension for the same three profiles of Fitz and Mann (2013b), estimated by calculating water-loaded subsidence values using flexural backstripping and structural retrodeformation, are larger, at $20.7 \mathrm{~km}(\beta=1.25), 9.2 \mathrm{~km}(\beta=1.4)$, and $11.1 \mathrm{~km}(\beta=1.25)$, respectively, confirming depth-dependent extension within the Woodlark Rift (Fitz and Mann, 2013b). 


\subsection{The Mai'iu Fault}

The Mai'iu Fault is a LANF located at the far western extremity of the Woodlark Rift, Eastern Papua New Guinea (Fig. 11). It is considered to be an extensionally reactivated part of the Owen Stanley Fault, an original Late Cretaceous-Paleocene subduction thrust which divides the Australian Margin to the south, from the SW-obducted Papuan Ultramafic Belt (PUB) to the north (Fig. 12, Fig. 8), (Webb et al., 2008). The SDM (Fig. 11, Fig. 8) is a MCC bounded on its northern side by the north-dipping Mai'iu Fault, which forms the Mai'iu Fault footwall. The SDM is large and corrugated and is the westernmost MCC within the Woodlark Rift. The surface of Dayman Dome is smooth and devoid of rider blocks (barren), with the exception of the Gwoira rider block, located within the Gwoira embayment, which is a depression in the Mai'iu Fault surface between Dayman Dome and Mt Masasoru (Fig. 11). While the domal nature of the SDM has been appreciated by many workers (e.g., Ollier and Pain, 1980; Smith and Davies, 1976), the SDM was only first identified as a MCC by Davies and Warren (1988).

Lindley (2014) and Lindley (2016) provide an alternative interpretation for the formation of the SDM. This author suggests that the SDM was exhumed due to $\sim 8 \mathrm{~km}$ of approximately vertical slip (up to the north) on the Keveri Fault, motivated by the buoyant ascent (e.g., Ollier and Pain, 1980, 1981) of the SDM as a roof pendant atop a large, buoyant igneous body (e.g., the Suckling Granite). In this model the metamorphic foliation within the Gorupu Metabasalt developed as a consequence of its adjacency to the rising igneous body (Lindley, 2014). Lindley (2014) also interprets the Suckling Dome and Dayman Domes as structures of differing ages, based on the greater degree of fluvial incision of the former. However I reject their interpretation for the following reasons. This interpretation of the Keveri Fault as a major dip-slip fault is inconsistent with the same author's observation of horizontal slickenlines on the Keveri Fault (Lindley, 2014). Additionally, this proposed mechanism for the formation of the metamorphic foliation within the Gorupu Metabasalt fails to explain the increase in metamorphic grade towards the north (Davies and Smith, 1974). Furthermore, this interpretation contradicts significant evidence for the exhumation of the SDM as a contiguous body along the north-dipping Mai'iu Fault (Daczko et al., 2011; Davies, 1980a; Davies and Warren, 1988), as will be discussed within this thesis. 


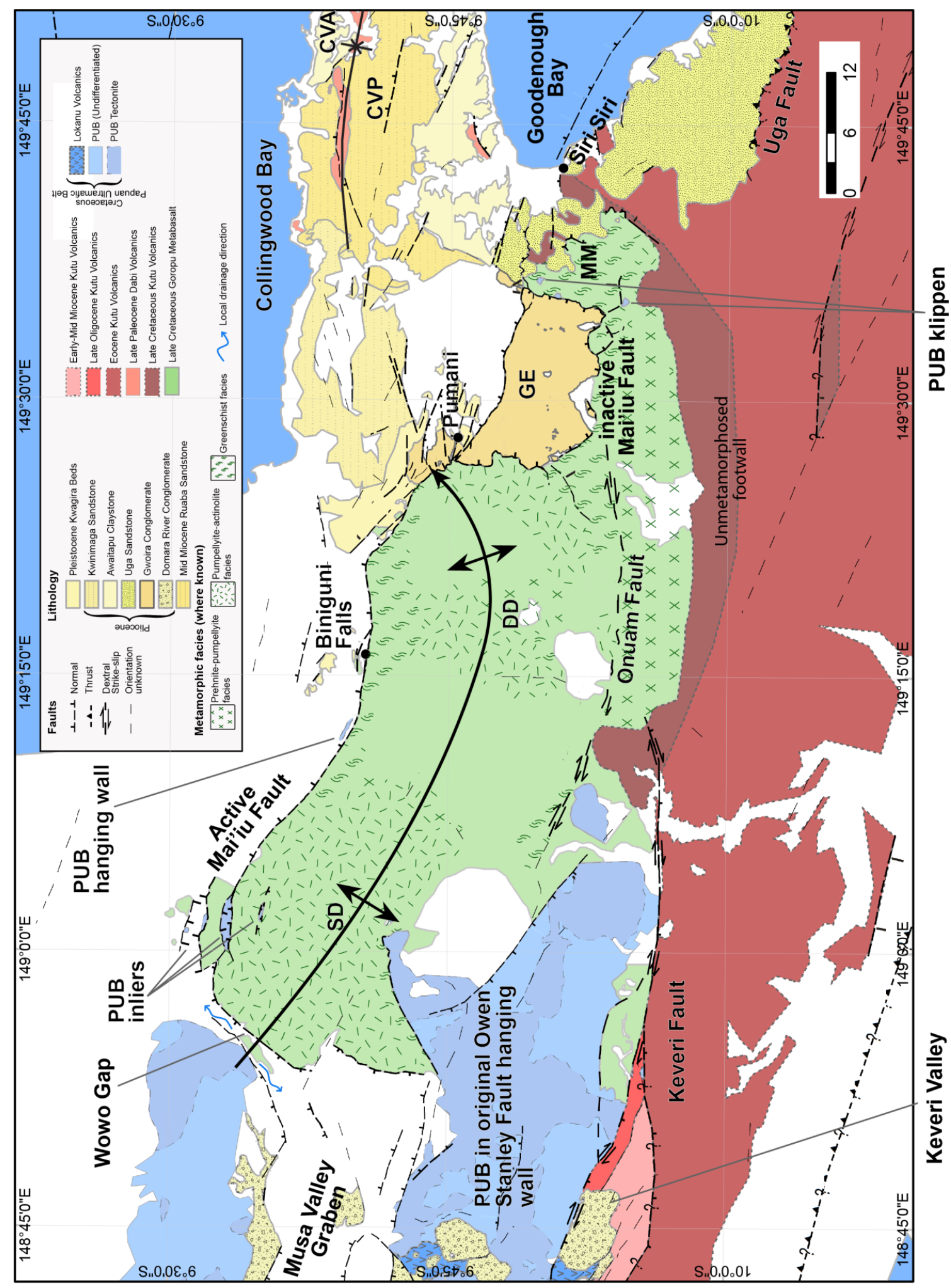

Fig. 11 - Geological Map of the SDM; Dayman Dome (DD), Suckling Dome (SD), and Mt Masasoru (MM). Note the corrugated Mai'iu Fault trace, which bounds the SDM; Cape Vogel Anticline (CVA); Cape Vogel Peninsula (CVP); the Gwoira embayment (GE); and the Papuan Ultramafic Belt (PUB). Geology after Davies and Smith (1974), Bickel (1974), Lindley (2014). Note PUB inliers (fault bounded); PUB klippens (on the present Mai'iu Fault hanging wall); a wind-gap located at Wowo Gap; and PUB located on the hanging wall of the Owen Stanley Fault (now located on the footwall of the Mai'iu Fault). The Uga Fault (new name) is discussed further in section 3.5.5. The fault contact between the PUB tectonite and the Gorupu Metabasalt represents the Paleogene Owen Stanley Fault, part of which has been extensionally reactivated by the Neogene Mai'iu Fault. 
As mentioned above, campaign GPS data of Wallace et al. (2014) suggest that the Mai'iu Fault may be rapidly slipping, accommodating 7-9 mm/yr of $\sim \mathrm{N}-\mathrm{S}$ horizontal extension (Fig. 9). At the surface the Mai'iu Fault dips north at $21^{\circ}$, though it may form a plane dipping $31^{\circ}$ between $12-29 \mathrm{~km}$ depths north of Cape Vogel Peninsula (Fig. 12, Fig. 10) as suggested by a dipping band of microseismicity that projects down-dip of the Mai'iu Fault as measured at the surface (Abers et al., 2016; Eilon et al., 2015). However this microseismicity is laterally discontinuous, with no microseismicity observed on the fault west of Cape Vogel Peninsula (Eilon et al., 2015). Wallace et al. (2014) also infer that the Mai'iu Fault may be slipping largely aseismically, based on faultlocking inversions of their campaign GPS data, and low rates of historical seismicity in the Woodlark Rift (Abers et al., 1997). 


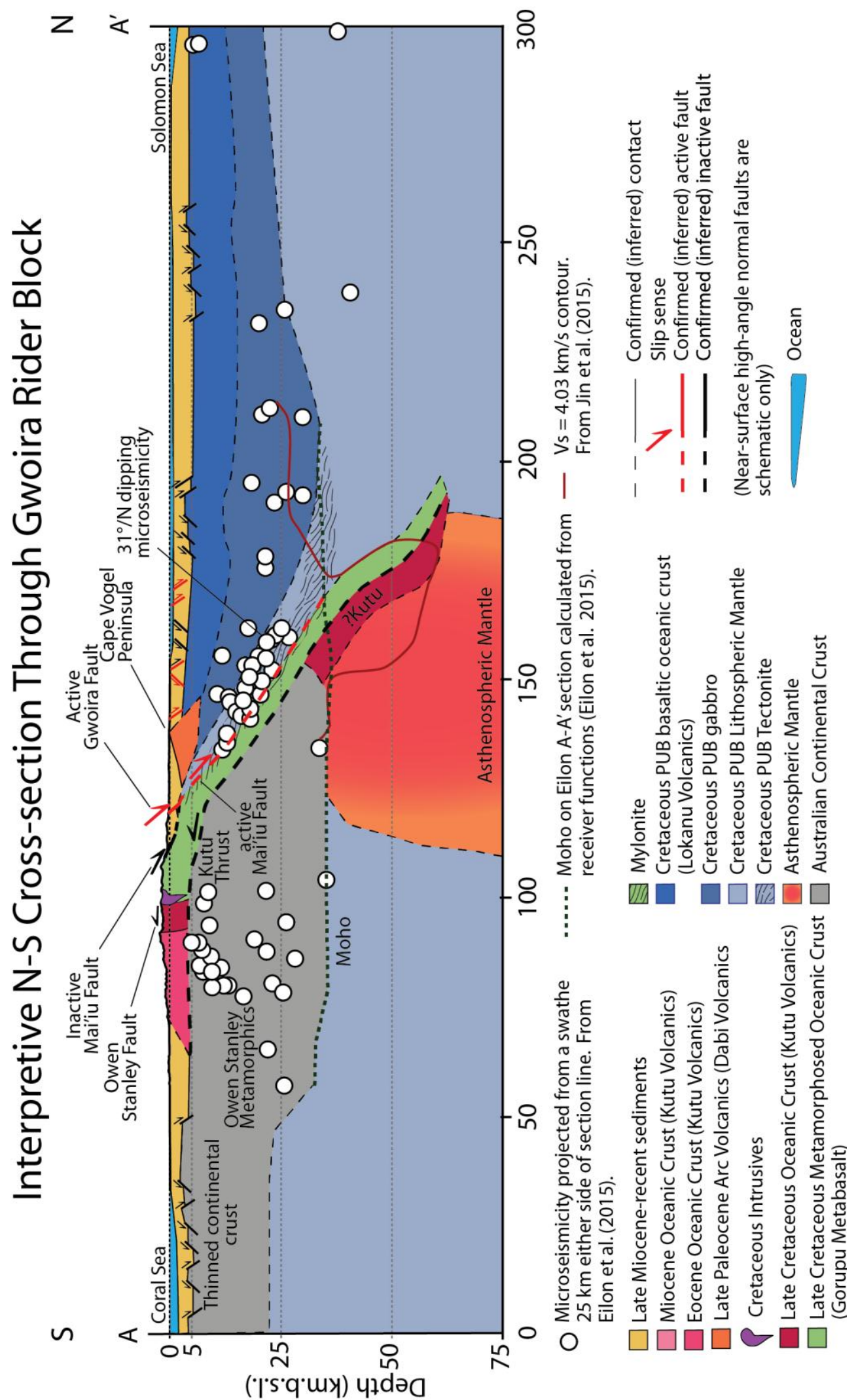

Fig. 12 - Interpretative cross-section of crustal structure beneath the Papuan Peninsula. Section line is N-S and located $12.5 \mathrm{~km}$ west of the profile A-A' of Eilon et al. (2015). On-shore geology after Davies and Smith (1974). Microseismicity, Moho and depth after Eilon et al. (2015). Mai'iu Fault orientation assumes planar dip indicated by microseismicity. Southern thinned continental crust and upper crustal faulting after Ott and Mann (2015); PUB configuration based on seismic profile $200 \mathrm{~km} \mathrm{NW}$ of Finlayson et al. (1977). Solomon Sea sedimentary thicknesses and faulting after Fitz and Mann (2013b). Slab of subducted material inferred based on mean shear wave velocity profile of Jin et al. (2015), and based on the bets-fit seismic model of Finlayson et al. (1977). 
The Mai'iu Fault is composed of two main strands (Fig. 11). The active Mai'iu Fault bounds the SDM to the north, and extends north of the main body of Gwoira Conglomerate. The inactive Mai'iu Fault bounds the Gwoira Conglomerate to the south, and merges with the active Mai'iu Fault to the east and west. The triple-junction formed by the intersection of the surface of Dayman Dome with the inactive Mai'iu Fault to the east (Fig. 11) is not understood (Davies, 1980a). Mylonites that are exposed in the Mai'iu Fault footwall provide evidence that the Mai'iu Fault has acquired significant displacement despite its shallow dip (Daczko et al., 2011). The Mai'iu Fault juxtaposes back-tilted metamorphic and sedimentary rocks in the southern footwall against PUB tectonite in the northern hanging wall (Smith \& Davies, 1976).

Lithologically, the SDM is principally comprised of the Gorupu Metabasalt. The metamorphic grade in general increases from south to north. Prehnite-pumpellyite facies assemblages are exposed south of the Onuam Fault (Fig. 11), and in isolated pods (Davies, 1980a). Davies (1980a) speculates that these pods may represent isolated bodies which did not equilibrate, or may be bounded by unmapped thrust faults that were active during Paleocene subduction. Further north, much of the SDM is characterised by pumpellyite-actinolite facies assemblages (Davies, 1980a). These pumpellyite-actinolite facies assemblages have been interpreted by Daczko et al. (2009) to be stable at 6.5-9 kbar (indicative of original burial to 20-30 km), based on the presence of glaucophane and lawsonite. Within $500 \mathrm{~m}$ of the Mai'iu Fault (Fig. 11) the metamorphic grade increases to greenschist facies (Davies, 1980a), which has been interpreted by Daczko et al. (2009) to represent peak metamorphism at 5.9-7.2 kbar and $425^{\circ} \mathrm{C}$.

A minimum amount of dip-slip accommodated by the Mai'iu Fault may be estimated in several ways. The length of sub-aerially exposed megamullions on the exhumed Mai'iu Fault surface of Dayman Dome (Fig. 11) suggests the Mai'iu Fault has accrued a minimum of $>24 \mathrm{~km}$ of horizontal extension. However the spatial distribution of Gorupu Metabasalt (Davies and Smith, 1974; Lindley, 2014) suggests it may have accrued a minimum of $43 \mathrm{~km}$ of horizontal extension at Mt Suckling, decreasing to a minimum of $13 \mathrm{~km}$ of extension at Mt Masasoru (Fig. 11). This alongstrike variability in total extension is supported by fault slip rates, informed by campaign GPS (Fig. 9). Exhumation of greenschist facies rocks along the Mai'iu Fault from $25 \mathrm{~km}$ depths (Daczko et al., 2009), assuming the fault is planar and dipping 30\% $\mathrm{N}$ (Abers et al., 2016; Eilon et al., 2015) requires on-fault slip of $\sim 50 \mathrm{~km}$, which increases our estimate of Mai'iu Fault horizontal extension of $\sim 40 \mathrm{~km}$ (Fig. 12). 
The Mai'iu Fault has probably been active since the Late Miocene-Pliocene (Daczko et al., 2011; Davies and Jaques, 1984; Smith and Davies, 1976). However, there is no direct evidence for the onset of exhumation, and no direct observations of fault slip rate have been made. The Gwoira Conglomerate, a proximal syn-tectonic sedimentary formation derived from the sub-aerial erosion of the SDM, is inferred to be Pliocene, based on correlation with other more distal correlative units of that age (Smith and Davies, 1976) - however the age of these formations are not tightly constrained. Assuming a horizontal slip rate of $7-9 \mathrm{~mm} / \mathrm{yr}$, indicated by campaign GPS measurements of Wallace et al. (2014), the observed $>25 \mathrm{~km}$ slip-parallel horizontal length of the smooth, corrugated surface of Dayman Dome suggests the Mai'iu Fault was active since ca. 2.83.6 $\mathrm{Ma}$ (assuming a constant rate of horizontal extension).

Motion on the Mai'iu Fault is also constrained by the Suckling Granite and Mai'iu Monzonite, which have both intruded the footwall. One LA-ICP-MS ${ }^{206} \mathrm{~Pb}-{ }^{238} \mathrm{U}$ age $(3.3 \pm 0.1 \mathrm{Ma})$ exists for a single granite float sample (inferred to be Suckling Granite; Caffi, 2008). This is consistent with one biotite K-Ar age for the Suckling Granite of $3.32 \pm 0.06\left(\sim 300^{\circ} \mathrm{C}\right.$ closure temperature), (Davies and Smith, 1974), and three hornblende K-Ar ages for the Mai'iu Monzonite, which range between 4.37-6.26 Ma ( $550^{\circ} \mathrm{C}$ closure temperature), (Davies and Smith, 1974). These intrusives cut the mylonitic fabric, placing a latest-age constraint upon the age of mylonite development (Davies and Smith, 1974). They are thought to have been intruded at depths of $\sim 12 \mathrm{~km}$ (4 kbar), based on andalusite and staurolite within Gorupu Metabasalt hornfels facies adjacent to the Mai'iu Monzonite (Daczko et al., 2009).

While the Goshen Fault Zone (Fig. 10) accommodates extension south of Cape Vogel Peninsula (Fitz and Mann, 2013b; Fitz, 2011), the Mai'iu Fault is thought to accommodate nearly 100\% of extension (Fig. 9) west of $\sim \mathrm{E} 149^{\circ} 30^{\prime}$ (Wallace et al. 2014). Patterns of faulting and microseismicity (Abers et al., 2016) suggest that the Goshen Fault Zone and the Ward Hunt Strait Fault Zone may merge with the active Mai'iu Fault near Pumani village (Fig. 8, Fig. 10). This point of intersection would lie $20 \mathrm{~km} \mathrm{SE}$ of the boundary between the Trobriand and Goodenough blocks of Wallace et al. (2014), (Fig. 9). While transtensional focal mechanisms have been calculated for the Ward Hunt Strait Fault Zone (Abers et al., 2016), the geometry of this fault zone is reminiscent of extensional transfer faults generated in analogue modelling of (Mattioni et al., 2006), where the authors model the lateral transition of high-angle normal faulting on the rift axis, into a LANF that reactivates an inherited nappe that dips obliquely to the rift axis. 
The Mai'iu Fault footwall has been exhumed and back-rotated, as suggested by its smooth, domed and corrugated morphology, with parallel drainages that parallel the extension direction (Spencer, 2010). Based on the occurrence of PUB in the Mai'iu Fault hanging wall, the fault is interpreted to represent an extensionally reactivated part of the Owen Stanley Fault (Abers et al., 1997; Daczko et al., 2009; Daczko et al., 2011; Davies, 1980a; Davies and Jaques, 1984; Davies and Warren, 1988; Spencer, 2010; Swift, 2015).

\subsection{Regional Stratigraphy}

\subsubsection{Basement Stratigraphy}

Basement rocks exposed on the Papuan Peninsula comprise several Cretaceous-Middle Miocene formations of ophiolitic, arc-volcanic, and oceanic affinity. These rocks structurally overlie Australian continental crust (including the Kagi Metamorphics), which is exposed west of Mt Suckling. Their tectono-stratigraphic relationships with one another are not completely understood. Of particular note in this study are the Gorupu Metabasalt and Papuan Ultramafic Belt. Their characteristics are outlined below:

\subsubsection{The Papuan Ultramafic Belt}

The Papuan Ultramafic Belt (PUB) is an ophiolitic association comprising layered serpentine tectonite (locally $\sim 3 \mathrm{~km}$ thick), overlain by gabbro ( $4 \mathrm{~km}$ thick), which is in turn overlain by the 4-6 km thick Lokanu Volcanics (MORB basalt; Davies, 1971; Davies and Jaques, 1984; Davies et al., 1984; Smith and Davies, 1976).

The crystallisation age of the Lokanu Volcanics has been dated at $116 \mathrm{Ma}$ using pyroxene $\mathrm{K}-\mathrm{Ar}$ (Smith and Davies, 1976) - however an age of 147-150 Ma is indicated by K-Ar of gabbro samples (Davies et al., 1984; Davies and Smith, 1971). Formation of PUB basalts continued until 71-65 Ma, constrained by the age of fine sediment foraminiferal assemblages within the PUB basalts (Davies, 2001). The crystallisation age of the metamorphic sole of the PUB is much younger, and is discussed in section 2.5.2.

The PUB is extensively exposed west of Mt Suckling, and is separated from the Gorupu Metabasalt by the Paleogene Owen Stanley Fault (Davies and Smith, 1974). The PUB tectonite principally comprises harzburgite tectonite, with underlying serpentinite, and is predominantly exposed south and west of Mt Suckling, only forming isolated klippens to the east (Davies, 1980a; Davies and Smith, 1974). The PUB tectonite appears to thin to the east (Smith and Davies, 1976). The 
Lokanu Volcanics have been encountered in Nubium-1 Well, suggesting that the PUB forms the basement for the Trobriand Platform (Buchan, 1985; Francis et al., 1987; Smith and Davies, 1976). The PUB was encountered as Paleocene gabbro and diabase in ODP leg 8 drilling near Moresby Seamount - it was there found to have a ca. 66 Ma diabase crystallisation age (Monteleone et al., 2001). The PUB forms the hanging wall basement of the Mai'iu Fault on which the Gwoira Conglomerate was deposited (Fig. 12, Fig. 13), (Davies and Smith, 1974), and also forms the basement of Cape Vogel Basin (Francis et al., 1987).

\subsubsection{The Dabi Volcanics}

The Dabi Volcanics comprise ca. $58 \mathrm{Ma}$ (whole rock K-Ar) submarine tholeiitic and boninite lavas (Walker and McDougall, 1982), and likely represent part of a volcanic arc generated during southward Paleocene obduction (Fig. 12, Fig. 13) of the PUB onto the Gorupu Metabasalt (Davies and Jaques, 1984; Davies and Warren, 1988; Lus et al., 2004). Dabi Volcanics pillow lavas, pyroclastics, and associated sedimentary components may also form the basement of Woodlark Island north of Woodlark Basin (Davies et al., 1984; Francis et al., 1987). 51-57 Ma hornblende diorites and tonalite stocks, such as the Imo Tonalite (Smith and Davies, 1976) which intrude the PUB metamorphic sole in the Musa-Kumusi divide (west of Suckling Dome, Fig. 11) may also mark Dabi Arc volcanic activity associated with the cessation of PUB emplacement (Lus et al., 2004; Smith and Milsom, 1984). The Dabi Volcanics outcrop in small fault-bounded slices on Cape Vogel Peninsula (Fig. 11).

\subsubsection{The Kutu Volcanics}

The Kutu Volcanics (nomenclature of Davies and Smith, 1974) are a 3-4 km thick Late Cretaceous-Early Miocene MORB submarine tholeiites and intercalated limestones (Chaproniere, 2009; Davies, 1980a; Davies et al., 1984). These MORB basalts formed far from terrigenous input (Davies, 1980a). While it is widely accepted that the Kutu Volcanics is structurally overlain by the allochthonous PUB (e.g. Daczko et al., 2011; Smith and Davies, 1976), its relationship with underlying Australian continental crust is not well known (Fig. 13). The Kutu Volcanics outcrop to the south of the SDM, and form much of the Papuan Peninsula (Fig. 8).

Rogerson et al. (1984) and Williamson et al. (1983) suggest that the Cretaceous part of the Kutu Volcanics may correlate with the Lokanu Volcanics (uppermost part of the PUB), which has been thrust above them. The Eocene part of the Kutu Volcanics includes the lenticular Godaguina Beds (Davies and Smith, 1974) south of Keveri Valley (Fig. 11), and may interfinger with the Kemp Welch 
Beds east of Mt Suckling (Pieters, 1978) and the Badila Beds (Smith I.E., 1970) at Mullins Harbour (Fig. 8). The Late Oligocene (Chaproniere, 2009) Ada'u Limestone is a probable sedimentary interbed within the Kutu Volcanics (Lindley, 2014; Macnab, 1967; Smith and Davies, 1976). The Kutu Volcanics have probably been thrust above Australian continental crust (Rogerson et al., 1984), which locally outcrops as the Kagi Metamorphics part of the Owen Stanley Metamorphics (Drummond et al., 1979; Smith and Davies, 1976), although this relationship is unclear (Ferris et al., 2006; Pieters, 1978).

A thin slice of Late Oligocene Kutu Volcanics has been dated using foraminiferal assemblages in the Kutu Volcanics and Ada'u Limestone in Keveri Valley (Chaproniere, 2009; Lindley et al., 2010). The youngest part of the Kutu Volcanics, south of Keveri Valley, is Early-Middle Miocene in age based on planktonic foraminifera described by Macnab (1967) from the Mount Clarence Calcilutite Member, and Argillaceous Limestone (nomenclature of Macnab, 1967). These ages are confirmed by recent revisional micropaleontological analyses of Chaproniere (2009).

The tectono-stratigraphic context of the Kutu Volcanics is not fully understood. The Kutu Volcanics, together with the Gorupu Metabasalt, probably comprise a single thrust sheet emplaced from the north (Davies, 1980a; Davies and Jaques, 1984), bounded above by the PUB and below by Australian continental crust. This thrust sheet represents an ophiolite that was emplaced more recently than the PUB (Rogerson et al., 1984; Williamson et al., 1983). However Pieters (1978) interpret the Kutu Volcanics to represent Late Cretaceous-Middle Eocene Coral Sea oceanic crust, and Davies et al. (1984) and Smith and Milsom (1984) note that it is possible that the Cretaceous section of the Kutu Volcanics is part of the PUB, while the Eocene is represented by Coral Sea mid-ocean basalts. However, these interpretations conflict with $>150 \mathrm{~km}$ separation of the Eocene Kutu Volcanics from Coral Sea basalts, and with the fact that the northern-most Coral Sea crust is 61.2 Ma (Paleocene; Gaina et al., 1999), while southern-most Kutu Volcanics are Middle Miocene. I prefer the interpretation that the Kutu Volcanics is entirely equivalent to the Lokanu Volcanics of the PUB.

\subsubsection{The Gorupu Metabasalt}

The Gorupu Metabasalt mainly comprises metamorphosed pillow lavas, with subsidiary schists (Bonenau Schist member) and intercalated limestones, derived from the metamorphism of midocean basalts and associated sediments (Davies and Smith, 1974; Smith and Davies, 1976). Metamorphic grade is up to greenschist facies at 6-9.5 kbar (20-30 km depths) and $425^{\circ} \mathrm{C}$, and was 
a consequence of Paleocene subduction (Daczko et al., 2009). The metamorphic grade of the Gorupu Metabasalt (Fig. 11) decreases southward to pumpellyite-actinolite closer to the interior of the SDM, and further decreasing to prehnite-pumpellyite to the south of the Onuam Fault (Davies, 1980a). The Gorupu Metabasalt is entirely Late Cretaceous (Maestrichtian; Davies and Smith, 1974), and may be equivalent to the Emo Metamorphics exposed further west, although the Emo Metamorphics have not been independently dated (Davies and Jaques, 1984; Pieters, 1978). The Gorupu Metabasalt shares a gradational contact with the unmetamorphosed Kutu Volcanics to the south (Davies and Smith, 1974; Smith and Davies, 1976).

\subsubsection{Plio-Pleistocene Stratigraphy}

Here I provide a broad overview of Late Miocene-recent sedimentary formation exposed on Cape Vogel Peninsula. Many of these formations have been correlated with formations encountered in the Goodenough-1 and Nubium-1 Wells (Francis et al., 1987). Of particular note in this study is the Gwoira Conglomerate; other Plio-Pleistocene formations are only discussed insofar as they relate to the Gwoira Conglomerate.

\subsubsection{The Gwoira Conglomerate}

The Gwoira Conglomerate (Fig. 13), as previously documented, is a 1050 m thick, well lithified, coarse, sparsely fossiliferous (Caffi, 2008), poorly sorted conglomerate with sandstone and siltstone interbeds, that was derived chiefly from erosion of the Gorupu Metabasalt of the SDM (Caffi, 2008; Smith and Davies, 1976). It has not been independently dated, and is inferred to be Pliocene based on correlation with the Uga Sandstone, Kwinimage Sandstone, and Awaitapu Claystone (Fig. 13), (outlined below; Bickel, 1969; Davies and Smith, 1974). The Domara River Conglomerate farther to the NW may also be a correlative formation. The Gwoira Conglomerate is exposed as a footwall-bounded slice (rider block) that is folded within a fault corrugation between Dayman Dome and Mt Masasoru (Fig. 11). This inactive fault slice is bounded by the inactive Mai'iu Fault to the south and the active Mai'iu Fault to the north. The Gwoira Conglomerate is inferred to have been deposited approximately at sea-level in a high-energy paralic environment (marine and freshwater influence at sea-level; Smith and Davies, 1976), although some beds may be shallow marine (Caffi, 2008).

\subsubsection{Correlative Formations of the Gwoira Conglomerate}

The Uga sandstone (Fig. 13) is a $300 \mathrm{~m}$ thick, unlithified sandstone with interbeds of siltstone and minor conglomerate (Bickel, 1969; Davies et al., 1968). The Uga Sandstone is inferred to be 
Pliocene, although fossil assemblages only constrain it to be younger than Late MiocenePleistocene (Smith and Davies, 1976). 20 m thick foreset beds are present, and a coalesced river delta/coastal plain has been inferred as its depositional environment (Smith and Davies, 1976). The Kwinimage Sandstone is a $200 \mathrm{~m}$ thick sandstone with cyclically interbedded conglomerate, siltstone and claystone. Plant fossils indicate a likely spurious Eocene depositional age, based on a passing similarity to fossil remains preserved in New South Wales (White, 1970). The formation is more likely Pliocene (Smith and Davies, 1976), and is inferred to be deposited in a marginal marine environment (Davies and Smith, 1974). The Awaitapu Claystone is a $360 \mathrm{~m}$ thick sparely fossiliferous calcareous claystone (Bickel, 1969). The northern part of the formation, on the northern coast of Cape Vogel Peninsula (Fig. 11), is dated as Pliocene based on foraminiferal assemblages (Bickel, 1969; Bickel, 1974), although no age constraints exist for the part on the southern coast of Cape Vogel Peninsula (Davies and Smith, 1974). The Awaitapu Claystone has been assigned a coastal plain-marine depositional environment - the SW is dominantly terrestrial with subsidiary shallow marine interbeds, while the NE is dominantly marine (Bickel, 1974).

The Domara River Conglomerate (Lindley, 2014; Macnab, 1967; Smith and Davies, 1976; Smith and Green, 1961), exposed in the Musa and Keveri Valleys south and east of Suckling Dome, may also be equivalent to the Gwoira Conglomerate. This formation is entirely fluvial, and is derived from erosion of the PUB and Gorupu Metabasalt (Smith and Davies, 1976). K-Ar dating of interbedded volcanics suggests a Pliocene age (Smith and Davies, 1976).

\subsubsection{The Kwagira Beds}

The Kwagira Beds are $\sim 100 \mathrm{~m}$ thick, poorly consolidated terrestrial conglomerates, with interbedded sandstones and siltstones. The formation dominantly comprises clasts of Gorupu Metabasalt, Bonenau Schist, and gabbro. A Pleistocene age is inferred (Smith and Davies, 1976). The Kwagira Beds lie in the immediate hanging wall of the active Mai'iu Fault between Biniguni and Pumani Villages. Davies and Smith (1974) mapped the Kwagira Beds as unconformably overlying the Kwinimage Sandstone, although it may also overlie the Gwoira Conglomerate (Fig. 13). 


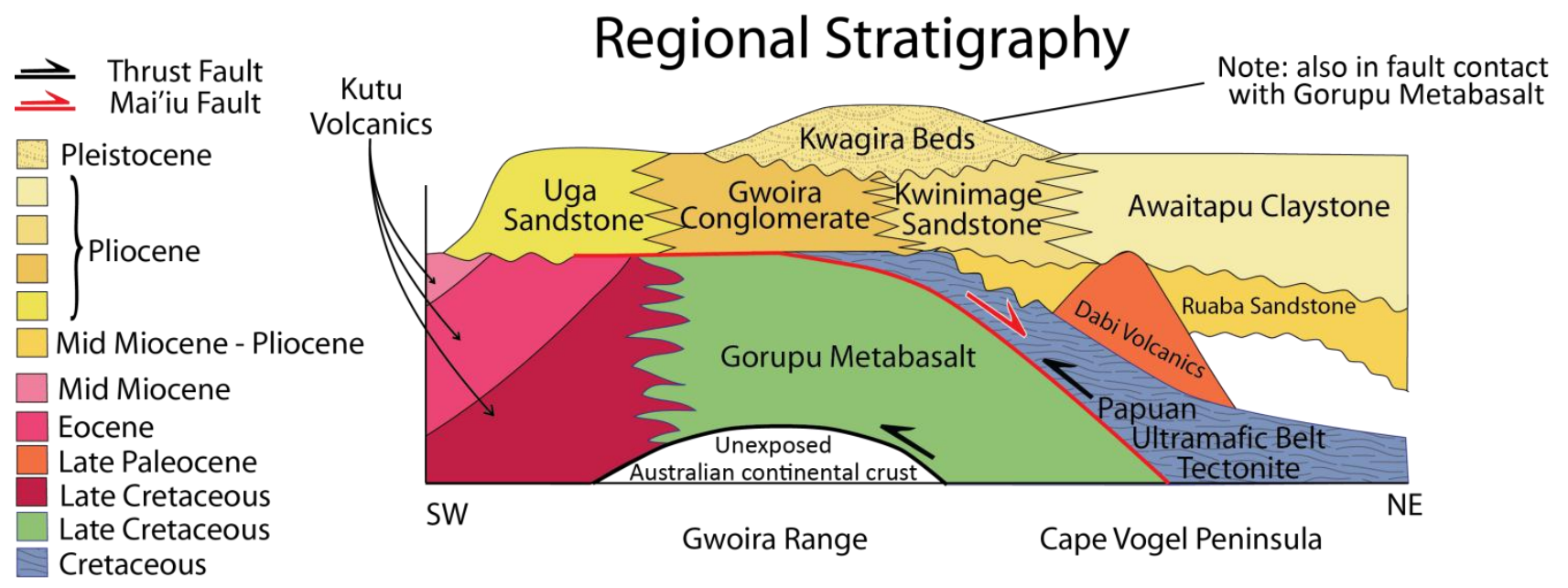

Fig. 13 - Simplified, pseudo-spatially resolved diagram illustrating stratigraphic relationships between basement formations, and Late Miocene-recent sedimentary formations exposed on Cape Vogel Peninsula. Shear sense indicators denote fault surfaces - part of the Paleocene Owen Stanley Fault (which divides the Gorupu Metabasalt from the PUB), has been reactivated during the Pliocene as the Mai'iu Fault. Modified after Davies and Smith (1974).

\subsection{Cenozoic Tectonic Evolution of the Papuan Peninsula}

Eastern Papua New Guinea's Cenozoic tectonic history is complex and highly contentious (cf. Hill and Hall, 2003; Holm et al., 2016; van Ufford and Cloos, 2005; Webb et al., 2014). A discussion of this evolution, subdivided by tectonic event, and arranged in chronological order, follows.

\subsubsection{Early Paleocene-Early Eocene Coral Sea Rifting}

NW-SE Coral Sea rifting is the oldest tectonic event known to have affected the Papuan Peninsula (Gaina et al., 1999; Ott and Mann, 2015; Smith, 1973; Weissel and Watts, 1979), although its age partly overlaps with the later obduction of the PUB (discussed in section 2.5.2). Eastern Papua New Guinea was at the northern edge of the Australian Plate as it migrated north during the Paleocene-Eocene (Heine et al., 2010; Zirakparvar et al., 2013). Coral Sea spreading (Fig. 14a), to the south of the present Papuan Peninsula, from 62-52 Ma (Gaina et al., 1999; Malusà et al., 2015) resulted in the separation of at least three hyper-extended continental fragments (the Eastern Plateau, Papuan Plateau, and Papuan Peninsula) from Australia (Ott and Mann, 2015; Pigram and Symonds, 1993). The northern flank of the Coral Sea Rift has been imaged by Swift (2012) and Ott and Mann (2015). This imagery suggests that Paleocene Coral Sea oceanic crust terminates to the north against the rifted continental margin of the Papuan Peninsula, and is unconformably overlain by Oligocene sedimentary rocks (Ott and Mann, 2015). 


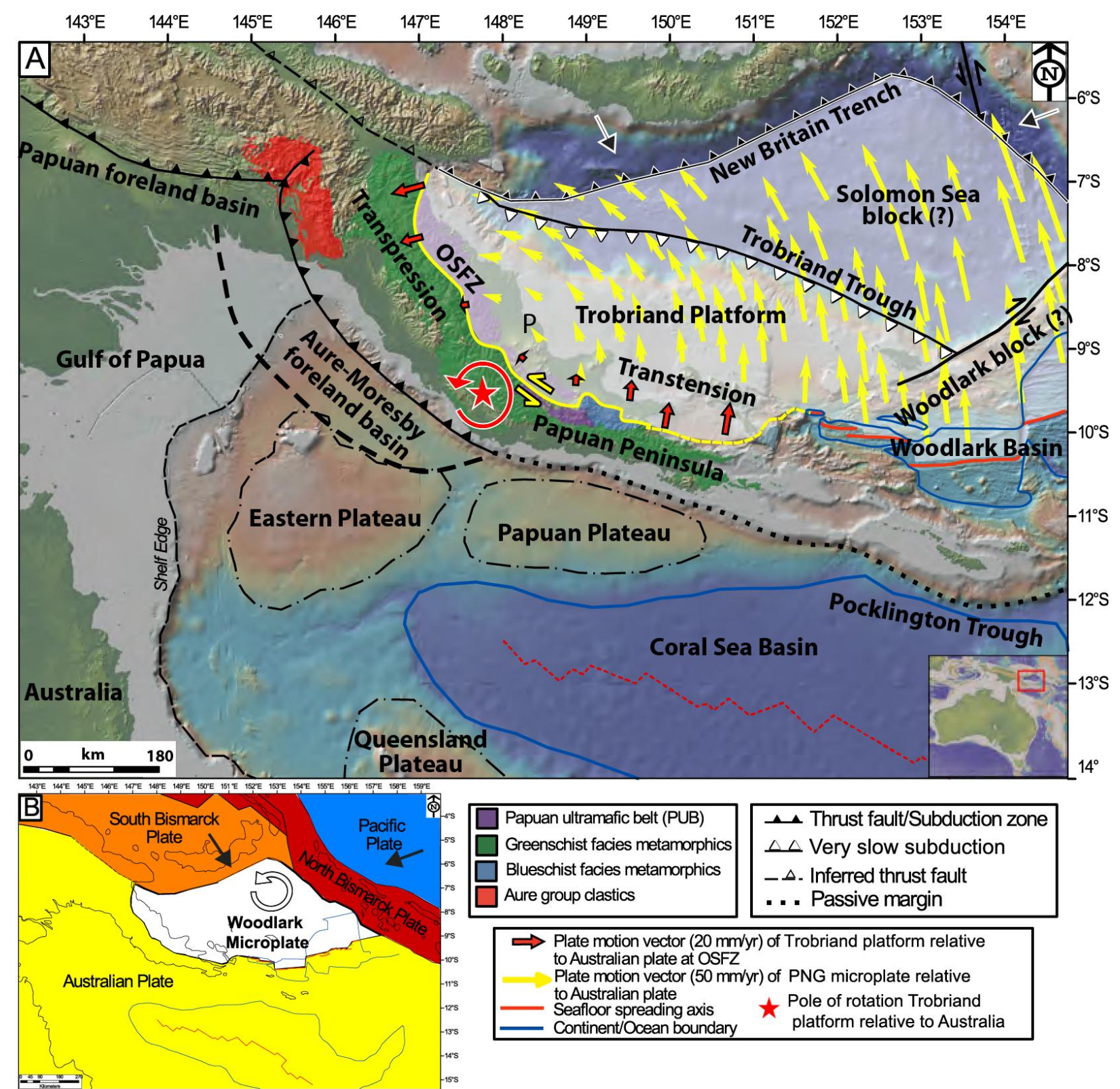

Fig. 14 - A) Detailed tectonic configuration of SE Papua New Guinea and the Woodlark Plate. Note anticlockwise rotation of the Woodlark Microplate, based on campaign GPS data (Wallace et al., 2014), and the evolution of the Owen Stanley Fault Zone (OSFZ) from transtensional to transpressional. Note the position of Popondetta $(\mathrm{P})$, and continental fragments: Eastern Plateau; Papuan Peninsula (PP); Papuan Plateau. B) Tectonic context of the Woodlark Plate. Minor modifications after Ott and Mann (2015).

\subsubsection{Late Paleocene-Early Eocene Obduction of PUB}

During the Paleocene, while Coral Sea spreading continued to the south, collision occurred between Pacific Plate oceanic lithosphere and the Gorupu Metabasalt, resulting in the subduction of the latter, and the generation of a Late Paleocene-Early Eocene island arc (Dabi Volcanics) within the former (Lus et al., 2004). This convergent event is termed the Peninsular Orogeny (van Ufford and Cloos, 2005). Davies and Jaques (1984) argue that for ca. 10-15 Myr during the Cretaceous-Late Paleocene, convergence was accommodated by a north-dipping subduction zone 
(The Owen Stanley Fault; Swift, 2015), which separated the down-going Gorupu Metamorphics and the continuous Cretaceous part of the Kutu Volcanics from the overriding PUB (Smith and Davies, 1976). The Gorupu Metabasalt was then metamorphosed under high PT conditions (Davies, 1980a; Davies and Jaques, 1984; Davies and Warren, 1988; Webb et al., 2014). This tectonic suture is preserved as the Owen Stanley Fault, which separates the PUB from the Emo Metamorphics and Kutu Volcanics along the Papuan Peninsula (Pieters, 1978), and which Finlayson et al. (1977) image dipping 15-25\%/N through Popondetta (Fig. 14a). Lindley (2014) has reinterpreted the location of the Owen Stanley Fault trace as running along the north of Cape Vogel Peninsula (north of the Mai'iu Fault), based on gravity anomalies within the 1:250,000 scale gravity dataset of (GSPNG \& BGS, 2004). However this interpretation is geologically unsubstantiated, and ignores the depth over which the gravity anomaly is resolved, and ignores the fact that the shallowest parts of the PUB within the Mai'iu Fault footwall are very thin and so likely contribute a very small gravitational signature.

Emplacement of the PUB in the Papuan Peninsula must have occurred subsequent to the formation of the Late Cretaceous Gorupu Metabasalt, which it structurally overlies (Davies and Smith, 1974). A 58.3 \pm 0.4 Ma cooling event (Lus et al., 2004), derived from K-Ar daring of granulites and amphibolite facies rocks at the metamorphic sole of the PUB, marks the initiation of the emplacement of the PUB ophiolite, and the timing of its cooling below $\sim 500^{\circ} \mathrm{C}$ (Hill and Hall, 2003). This obduction event is thus contemporary with the formation of the Dabi Volcanics arc-volcanic system exposed on Cape Vogel Peninsula (Davies and Smith, 1971; Walker and McDougall, 1982), and Coral Sea spreading (Gaina et al., 1999). Obduction probably stalled due to the subduction of buoyant Australian continental crust (Kagi Crustal Unit), (Davies and Jaques, 1984).

\subsubsection{Eocene-Present (?) North Solomon Trench Subduction}

A period of south-dipping subduction at the North Solomon Trench (Fig. 8 inset) initiated at ca. 45 Ma (Holm et al., 2013), which accommodated several hundred kilometres of convergence between the Australian and Pacific Plates until it slowed following the ca. 22 Ma partial subduction of the Ontong Java Plateau (Holm et al., 2013; Mann and Taira, 2004; Petersen and Buck, 2015; van Ufford and Cloos, 2005). The North Solomon Trench propagated rapidly to the south, reaching northern New Zealand during the Late Oligocene-Early Miocene (King, 2000). Some western parts of the North Solomon Trench remain active, although less seismogenic than the north-dipping San Cristobal Trench (Holm et al., 2016; Mann and Taira, 2004). 


\subsubsection{Miocene (?) Trobriand Trough Subduction}

The evolution of the Trobriand Trough (Fig. 14a) is not well known (Holm et al., 2016; Holm et al., 2015). Seismic reflection data suggest the Trobriand Trough may have accommodated southwestdirected subduction until very recently (Lock et al., 1987). However Webb et al. (2014) and Hall and Spakman (2002) have highlighted the paucity of geophysical evidence for a south-dipping slab at the Trobriand Trough.

Some workers prefer the interpretation that the Trobriand Trough was active from the Late Oligocene-Miocene (van Ufford and Cloos, 2005). This interpretation is partly constrained by the Oligocene age of the deepest Cape Vogel Basin forearc sedimentary rocks presumably associated with this subduction, deposited on the underlying Lokanu oceanic crust (Francis et al., 1987). Subduction may have been initiated due to the jamming of the North Solomon Trench due to the impact of the buoyant Ontong Java Plateau between 25-20 Ma (Knesel et al., 2008). Subduction at the Trobriand Trough has been inferred from the Miocene (20-10 Ma) age of the so-called Maramuni Arc, an extensive chain of volcanic and intrusive complexes extending from the Papuan Central Highlands to south of Port Moresby (east of $140.5^{\circ} \mathrm{E}$ ), (Dow, 1977; van Ufford and Cloos, 2005). Trobriand Trough subduction has also been inferred to be recorded by the Early Miocene Luaga volcanic tuff and tuffaceous conglomerate (interpreted as arc volcanics), encountered at the base of Goodenough-1 Well (Fitz, 2011; Francis et al., 1987; Taylor and Huchon, 2002). However Holm et al. (2016) reject that such volcanics are associated with Trobriand Trough subduction, and instead suggest, based on plate tectonic modelling, that the Trobriand Trough may have formed at $5 \mathrm{Ma}$ in response to an anticlockwise torque applied by the anticlockwise rotation of the New Britain Trench, remaining active until $1 \mathrm{Ma}$. These authors propose that the Trobriand Trough accommodated only a small amount of shortening in the vicinity of the Papuan Peninsula (Holm et al., 2016; Holm et al., 2013).

The Trobriand Trough is presently inactive (Abers et al., 2002; van Ufford and Cloos, 2005), as evidenced by the lack of Benioff Zone seismicity (Ekström et al., 2012; Taylor and Huchon, 2002), although no direct GPS observations are available to confirm this. However, regional GPS inversion models (Wallace et al., 2014; Wallace et al., 2004), and observations of nearby normal faults (SotoCordero, 1998), suggest that if it exists, the Trobriand Trough is more likely to presently be undergoing extension than compression. 


\subsubsection{Middle Miocene (?) Subduction at Pocklington Trough}

Webb et al. (2014) propose that the Lousiade Archipelago represents the accretionary wedge of NNE-SSW oriented, north-dipping subduction of the oceanic Australian Plate beneath Papuan crust at the Pocklington Trough (Fig. 14a). The timing of Pocklington Trough subduction is not tightly constrained: a maximum age is provided by the Middle Cretaceous (120-90 Ma) depositional age of the Calvados Schist (Baldwin et al., 2012), which is a correlative of the Owen Stanley Metamorphics (Davies and Smith, 1971); and minimum age is provided by the 11-12 Ma ${ }^{40} \mathrm{Ar} /{ }^{39} \mathrm{Ar}$ age of the Panarora Volcanics (Webb et al., 2014), which cross-cuts the Calvados Schist (Smith, 1973; Webb et al., 2014). The Pocklington Trough is now inactive (Hill and Hall, 2003; Holm et al., 2016; van Ufford and Cloos, 2005; Webb et al., 2014).

\subsubsection{Late Miocene Subduction at Aure Trough}

Subduction at the Pocklington Trough may be equivalent along strike with Late Miocene subduction at the north-dipping Aure Trough (Fig. 14a) further to the NW (Ott and Mann, 2015). Seismic reflection has imaged this subduction zone SE offshore of Port Moresby (Davies et al., 2014; Ott and Mann, 2015; Swift, 2012; Williams, 2011). During the Late Miocene, convergence was accommodated in the Gulf of Papua between the down-going thinned Continental Papuan Plateau, and Papuan Peninsula continental lithosphere. This subduction zone transitioned to the SE into a Cenozoic passive margin near Hood Lagoon ( 100 km SE of Port Moresby; Ott and Mann, 2015), although discontinuous fold thrust belts persist south of Mt Suckling (Swift, 2015). Convergence is inferred to have been driven by anticlockwise rotation of the Woodlark Microplate with respect to the Australian Plate (Swift, 2015), and may still be active. Cairns et al. (2015) speculate that their observations, based on paleomagnetic data, of anticlockwise vertical-axis rotation of the Papuan Peninsula between the Early-Late Miocene may record subduction at the Pocklington Trough.

\subsubsection{Middle Miocene (?) Obduction of the Kutu Volcanics}

It is possible that one or more of these subduction episodes correspond to the emplacement of the Late Cretaceous-Middle Miocene Kutu Volcanics onto the Papuan Peninsula. The Gorupu Metabasalt and Kutu Volcanics constitute a separate ophiolite which underlies the PUB (Davies, 1980a; Rogerson et al., 1984; Williamson et al., 1983). Their emplacement must have occurred post-Middle Miocene, as the Middle Miocene (Chaproniere, 2009) part of the Kutu Volcanics lies 
structurally above the Owen Stanley Metamorphic Complex. Davies and Jaques (1984) speculate that the Kutu Volcanics and Gorupu Metabasalt may have been emplaced along a secondary rupture, following cessation of PUB obduction. I here term this thrust surface the 'Kutu Thrust'. Emplacement of the Kutu Volcanics over the Owen Stanley Metamorphic Complex is comparable along strike with the emplacement of the Emo Metamorphics above the buoyant continental Kagi Metamorphics (Fig. 15), to the west of Mt Suckling (Pieters, 1978). I suggest that the Emo crustal unit and the Kutu Volcanics-Gorupu Metabasalt comprise a contiguous thrust sheet, emplaced during the Middle-Late Miocene, enclosed within two north-dipping paleo-subduction interfaces. The basis for this model has been described near Popondetta (Davies and Jaques, 1984) sometime following the emplacement of the PUB the subduction zone stepped backwards to the south, developing a second low-angle suture between the Kagi and Emo Metamorphics (Davies and Jaques, 1984; Davies et al., 1997). The initiation of this event may be recorded by the EoceneOligocene greenschist facies metamorphism of the underlying Kagi Metamorphics (Pieters, 1978).

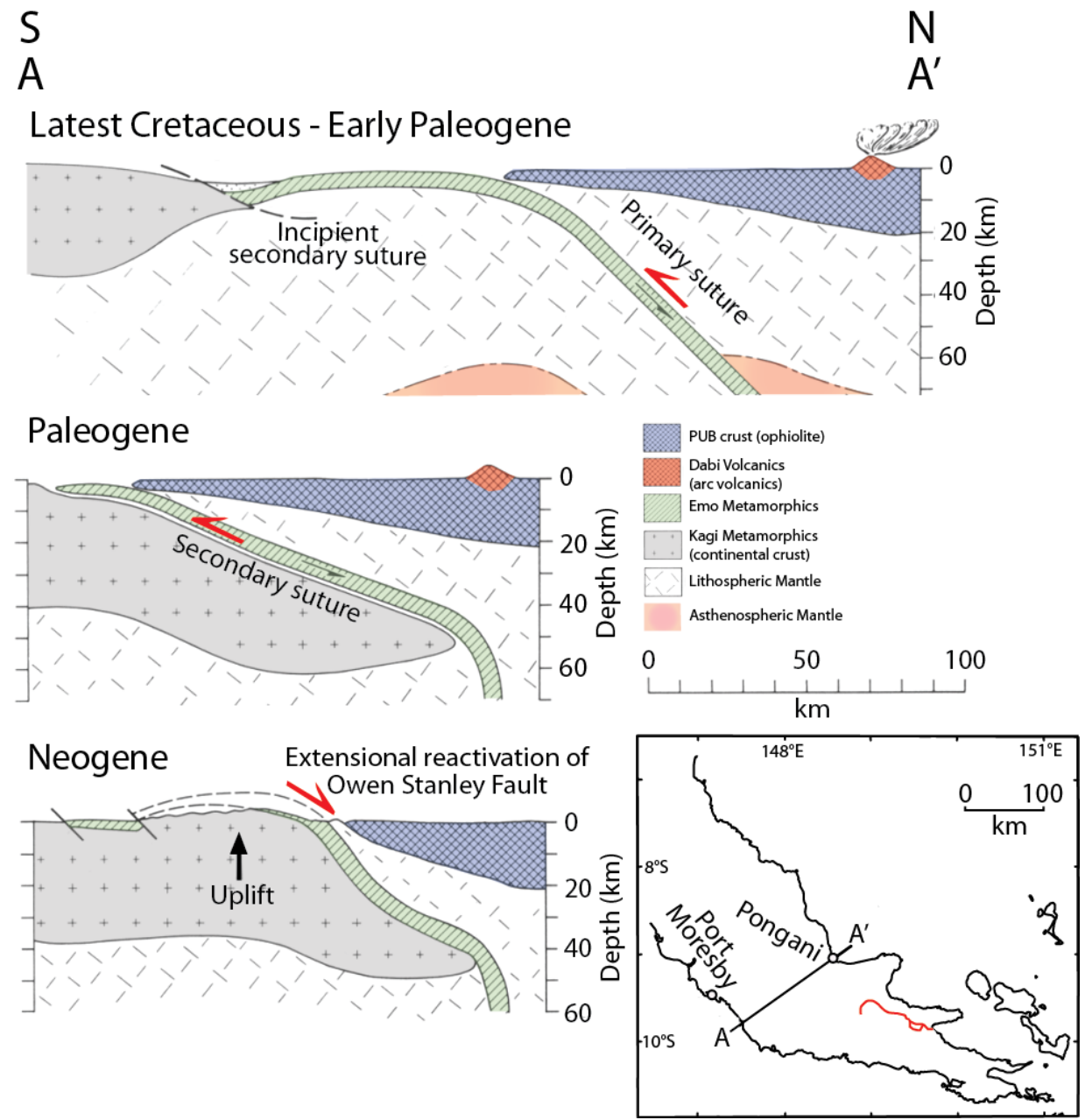

Fig. 15 - Cartoon illustrating a model for the successive emplacement of the PUB and Emo Metamorphics. Note primary and secondary sutures and Neogene extensional reactivation of the Owen Stanley Fault. I consider this model an analogue for successive emplacement of the PUB along the Owen Stanley Fault, and of the Kutu Volcanics along the 'Kutu Thrust' further to the SE see text for details. Mai'iu Fault in red in map inset. Modified from Davies and Jaques (1984). 


\subsubsection{Middle Miocene-Present Subduction at the New Britain and San Cristobal}

Trenches

The Solomon Sea oceanic plate is presently subducting to the north at the New Britain and South Solomon Trenches (Webb et al., 2014), which together accommodate most of the tectonic convergence in Eastern Papua New Guinea (van Ufford and Cloos, 2005). Following the collision of Australian continental crust with Papua New Guinea in the Central Highlands at ca. 12 Ma (van Ufford and Cloos, 2005), and perhaps concurrent cessation of Pocklington Trough subduction further to the SE (Webb et al., 2014), the modern New Britain-San Cristobal subduction zone and associated arcs developed (Holm et al., 2016; van Ufford and Cloos, 2005). Anticlockwise rotation of the New Britain Trench since ca. $6 \mathrm{Ma}$, and increased curvature of the subduction zone from 6$3 \mathrm{Ma}$, has increased the westward component of slab-pull (Holm et al., 2016). This has induced an anticlockwise torque imparted on the Solomon Sea plate, leading to Woodlark Basin seafloor spreading (Fig. 14a, b) , and perhaps convergence at the Trobriand Trough (Holm et al., 2016). This anticlockwise rotation may have been detected by (Cairns et al., 2015), who calculate anticlockwise vertical axis rotations of $19-35^{\circ}$ for the Papuan Peninsula between the Early-Late Miocene.

\subsubsection{Late Miocene-Recent Oceanic Spreading and Rifting}

The Papuan Peninsula is presently dominated by extension associated with the westward propagation of Woodlark Basin (Fig. 14a), although this is accompanied by some convergence within the Aure Moresby Fold Thrust Belt south of the Papuan Peninsula (Pigram and Symonds, 1993; Swift, 2015). Woodlark Basin sea-floor spreading commenced prior to ca. $6 \mathrm{Ma}$, and has propagated west at $14 \mathrm{~cm} \mathrm{yr}^{-1}$ (Holm et al., 2016; Taylor et al., 1995; Taylor et al., 1999). Woodlark Plate extension is inferred to be a consequence of anticlockwise rotation of the Woodlark Plate relative to the Australian Plate (Fig. 14b), due to slab-pull forces due to subduction of the Solomon Sea at the New Britain and San Cristobal Trenches (Hall, 2001; Taylor et al., 1999; Wallace et al., 2004; Webb et al., 2014; Webb et al., 2008; Weissel et al., 1982). While the Woodlark-Pacific plate interface is transtensional near the SDM, it is transpressional to the northwest (Fig. 14a, b), with motion relative to the Australian Plate being taken up by the Owen Stanley Fault Zone (Holm et al., 2016; Wallace et al., 2004). Extension may have nucleated along the northern coast due to the buoyant ascent of Australian continental crust (Kagi Metamorphics), subducted along the OwenStanley Fault during the Cretaceous (Daczko et al., 2011; Davies, 1980a; Davies and Smith, 1971). 
However rotation of the Solomon Sea Plate with respect to the Australian Plate may have slowed from $2 \mathrm{Ma}$, based on plate tectonic modelling of Holm et al. (2016).

The modern distribution of extensional structures in the Woodlark Rift (Fig. 8) is reasonably well understood (e.g., Little et al., 2011; Smith and Davies, 1976; Taylor and Huchon, 2002; Taylor et al., 1999; Wallace et al., 2014; Wallace et al., 2004). Uplift rates derived from sub-aerially exposed Quaternary coral reefs suggest that coastlines of the D'Entrecasteaux Islands are topographically stable (Mann and Taylor, 2002) - however geological observations, GPS studies and microseismicity patterns indicate the normal faults bounding the D'Entrecasteaux Islands are still active (Eilon et al., 2015; Little et al., 2011; Wallace et al., 2014). Microseismicity patterns (Eilon et al., 2015) and inversions of campaign GPS data (Wallace et al., 2014) indicate the Milne Bay Graben is inactive, and indicate that active rifting west of $\sim 150^{\circ} \mathrm{E}$ is now concentrated onto the active Mai'iu Fault, which is rapidly exhuming the SDM along the SW margin of the Woodlark Rift (Davies, 1980a).

\subsection{Initiation of Woodlark Rift Extension}

It is not well known when extension in the Woodlark Rift initiated (Petersen and Buck, 2015). The oldest preserved oceanic crust in Woodlark Basin is $6 \mathrm{Ma}$, although older oceanic crust has been subducted at the San Cristobal Trench (Taylor et al., 1999). It is proposed that Woodlark Basin has propagated westwards into orogenically thickened crust since that time, separating the Woodlark Rise to the north from the Pocklington Rise to the South (Finlayson et al., 1977; Taylor et al., 1995; Taylor et al., 1999).

The onset of Woodlark Rift extension may be marked by the 8.4 Ma Horizon A regional unconformity (Taylor and Huchon, 2002). This unconformity is inferred to represent spatially variable erosion in response to Trobriand forearc basin emergence (Taylor and Huchon, 2002), and is inferred to approximate paleo-sea level. However, the unconformity may also be in part due to a 225 m drop in Eustatic sea-level between ca. 15-10 Ma (Haq, 1988; Taylor and Huchon, 2002). This unconformity is defined as the base of the Ruaba Unit encountered in Goodenough-1 and Nubium-1 Wells (Taylor and Huchon, 2002). Its age is constrained between 9.3-8.3 Ma, and is generally held to be $8.4 \mathrm{Ma}$ based on the intersection of the Minylitha convallis biozone with the linear age model in Goodenough-1 Well, assuming a constant rate of deposition (Taylor and Huchon, 2002). However Taylor et al. (1999) suggest that since deposition of paralic sediments in the Woodlark Rift persisted until $6 \mathrm{Ma}$, the onset of rifting is more likely $6 \mathrm{Ma}$. This interpretation 
would suggest synchronous onset of Woodlark Plate continental rifting and oceanic spreading (Taylor et al., 1999).

Rifting may have initiated in the western Woodlark Rift more recently. Petersen and Buck (2015) find that the present bathymetry of the Woodlark Rift, in particular the separation of the Pocklington Rise from the Woodlark Rise, is better described by extension beginning from 3.6 Ma, assuming extension consistent with the Woodlark Basin 3.6-0.5 Ma Euler rotation pole (Taylor et al., 1999), and assuming all extension is due to the Late Miocene-Pliocene Woodlark Rift. Under the same conditions and assumptions, spreading from $6 \mathrm{Ma}$ would imply too much (150 km) extension, which cannot be reconciled with known separation of continental blocks (Pocklington Rise and Woodlark Rise; Petersen and Buck, 2015). However Taylor et al. (1999) note that extension in the western Woodlark Rift is inconsistent with the orientation of extension described by the Woodlark Basin 3.6-0.5 Ma Euler rotation pole - therefore application of Euler poles calculated from Woodlark Basin may not be appropriate when inferring the inset and magnitude of extension within the Woodlark Rift.

The ages of UHP mineral assemblages from the D'Entrecasteaux Islands partly constrain the timing of extension within the Woodlark Rift. Baldwin et al. (2004) have determined U-Pb zircon ages from eclogite facies rocks from Fergusson Island of 4.33 $\pm 0.36 \mathrm{Ma}(2 \sigma)$, and Baldwin et al. (1993) have determined ${ }^{40} \mathrm{Ar} /{ }^{39} \mathrm{Ar}$ hornblende and biotite ages for the gneissic cores of the D'Entrecasteaux Islands domes of 2.7-3.0 Ma. Similarly, Gordon et al. (2012) find that eclogites exposed within the $D^{\prime}$ Entrecasteaux Islands were metamorphosed prior to $3.8 \pm 1.0 \mathrm{Ma}$. These data collectively constrain the timing of peak metamorphism, which occurred at $>100 \mathrm{~km}$ depths (Monteleone et al., 2007). Thermal histories calculated from step heating experiments suggest extremely rapid cooling of rocks within the D'Entrecasteaux Islands (cooling through $550-100^{\circ} \mathrm{C}$ closure temperatures) since <4 Ma (Baldwin et al., 1993). This result is consistent with Fergusson Island UHP apatite fission-track ages of $>0.5 \mathrm{Ma}$, which indicate the timing of cooling through 110$70^{\circ} \mathrm{C}$ closure temperatures (Webb et al., 2008). Furthermore, magmatic intrusions which cut UHP rocks within the $D^{\prime}$ Entrecasteaux Islands, interpreted as syn-tectonic magmatism, are dated at $<4$ Ma (Hill et al., 1995). Thus it is likely that rapid exhumation of UHP rocks within the D'Entrecasteaux Islands, in response to extension within the Woodlark Rift (Little et al., 2011), initiated at <4 Ma.

However the onset of rifting in the Papuan Peninsula may have been much earlier, during the Early-Late Miocene (Cairns et al., 2015). Cairns et al. (2015) infer from a paleomagnetic study of rocks in the Woodlark Rift that the Papuan Peninsula has undergone $19-35^{\circ}$ of anticlockwise 
vertical axis rotation between the Early-Late Miocene. Based on these findings they speculate that the Woodlark Rift may have been incipiently active at that time, with rifting occurring primarily south of the Papuan Peninsula. However, they acknowledge that such extensional structures that were active at that time have not been identified, and they state that vertical axis rotations may instead have been due to transtension or transpression (Cairns et al., 2015).

\subsection{Tectonic Evolution of the Mai'iu Fault}

I prefer the following interpretation of the evolution of the Papuan Peninsula. A fragment of Australian continental crust was separated from the Australian continent to the south, by LateCretaceous-Paleocene Coral Sea rifting (Fig. 14a). The late Cretaceous Kutu Volcanics and Gorupu Metabasalt were formed at a spreading-ridge some unknown distance north of this continental fragment (Fig. 16a). The PUB was obducted along the Owen Stanley Fault onto the Cretaceous sequence of the Kutu Volcanics during the Late Cretaceous-Paleocene. The Gorupu Metabasalt was then subducted to $>25 \mathrm{~km}$ depth and metamorphosed to greenschist facies at the leading edge. The Kutu Volcanics continued to form at the mid-ocean spreading ridge (Fig. 16b) until the Middle Miocene (Chaproniere, 2009). Eventually a new tectonic suture formed following the Middle Miocene, which emplaced the Kutu Volcanics above the Australian continental crust fragment (Fig. 16c). Extension within the Woodlark Rift resulted in the extensional reactivation of the Owen Stanley Fault during the Pliocene, forming the Mai'iu Fault, resulting in the exhumation of the Gorupu Metabasalt on the Papuan Peninsula (Fig. 16d). 

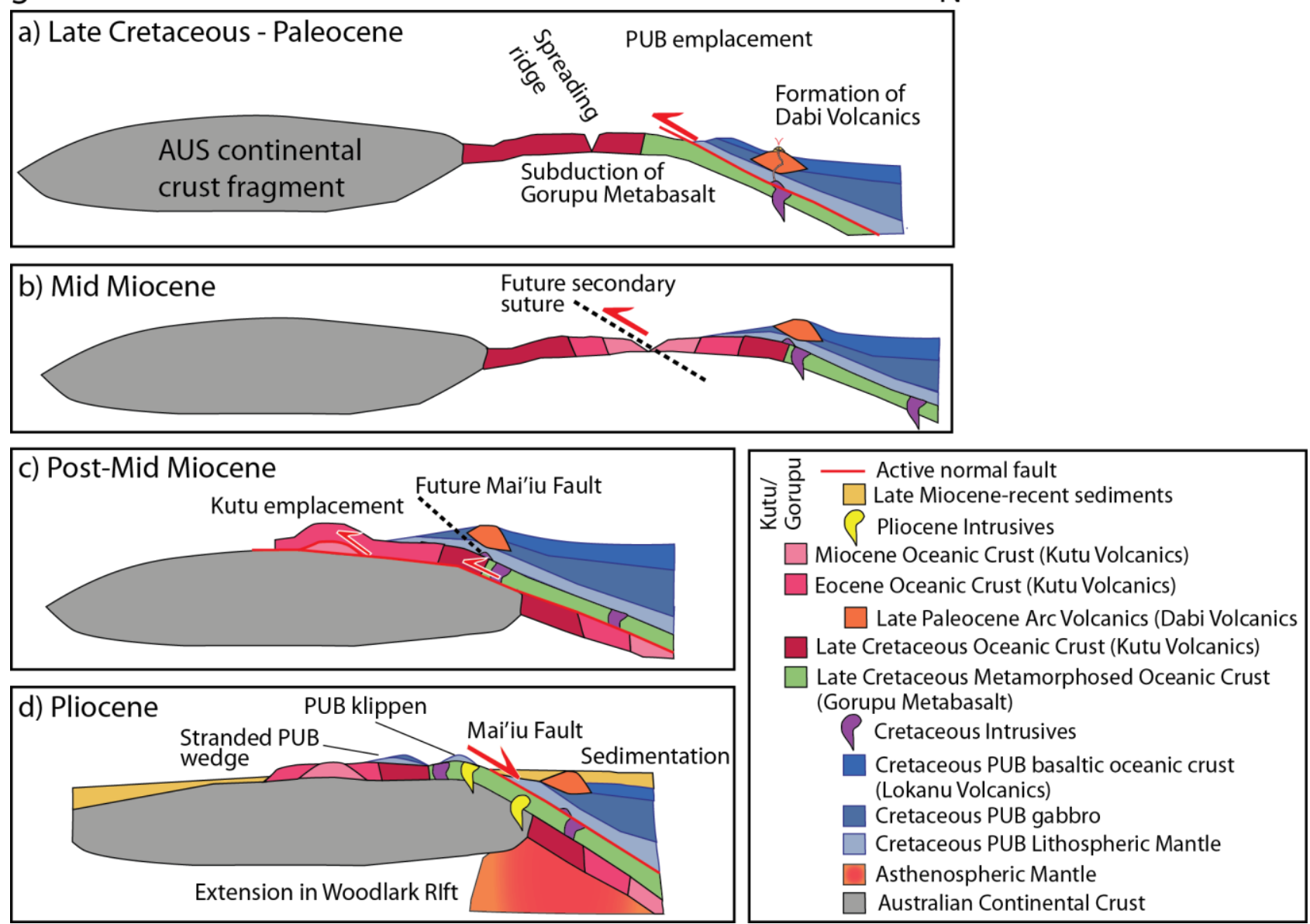

Fig. 16 - Cartoon cross-sections illustrating my interpretation of the tectonic evolution of the Eastern Papuan Peninsula and the Mai'iu Fault. Cross-sections are oriented N-S and pass through The Gwoira rider block (Fig. 11). In particular note the Late Cretaceous-Paleocene obduction of the PUB (a); inferred post-Mid Miocene emplacement of the Kutu Volcanics (c); and Pliocene extensional reactivation of the Owen Stanley Fault as the Mai'iu Fault (d). See text for details.

\subsection{Conclusions}

- Eastern Papua New Guinea is a region of significant tectonic complexity, whose Cenozoic evolution is not fully understood. The Papuan Peninsula is a fragment of Australian continental crust, which has been over-thrust during the Cenozoic by at least two ophiolites. Extension within the Woodlark Basin commenced prior to $6 \mathrm{Ma}$, although it is unknown when extension initiated within the western Woodlark Rift.

- The Mai'iu Fault, located on the Papuan Peninsula, is an active and rapidly slipping LANF, and so represents a unique opportunity to study LANFs prior to abandonment. It represents an extensionally reactivated part of the Paleocene Owen Stanley Fault, which has accommodated more than $25 \mathrm{~km}$ of horizontal extension since the Pliocene (?). The smooth, corrugated SDM is a MCC that forms the exhumed footwall of the Mai'iu Fault. 
- The syn-tectonic Gwoira Conglomerate has been deposited within a large corrugation in the Mai'iu Fault surface, and presents an opportunity to investigate the Pliocene-recent deformation on the Mai'iu Fault.

The following chapters describe the Gwoira Conglomerate (Chapter 3), and relate structures and observations to slip on the Mai'iu Fault (Chapters 4, 5). In Chapter 6 these findings are used to inform Mohr-Coulomb modelling of the Mai'iu Fault, and Chapter 7 draws broad conclusions from the findings of this study. 


\section{Chapter 3: Stratigraphy and Structure of the Gwoira Embayment}

\subsection{Introduction}

In this chapter I describe the stratigraphy and structure of the Gwoira rider block. The Gwoira rider block is a large, $\sim 150 \mathrm{~km}^{2}$, fault-bounded slice, comprising a thick sequence of indurated inferred Pliocene sedimentary rocks (the Gwoira Conglomerate), (Davies and Smith, 1974; Smith and Davies, 1976), and overlying Late Quaternary (?) alluvium. It lies atop a large corrugation in the inactive Mai'iu Fault surface, here termed the Gwoira embayment. The Gwoira embayment is the largest corrugation in the Mai'iu Fault surface. The Gwoira rider block is bounded between the inactive Mai'iu Fault to the south, and the younger, active Gwoira Fault to the north. Within the Gwoira embayment the inactive Mai'iu Fault has been abandoned in favour of the Gwoira Fault, which is the currently active splay. Fault abandonment and rider block formation is not observed elsewhere on the Mai'iu Fault - as such the Gwoira rider block forms the only sub-aerially exposed rider block on the otherwise barren Mai'iu Fault surface. Furthermore, because the Gwoira rider block occupies a position within a large corrugation, it is possible that the processes of corrugation formation and rider block abandonment are interrelated.

The Gwoira Conglomerate, which forms the bulk of the Gwoira rider block, was deposited concurrent with extension on the Mai'iu Fault (Davies, 1980a; Smith and Davies, 1976); therefore the Gwoira Conglomerate can be used to investigate deformation of the Mai'iu Fault. Until now the Gwoira Conglomerate has not been radiometrically dated (Bickel, 1969; Davies and Smith, 1974). Because the Gwoira Conglomerate was formed from the erosion of the Suckling-Dayman massif (SDM), (Caffi, 2008; Smith and Davies, 1976), dating the oldest Gwoira Conglomerate strata will place a minimum limit upon the onset of sub-aerial exposure of the SDM, and thus the onset of motion on the Mai'iu Fault. Here, I employ ${ }^{26} \mathrm{Al} /{ }^{10} \mathrm{Be}$ Terrestrial Cosmogenic Nuclide (TCN) burial dating of Gwoira Conglomerate strata to provide a suite of depositional ages for the Gwoira Conglomerate.

In this chapter, I present field data and observations detailing the stratigraphy and internal architecture of the Gwoira rider block. I first provide an overview of the local tectonic setting. Following this I present the revised stratigraphy of the Gwoira embayment, based on structural observations; unfortunately, ${ }^{26} \mathrm{Al} /{ }^{10} \mathrm{Be}$ burial data for conglomeratic sedimentary rocks was not available at the time of thesis presentation. Next I describe the structure of the Gwoira embayment and Gwoira Fault hanging wall. Subsequently I estimate E-W shortening 
accommodated within the Gwoira embayment; model maximum the burial depth of strata using vitrinite reflectance data; and investigate progressive tilting of fluvial terraces. Finally, I investigate the origin of convex-up stream profiles, and model uplift rates within the Gwoira embayment through Monte-Carlo modelling of stream profiles. In this chapter I continually refer to geographic localities in Fig. 24, which will be referred to out of sequence. In the interests of efficiency and readability, the details of TCN sample processing are in Appendix A. In Chapter 4, I then relate deformation and sedimentary structures within the Gwoira rider block to the deformation style and evolution of the Mai'iu Fault.

\subsection{Theoretical Background}

\subsubsection{LANF Rider Blocks}

Rider blocks (previously introduced in Chapter 1) are fault slices that form as a consequence of the abandonment of the upper part of a LANF. This process of LANF 'partial abandonment' is the consequence of the formation of a new fault splay, typically a high-angle synthetic fault that cuts the previous hanging wall (Reston and Ranero, 2011). This younger high-angle fault roots into the LANF at depth; above this point of intersection it replaces the LANF as the active detachment. Because LANFs generally form convex-up surfaces of approximately constant curvature (Choi and Buck, 2012), the shallowest portions of the LANF are generally the most misoriented for slip. Therefore rider blocks form due to the abandonment of the shallowest part of the LANF. With progressive back-rotation of the LANF footwall with increased slip, shallow portions of a LANF may become severely misoriented, and thus become abandoned. The rider block is contained between the older abandoned and inactive fault, and the younger active fault. This block is then uplifted as part of the new LANF footwall (Fig. 1). Rider blocks have been described in numerous active submarine LANFs (Reston and Ranero, 2011), and mostly commonly above now inactive sub-aerially exposed detachment faults (Holm et al., 1994). However, not all LANFs are adorned with rider blocks (Fig. 6), which may have implications for LANF strength in those areas (Choi and Buck, 2012).

It is thought that LANF rider block abandonment is generally controlled by fault strength, fault geometry, and the thickness of the overlying volcanic or sedimentary cover (Reston and Ranero, 2011). However, it has instead been suggested in the case of Oceanic Core Complexes (OCCs) that rider block formation may occur due to magmatic intrusions that cut the LANF, thus warming and weakening the hanging wall lithosphere to the point that a new fault is locally initiated in the 
hanging wall (Tucholke et al., 1998). Rider blocks are predicted to preferentially form above relatively strong LANFs that are overlain by significant sedimentary infill (Reston and Ranero, 2011). Thus, given knowledge of the LANF geometry and the thickness of sedimentary infill, the presence of a rider block has the potential to place a minimum constraint upon LANF friction and cohesion (Choi and Buck, 2012; Lavier et al., 2000; Reston and Ranero, 2011).

\subsubsection{Metamorphic Core Complex Megamullions}

Metamorphic Core Complexes (MCCs) commonly exhibit a large-scale (> $20 \mathrm{~km}$ diameter) domal structure (termed 'megamullions' in the case of OCCS), with a superimposed second-order corrugated structure (mullions), and often smaller (1-2 km wavelength) corrugations (Seiler et al., 2010); I refer to these features collectively as corrugations. Corrugation hingelines are characteristically oriented parallel to the extensional slip direction, although the precise reason for this is debated (Whitney et al., 2013). MCC corrugations typically have wavelengths of 2-20 km (Spencer, 1999). Whether corrugations are inherited from an older fault, or instead formed concurrent with extension, has been subject to much debate (e.g., Singleton, 2013; Whitney et al., 2013). Four principle models for corrugation formation have been proposed: inheritance of fault roughness; magmatic moulding; the development of bending folds due to along-strike variability in vertical stress magnitude; and buckle folding due to a constrictive stress field (Fletcher et al., 1995; Singleton, 2013; Tucholke et al., 1998). Less widely accepted theories (Singleton, 2013) include volume increase of the lower plate due to decompression during exhumation (Spencer, 1982), boudinage of the lower plate due to bidirectional extension (Perry, 2005), and 'continuous casting' of grooves in a plastic lower plate against a stronger, asperity-ridden or grooved upper plate (Spencer, 1999). However, while corrugations are common to many LANFs (Fletcher et al., 1995; Whitney et al., 2013), which suggests that whatever process is responsible for their formation is common to a wide range of extensional tectonic settings, it may be that corrugations develop as a consequence of some combination of the above processes (Singleton, 2013; Yin, 1991). The processes responsible for corrugation formation will be discussed further in Chapter 4. 


\subsection{Local Geological Setting}

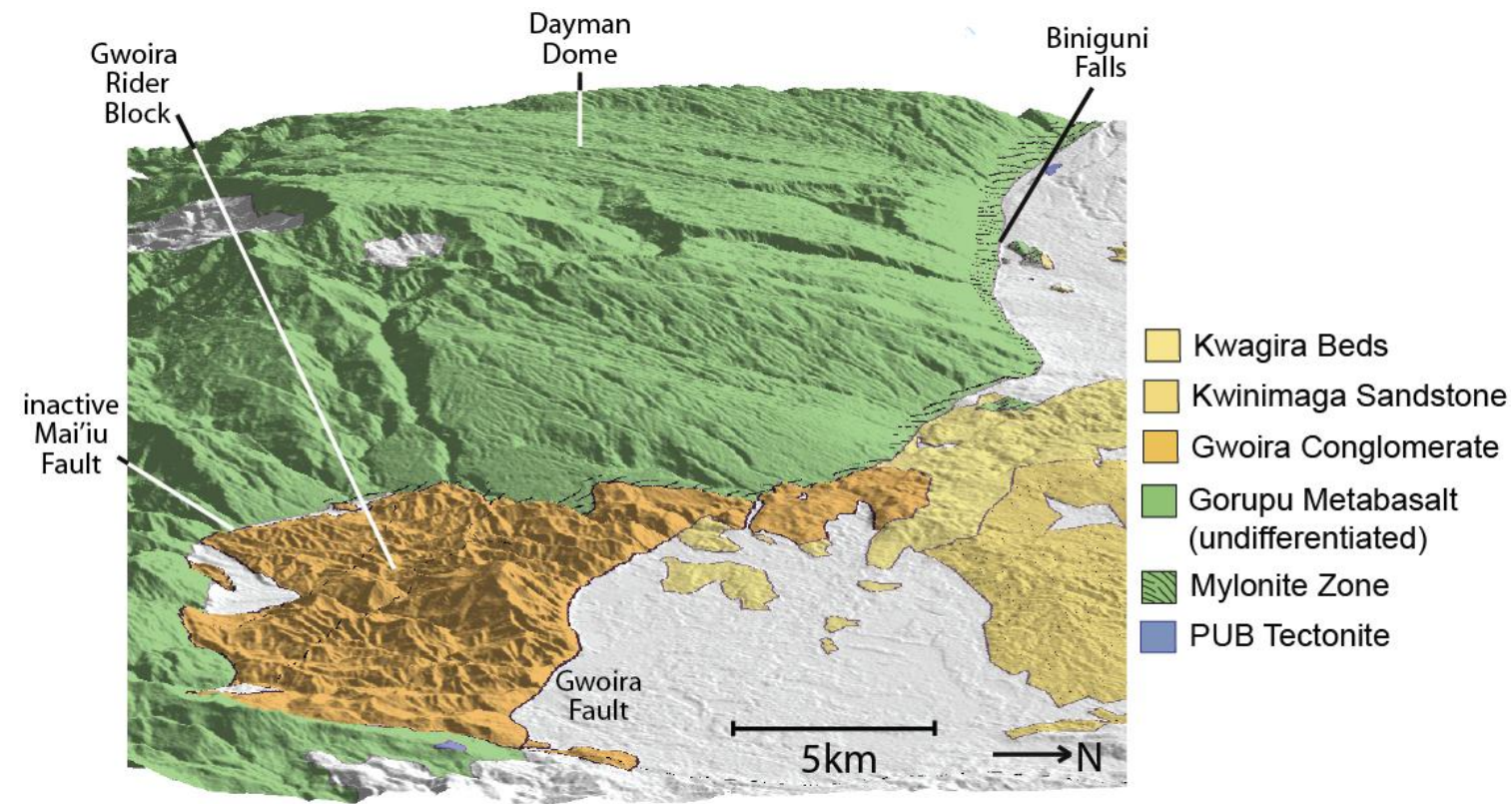

Fig. 17 - East-facing view of Dayman Dome and the Gwoira Rider Block (zero vertical exaggeration). The Gwoira Conglomerate (orange) forms the fault-bounded Gwoira rider block, which lies atop the undifferentiated Gorupu Metabasalt (green). Model generated in ArcScene by draping geologic features over the SRTM 30 m DEM (map area S10E149, 1 arc). No vertical exaggeration.

\subsubsection{The Gwoira Conglomerate}

The Gwoira Conglomerate is a syn-extensionally deposited formation formed from clasts eroded from the SDM (Smith and Davies, 1976). It has been deposited within a broad corrugation (embayment) within the inactive Mai'iu Fault surface (Fig. 17). The Gwoira Conglomerate overlies the inactive Mai'iu Fault, although it locally overlies serpentine tectonites of the PUB at the eastern-most extremity of the Gwoira embayment (Fig. 2; Davies and Smith, 1974). Based on its clast content, the Gwoira Conglomerate has been derived from sub-aerial erosion of the Gorupu Metabasalt, Bonenau Schist, and Yau Gabbro. Thus its deposition must record uplift of the SDM with slip on the Mai'iu Fault.

The Gwoira Conglomerate was first visited by Stanley (1923), and was then defined as part of a package of pre-Miocene indurated massive sandstone. To date the internal architecture and structure of the Gwoira Conglomerate has not previously been studied in any detail. The regional geology of the Owen Stanley Ranges and Cape Vogel Peninsula, including the Gwoira Conglomerate, was originally mapped at 1:250,000 scale by Davies et al. (1968) and Davies and Smith (1974), who capture a broad synclinal geometry, and who suggest large-scale dip fanning (shallowing of stratal orientation up-section) within the Gwoira Conglomerate (Fig. 18). However 
previous studies do not isolate the component of sedimentary dip fanning attributable to slip on the now inactive Mai'iu Fault, from the total amount of back-tilting due to uplift along the Gwoira Fault. The Gwoira Conglomerate has been studied more recently by Caffi (2008), who undertook petrologic analyses and broadly described sedimentary and deformation structures (Daczko et al., 2011). However this investigation was limited to the structurally deepest (NW) part of the formation near Pumani (Fig. 18). The evolution of the Gwoira Conglomerate has not been previously documented, and will be the focus of this chapter.

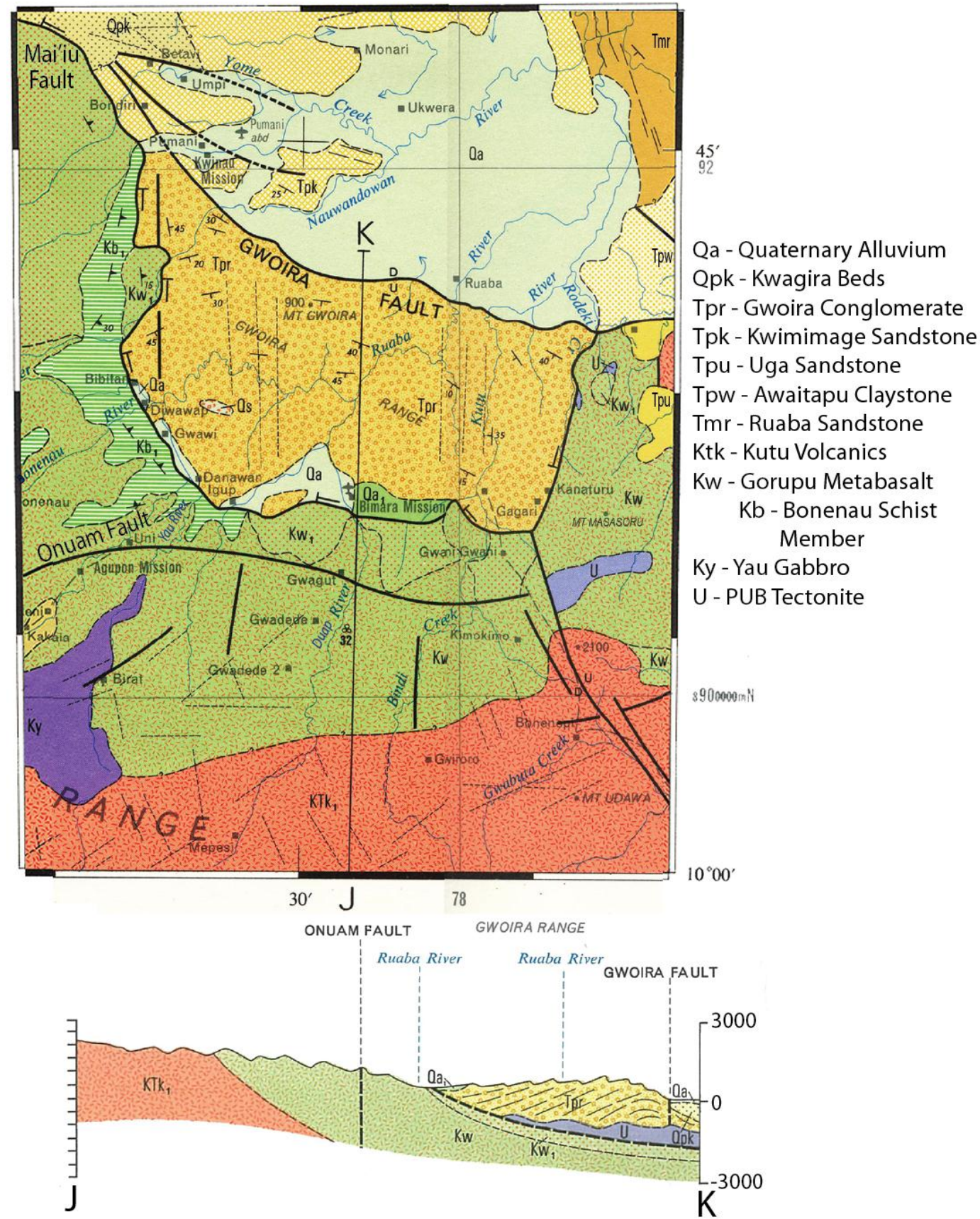

Fig. 18 - Map excerpt showing the Gwoira Conglomerate as mapped by Davies and Smith (1974). Bedding attitudes suggest a broad synclinal geometry of the Gwoira Conglomerate. Note the position of the Mai'iu Fault and Gwoira Fault; here the Mai'iu Fault has been incorrectly interpreted as a low-angle thrust surface. Cross-section J-K shows back-tilting and dip-fanning of the Gwoira Conglomerate. 


\subsubsection{The Inactive Mai'iu Fault}

The inactive part of the Mai'iu Fault (the 'inactive Mai'iu Fault') bounds the Gwoira rider block to the south. The Mai'iu Fault was recognised by Smith and Davies (1976), and its relative slip sense and approximate timing of deformation was identified by Davies (1980a). The inactive Mai'iu Fault is contiguous with the active Mai'iu Fault at depth (collectively referred to as the 'Mai'iu Fault'), and the two are separated by the active Gwoira Fault (described below). The exposed scarp of the inactive Mai'iu Fault forms a series of smooth dip slopes, whose collective synclinal geometry is suggestive of a broad embayment of the fault, (here termed the 'Gwoira embayment'), beneath the Gwoira rider block.

\subsubsection{The Gwoira Fault}

The Gwoira Fault bounds the Gwoira rider block on its northern side. It was recognised by Stanley (1923), and by Davies and Smith (1974) and Smith and Davies (1976), who assumed it to be a young fault rooting into the Mai'iu Fault. It has accommodated more than a thousand metres of vertical displacement, indicated by the height of Mt Gwoira. Caffi (2008) and Daczko et al. (2011) suggest that the Gwoira Fault may represent a listric normal fault that roots into the Mai'iu Fault, which itself forms a listric detachment beneath the Gwoira Conglomerate. Contrastingly, Bickel (1969) and Davies (1980a) interpret the Gwoira Fault as having offset the inactive Mai'iu Fault at depth. However, the geometry of the Gwoira Fault is consistent with that of a detachment that merges down-dip with the inactive Mai'iu Fault at depth. The well preserved, 2 km high scarp of the Gwoira Fault, and back-tilting of the uppermost part of the Gwoira Conglomerate in the footwall of the fault evidence that this fault is active (Davies and Smith, 1974). Caffi (2008) recognised that brittle deformation associated with slip on the Gwoira Fault probably post-dates ductile fabrics preserved within the Gorupu Metabasalt immediately below the active Mai'iu Fault at Biniguni Falls, although no specific overprinting relationships were described.

Based on campaign GPS data, Wallace et al. (2014) model the Gwoira-Mai'iu Fault system to accommodate NNE-SSW oriented horizontal extension at a rate of 7-9 mm/yr. This is consistent with $4.9 \pm 0.3 \mathrm{~mm} \mathrm{yr}^{-1}$ uplift rates calculated for uplifted Late Quaternary coral reefs located on the SW coast of Goodenough Bay (Mann and Taylor personal communication, 2016), which implies a dip-slip rate of 9.2-10.4 $\mathrm{mm} \mathrm{yr}^{-1}$ for an assumed fault dip of $30^{\circ}$. Active uplift of the Gwoira Fault footwall is suggested by flights of well-preserved fluvial terraces near Biman (see Fig. 24 for 
location); and back-tilted (south-dipping) Late Quaternary (?) fluvial terraces located immediately north of the Gwoira Fault in Dare Stream (Caffi, 2008).

\subsubsection{The Gwoira Rider Block}

The Gwoira rider block (Fig. 19) is a fault-bounded slice of Gwoira Conglomerate that lies within the Gwoira embayment. It has been "transferred" to the footwall of the active Mai'iu Fault (Gwoira Fault) due to the initiation of the Gwoira Fault, with associated abandonment of the now inactive Mai'iu Fault. The Gwoira rider block is presently being uplifted. Davies and Smith (1974) and Smith and Davies (1976) used sparse structural measurements (Fig. 18) to suggest that Gwoira Conglomerate strata are geometrically complex: they are back-tilted to the south, which they interpret as being due to slip on the Gwoira Fault; strata exhibit dip fanning (shallow in dip to the south); and they are folded into a broad south-plunging syncline. However it is possible that the present south-dipping attitude of the Gwoira Conglomerate is instead the consequence of shallowing of the Mai'iu Fault, or due to the development of a rollover anticline above the listric inactive Mai'iu Fault (Daczko et al., 2011). Davies and Smith (1974) also infer, based on very sparse bedding orientation data, the presence of an E-W trending anticline in the immediate footwall of the Gwoira Fault. The Gwoira embayment has not previously been described as a rider block, and the structural evolution of the Gwoira rider block has not been described in detail. Furthermore, the relationship between folding, continued LANF slip, and formation of the Gwoira embayment has not previously been described; this subject will be addressed in the following sections.

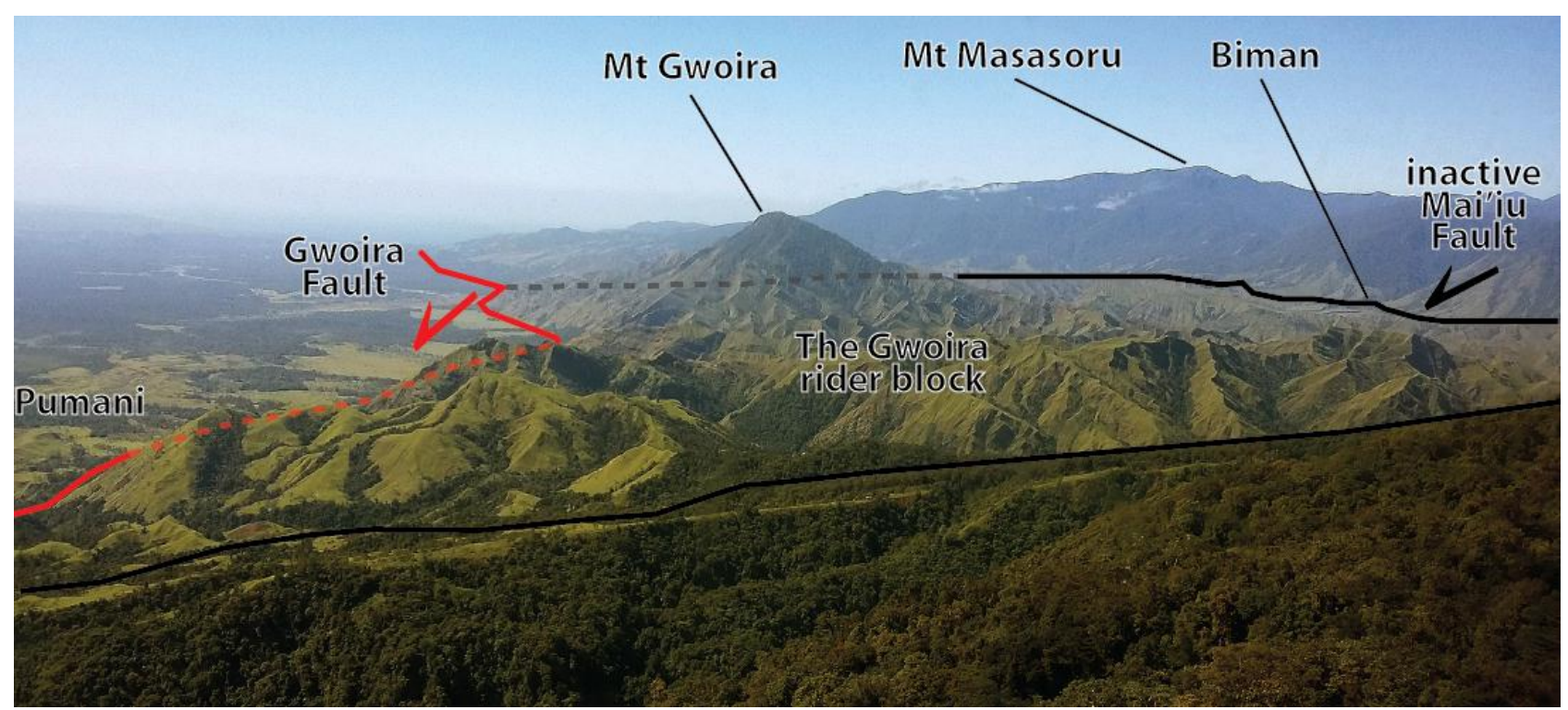

Fig. 19 - East-facing photo of the Gwoira rider block, taken from the NE flank of Dayman Dome. The Gwoira rider block is bounded by the Gwoira Fault to the north and by the inactive Mai'iu Fault to the south. 
The Gwoira rider block is the only known rider block of the Mai'iu Fault. The SDM is otherwise devoid of rider blocks, and forms a smooth, unornamented domal surface (Fig. 3). Other rider blocks have been inferred to exist submerged in southern Goodenough Bay by Fitz (2011), above what the author terms the Owen Stanley Fault (OSF) - however this interpretation is equivocal, as these workers do not image the OSF itself. Several small PUB tectonite klippens exposed on the northern flank of Suckling Dome and on Mt Masasoru, (Davies and Smith, 1974) are probably not remnants of eroded rider blocks, and likely constitute part of the Mai'iu Fault footwall (this subject will be discussed in Chapter 5). In this model, the Mai'iu Fault anastomosed above lenses of PUB when it extensionally reactivated the OSF during the Pliocene.

\subsection{Stratigraphy of the Gwoira Embayment}

In this section I present the revised stratigraphy of the Gwoira embayment. Because stratigraphic distinctions are partially based on structural interpretations, these structures are briefly introduced within this section; the detailed structure of the Gwoira embayment is presented in section 3.5.

\subsubsection{The Gwoira Conglomerate}

The Gwoira Conglomerate is well-lithified, generally poorly (or bi-modally) sorted, and is coarsegrained, being typically characterised by a sandy matrix with cobbles and subsidiary boulders up to $\sim 1 \mathrm{~m}$ in diameter. Clasts are sub-rounded to sub-angular. The Gwoira Conglomerate is generally green-grey or orange-brown in colour (Fig. 20), and comprises interbedded layers of pebble/cobble conglomerate, sandstone, and rarer siltstone (Caffi, 2008; Smith and Davies, 1976). Normally-graded sequences of conglomerate-sandstone-siltstone are up to $7 \mathrm{~m}$ thick. They typically have scoured basal surfaces that divide overlying conglomeratic units from underlying syn-depositionally deformed siltstones and sandstones (Caffi, 2008). Cross-bedding in sandstones suggests mostly east-directed flow (Davies et al., 1968).

Within the Gwoira Conglomerate, clasts are mostly comprised of Gorupu Metabasalt; less abundant are clasts of gabbro, granophyric microgranite, clinopyroxenite; and rarer still are clasts of schist (Bonenau Schist), red chert, and reworked clasts of Gwoira Conglomerate and fossiliferous limestone (Caffi, 2008). Gorupu Metabasalt clasts often preserve primary igneous textures and mylonitic fabrics (Caffi, 2008). Mineral compositions were determined for several whole rock Gwoira Conglomerate samples using electron microprobe analysis (Caffi, 2008). 
Principle bulk mineral constituents are albite, chlorite (penninite/talc-chlorite), epidote (pistacite), prehnite, pumpellyite, clinopyroxene (Al/Cr-augite), and rare hydrated volcanic glass (mafic). Bulk chemical composition does not appear to vary with grain size (Caffi, 2008). Clasts are cemented by authigenic clays, including smectite which weathers from plagioclase (Caffi, 2008). Calcite cement is present along some pebbly horizons, and quartz cement is present within sandy intervals. Volcanic glass fragments altered to diagenetic smectite is consistent with hydrothermal alteration at $90-100^{\circ} \mathrm{C}$ (Caffi, 2008; Cuadros et al., 1999; Tomita et al., 1993); similarly, the absence of dolomite, talc, muscovite and zeolite minerals (Caffi, 2008) suggests a peak burial temperature of $<110^{\circ} \mathrm{C}$. Pressure-solution textures such as concavo-convex grain contacts are only rarely present, and are thought to be produced during diagenesis (Caffi, 2008). The presence of authigenic framboidal pyrite is suggestive of leaching of iron sulphides in the presence of a hydrothermal fluid (Caffi, 2008; Neumann et al., 2006; Newman et al., 2013) - this is consistent with the presence of hydrothermal springs and travertine mounds along the active Mai'iu Fault near Wapon (Fig. 24) (Davies and Smith, 1974; Latter, 1964), and our observations of calcitic flow stones in Kwan River and Tame Creek.

The Gwoira Conglomerate has sparse fossil content. Rare in situ fossil wood fragments are present, and rare bivalve shells have been observed within rare mudstone clasts collected as float in Dare Creek (Caffi, 2008). We collected a similar fossiliferous mudstone float boulder in lower Nowandowan River (sample PNG16-104a). Fossiliferous float clasts contain coral, echinoderm spikes, and foraminifera, although the fossil assemblage only constrains the depositional age to the Tertiary (Caffi, 2008). However, because such fossils have only been observed in float clasts, their significance is ambiguous. While float clasts are only moderately indurated (and so unlikely to have been recycled from structurally deeper formations), it is possible that this boulder was reworked from Pliocene coral reefs that were uplifted by faulting associated with motion on the Mai'iu Fault.

Smith and Davies (1976) suggest a paralic (near-shore terrestrial to marine) depositional environment for the Gwoira Conglomerate, and Caffi (2008) infers that deposition was accomplished initially by fluvial processes (indicated by the prevalence of rounded clasts). In addition, Caffi (2008) infers deposition by cohesive debris flows and turbidity currents (indicated by graded bedding); and a shallow water $(<5-20 \mathrm{~m}$ ) photic zone water depth based on fossil algae (in particular the absence of deep water fauna) within the single fossiliferous float boulder described above (once again, this boulder may have been reworked). 
In contrast to these previous interpretations I find evidence that, contrary to the interpretations of Smith and Davies (1976) and Caffi (2008), (see Chapter 2), the Gwoira Conglomerate represents entirely fluvial deposition. Dominant conglomerates (Fig. 20a) with undulatory erosional bases (Fig. 20c), abundant interbedded cross-bedded sands, and subordinate interbedded clays (Fig. 20b) are consistent with deposition within a flood plain dominated by aggrading meandering rivers. A depositional analogue is the modern floodplain on the footwall of the Gwoira Fault. This interpretation is further supported by the presence of rare coalified wood fragments (Fig. 20f), leaf fossils, and coalified roots and tree trunks in growth position at all structural depths (although admittedly this material could be transported down-slope), and the lack of any definite evidence for marine deposition. This interpretation is consistent with the suggestion that the Gwoira Conglomerate represents a proximal correlative facies of the Uga Sandstone (intermediate/coalesced river delta and coastal plain), the Pliocene (?) Kwinimage Sandstone (distal/marginal marine), and the Pliocene Awaitapu Claystone (distal/coastal plain-marine; Bickel, 1969; Davies and Smith, 1974). 

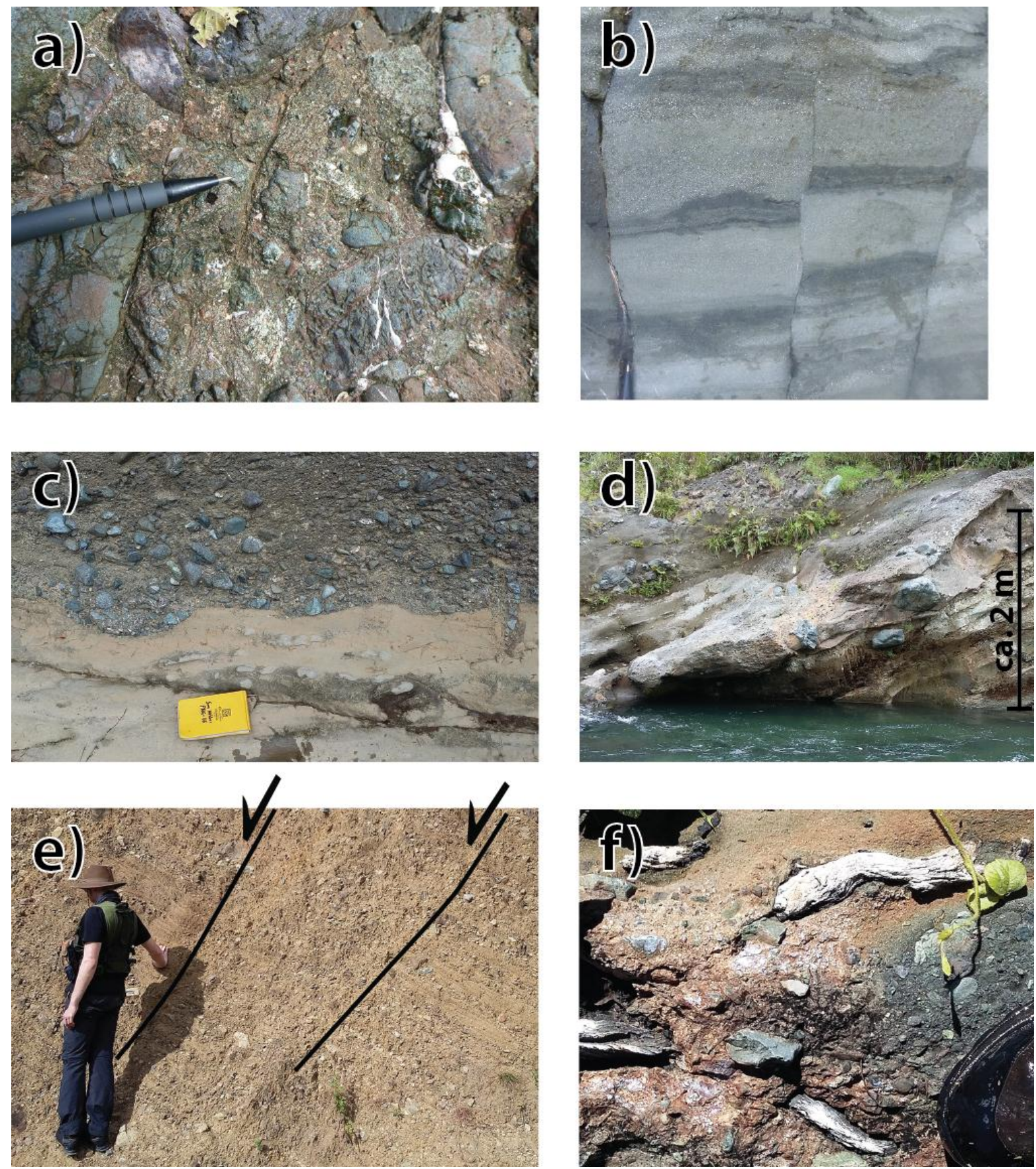

Fig. 20 - Photos of the Gwoira Conglomerate. a) Sheared pebble conglomerate of SP1 in Kwan River, with quartz (thin, grey) and calcite (voluminous, white) between grains. b) Interlaminated sandstone-siltstone sequence of SP1 in Kwan River, which is suggestive of alternating energy within an aggrading meandering river depositional environment. c) Scoured basal contact in lower SP2, Ruaba River. This exemplifies the erosive, depositional environment. d) $\sim 40 \mathrm{~cm}$ boulders suspended within a well-sorted sandstone matrix - lower SP2 in the Ruaba River, evidencing highenergy deposition. e) Non-indurated, interlaminated sandstone and pebble conglomerate near Danawan, characteristic of upper SP2 strata. Sandstone intervals are offset by outcrop-scale synthetic normal faults. f) Lignite grade coalified wood fragments within lower SP2 strata, Duap River. The prevalence of large, $<10 \mathrm{~cm}$ wood fragments evidences terrestrial deposition. 
The distribution of the Gwoira Conglomerate has previously been defined as the area within the Gwoira embayment, although the formation is inferred to grade laterally with the Kwinimage Sandstone, Uga Sandstone, and Awaitapu Claystone (Davies and Smith, 1974; Smith and Davies, 1976). I find that the distribution of the Gwoira Conglomerate (Fig. 24) is more widespread than previously described (Davies and Smith, 1974), and that it extends north of the Gwoira Fault. Based on cross-sections presented in section 3.5, I show the thickness of the Gwoira Conglomerate to be $2600 \mathrm{~m}$ thick at Mt Gwoira, although its thickness is spatially variable due to dip-fanning. Other moderately indurated sandstones and conglomerates to the north of the Gwoira Fault, originally mapped as Kwinimage Sandstone, have been re-mapped as Kwagira Beds based on their low degree of induration, and their dominantly fluvial facies architecture. This implies that the Gwoira Conglomerate, which underlies the Kwagira Beds (Smith and Davies, 1976), lies structurally below the floodplain north of the Gwoira Fault and east of Pumani (Fig. 24).

Most importantly I identify a major WNW-ESE trending angular unconformity that divides Gwoira Conglomerate strata of differing orientations and folding amplitudes (Fig. 21). It strikes at an azimuth of $\sim 120^{\circ}$ (sub-parallel to the Gwoira Fault; Fig. 24). The unconformity was not directly observed in outcrop, although it has been photographed at its western extremity during helicopter fly-overs (Fig. 21), and its presence has been determined by the sharp discordance in bedding orientations south of Mt Gwoira and along the Ruaba River. The unconformity passes through the confluence of the Ruaba River with the Duap River (Fig. 24), which is marked by a $30 \mathrm{~m}$ high waterfall and a fluvial knickpoint corresponding to a change in stream concavity (discussed in section 3.5.8). The knickpoint may be a consequence of a local contrast in erodibility, a fault (up to the south), or a stream-capture event. The unconformity is most recognisable in the headwaters of Kwan River, where it divides ESE-dipping strata to the north from SSE-dipping strata to the south. As with the Silver Peak-Lone Mountain detachment (Oldow et al., 2009), hanging wall unconformities are back-tilted and dip towards the detachment trace (discussed in section 3.5).

I divide conglomeratic strata within the Gwoira rider block into two unconformity-bounded stratigraphic packages (SP), based on structural discordance between parts of the Gwoira Conglomerate within the Gwoira embayment. These units are differentiated partially based on their structural properties - therefore their structure will be briefly discussed in this section. The structurally deepest unit, SP1, defines a broad SSW-plunging syncline, which dips overall to the S/SW (Fig. 24). SP1 dips more steeply to the south with increasing structural height and with increasing distance from the Gwoira Fault - this is an unexpected observation that contrasts with the shallowing of strata with increased structural height (dip-fanning) expected for strata 
deposited on a normal fault hanging wall. SP1 does not exhibit N-S dip-fanning, although it expresses weakly developed E-W dip-fanning.

SP2, which overlies SP1, is an indurated sand-supported pebble conglomerate, and is lithologically indistinguishable from unit SP1, although the proportion of sandstone gradually increases and the proportion of siltstone decreases with structural height. SP2 dips less steeply to the south than the southern part of unit SP1, and though it is also folded into a S/SW-plunging syncline, the amplitude of folding is distinctly less. Unit SP2 is further subdivided into the lower SP2 and upper SP2. Lower SP2 is self-parallel, and exhibits no discernable dip-fanning. SP2 is unconformably overlain by the Biman Sandstone (new name; discussed in section 3.4.3; Fig. 22), and Late Quaternary (?) alluvial terraces (discussed in section 3.4.4; Fig. 23).

Lithified conglomerates of lower SP2 (Fig. 25B, C, C2) grade upwards into unlithified sandstones and conglomerates of the upper SP2 unit. Upper SP2 strata are also folded into a N-S trending syncline, although the amplitude of folding is less than that of lower SP2. Upper SP2 exhibits significant dip-fanning, such that bedding dips shallow up-section (Fig. 25B, C, C2). Upper SP2 horizons, when projected up-dip, on-lap against underlying horizons. The location of these on-lap terminations migrates to the south up-section (Fig. 25B, C, C2); this subject will be discussed further in section 3.5.4.4. I also suggest that, based on their indistinguishable facies architecture (poorly indurated, massive, poorly sorted conglomerates with a sandy matrix), that upper SP2 strata are laterally equivalent to the Kwagira Beds (discussed below), and to Quaternary conglomerates exposed east of Biman (Qpk and Qa ${ }_{1}$ of Fig. 18), of Davies and Smith (1974). 

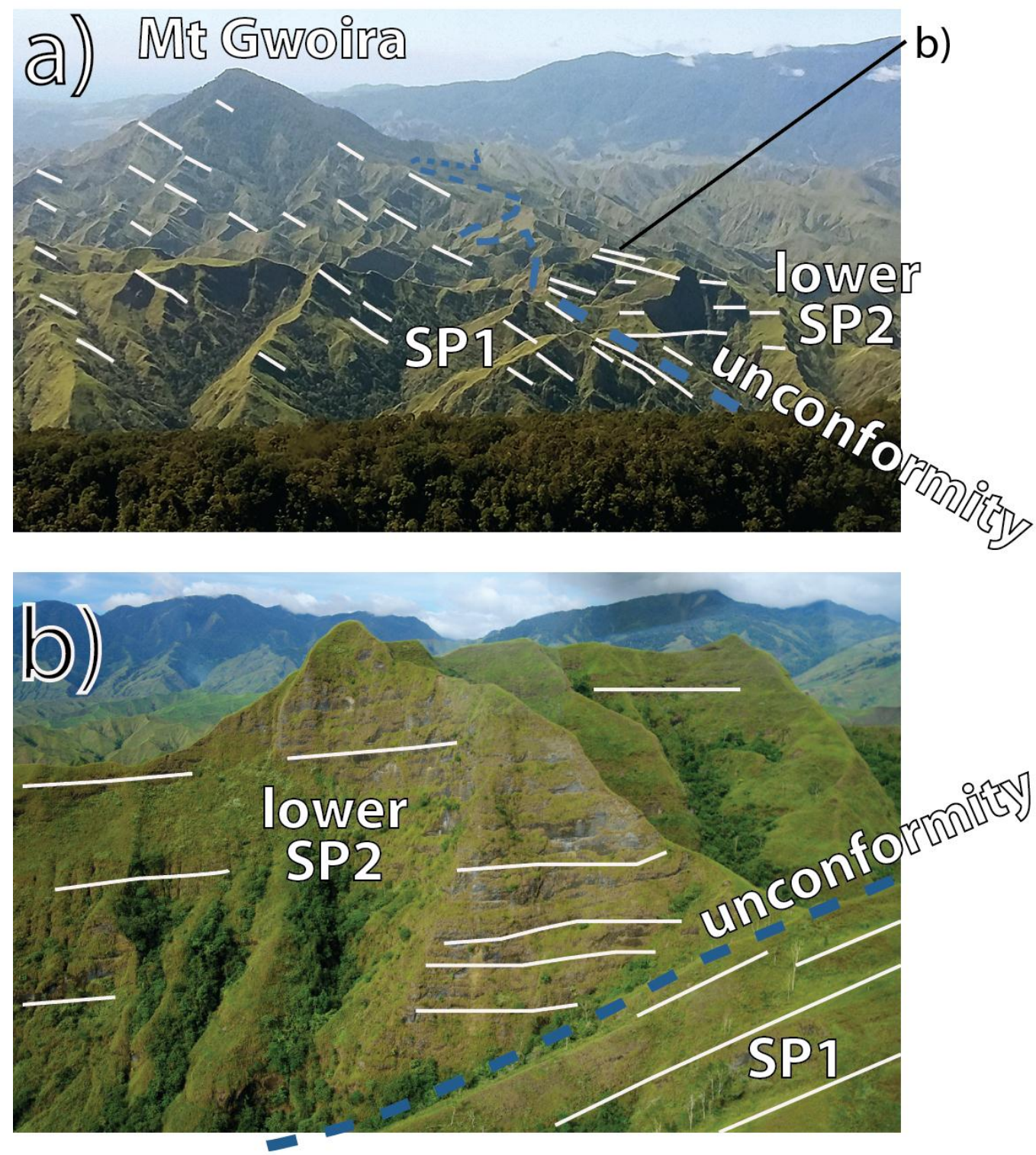

Fig. 21 - Photos illustrating the angular unconformity that separates SP1 from overlying SP2 - see text for details. Note bedding apparent dips (white). a) East-facing view; b) South-facing view.

\subsubsection{The Kwagira Beds}

As previously introduced in Chapter 2, the Kwagira Beds are $\sim 100 \mathrm{~m}$ thick, poorly consolidated terrestrial conglomerates with interbedded sandstones and siltstones of inferred Pleistocene age (Smith and Davies, 1976). They lie in the immediate hanging wall of the Gwoira Fault near Pumani (Fig. 24), and define the uppermost lithified unit in this region, as mapped by Davies and Smith (1974). The Kwagira Beds in lower Dare Creek (Fig. 24) have been tilted to the south by $25-36^{\circ}$, and comprise poorly lithified sand-supported angular to sub-angular conglomerates, with rare subrounded cobble horizons, and coarse cross-bedded sandstone intervals (Caffi, 2008). 


\subsubsection{The Biman Sandstone (New Name)}

The Biman Sandstone (new name, not previously described) outcrops along the Duap River $1 \mathrm{~km}$ north of Biman (Fig. 24). It is a poorly indurated, interbedded sandstone and siltstone (Fig. 22), with abundant wood and leaf fragments. The Biman Sandstone unconformably overlies lower SP2 strata of the Gwoira Conglomerate, and is itself overlain by Late Quaternary (?) terraces. Based on the rhythmically interbedded sandstone and subsidiary siltstone (e.g., Fig. 22), abundant leaf fossils, and rare $\sim 1 \mathrm{~cm}$ long gastropods, I infer a lacustrine depositional environment. The Biman Sandstone is shallow dipping and is of unknown age. The formation is weakly folded, with one fold hingeline trending NNE-SSW, and beds display cm-scale normal faulting.

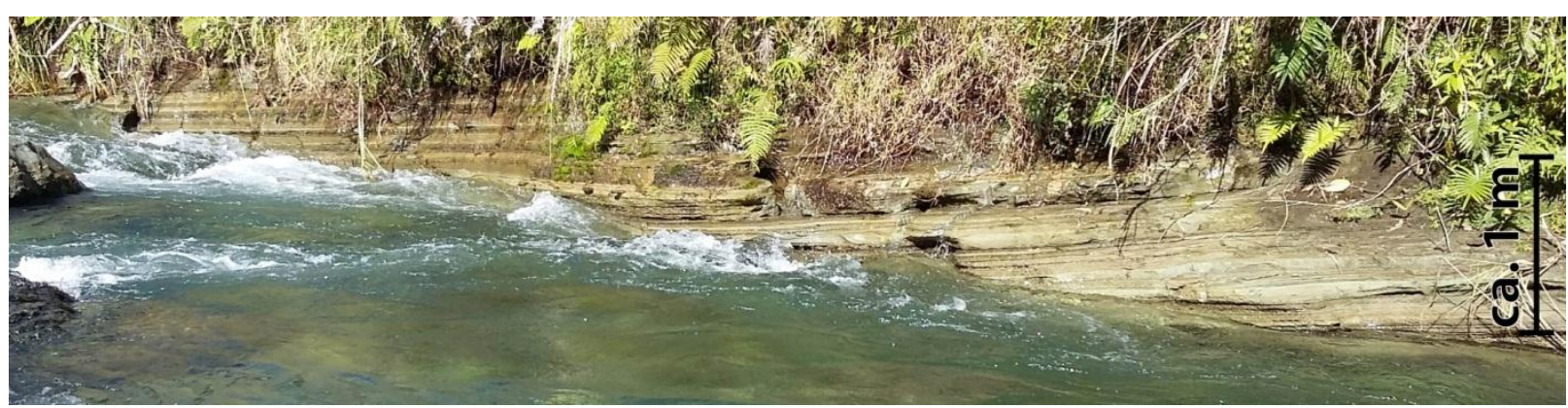

Fig. 22 - Photo (SW-facing) of the Biman Sandstone in Duap River, which directly underlies Late Quaternary (?) terraces near Biman.

\subsubsection{Alluvial Terraces}

The youngest sediments atop the Gwoira embayment are within flights of well-preserved Late Quaternary (?) fluvial terraces (Qa in Fig. 18; Fig. 23; Fig. 24) deposited north of Biman (Fig. 24). The terraces principally comprise unconsolidated conglomerates of sub-rounded pebbles, cobbles, and small boulders, with interlaminated sandstone layers. These terraces lie atop the Biman Sandstone, and are nearly flat-lying, in contrast to the south-dipping Gwoira Conglomerate; therefore these terraces have not had sufficient time to become back-tilted themselves, and so must be geologically very young. Terrace correlations (Fig. 23) are discussed in section 3.5.7. 


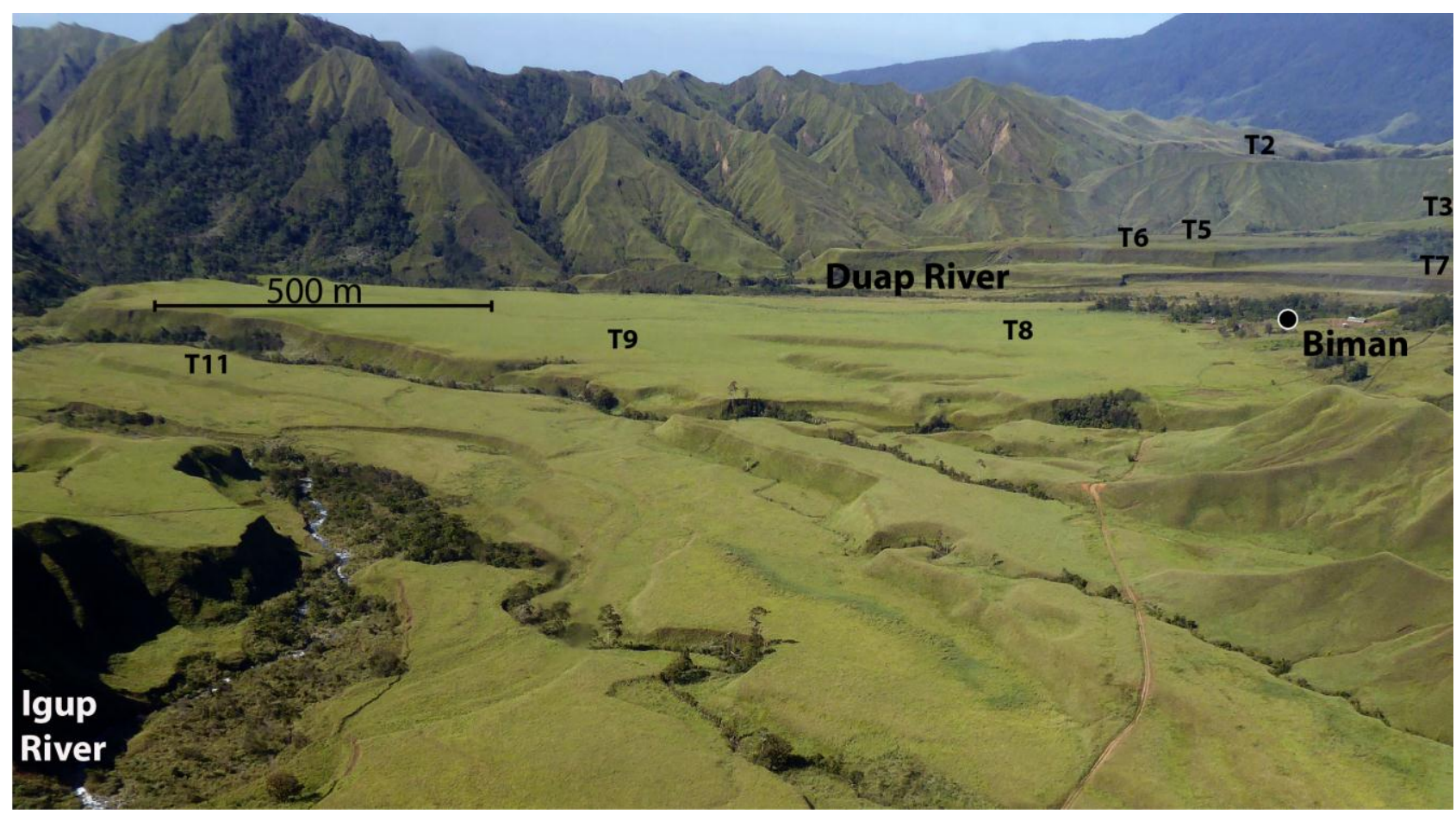

Fig. 23 - Northeast-facing photo showing fluvial terraces north of Biman. Photo taken by Jürgen Öesterle (2016).

\subsubsection{Dating of Conglomeratic Sedimentary Rocks}

I employ TCN burial dating in order to produce a suite of depositional ages for the formation. Unfortunately, TCN burial age data were not available at the time of thesis presentation. I date conglomeratic strata using ten quartz pebble samples (Fig. 24), which provide ${ }^{26} \mathrm{Al} /{ }^{10} \mathrm{Be}$ cosmogenic burial ages. Eight of these samples were collected from the Gwoira Conglomerate, one from a fluvial terrace deposited immediately north of the Gwoira Fault, and one from the Kwinimage Sandstone. Gwoira Conglomerate samples were distributed through a wide range of structural depths; however, the uppermost strata were not sampled. The details of TCN sample preparation are provided in Appendix A.

Although beyond the scope of this study, the Gwoira Conglomerate may also potentially be dated using interbedded tephra samples that were collected during the June-July 2016 field season. Radiocarbon samples collected from overlying lacustrine and terrace deposits may also potentially be used to constrain the minimum age of the Gwoira Conglomerate.

\subsection{Structure of the Gwoira Embayment}

In this section I describe the structure of the Gwoira rider block (Gwoira Fault footwall), and of the Gwoira Fault hanging wall. Structures are constrained by field observations made during three field seasons (2014-2016), the second two of which were completed as part of this thesis. These 
data are extended through interpretation of photography (Fig. 24) taken from helicopter flyovers (i.e., data presented in Webber S. et al., 2015), and the analysis of aerial photographs and remotely sensed data (FUGRO 30 m, FUGRO 5 m, ASTER 30 m, SRTM 30 m, and Google Earth). Data derived from photography are labelled separately in Fig. 24 and Fig. 25, and are generally concordant with measurements made in the field. These data are complimented by field measurements of Caffi (2008), Davies and Smith (1974), and Davies et al. (1965-1972; unpublished field notes). All field data used within this thesis are supplied within Appendix D (attached CDROM). Observations and structural interpretations are synthesised into a tectonic evolution of the Gwoira rider block in Chapter 4. 


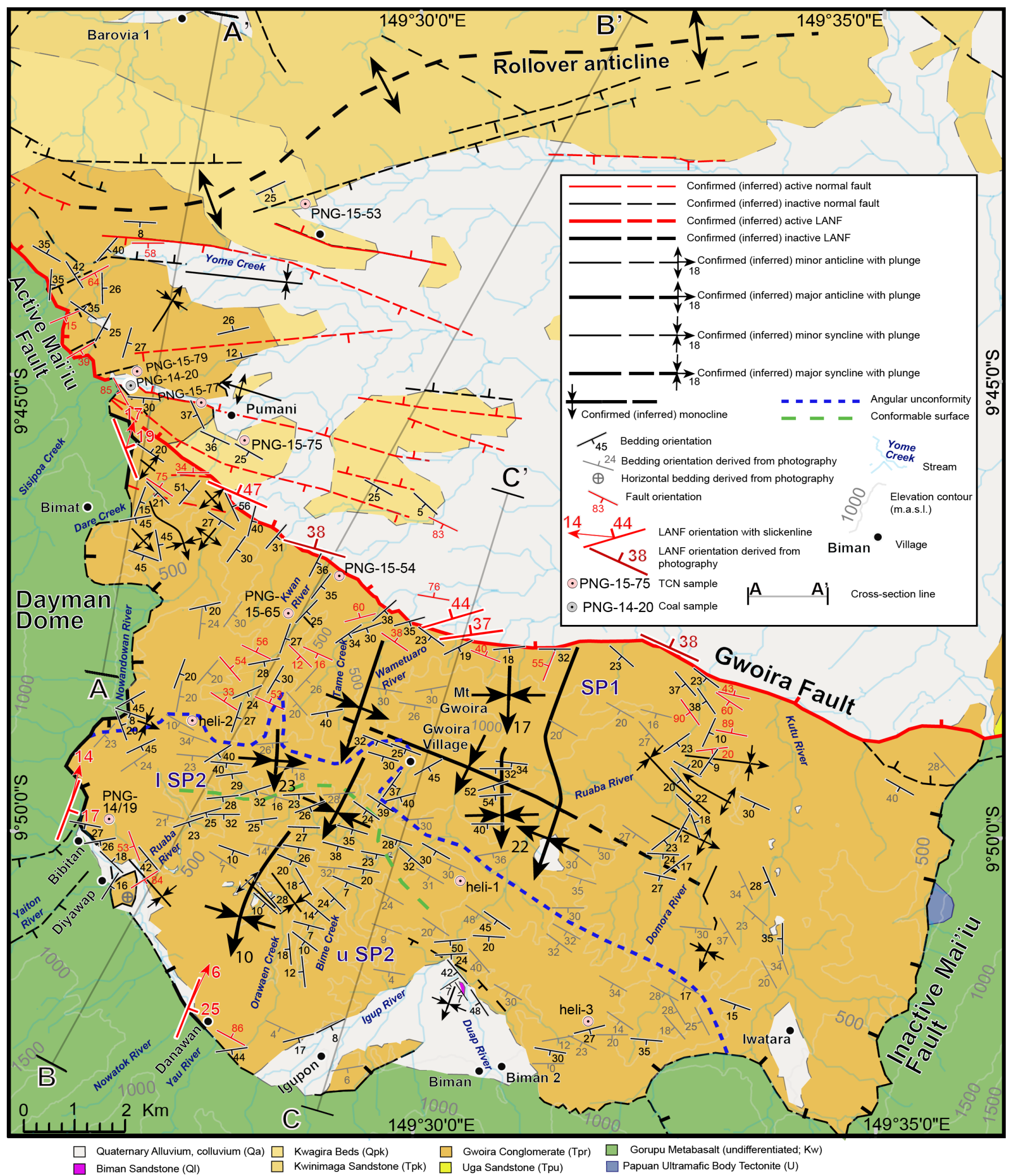

Fig. 24 - Geological map of the Gwoira embayment. The Gwoira rider block is bounded by the inactive Mai'iu Fault and the Gwoira Fault. The Gwoira Conglomerate is divided into two stratigraphic packages, SP1 and SP2, by an unconformity. SP1 steepens to the south. Lower SP2 (I SP2) is conformably overlain by upper SP2 (u SP2), which shallows towards the south. Strata are folded into SW-plunging synclines. The Gwoira Fault hanging wall faulted, and folded by a large inferred rollover anticline. Note the positions of crosssections A, B and C, and TCN and coal sample locations. Includes data from Caffi (2008); Davies et al. (1968); Davies and Smith (1974); Davies et al. (unpublished data; 1965-1972). 


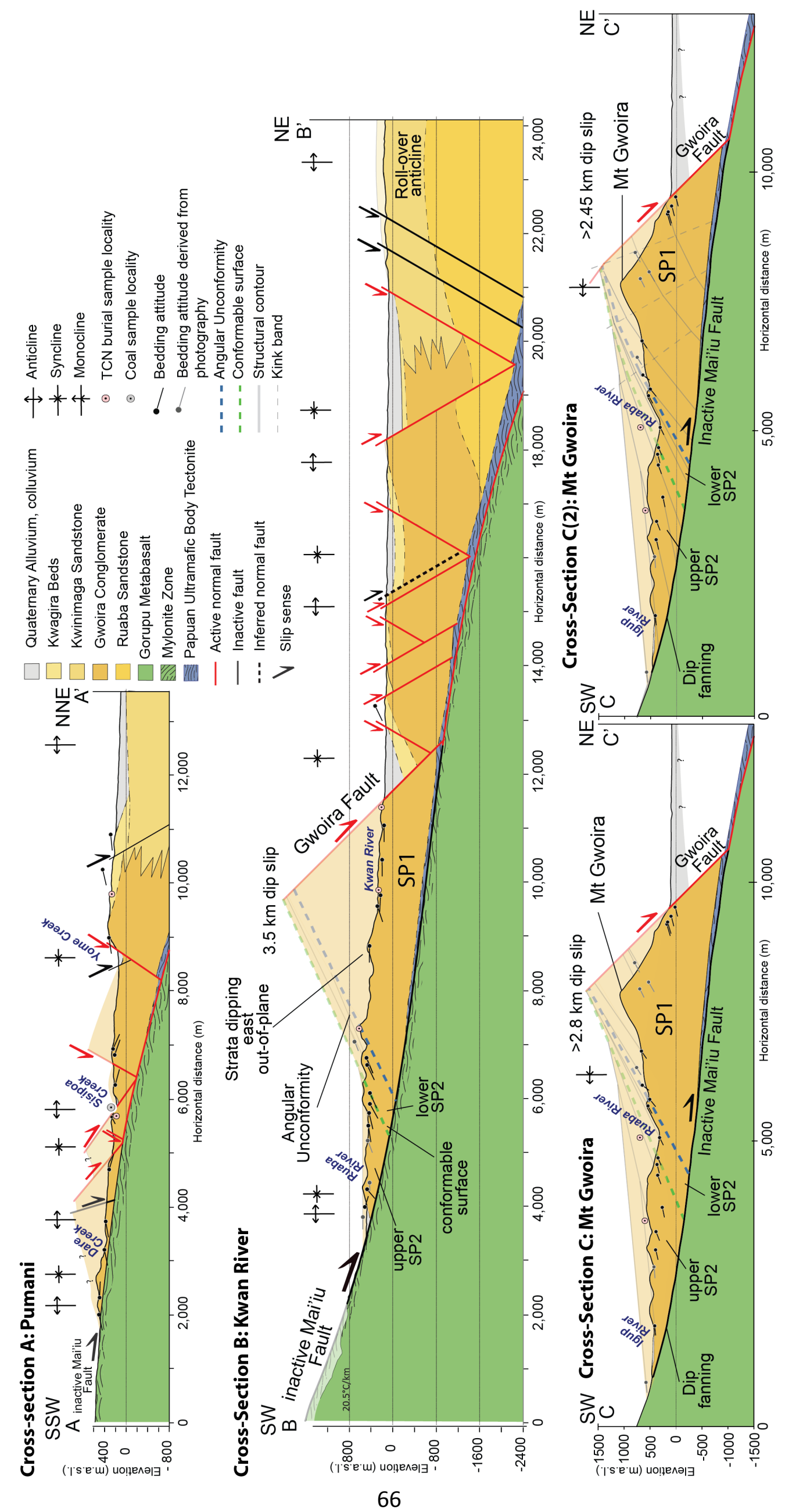


Fig. 25 - Geologic cross-sections through the Gwoira rider block (see Fig. 24 for locations). Sections A) and B) are drawn perpendicular to hanging wall structures, while section C) is drawn perpendicular to the extension direction. The subsurface geometry of inactive Mai'iu Fault is modelled by generating a surface from surface dip slopes using a linear interpolation algorithm in Leapfrog Geo (see section 3.5.1). Sections assume at $45 \% \mathrm{~N}$ dip for the Gwoira Fault. Section C) illustrates an interpretation in which SP2 strata are planar bedded, and overlie SP1 strata which have been tilted to the north. Section $\mathbf{C}(2)$ illustrates an interpretation of section $\mathrm{C}$ in which lower SP2 and SP1 strata have both been folded (according to the half-angle rule) about a fold defined by the variation in the dip of SP1 strata.

\subsubsection{The Inactive Mai'iu Fault}

The inactive Mai'iu Fault (Fig. 26a, b) outcrops near Bibitan (Fig. 24) as a $2 \mathrm{~m}$ thick fault zone. From top to bottom, this zone comprises foliated and massive gouge $(<0.5 \mathrm{~m})$, cataclasite and fault breccia with local pseudotachylite veins (1-2 m), and relict Bonenau Schist (Little et al., 2015). At this outcrop the fault is directly overlain by undeformed Gwoira Conglomerate. The lack of observable deformation (small faults or joints) within the hanging wall Gwoira Conglomerate suggests that the inactive Mai'iu Fault is very weak (Little et al., 2015). Elsewhere near Biman (Fig. 24) the fault trace is overlain by unfaulted Quaternary alluvium. Pseudotachylite veins observed within footwall Bonenau Schist at the outcrop near Bibitan evidence seismic slip (Little et al., 2015). These pseudotachylite veins have recently been dated using ${ }^{49} \mathrm{Ar} /{ }^{39} \mathrm{Ar}$ (Little et al., 2016) and yield ages of $1.85 \pm 0.17 \mathrm{Ma}, 2.24 \pm 0.29 \mathrm{Ma}$. Back-tilting of the inactive Mai'iu Fault footwall is evidenced by wind-gaps at the headwaters of the Agaun and Duap Rivers, that record stream piracy resulting from back-tilting of the landscape to the south.
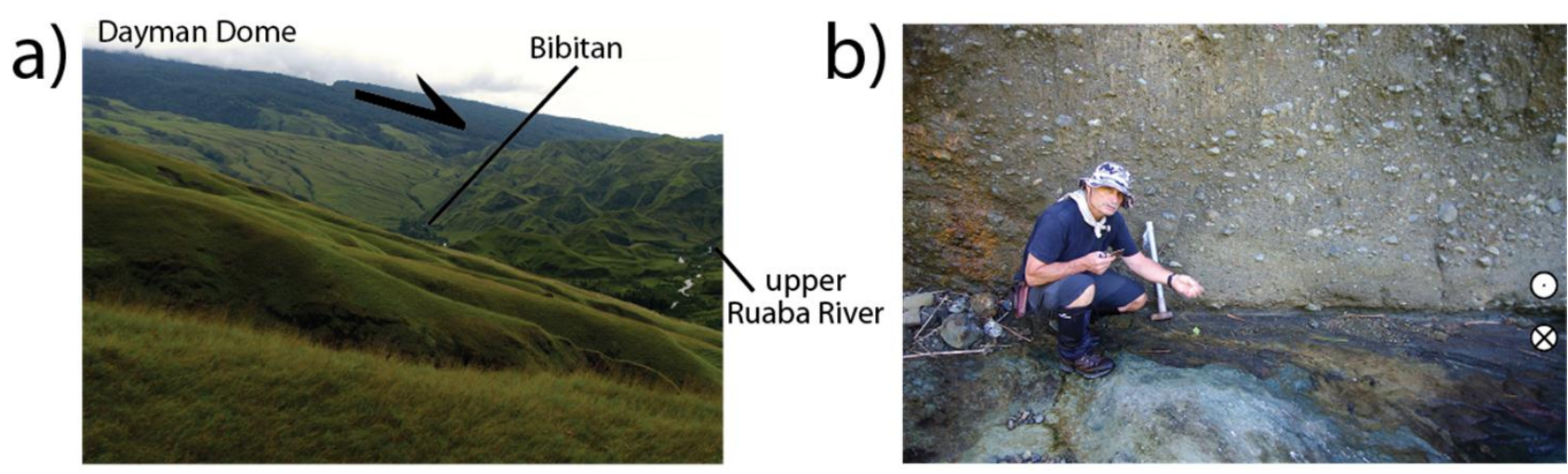

Fig. 26 - Photographs illustrating the outcrop and landscape-scale morphology of the inactive Mai'iu Fault. a) North-facing view, showing east-dipping dip slopes. Photo taken by Tim Little (2014). b) NE-facing view, of an outcrop of the inactive Mai'iu Fault plane (here dipping $17^{\circ} / \mathrm{SE}$ ) near Bibitan (see Fig. 24 for location). Photo taken by Kevin Norton (2014). 


\subsubsection{Modelled Geometry of the Mai'iu Fault}

The geometry of the Mai'iu Fault at depth is not well known. Microseismicity north of Cape Vogel Peninsula (Fig. 12), presented by Eilon et al. (2015) dips $31^{\circ} / \mathrm{N}$ and is co-linear with the surface trace of the Mai'iu Fault; this has been interpreted as defining the Mai'iu Fault plane at depth (Abers et al., 2016). However there has been no instrumentally recorded microseismicity east of E149 $4^{\prime}$ attributed to slip on the Mai'iu Fault (Abers et al., 2016; Abers et al., 1997; Eilon et al., 2015). Thus the down-dip geometry of the Mai'iu Fault is very poorly constrained.

While the relationship between the Mai'iu Fault and the Owen Stanley Fault beneath Goodenough Bay is equivocal (see Chapter 2; Fig. 27), Fitz (2011) has employed 2D-Move using the inclinedshear method of Dula Jr (1991) in order to estimate the geometry of this detachment, which he calls the Owen Stanley Fault (OSF). There the OSF is arguably an along-strike equivalent of the Mai'iu Fault (Davies and Smith, 1974). Fitz (2011) employs inclined shear angles of $52^{\circ}$ and $60^{\circ}$ for the two modelled sections, which are based on depth-migrated seismic reflection profiles; one of these sections (MCS line 1190) is shown in Fig. 27. The inclined-shear method assumes that the detachment fault is listric in shape (Dula Jr, 1991). The model assumes a hanging wall structure based on the interpretation of seismic reflection imagery. Calculation of the detachment geometry requires identification of a presumptive original horizontal datum. For this Fitz (2011) selected the basement reflector (top of the Dabi Volcanics; Fig. 27), because this horizon appears to have been sub-aerially eroded - however the author admits that this reflector could potentially have had significant original topographic relief.

The model of Fitz (2011) is capable of accurately reproducing the geometry of OSF hanging wall strata and faults, and model results are consistent with a listric OSF that becomes listric (i.e., roots into a horizontal detachment) at 12.7-16 km depth (Fig. 27). However, due to the lack of coherent reflections, the model is probably poorly resolved at depths greater than $\sim 5 \mathrm{~km}$. Significantly, the OFZ itself was not imaged, so modelling required an additional assumption regarding its initial dip angle (prior to Pliocene (?) extensional reactivation) within the upper crust - Fitz (2011) assumes this angle to be $35^{\circ} / \mathrm{N}$, supposedly based on attitudes for the Mai'iu Fault from Spencer (2010) and Daczko et al. (2011), although these authors nowhere describe Mai'iu Fault attitudes that steep, so this seems unjustified. It is likely that this assumed initial fault dip angle strongly preconditioned the modelled fault dip angle ( $37^{\circ}$ between $0.5-12.5 \mathrm{~km}$ depths for MCS line 1191). 


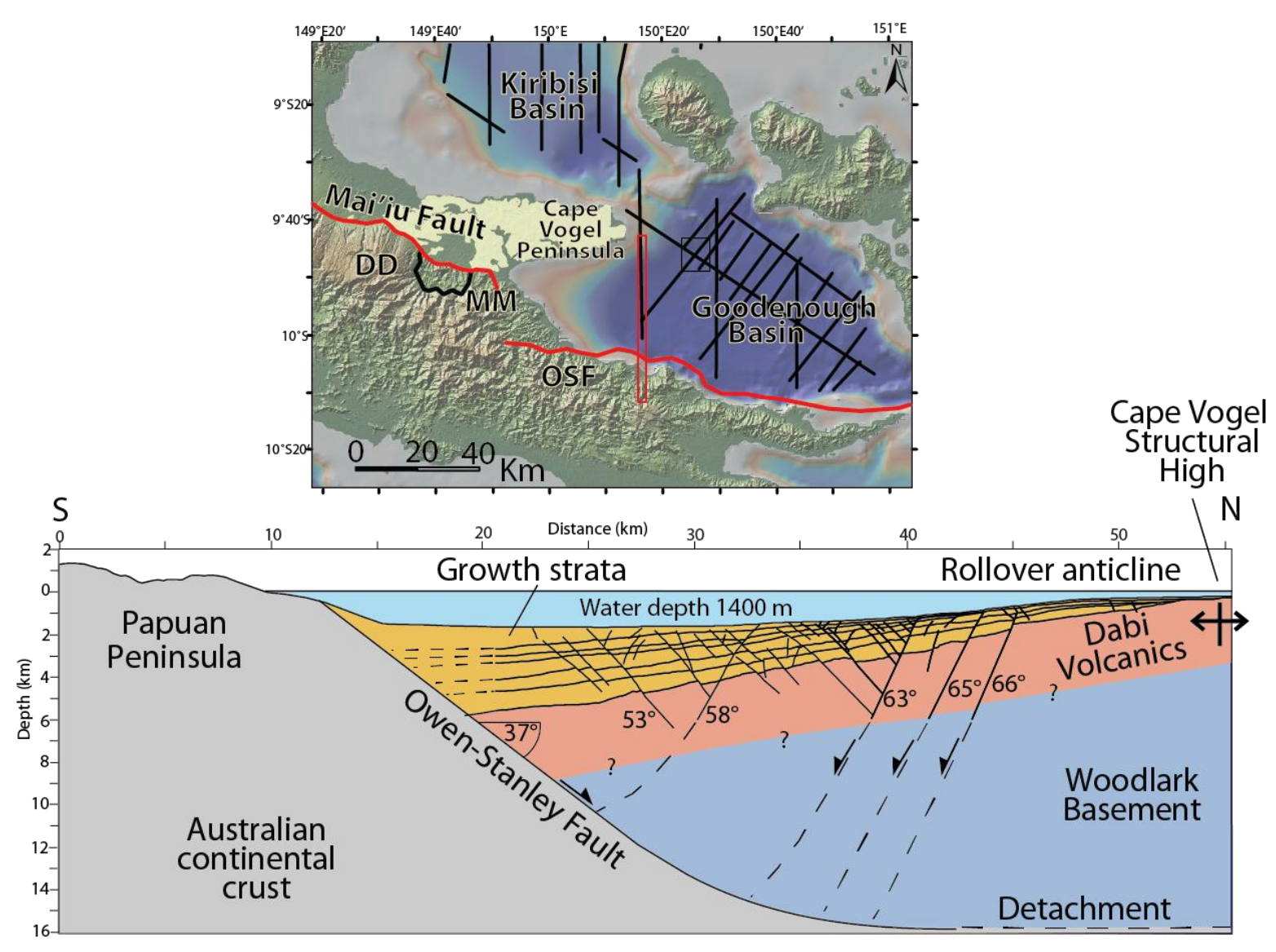

Fig. 27 - Modelled geometry of the OFZ, generated based on a depth-migrated seismic reflection section (MCS line 1190) using 2d-Move; with minor modifications after Fitz (2011). Map: location of MCS line 1190 (red), and of other seismic reflection profiles (black) described by Fitz (2011). Modified after Fitz (2011). Section: modelled fault and hanging wall geometry. Note the OwenStanley Fault, which is modelled to dip $37^{\circ} / \mathrm{N}$ - see text for details. Also note Dayman Dome (DD); Mt Masasoru (MM); and the Owen Stanley Fault (OSF). An inclined shear angle of $60^{\circ}$ was used, informed by the dip of hanging wall antithetic faults.

The morphology of preserved fault dip slopes (Fig. 26), and outcrop structural data (Fig. 24) both suggest that the inactive Mai'iu Fault forms a synclinal surface beneath the Gwoira embayment. It is possible to estimate the geometry of the Mai'iu Fault surface at depth using preserved scarp dip-slopes (Fig. 17; Fig. 26). I model the shape of the inactive Mai'iu Fault beneath the Gwoira rider block using the software LeapFrog Geo (Fig. 28). Dip slopes were manually delineated through visual evaluation of the $30 \mathrm{~m}$ SRTM DEM in ArcMap. Dip slopes and local surface topography were then exported to Leapfrog Geo as separate point clouds. Within Leapfrog Geo I generated a mesh surface from the dip-slope data, which uses a linear meshing-finding interpolation algorithm to estimate fault sub-surface geometry. This approach assumes zero erosion of dip slopes has occurred. Because dip-slope data only constrain the model well in the near-surface, I supplemented this dataset with on-fault microseismicity data (Abers et al., 2016) north of Cape Vogel Peninsula (depths greater than $\sim 12$ km), from Eilon et al. (2015), (i.e., microseismicity in Fig. 
12). I also constrain the model in the near-surface west of the Gwoira Rider block with a short N-S profile ( $n=3$ points) of constant curvature with depth, that extends to a depth of $\sim 1400 \mathrm{~m}$, modelled after Choi and Buck (2012), (see Appendix B), located $\sim 9$ km NW of Pumani. These additional constraints were required in order to model the Mai'iu Fault surface north of the Gwoira embayment, because the mesh-finding algorithm can only accurately constrain a surface within the spread of input data. These additional constraints do not control the geometry of the Mai'iu Fault within the Gwoira embayment.

The modelled fault surface (Fig. 28) forms a broad synformal corrugation beneath the Gwoira embayment, with a fold hingeline trending approximately NNE-SSW. It also suggests that the inactive Mai'iu Fault is concave-up (listric) beneath the Gwoira Conglomerate, although it begins to steepen north of an its intersection with the Gwoira Fault - this is suggestive of a ramp/flat listric fault geometry (cf. McClay, 1989). I assume that the Mai'iu Fault approaches a planar geometry at depth, consistent with the planar $31^{\circ} / \mathrm{N}$ dipping on-fault microseismicity pattern north of Cape Vogel Peninsula of (Abers et al., 2016; Eilon et al., 2015). Consequently the modelled fault surface is planar dipping $31^{\circ} / \mathrm{N}$ at depths greater than $\sim 4 \mathrm{~km}$ depth. 

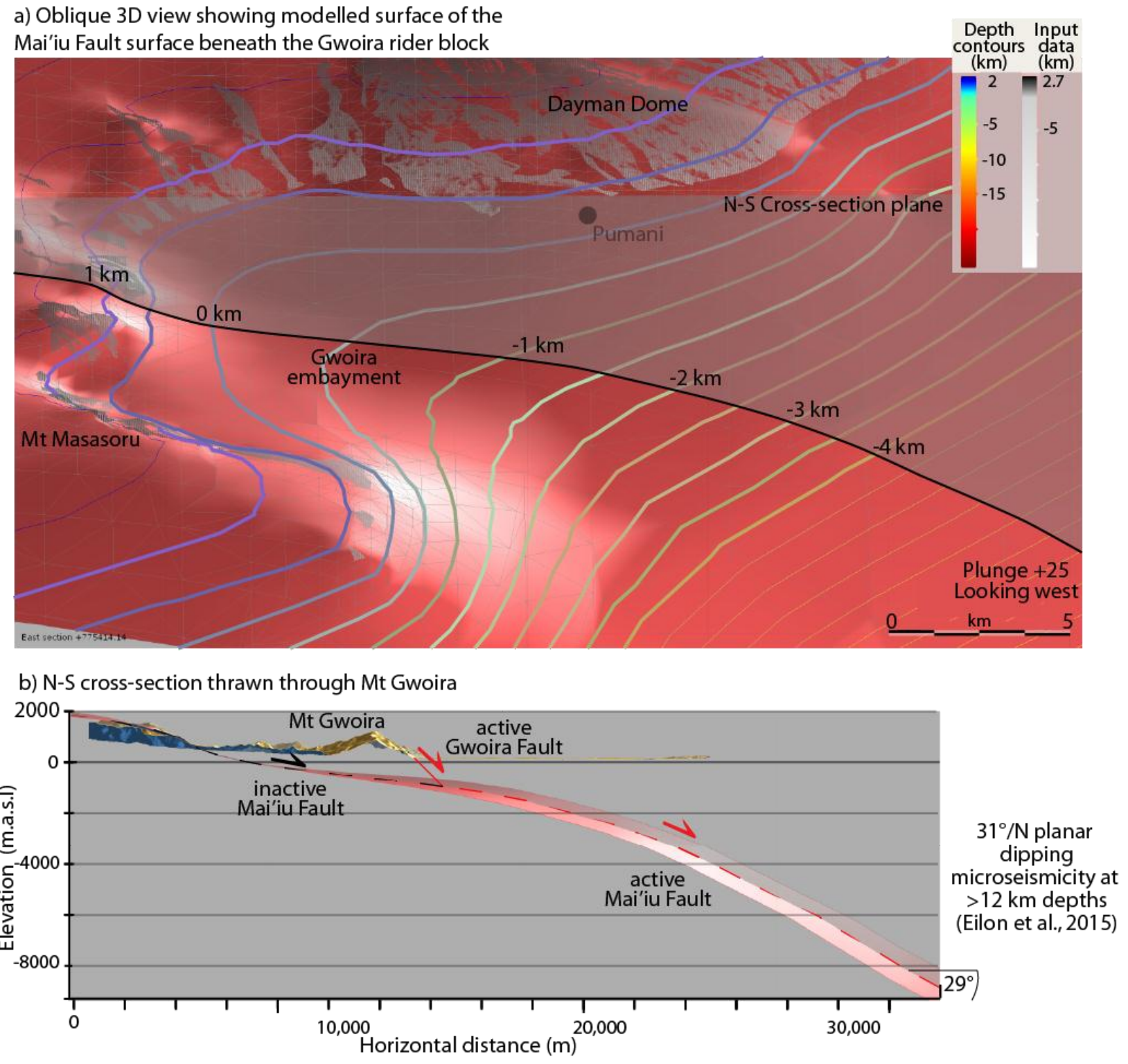

Fig. 28 - The modelled Mai'iu Fault surface generated in Leapfrog Geo through linear interpolation of preserved dip slopes of the exhumed Mai'iu Fault scarp. a) Oblique W-facing 3D view of the modelled Mai'iu Fault surface. Note dip slope point data (grey points); the N-S cross-section plane (grey surface); and labelled depth contour lines. b) N-S cross-section through Mt Gwoira. Also note topography with hillshade (yellow: upper surface; blue: lower surface), and the Mai'iu Fault surface (red). Profile is vertical and trends N-S, and includes a swathe $1.5 \mathrm{~km}$ wide to either side of cross-section line - thus a $3 \mathrm{~km}$ wide swathe is drawn. The Mai'iu Fault surface is bisected by the transparent grey cross-section plane.

\subsubsection{The Gwoira Fault}

Based on outcrop measurements made in 2016 along the Gwoira Fault trace, the Gwoira Fault (Fig. 29a) dips $37-47^{\circ} / \mathrm{NE}$ at the surface (Fig. 24). Given that the footwall of the Gwoira Fault has been back-rotated to the south by $17^{\circ}$, as indicated by bedding orientations (Fig. 25C), I interpret that the Gwoira Fault has been back-rotated to the south from an ideal initial dip of $60^{\circ} / \mathrm{NE}$, which would imply $13-23^{\circ}$ of shallowing as a consequence of footwall back-rotation. In other words, 
restoring the Gwoira Fault to a dip of $60^{\circ} / \mathrm{N}$ has the effect of restoring bedding in the immediate footwall of the fault (which dips $10-22^{\circ} / \mathrm{SW}$ ) to horizontal.

I analyse the structure of the Gwoira Fault with reference to two geologic cross-sections (Fig. 25B, C). While section B better constrains the structure of the Gwoira Fault hanging wall, section C better constrains the structure of the Gwoira Fault footwall, for it passes through the centre of the Gwoira embayment. Section C2 provides an interpretation of structures shown in section C. I estimate the amount of dip slip accommodated by the Gwoira Fault by linearly projecting Gwoira Conglomerate strata (structural contours) up-dip to the Gwoira Fault surface, and linearly projecting the inferred top of the Gwoira Conglomerate north of the fault down-dip to the Gwoira Fault surface (see Fig. 25). I measure the total dip-slip accommodated by the Gwoira Fault by measuring the stratal offset of the top of the Gwoira Conglomerate; this suggests $3.5 \mathrm{~km}$ dip slip on the Gwoira Fault at Kwan River (Section B), and $>2.8$ km of dip slip at Mt Gwoira (section C). In Fig. $25 \mathrm{C}(2)$, I interpret that SP1 strata, as well as the now eroded lower SP2 strata, have been folded about an E-W trending monocline (discussed further in section 3.5.4.1). Section $C(2)$ implies a slightly lower magnitude of total dip-slip, of $>2.45 \mathrm{~km}$. To the west of Pumani, extension is instead distributed across multiple young splay faults in the hanging wall of the Gwoira Fault. There the thickness of the Gwoira Fault footwall strata is not well constrained.

Active seismic slip along the Gwoira Fault is evidenced in Nowandowan River, where alluvium is truncated against the paleo-fault scarp, which is itself overlain by completely unfaulted alluvium (Fig. 29b). This is suggestive of a discrete Holocene seismic event, followed by quiescence, as opposed to on-going aseismic creep. 
a)

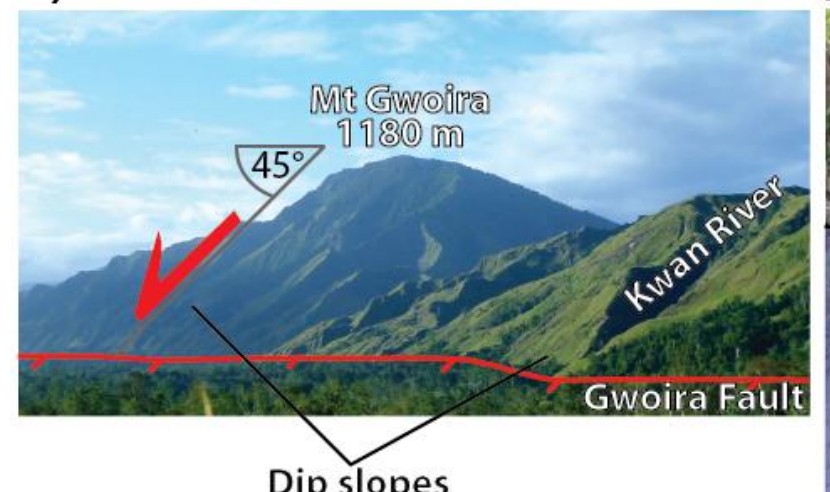

Dip slopes b)

Fault gouge, breccia

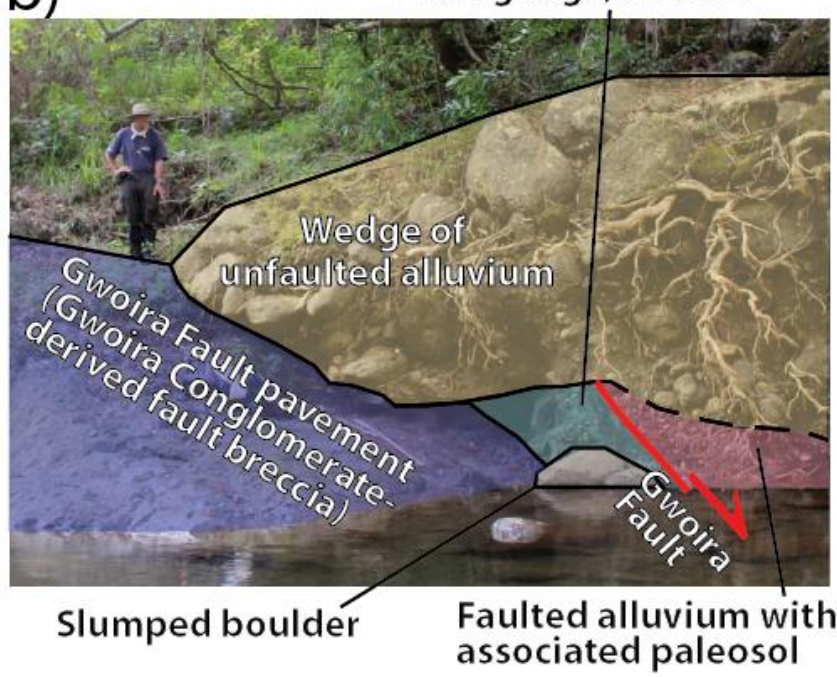

Fig. 29 - Photographs illustrating the outcrop and landscape-scale morphology of the active Gwoira Fault. a) Southeast facing view of the Gwoira Fault and Mt Gwoira. b) Southwest view in Nowandowan River, of the Gwoira Fault. The Gwoira Fault surface is defined by a principle slip zone comprising 5-7 cm of fault gouge underlain by $5 \mathrm{~cm}$ of fault breccia (light blue); underlain by a pavement of indurated fault breccia comprising sheared blocks of Gwoira Conglomerate (dark blue). A prism of faulted alluvium and an associated red coloured paleosol (red) are smeared against the Gwoira Fault; both this unit and the Gwoira Fault itself are unconformably overlain by coarser, unfaulted alluvium (yellow). Deformation of the faulted alluvial unit evidences that the Gwoira Fault slipped during the Holocene. That this unit and the Gwoira Fault are unconformably overlain by an undeformed unit evidences that slip on the Gwoira Fault is not characterised by aseismic creep. Slip on the Gwoira Fault must therefore be seismic.

The onset of motion on the Gwoira Fault initiated the stranding of the Gwoira rider block. While the timing of onset of motion on the Gwoira Fault is unknown, it must pre-date the age of approximately flat-lying Quaternary alluvial terraces that unconformably overlie the uplifted Gwoira Conglomerate near Biman (see Fig. 24 for location). Additionally it is possible to constrain the age of onset of motion on the Gwoira Fault through analysis of the nature of dip fanning within the Gwoira Conglomerate, combined with ${ }^{26} \mathrm{Al} /{ }^{10} \mathrm{Be} \mathrm{TCN}$ dating (further discussed in section 3.5.4.4).

I estimate the age of the Gwoira Fault based on the magnitude of fault throw, and the regional rate of horizontal extension. Mt Gwoira (1180 m elevation) is elevated $1060 \mathrm{~m}$ above the alluvial plane to the north (Fig. 29a). Assuming a horizontal rate of extension of 7-9 mm/yr (equivalent to a dip-slip rate of 7.5-9.6 mm/yr) indicated by modelling of regional GPS velocities of Wallace et al. (2014); and assuming a dip for the Gwoira Fault of $37-47^{\circ} / \mathrm{N}$; the Gwoira Fault must have initiated at $169(+54,-47) \mathrm{ka}$, in order for the Gwoira Fault to uplift the footwall by $1180 \mathrm{~m}$. However, the topography of Mt Gwoira may have been significantly eroded, and so may provide an 
underestimate of fault abandonment age. Instead assuming the eroded topography projected updip of SP2 strata in section C2 (Fig. 25) yields an older age for the Gwoira Fault of $248(+80-69)$ ka. However, because the Gwoira Fault may have been back-rotated from an ideal initial dip of $60^{\circ}$ over the course of its evolution, the calculated age of the Gwoira Fault may be over-estimated. Thus this age represents a maximum age of the Gwoira Fault, and for the Gwoira rider block. 


\subsubsection{Structure of the Gwoira Conglomerate}
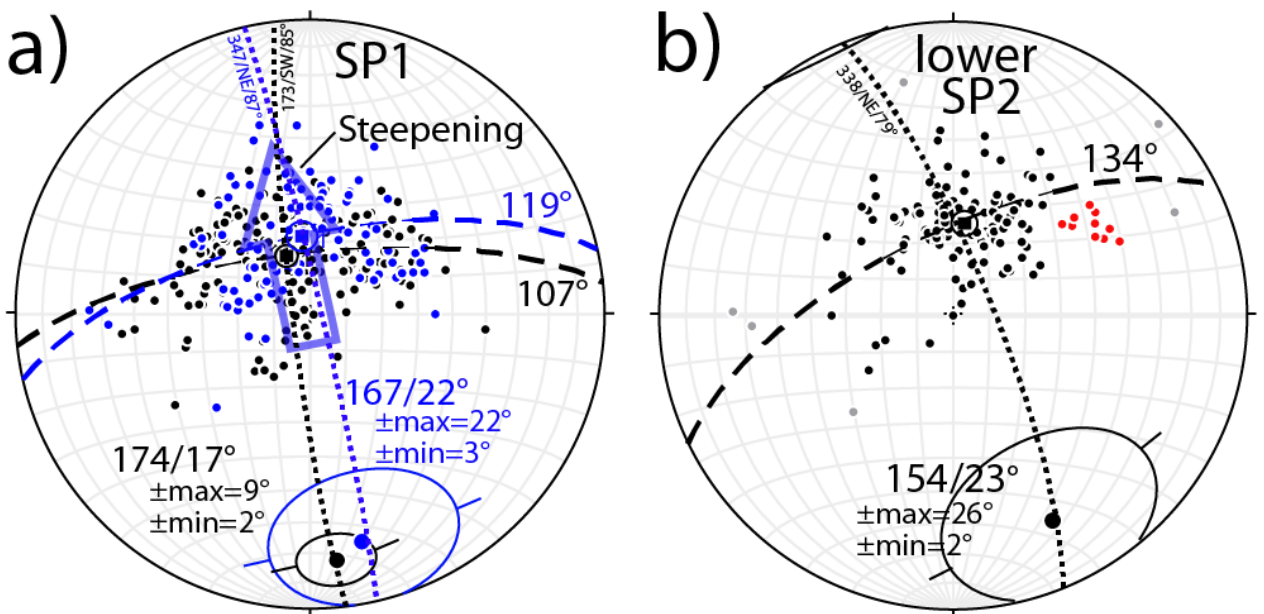

- Pole to bedding

(-) Mean bedding pole and $95 \%$ confidence

$\overline{107^{\circ}}$ - Best fit great circle and interlimb angle

174/17 Syncline hingeline and error ellipse ( \pm max)

North of Mt Gwoira;

- Pole to bed'ding

- Pole to bedding in Duap River

- Pole to bedding (outliers)

73/5w/85\%" Axial plane

(-) Mean bedding pole and $95 \%$ confidence

$\overline{134^{\circ}}-$ Best fit great circle and interlimb angle

Excluding

$154 / 23^{\circ} \bigcirc$ Syncline hingeline and error ellipse ( \pm max)

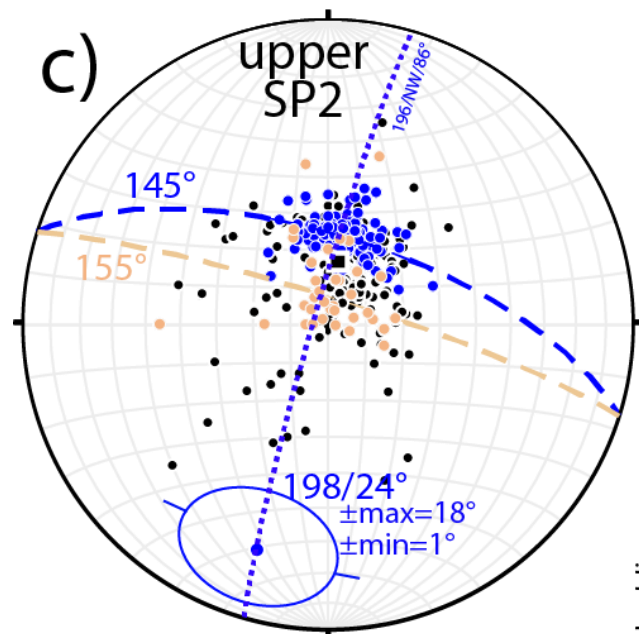

338/NE/79.** Axial plane outliers

- Pole to bedding (upper SP2 undifferentiated)

- Pole to bedding (SP2a)

Pole to bedding (SP2d)

-) Mean bedding pole and $95 \%$ confidence-

- Pole to bedding for upper SP2 (a) only

$\widehat{145^{\circ}}-$ Best fit great circle and interlimb angle for SP2(a) only

- Syncline hingeline and error

$174 / 17^{\circ}$ ellipse ( \pm max) for SP2(a) only

d)

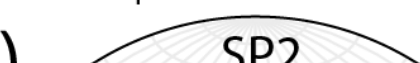

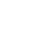

$\overline{155^{\circ}}-$ Best fit great circle and interlimb angle for SP2(d) only

$338 / \mathrm{NE} / 79^{\circ * * *}$ Axial plane

Fig. 30 - Lower-hemisphere stereograms showing bedding orientations for Gwoira Conglomerate. a) SP1, divided into strata north and south of Mt Gwoira. Bedding steepens to the south of Mt Gwoira; b) lower SP2. Strata in Duap River are considered outliers (see text for details); c) upper SP2. SP1, lower SP2, and upper SP2 are folded about south-plunging synclines. The uncertainty ellipses for hingeline locations are overestimated, for both axes are equal to \pm max. The orientation of \pm max is approximately is approximately parallel to the spread of bedding pole data; the orientation of \pm max is indicated by diametrically opposed ticks. Includes bedding information from Davies and Smith (1974) and Davies et al. (unpublished data, 1965-1972). Data plotted using Stereonet 8 (Allmendinger et al., 2011; Cardozo and Allmendinger, 2013). 


\subsubsection{Synclinal Folding of the Gwoira Conglomerate}

Gwoira Conglomerate strata within the Gwoira rider block form nested SSW-plunging synclinal folds of systematically varying fold amplitude. These synclinal structures are consistent with sparse bedding orientations documented by Davies and Smith (1974) and Bickel (1969), derived from field measurements and interpretation of aerial photographs. While Bickel (1969) has previously described the structure of the Gwoira embayment based on the interpretation of aerial photography, inferred bedding dips are binned into broad intervals (i.e., $0-3^{\circ}, 3-10^{\circ}, 10-25^{\circ}, 25-$ $45^{\circ}$, and $>45^{\circ}$ ). However, the strikes of bedding of these aerial-photography derived measurements largely conform to our field measurements.

SP1 strata form a broad S-SW-plunging syncline. SP1 Strata have been shortened E-W - this topic will be addressed further in section 3.5.5. The syncline axis passes through Mt Gwoira; however most folding is not concentrated at the synclinal hingeline, and rather mostly occurs on inwarddipping conjugate monoclinal surfaces, one in Wametuaro River, and the other on the east flank of Mt Gwoira (Fig. 24). Thus the syncline forms a large box fold. I have used stereoscopic analysis (Fig. 30) using Stereonet 8 (Allmendinger et al., 2011; Cardozo and Allmendinger, 2013) to determine the attitudes of broad scale synclines that deform the Gwoira Conglomerate, based on bedding data measured in the field, bedding information of Davies and Smith (1974) and Davies et al. (unpublished data, 1965-1972). These data are supplemented by bedding attitudes calculated from photography acquired from helicopter flyovers made during 2015. The mean syncline axial

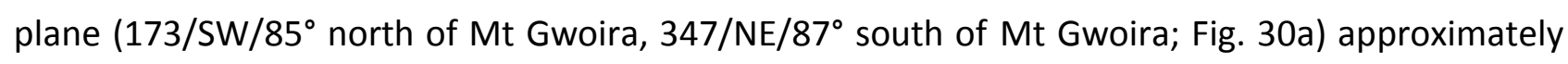
parallels slickenline measurements within the Gwoira embayment (Fig. 24). The synclinal hingeline trends parallel to the hingeline that deforms the inactive Mai'iu Fault, but plunges in the opposite direction (this hingeline can be visualised in Fig. 28a). The syncline interlimb angle, calculated based on the spread of bedding pole data with respect to the best fit plane (profile plane; Fig. 30a) is $107^{\circ}$ north of Mt Gwoira, increasing to $119^{\circ}$ south of Mt Gwoira; this indicates that the amplitude of folding increases with structural depth. However it should be noted that since interlimb angles are calculated as best-fits based on the spread of the poles to bedding, stratigraphic packages that were under sampled may be overestimated. The axial trace in stereonet view (Fig. 30a) differs from the axial trace observed in map view (Fig. 24); this is because folding is not accommodated by a single axial trace (as suggested by the stereonet), and is instead largely accommodated by these inward-dipping monoclines. The mean hingeline, determined using a Bingham Analysis routine in Stereonet 8 (Allmendinger et al., 2011; Cardozo and Allmendinger, 2013), cannot be distinguished from a trend of $180^{\circ}$ based on its errors (Fig. 30a); 
the hingeline on average plunges $174 / 17^{\circ}\left( \pm \max =9^{\circ}\right)$ for strata north of Mt Gwoira, and $167 / 22^{\circ}$ $\left( \pm \max =22^{\circ}\right)$ for strata south of Mt Gwoira. Beyond these large-scale structures, in detail there exists variability in SP1 bedding orientation. The hingeline of this syncline is not self-parallel, and migrates east by $\sim 500 \mathrm{~m}$ south of Mt Gwoira (Fig. 24). SP1 strata in Kutu River form the eastern limb of the large-scale syncline; there strata are also folded into smaller-scale E-W trending synclines and anticlines, and between upper Domora River and Kutu River they form a SSEtrending syncline that has been previously inferred by Bickel (1969) based on the interpretation of aerial photography. An inferred syncline between the Domora and Kutu rivers may potentially represent a parasitic fold. It is unknown whether an unmapped anticline exists between this syncline and the major syncline deforming the Gwoira embayment; these two folds may instead represent a compound syncline. SP1 strata in Kwan River form the western limb of the large-scale syncline, and are relatively undeformed. SP1 strata in Dare Creek and Nowandowan River, near the intersection of the Gwoira Fault and Mai'iu Fault, are highly deformed.

Dipping SE to SW/27-30', the base of SP2 is an angular unconformity (Fig. 21) that truncates more steeply dipping and discordantly-striking SP1 strata throughout the Gwoira rider block (Fig. 24). SP2 strata are also folded into a broad south-plunging syncline; however, much like SP1, much of the folding of this unit is concentrated onto an inward-dipping monocline located south of Kwan River. However, the structure of the eastern limb is only constrained by structural measurements determined from photography obtained during helicopter flyovers (Fig. 24). The axial trace in map view (Fig. 24) differs from the orientation suggested by stereonet analysis (Fig. 30b); this is because, as with SP1, folding may not be accommodated by a single axial trace (as suggested by the stereonet). The trend of this hingeline cannot be distinguished from a trend of $180^{\circ}$ based on its errors (Fig. 30b). The synclinal hingeline on average plunges $154 / 23^{\circ}\left( \pm \max =26^{\circ}\right)$. Lower SP2 strata in Ruaba River form the syncline core and dip $>28^{\circ} / \mathrm{SW}$. The amplitude of synclinal folding is less than that of SP1 strata; the lower SP2 interlimb angle is equal to $134^{\circ}$, excluding outlying data (Fig. 30b). Excluded data include steeply dipping (45-85\% SW) strata in Duap River, whose attitudes are not coherent with nearby attitudes, and which I infer to have been tilted against an obscured fault. SP2 strata exhibit less internal variability than SP1, with the exception of afore mentioned steeply dipping strata in Duap River. Immediately north of these SW-dipping strata in lower Duap River, bedding locally steepens to $45-50^{\circ} / \mathrm{S}$ (Fig. 24), which I infer to be due to drag-folding in the footwall of a south-dipping normal fault. Bedding attitudes of SP2 strata east of Biman are not well constrained. 
Upper SP2 strata lie above lower SP1 strata, above a gradational, conformable upward transition from the self-parallel, non-fanning strata of lower SP2. Upper SP2 strata are also synclinally folded about a south-plunging hingeline, and are confined to the southwest-portion of the Gwoira rider block. The synclinal hingeline is non-linear at the map-scale, and steps to the west within lower Orawaen Creek (Fig. 24). This hingeline is approximately coincident with the western N-S trending monocline that folds SP1, suggesting that the former may be an upward continuation of the latter. I have divided upper SP2 into four subunits (a, b, c, d; Fig. 30d), which are divided based on their structural depth; while this subdivision is not geologically meaningful, it simplifies the presentation of data (Fig. 30c, d). The amplitude of folding is less than that of lower SP2 strata, and decreases up section from an interlimb angle of $145^{\circ}$ for lower SP2a (Fig. 30c), to $155^{\circ}$ for lower SP2d (Fig. 30c). Strata near the inactive Mai'iu Fault, SE of Danawan, are locally steepened to $44^{\circ} / \mathrm{SSW}$. Strata in Orawaen Creek and near the inactive Mai'iu Fault in the Ruaba and Nowandowan Rivers are locally deformed into NW-SE trending synclines and anticlines.

Synclinal folding affects all strata within the Gwoira embayment. The amplitude of N-S trending synclinal folding decreases with stratigraphic height, as evidenced by the variation in syncline interlimb angles with structural depth, from $107^{\circ}$ for SP1 north of Mt Gwoira, to $155^{\circ}$ for upper SP2d (Fig. 30a, b, c). However, this systematic increase in fold amplitude with structural depth is interrupted by a discontinuity in the location of the axial trace, which migrates abruptly to the west at the SP1-SP2 boundary. This discordance in the location of the syncline axis is relatively well constrained by field data (Fig. 24). It is likely that the focus of deformation, which was initially located on two inward-dipping monoclines within SP1, was later focused onto the western monocline, of which the syncline in upper SP2 is an upward continuation.

The fold hinge of this syncline roughly parallels the regional extension direction (indicated by the orientation of slickenlines; Fig. 24), and syncline axial planes are roughly coincident with the axial plane of the corrugated inactive Mai'iu Fault surface. This suggests that both folds developed in response to the same tectonic event. The axial trace of this syncline continues south of the inactive Mai'iu Fault trace, for folding also affects the inactive Mai'iu Fault footwall. The axial trace approximately parallels the Nowatok River (Fig. 24), as indicated by the low topographic relief there (Fig. 3). 


\subsubsection{Southward-tilting of the Gwoira Embayment}

The cut-off angle (acute angle between bedding and fault orientations) of down-dip projected SP1 strata against the inactive Mai'iu Fault is $40-49^{\circ}$ (based on the interpretation of section C2; Fig. $31 \mathrm{a}, \mathrm{b})$, which implies that the Mai'iu Fault locally dipped north at $40-49^{\circ}$ (Fig. 31c) at the time of the deposition of SP1. SP2 strata are also tilted to the south, dipping SW/27-30 . The cut-off angle against the inactive Mai'iu Fault of lower SP2 strata projected down-dip is $29-31^{\circ}$ (depending on the structural interpretation; Fig. 31a, b), which implies that the Mai'iu Fault locally dipped north at $29-31^{\circ}$ at the time of the deposition of lower SP2 (Fig. 31c). Upper SP2 strata progressively shallow to the south, which is interpreted to be due to dip-fanning (described further in section 3.5.4.4). The fault cut-off angle against the inactive Mai'iu Fault of upper SP2 strata projected down-dip is $21-24^{\circ}$ (depending on the structural interpretation; Fig. 31a, b), which implies that the Mai'iu Fault locally dipped north at $21-24^{\circ}$ at the time of the deposition of upper SP2 (Fig. 31c). This implies a chronology of backward tilting of the Mai'iu Fault (Fig. 31c).

The southward tilting of SP1 and lower SP2 requires some explanation. I suggest that a component of back-tilting is due to back-rotation of the Mai'iu Fault, concurrent with deposition of the Gwoira Conglomerate. Based on the change in dip angles between SP1, lower SP2, and upper SP2 (described above), the Mai'iu Fault must have undergone $8-20^{\circ}$ of back-tilting between the deposition of SP1 and lower SP2, and a further $6-11^{\circ}$ of back-tilting between the deposition of lower SP2 and upper SP2 (Fig. 31c). From this I infer that, as a consequence of back-tilting of the Mai'iu Fault, that SP1 has undergone $14-30^{\circ}$ of southward back-tilting, and lower SP2 has undergone $6-11^{\circ}$ of back-tilting (Fig. 31d). Upper SP2 strata have on average undergone $\sim 10^{\circ}$ of back-tilting as indicated by mean dip attitudes (Fig. 31d), but it is impossible to attribute this backtilting to motion on a particular fault based on cut-off angles. I infer that this back-tilting of upper SP2 has occurred concurrent with slip on the Gwoira Fault (Fig. 31c).

The discrepancy between the amounts of back-rotation estimated above and the dip angle of each unit, I infer to be due to back-tilting concurrent with slip on the Gwoira Fault, following deposition of the Gwoira Conglomerate. This is because while back-tilting of the Mai'iu Fault, concurrent with on-going deposition, will result in a progressive reduction in the fault-cut off angle for strata of younger age, back-tilting subsequent to deposition of the upper-most Gwoira Conglomerate strata, cannot. This later back-tilting is most likely due to back-rotation of the Gwoira rider block concurrent with slip on the Gwoira Fault (Fig. 31c); back-rotation is presumably accompanied by some on-going shallowing, or flexure, of the Mai'iu Fault footwall. Because SP1 strata north of Mt Gwoira dip more shallowly to the south $\left(17^{\circ}\right)$ than SP1 strata to the south of Mt Gwoira (39 ; 
discussed further below), these strata have undergone additional deformation that would confound the arithmetic of this approach. However SP1 strata south of Mt Gwoira are approximately planar bedded; as such I estimate that SP1 south of Mt Gwoira has been backrotated $9-25^{\circ}$ as a consequence of slip on the Gwoira Fault (Fig. 31d). This is consistent with the interpretation, put forward in section 3.5.3, that the Gwoira Fault has been back-rotated from an ideal initial $60^{\circ}$ dip, to its present dip of $37-47^{\circ}$; this implies $13-23^{\circ}$ of back-rotation (Fig. 31c). Similarly, lower SP2 has been back-rotated $18-20^{\circ}$ as a consequence of slip on the Gwoira Fault (Fig. 31d).

SP1 strata north of Mt Gwoira dip less shallowly to the south than SP1 strata south of Mt Gwoira (Fig. 30a); north of Mt Gwoira bedding on average dips $S / 17^{\circ}$, while south of Mt Gwoira they dip S/22 (Fig. 25C, C2; Fig. 30a, b). SP1 strata on the southern flank of Mt Gwoira locally dip as steeply as $52^{\circ} / \mathrm{SW}$ (Fig. $25 \mathrm{C}$ ). This behaviour is unexpected given that strata within the Gwoira embayment generally steepen with structural depth. I infer that these strata north of Mt Gwoira have been deformed about an E-W trending monocline (Fig. 24; Fig. 25C, C2). Because the gradient in southward tilting is spread over $\sim 5 \mathrm{~km}$ (Fig. $25 \mathrm{~B}, \mathrm{C}$ ), it is unlikely that this effect is attributable to drag folding against the Gwoira Fault. This may represent a rollover anticline (e.g., Fig. 32) associated with slip on the listric part of the inactive Mai'iu Fault; however there is no evidence to suggest that SP1 exhibits dip-fanning, which would be expected in the case of a rollover anticline. Alternatively this deformation may be a consequence of 'rolling-hinge' style back-rotation of the Gwoira embayment, driven by flexure of the Mai'iu Fault footwall. In this model of footwall exhumation, an additional increment of southward tilting occurs with increasing distance south from the Gwoira Fault trace. It is not known at what time this flexure occurred, although it probably post-dates deposition of SP1, because SP1 strata do not exhibit dip-fanning, which would be expected if these strata were tilted. 

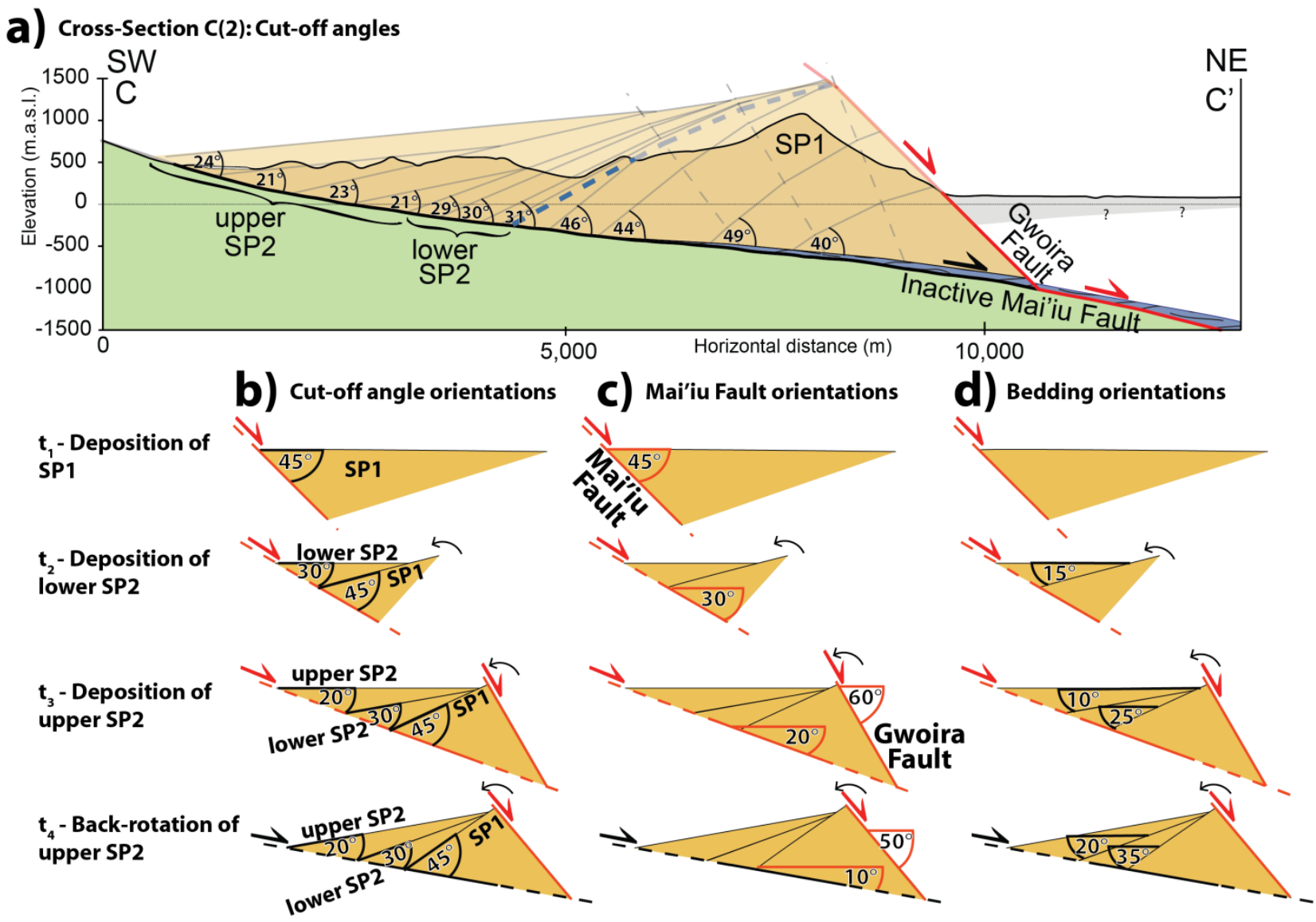

Fig. 31 - Cartoon illustrating the progressive back-rotation of the Gwoira embayment. a) Crosssection C2, highlighting measured cut-off angles of strata projected against the inactive Mai'iu Fault. b) Cartoon illustrating the preservation of cut-off angles with time. c) Cartoon illustrating the orientation of the inactive Mai'iu Fault implied by the reduction in cut-off angle of progressively younger strata. Note also the inferred shallowing of the Gwoira Fault. d) Cartoon illustrating the orientation of bedding implied by the reduction in cut-off angle of progressively younger strata. Note that this model, while assuming a planar fault and rigid block rotation, closely reproduces the orientation of the inactive Mai'iu Fault beneath SP1, and the orientations of SP1 (south of Mt Gwoira) and lower SP2. Note also that this model ignores the E-W monoclonal folding of strata in the footwall of the Gwoira Fault (discussed below).

\subsubsection{Hanging Wall Anticline}

The hanging wall of the Gwoira Fault is folded into a large anticline, as suggested by a broad topographic ridge $\sim 10 \mathrm{~km}$ north of the Gwoira Fault (Bickel, 1969), and sparse bedding measurements from its southern limb (Fig. 24). I infer this to represent a rollover anticline which has formed in response to sustained slip on the Mai'iu Fault (Fig. 24, Fig. 25). Rollover anticlines are predicted to form above listric normal faults (Dula Jr, 1991; McClay, 1989), and above planar normal faults, as a consequence of sustained slip. This hanging wall anticline is oblique to the Mai'iu Fault trace, and intersects the Mai'iu Fault northwest of Pumani (Fig. 24). This may be a consequence of a change in geometry of the Mai'iu Fault to either side of this intersection point, 
such as a change from a convex-up surface west the intersection of the hanging wall anticline, to a listric geometry north of the Gwoira embayment.

The hanging wall anticline appears to be continuous along strike with the Cape Vogel anticline (Fig. 11) and Cape Vogel Structural High (Fig. 27; Fig. 32b), which exposes the Paleocene Dabi Volcanics within its core (Davies and Smith, 1974). Sedimentary rocks to the south of the Cape Vogel Structural High fan towards the Owen Stanley Fault (Fitz, 2011), and are inferred to represent a rollover anticline associated with slip on the fault (Fitz and Mann, 2013a, 2013b). Cairns et al. (2015) calculate based on paleomagnetic data, anticlockwise vertical axis rotations of $19-35^{\circ}$ for the Papuan Peninsula between the Early-Late Miocene. Retro-deformation of this rotation would put the Cape Vogel anticline parallel to the Mai'iu Fault - this relationship is not understood.

\subsubsection{Dip-Fanning of the Gwoira Conglomerate}

SP1 strata do not exhibit discernible N-S dip-fanning; however they do exhibit slight E-W dipfanning (briefly discussed in section 3.5.5), as indicated by sparse bedding measurements on Mt Gwoira (Fig. 24). SP2 strata also do not exhibit any systematic change in dip orientation with height (the unit is defined on this basis), as reflected by the relatively narrow spread of bedding poles (Fig. 25B, C). While SP2 and lower SP2 probably exhibit some dip-fanning as a consequence of tilting associated with slip on the now inactive Mai'iu Fault, this is not discernible from our data (Fig. 25C, C2), and those strata appear to be approximately parallel-bedded.

In contrast, upper SP2 exhibits rapid dip-fanning (measured in terms of $\% / \mathrm{km}$ of horizontaldistance), which is clearly visible in map view (Fig. 24), in cross-section (Fig. 25B, C), and in stereographic view (Fig. 30d). In order to illustrate this fanning, upper SP2 strata have been further subdivided into four subunits (a, b, c, and d; Fig. 30d), which are arbitrarily delineated and distinguished based on their structural depth. Upper SP2a are those strata located along the Ruaba River; upper SP2a, b and c are located at progressively southerly locations along Orawaen and Bime Creeks; and some additional upper SP2d strata were measured along the Igup River and near Danawan (Fig. 24). The lowermost upper SP2a strata (upper SP2a; Fig. 30d) along the Ruaba River (Fig. 24) on average dip 099/SW/24', while the uppermost strata (upper SP2d; Fig. 30d) sampled within Bime Creek and Igup River on average dip far more shallowly, at 094/SW/10 . While shallowing is not statistically distinguishable from lower SP2 to upper SP2a, and from upper SP2b to upper SP2c (Fig. 30d), there is a clear and statistically robust shallowing of dip orientations from lower SP2 through to upper SP2d. Furthermore, the style of sedimentary dip-fanning within 
upper SP2 is distinctive; upper SP2 strata on-lap against lower SP2 strata, in what appears to be a sequence of uninterrupted deposition. Within upper SP2, shallower strata, when projected up-dip, lap onto underlying strata at progressively south-westerly locations (Fig. 25B, C). This dip-fanning has previously been documented by Davies and Smith (1974), (Fig. 18), and by Bickel (1969), although these previous interpretations were not supported by direct field observations.

The origin of N-S dip-fanning within upper SP2 is unclear. Dip-fanning of syn-extensionally deposited hanging wall strata is expected as a natural consequence of progressive slip on any normal fault, and could have developed within the Gwoira embayment as a consequence of either back-rotation of the underlying Mai'iu Fault, or of the Gwoira Fault. Of note, dip-fanning within upper SP2 against the inactive Mai'iu Fault is distinctly different in nature from the behaviour of underlying Gwoira Conglomerate SP1 and lower SP2 strata, which do not exhibit discernable dipfanning (Fig. 25B, C, C2). Upper SP2 dip-fanning is also much more rapid $(4.2 \% \mathrm{~km}$ ) than both onshore dip-fanning south of Cape Vogel anticline (Fig. 11), (1.5\%/km; Davies and Smith, 1974; Papp, 1928), and south of the Cape Vogel Structural High $\left(0.54^{\circ} / \mathrm{km}\right.$; Fig. 32b), (Fitz, 2011). Additionally, non-fanned lower SP2 strata separate upper SP2 strata from the rollover anticline in the Gwoira Fault hanging wall (Fig. 32). Therefore, this dip fanning is unlikely to be related to the rollover anticline described in section 3.5.4.3.

Upper SP2 strata may represent an inner rollover anticline (Fig. 32c) that formed concurrent with slip on the now inactive Mai'iu Fault. The geometry of the now inactive Mai'iu Fault resembles that of a ramp/flat listric geometry (Fig. 32a), as described by McClay (1989). McClay (1989) investigates processes of syn-extensional deposition through simulating extension of interlayered sand and mica, concurrent with on-going deposition. Although the imposed fault geometry of the analogue experiment of McClay (1989) is much steeper than that inferred for the Mai'iu Fault (Fig. 32), and although these analogue experiments do not predict abandonment of the main detachment fault, the ramp/flat listric fault geometry resembles that of the Mai'iu Fault (Fig. 32a). In this interpretation, upper SP2 were deposited against the inactive Mai'iu Fault concurrent with slip on the fault. However, there are discrepancies between the geometry of SP2 strata (Fig. 25B,C) and the experimental model of McClay (1989). Self-parallel lower SP2 strata beneath fanned strata (upper SP2) are not predicted in this model. Additionally, upper SP2 strata only occupy a small cross-sectional area with respect to the Gwoira embayment; whereas the inner rollover anticline of the McClay (1989) model occupies the entire inner embayment. Finally, in contrast to onlapping of upper SP2 strata (Fig. 25B, C; Fig. 32a), and sedimentary rocks south of the Cape Vogel Structural High (Fig. 32b) where on-lap terminations migrate north with increasing structural 
depth, the experimental model of McClay (1989) predicts radial dip-fanning of both inner and outer rollover anticlines (Fig. 32c), where bedding, projected up-dip, converge on a single point. Thus there are differences between the geometry of the modelled inner rollover anticline of McClay (1989), and the observed pattern of fanning within upper SP2, which suggests that these structures may not represent the same type of features.

I prefer an alternative interpretation; I suggest that upper SP2 strata were deposited within a basin bounded to the north by a proto-Mt Gwoira, following the onset of motion on the Gwoira Fault. In section 3.5.4.2 I show that SP1 and lower SP2 strata have been back-tilted to the south as a consequence of slip on the Mai'iu Fault, and slip on the Gwoira Fault; however, neither SP1 nor lower SP2 exhibit significant dip-fanning. In order to explain the rapid dip-fanning of upper SP2, I suggest that flexure of the Mai'iu Fault footwall, which resulted in steepening of SP1 strata to the south (section 3.5.4.2) was on-going during the deposition of upper SP2. In this interpretation, upper SP2 was deposited onlapping against the paleo-topography of proto-Mt Gwoira, which was itself being progressively back-rotated to the south with slip on the Gwoira Fault (Fig. 32a). This is consistent with the observation that onlap terminations for individual upper SP2 horizons are all south of Mt Gwoira (Fig. 25C, C2). This would imply that the $10^{\circ} / \mathrm{S}$ dip of uppermost upper SP2 strata occurred subsequent to the onset of motion on the Gwoira Fault. 

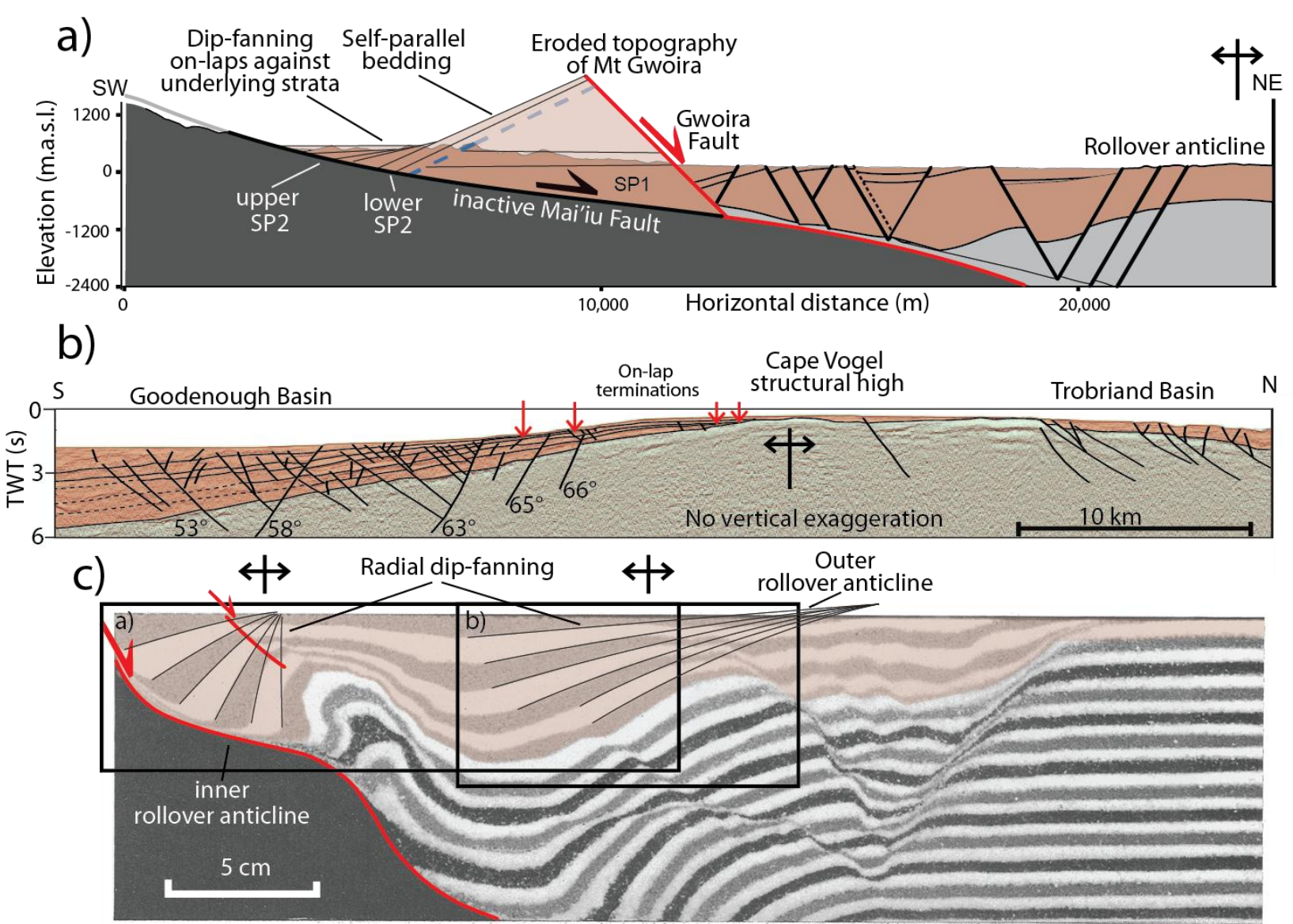

$\square$ Syn-rift sediments $\square$ Pre-rift units $\square$ Footwall units |Active fault $\mid$ Inctive fault $\quad$ Angular unconformity $\left.\right|_{\text {Bedding orientations }} \downarrow \begin{gathered}\text { On-lap } \\ \text { terminations }\end{gathered}$

Fig. 32 - Comparison of sedimentary dip-fanning within the Gwoira Conglomerate with strata south of the Cape Vogel structural high, and experimental results of (McClay 1989). a) Crosssection B (see chapter 3); note the concave-up (listric) geometry of the inactive Mai'iu Fault south of the Gwoira Fault, and on-lapping of fanned sedimentary rocks against underlying strata. b) Depth-migrated seismic reflection MCS Line 1190, oriented N-S $\sim 5 \mathrm{~km}$ east of Cape Vogel Peninsula (Fitz, 2011). Strata onlap against underlying horizons. While the Mai'iu Fault was not intersected in this profile, it is inferred to lay $\sim 7 \mathrm{~km}$ south of the southern limit. c) Result of experimental deformation of inter-layered sand and mica, above a ramp/flat listric detachment (McClay, 1989). Note rectangles illustrating approximate equivalent positions of a) and b). Strata within the inner and outer rollover anticlines exhibit radial dip-fanning (see text for details). Note that upper SP2 strata fan more rapidly than sedimentary rocks within Goodenough Basin (b), and occupy a smaller cross-sectional area than in expected for an inner rollover anticline (c). 


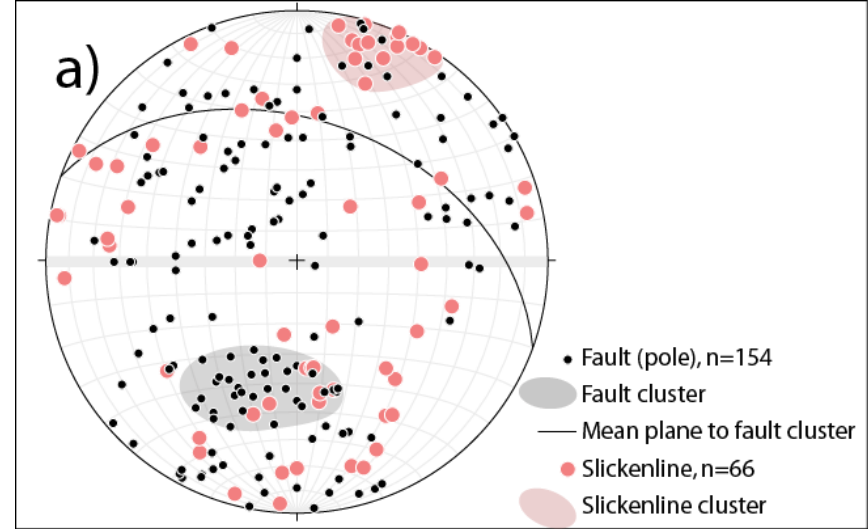

PNG-16-108 (Nowandowan River)

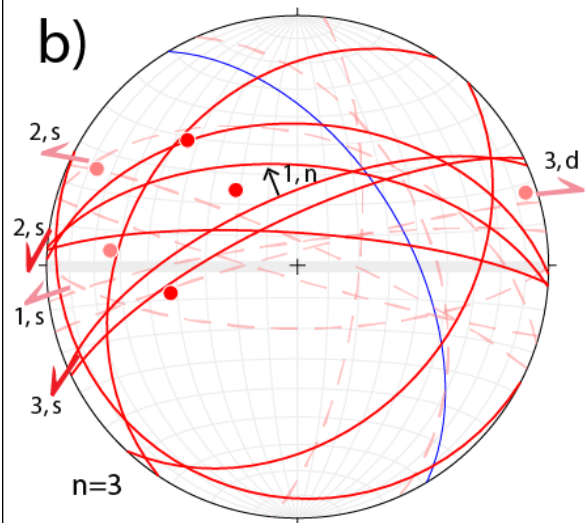

PNG-16-1098 (Tame Creek)
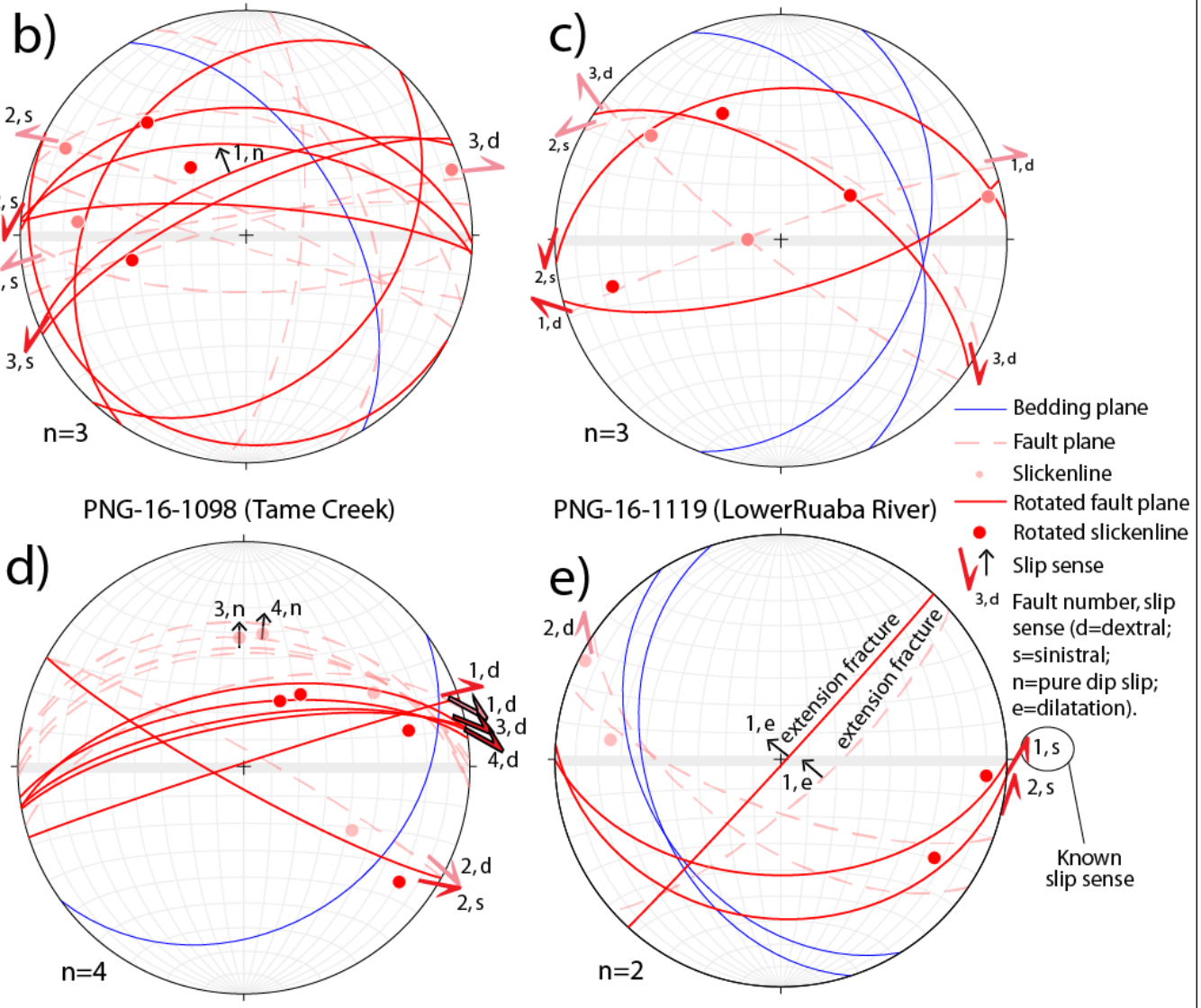

Fig. 33 - Lower-hemisphere stereograms showing: a) poles to fault planes, and fault slickenlines, located within the Gwoira Fault footwall and hanging wall, within the map area (Fig. 24). Note that fault and slickenline orientations have not been restored to account for local bedding orientation. Fault orientations are highly variable, but cluster around 290/NE/43. This shallow orientation is consistent with fault backrotation. Slickenline vectors are also variable, but cluster around 021/7, approximately parallel to the regional extension direction suggested by corrugation orientations (Daczko et al., 2011) and regional campaign GPS data of Wallace et al. (2014). Includes several data (faults $n=14$; slickenlines $n=6$ ) from Caffi (2008), in addition to our own measurements. b), c), d) Fault planes and corresponding slickenlines for selected sites that have been rotated such that local bedding is restored to horizontal. Inferred fault slip sense assumes a normal component of dip-slip - this assumption may not be realistic for sub-vertical faults (see text for details). Note that for both restored and unrestored scenarios, slickenline orientations are consistent with mostly sinistral motion for Nowandowan River, and dextral motion for Tame Creek (assuming a normal sense of dip-slip). Slip sense is not well constrained for lower Ruaba River, although one sinistral shear-sense indicator was observed in the field. Data plotted using Stereonet 8 (Allmendinger et al., 2011; Cardozo and Allmendinger, 2013). 
The hanging wall of the Gwoira Fault is dissected by NW-SE trending synthetic and antithetic high-angle normal faults (Fig. 33). These faults are presumed to root into the active Mai'iu Fault (Fig. 25A,B) at depth (cf. Yin and Dunn, 1992). In Fig. 33a I plot poles to fault orientations and slickenline orientations measured in outcrop from both the Gwoira Fault footwall and hanging wall, within the map area. There is significant variation in orientation; antithetic faults appear to show no preferred orientation, although synthetic faults cluster around 290/NE/43 (approximately the orientation of the Gwoira Fault; Fig. 33a). Rare shallow-dipping faults are likely normal faults that have been back-rotated from their original orientations. Faulting in the hanging wall of the Gwoira Fault south of Yome Creek forms a $\sim 5 \mathrm{~km}$ wide graben, that narrows to the west with faults converging within a narrow corner zone $\sim 4 \mathrm{~km}$ northwest of Pumani (Fig. 24). This convergence of fault strands suggests that the Goshen Fault Zone (Fig. 7) may merge with the Mai'iu Fault near Pumani Village. This would imply a westward increase in the proportion of N-S extension accommodated by the Mai'iu Fault. This westward reduction in the amount of extension accommodated within the Mai'iu Fault hanging wall requires either a component of $\mathrm{N}-\mathrm{S}$ trending dextral strike-slip in the Mai'iu Fault hanging wall; or a rotation of the direction of extension within the hanging wall. Additionally, while the interior of the Gwoira rider block is relatively undeformed, there is significant normal and strike-slip faulting in the footwall of the Gwoira Fault in Kwan River, Tame Creek, and Ruaba River (Fig. 24).

A large number of slickenlines ( $n=14$; Fig. 33a) cluster about an orientation of $020 / 7^{\circ}$. This slip direction is consistent with extension parallel to slip on the Mai'iu Fault, as indicated by slickenlines on the LANF surface (Fig. 24). These slickenlines are also parallel to the orientation of corrugations on the SDM (Daczko et al., 2011), which trend 006-015, which bolsters the idea that these drainages run parallel to the extension direction (Spencer, 2000). These slickenlines are also approximately parallel to the regional extension direction as indicated by campaign GPS data of Wallace et al. (2014). However, in contrast to these orientations, a category of sub-vertical faults with horizontal slickenlines suggest both sinistral and dextral oblique strike-slip faulting (Fig. 33a, b, c, d, e); however, this analysis takes no account of spatial variability, and because local bedding proximal to fault and slickenline measurements is generally inclined, it is ambiguous whether faults accrued slip prior to, or subsequent to, tilting. As such faults may not have slipped at their present orientations, and slickenline orientations may not be representative of the paleo-slip vector. This will be discussed further below.

Because specific observations of stratal offset on a fault are rare, it is impossible to ascertain the true slip vector from slickenline orientations. However, one way to extend this analysis is to 
analyse data from a specific locality, and to rotate local fault and slickenline orientations about the strike of local bedding, such that bedding is restored to the horizontal (15b, c, d, e). In this way I identify the strike-slip component of slip, assuming a normal component of dip-slip. Note that this assumption is probably not reasonable for sub-vertical faults. This approach yields two endmember scenarios. Firstly, faults may have offset bedding that was already inclined, with slip parallel to present slickenline orientations as measured in the field. Secondly, faults may have offset horizontal bedding, with slip occurring parallel to a slickenline orientation that has since been rotated. Faults must be considered individually, for there is no requirement that all faults at a particular locality were active simultaneously. Unfortunately, it is impossible to say which of these end-member scenarios is most applicable for a particular fault, though for most faults the sense of strike-slip motion does not change between end-members (again, assuming a normal sense of dip-slip).

Given my assumptions, selected localities (Nowandowan River, Tame Creek, lower Ruaba River; Fig. 24), which were selected for analysis based on the number of fault-slickenline measurements made, locally display a preference for a particular sense strike-slip motion $(15 b, c, d, e)$. Faults in Nowandowan River are generally consistent with a sinistral component of strike-slip motion (15b); faults in Tame Creek generally exhibit dextral motion; and faults in lower Ruaba River do not constrain motion well, although one fault (Fig. 33e, fault 1) was observed in the field to have a sinistral offset. This analysis is not robust, and is limited by the small number of locations assessed; the relatively small number of faults and slickenlines assessed ( $n=12$; Fig. 33b, c, d, e); and the lack of observations of stratal offset. This prohibits drawing conclusions regarding whether strike-slip faults accommodate E-W shortening, or extension.

\subsubsection{Estimates of $E$-W Shortening}

It is possible to estimate E-W shortening of the structurally deepest strata within the Gwoira Conglomerate (SP1) through construction of an inclined section that is oriented perpendicular to the mean bedding orientation. This non-vertical section, shown in Fig. 34, is oriented parallel to the Gwoira Fault, and dips $60^{\circ} / \mathrm{N}$. Bedding attitudes are projected onto this section, generally in the down-dip direction, though occasionally along-strike. Strata have been shortened $2.51 \% \mathrm{E}-\mathrm{W}$, which is equivalent to $\sim 230 \mathrm{~m}$ of shortening across the width ( 9000 $\mathrm{m}$ ) of the Gwoira embayment. Strata also exhibit some E-W fanning, where shallower strata lap onto underlying strata (Fig. 34). 


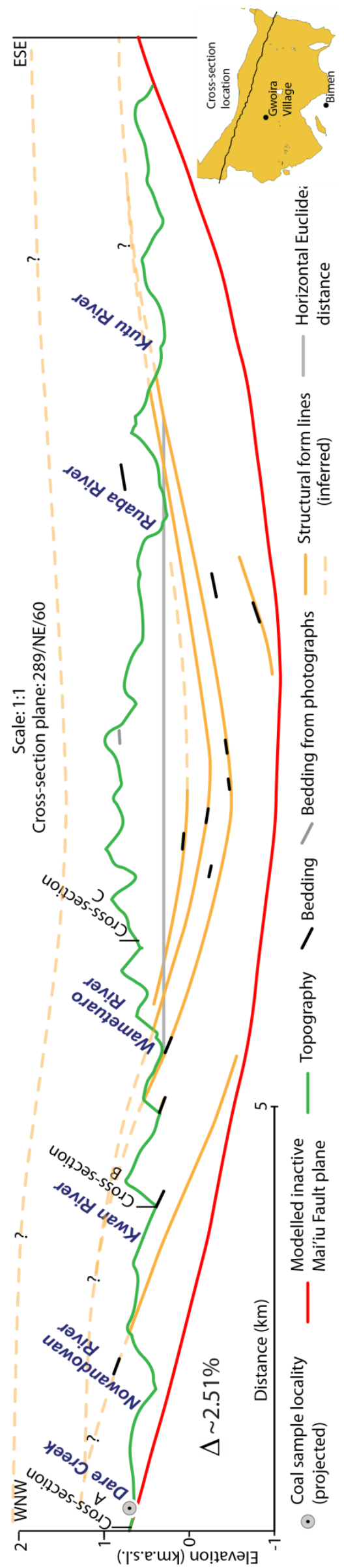

Fig. 34 - WNW-ESE non-vertical cross-section drawn through SP1 strata. Section plane dips $60^{\circ} / \mathrm{NW}$, perpendicular to local bedding orientation on Mt Gwoira. Location shown in map inset. Strata are folded into a N-S trending syncline, and are shortened E-W by $2.56 \%$. 
It is also possible to estimate E-W shortening within the Gwoira embayment through analysis of the modelled Mai'iu Fault surface (see section 3.5.2). As discussed in sections 1.1.3 and 3.2.2, MCC megamullions may amplify through extension-perpendicular folding of the fault, due to a constrictional stress field (Fletcher et al., 1995; Singleton, 2013; Tucholke et al., 1998). Assuming an average dip for each corrugated fault surface, I compare the curvilinear line length of a line drawn along the fault surface, within the cross-section plane, and parallel to the shortening direction, with the Euclidean lengths of the same line, in order to calculate the apparent shortening accommodated by folding of a once planar fault surface. The inactive Mai'iu Fault has an apparent shortening of 1.15\% ( $\sim 320 \mathrm{~m}$ over the total $\sim 28 \mathrm{~km}$ length; Fig. 35d), assuming an initial planar fault geometry, and no inheritance of fault roughness from the OSF, which it has extensionally reactivated. Perpendicular to mean fault dip, the amplitude of the Suckling DomeDayman Dome synformal megamullion is $0.92 \mathrm{~km}$, while the amplitude of the Dayman Dome-Mt Masasoru synformal megamullion (Gwoira embayment) is $1.14 \mathrm{~km}$ (Fig. 35e). That the Gwoira embayment has an apparent shortening similar to the amount of shortening accommodated by the Gwoira Conglomerate implies that both were shortened together during the same tectonic event. This analysis also suggests that the Gwoira embayment has been shortened more (1.15\%) than the Mai'iu Fault as a whole (0.79\%).

I also estimate fault roughness of the OSF (Fig. 35a, b), and of a possible along-strike equivalent of the OSF, which I here term the Uga Fault (Fig. 35c), through calculation of apparent along-strike shortening (fault roughness) based on preserved dip-slope remnants. While this 'apparent shortening' of the OSF does not represent true along-strike shortening, it is important to estimate the roughness of the OSF since it has been extensionally reactivated by the Mai'iu Fault (Davies, 1980a; Swift, 2015). Thus, roughness of the OSF may have been inherited by the Mai'iu Fault. Portions of the OSF that have not been significantly reactivated are preserved to the northwest of the SDM on the Papuan Peninsula, west of $148^{\circ} 30^{\prime} \mathrm{E}$. While the OSF have been extensionally reactivated to some small extent (Davies and Jaques, 1984), the fault has certainly accomplished less extension there, so the magnitude of any fold amplification during extension is probably far less. The OSF northwest of the SDM is characterised by a significantly eroded corrugated fault surface. The apparent shortening of the Uga Fault (Fig. 11, Fig. 35c), which outcrops east of $149^{\circ} 41^{\prime}$, is similar to that of the OSF, supporting the idea that the former may be an along-strike equivalent of the latter (e.g., tectonic map of Abers et al., 1997). This is consistent with the theory that the Mai'iu Fault has extensionally reactivated part of the OSF, while relict parts of OSF are 'stranded' further south. 
Additionally, the wavelengths of the largest corrugations of the OSF ( $\sim 30 \mathrm{~km}$; Fig. 35a, b) are comparable to those of the Mai'iu Fault (Fig. 35d), but the amplitudes of these corrugations $(0.43$ $\mathrm{km}$ ) is less than those of the Mai'iu Fault. If the Mai'iu Fault has inherited roughness from the OSF, then one may subtract the apparent amount of shortening accomplished by the OSF from that of the Mai'iu Fault (assuming that the roughness of the Owen Stanley Fault does not vary alongstrike). The resultant residual shortening $(\Delta)$ accommodated by the inactive Mai'iu Fault is $0.62 \%$ (Fig. 35). This value is far less than the estimated amount of horizontal shortening (2.51\%) accommodated by the Gwoira Conglomerate (Fig. 34). Therefore the Mai'iu Fault cannot have inherited roughness from the OSF.

Using the same approach, I also estimate possible shortening of the Gwoira Fault (Fig. 35f) through analysis of preserved dip-slopes. This assumes an initial planar geometry for the Gwoira Fault. This amount of shortening is equal to $0.51 \%$, which is consistent with the younger Gwoira Fault having undergone less shortening than the older inactive Mai'iu Fault.
a)
Horizontal Shortening
Owen Stanley Fault: $14^{\circ}$ dip
$0.38 \%$ shortening
.

b) Owen Stanley Fault: $12^{\circ}$ dip

C) Owen Stanley Fault:

$0.62 \%$ shortening

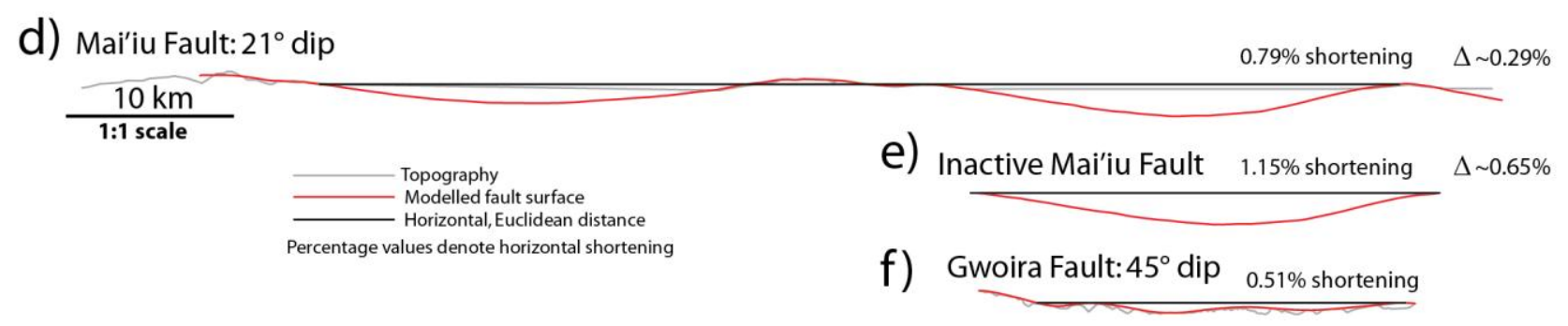

$0.63 \%$ shortening

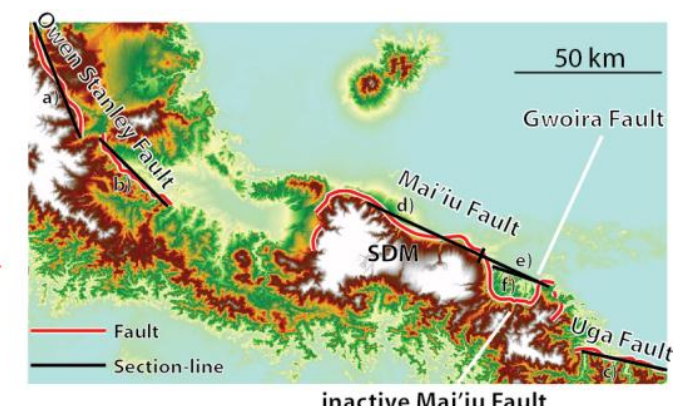

inactive Mai'iu Fault

Fig. 35 - Calculation of horizontal shortening accommodated by the Owen Stanley Fault, Uga Fault, Mai'iu Fault, and Gwoira Fault. Map inset details the location of each transect. Profiles are drawn parallel to mean fault strike in a plane drawn perpendicular to mean fault dip (corrugation profile plane). The Mai'iu Fault modelled surface was generated using Leapfrog Geo (see section 3.5.1). See text for details.

\subsubsection{Maximum Burial Depth of the Gwoira Conglomerate}

Vitrinite-inertinite reflectance and fluorescence (VIRF) has been used to estimate the maximum burial depth of a single coal sample (sample PNG-14-20), preserved within the Gwoira Conglomerate, exposed in Sisipoa Creek (Fig. 24). VIRF was determined by Jane Newman at Newman Research, and sample moisture was determined by Grant Murray at CRL Energy Ltd. For 
the preferred interpretation (interpretation 1) that normal vitrinite includes phlobaphenite-like material and cell wall tissue with fluorescence $\leq 4 \%$, reflectance $\left(R_{0}\right)$ was calculated to be $0.29 \pm 0.053 \%(1 \sigma ; N=27)$. The sample is located in a zone of deformation in lower SP1 near the junction of the Gwoira and inactive Mai'iu Faults (location shown in Fig. 24, and in Fig. 25A). I estimate that the sample is located $\sim 1400 \mathrm{~m}$ down-section from the top of the Gwoira Conglomerate (Fig. 34) - however, structural thicknesses are poorly constrained in this area, owing to the highly deformed nature of the locality (Fig. 24). Unfortunately the interpretation of results is not straightforward. Traditional interpretation of coal grade in terms of Suggate Rank (Sr) suggests $\mathrm{Sr}^{\sim}$ 2, near the average type line (Suggate, 2000), which suggests an expected vitrinite reflectance $\left(R_{0}\right) \sim 0.3 \%$ (Jane Newman, personal communication 2015). This is indicative of lignite grade coal.

I estimate maximum burial depth for the Gwoira Conglomerate at the location of PNG-14-20 using a simple 2D Monte-Carlo model in which I randomly vary maximum burial depth and sample depositional age. The model is based on a burial model developed by Middleton et al. (1987). Equation 1 (Middleton, 1982) outputs $R_{0}$ values, which are then compared to the measured sample $\mathrm{R}_{0}$ value $(0.29 \pm 0.053 \% ; 1 \sigma ; \mathrm{N}=27)$. I then calculate the residual anomaly between modelled $\mathrm{R}_{0}$ and sample $\mathrm{R}_{0}$.

\begin{tabular}{ccc}
\hline Symbol & Quantity & Units \\
\hline $\mathrm{R}_{0}$ & Vitrinite reflectance. & $\%$ \\
$\mathrm{R}$ & Initial vitrinite reflectance for peat, equal to 0.22. & $\%$ \\
$\mathrm{a}$ & Constant. & - \\
$\mathrm{b}$ & Constant. & - \\
$\mathrm{C}$ & Constant. & - \\
$\mathrm{T}_{0}$ & Local average annual surface temperature, equal to $25^{\circ} \mathrm{C}$ (Osborn and Jones, 2014). & $\mathrm{C}$ \\
$G$ & Geothermal gradient. & $\mathrm{C} / \mathrm{km}$ \\
$v$ & Constant subsidence rate. & $\mathrm{km} / \mathrm{Myr}$ \\
$z$ & Maximum burial depth. & $\mathrm{km}$ \\
$h$ & Magnitude of instantaneous erosion. & $\mathrm{km}$ \\
$\mathrm{t}_{\mathrm{q}}$ & Duration of tectonic quiescence, here equal to $0 \mathrm{Myr}$. & $\mathrm{Myr}$ \\
\hline
\end{tabular}

Table 1 - Table of quantities for modelling of maximum burial depth from coal vitrinite reflectance data.

$$
\left(R_{o}\right)^{a}=R^{a}+\frac{b \exp \left(c T_{0}\right)}{c G v}\{\exp [c G(z+h)]-1\}+b t_{q} \exp \left[c T_{0}+c G(z+h)\right]
$$

Equation 1 - Calculation of maximum burial depth. Quantities are listed in Table 1; see text for details. From Middleton (1982). 
This model assumes a tectonic evolution in which the sample is buried at a constant rate ( $\mathrm{v}$; Table 1) to some maximum burial depth $(z)$. In the model scenario this is followed by a period of tectonic quiescence $\left(T_{q}\right)$ - I assume the duration of this quiescent event to be equal to zero; thus the last term of Equation 1 is equal to zero. The model domain is then instantaneously unroofed due to erosion of magnitude $h$; I equate this instantaneous erosion event to rapid uplift along the Gwoira Fault, which for simplicity is assumed to have occurred at the present day. This instantaneous unroofing is accompanied by instantaneous cooling of the model domain. This model construct approximates what we understand of the evolution of the Gwoira Conglomerate (sections 3.4, 3.5).

The model assumes that the geothermal gradient $(G)$ does not vary spatially or temporally. I assume a geothermal gradient of $22.5^{\circ} \mathrm{C} / \mathrm{km}$ based on the result of modelling of thermal heat flow for sediments deposited within the southern extremity of Goodenough Bay of Martinez et al. (2001). This value is not well constrained, and is based on a transect of data located $\sim 85 \mathrm{~km}$ to the SE. The only other local constraints on the geothermal gradient are based on the distant Goodenough-1 Well ( $125 \mathrm{~km}$ to NE; $14.4^{\circ} \mathrm{C} / \mathrm{km}$ ), (Garside I.E., 1973), and for Nubiam-1 Well ( $190 \mathrm{~km}$ to NE; $15.3^{\circ} \mathrm{C} / \mathrm{km}$ ), (Stoen J .D., 1973). The latter two values are less reliable, as they are each calculated based on a single bottom-hole temperature reading, assuming a sea-floor temperature of $10^{\circ} \mathrm{C}$. A low geotherm within the Gwoira embayment is supported by extremely low calculated moisture content for the sample (13.9\% moisture compared with $>20 \%$ expected for low hydrogen lignites; Jane Newman, personal communication 2015). These observations are consistent with rapid burial within a very low geothermal gradient and low thermal conductivities adjacent to the Mai'iu Fault.

The model is reiterated for random values of $z$ and local depositional age. I allow $z$ to vary randomly between 0-3 km, and I allow the age of the sample (which controls the constant subsidence rate $v$ ) to vary randomly between 1-3 Ma. I calculate a residual anomaly $(\mathrm{A})$ between the measured vitrinite reflectance values ( $\left.R_{0 \text { sample }}\right)$ and the modelled TCN concentration $\left(R_{0 \text { model }}\right)$. I then calculate the absolute value of the difference between $A$, and the magnitude of error of measured vitrinite reflectance data $\left(E_{\text {sample } n o}\right)$; this is a measure of the reliability of a particular model run. The sum of $\left|A-\mathrm{E}_{\text {sample 1o }}\right|$ for all samples is termed $1 \sigma_{\text {sum; }}$ model runs with $1 \sigma_{\text {sum }}<0$ are

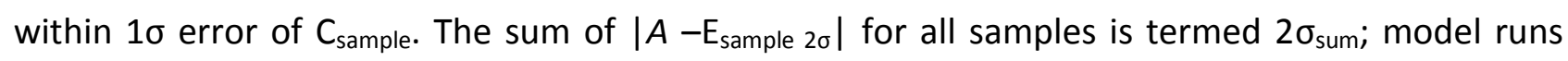
with $2 \sigma_{\text {sum }}<0$ are within $2 \sigma$ error of $C_{\text {sample. }}$ 
Modelling results (Table 2; Fig. 36) suggest a maximum burial depth of $1.34 \pm 0.33 \mathrm{~km}(1 \sigma)$, and $0.97 \pm 0.61 \mathrm{~km}(2 \sigma)$. However while $1 \sigma$ fits appear to be uniformly distributed, $2 \sigma$ fits are not; therefore I consider the $1 \sigma$ data to be a more robust indication of maximum burial depth. The width of the spread of model results about the overall curve (Fig. 36) is a function of the range of allowable ages for the Gwoira Conglomerate; this spread would reduce to a line for a precisely known formation age.

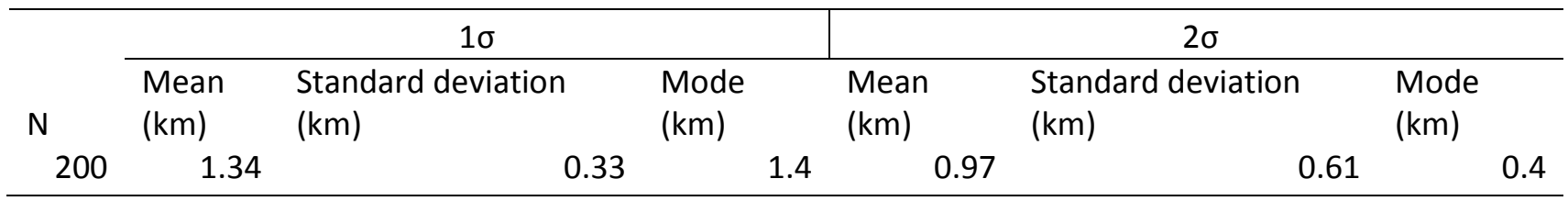

Table 2 - Summary of results of modelling of maximum burial depth for sample PNG-14-20, based on modelling of coal vitrinite reflectance $\left(R_{0}\right) . N=200$.

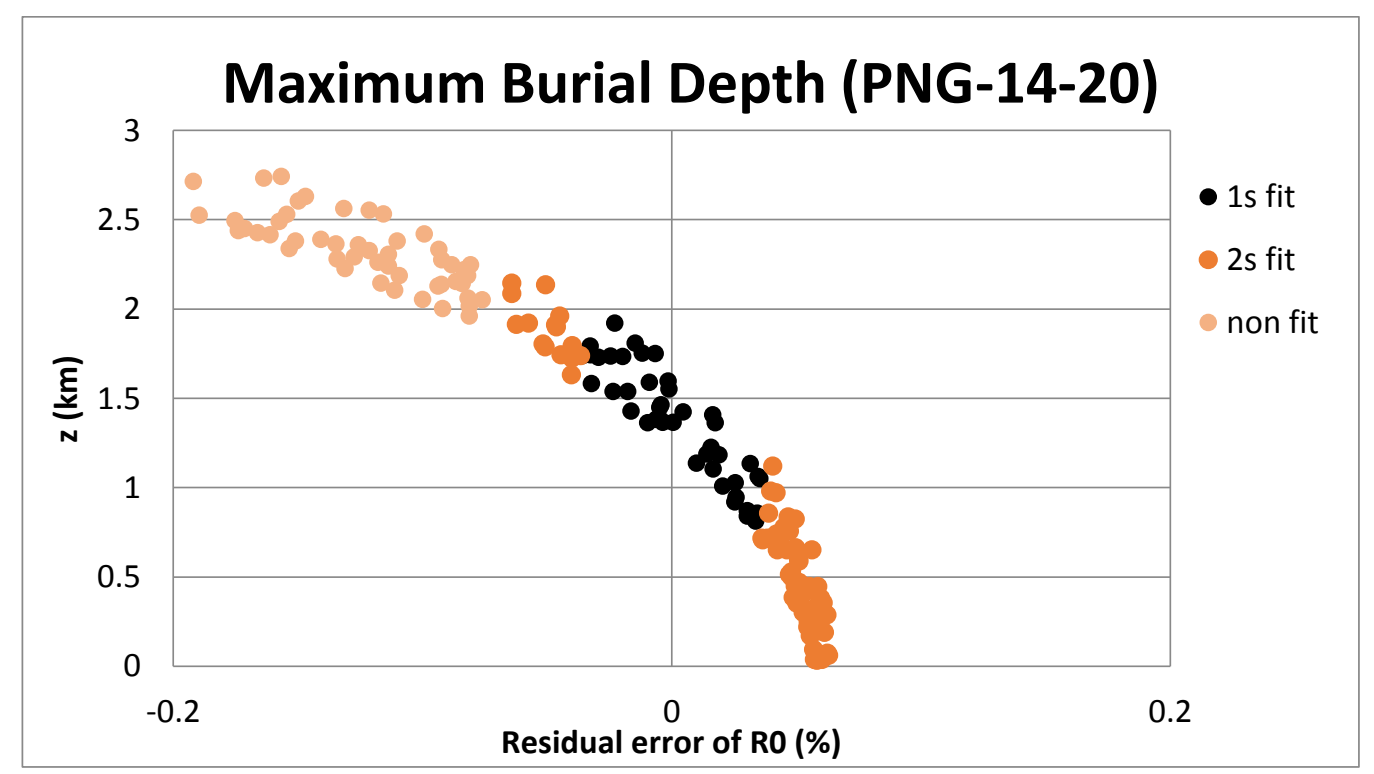

Fig. 36 - Plot of modelled maximum burial depth $(z)$ for sample PNG-14-20. $1 \sigma$ fits indicate burial to $1.34 \pm 0.33 \mathrm{~km}$, while $2 \sigma$ fits indicate burial to $0.97 \pm 0.61 \mathrm{~km}$. Note that the thickness of the zone of model outputs is a function of the range of allowable ages for the Gwoira Conglomerate (here 1-3 Ma). $N=200$.

Modelling of maximum burial depths suggests shallow burial of the Gwoira Conglomerate. Results are consistent at $1 \sigma$ with the $\sim 1.4 \mathrm{~km}$ of local overburden independently estimated in Fig. 34 . Modelled burial depths are consistent at $1 \sigma$ with coal samples within wells drilled north of the D'Entrecasteaux Islands, which have similar $R_{0}$ values and a similar local geotherm (Shibaoka M., 1973; Tjhin, 1976); i.e., 13.5\% moisture, $R_{0}=0.22 \%$ (Goodenough-1 well, $1477 \mathrm{~m}$ ); $R_{0}=0.30 \%$, (Nubiam-1 well, 1227 m). These sedimentary rocks within the Goodenough-1 and Nubiam-1 wells have not undergone additional burial (Fitz and Mann, 2013a). However these coal-bearing 
sedimentary rocks are older than the Gwoira Conglomerate (>10 Ma), and will have undergone different burial histories. Therefore, this comparison is only of limited use.

It is possible that the modelled maximum burial depth is underestimated. This is because the coal sample may have been 'chemically damaged', such that it does not record peak burial temperatures (Jane Newman, personal communication 2015). Hydrothermal damage is consistent with the very low sample moisture content, and the absence of desiccation cracks (Jane Newman, personal communication 2015); these characteristics are expected for coal of high physical rank, and are inconsistent with the low chemical rank suggested by coal $R_{0}$ values. This discrepancy may arise due to arrested development of reflectance due to the presence of a hydrothermal fluid, such that the sample may have once been buried more deeply than suggested by $R_{0}$ values (Newman et al. (2013); Jane Newman, personal communication 2015). The presence of a hydrothermal fluid is supported by observations of overgrowths on framboidal and euhedral pyrite in coal samples, and by observations of hot springs along the active Mai'iu Fault (Davies and Smith, 1974; Latter, 1964). Processing and modelling of 12 additional lignite samples collected from the Gwoira Conglomerate during the June-July 2016 field season will help to clarify this ambiguity.

\subsubsection{Structure of Late Quaternary (?) Deposits atop the Gwoira Rider Block}

The structure of the Biman Sandstone and fluvial terraces north of Biman (Fig. 24) may be used to constrain recent deformation of the Gwoira rider block. The Biman Sandstone was observed in outcrop to be folded into a SW-plunging syncline over $\sim 50 \mathrm{~m}$. The orientations of the northern $\operatorname{limb}\left(058 / \mathrm{SE} / 7^{\circ}\right)$, and of the southern $\operatorname{limb}\left(147 / \mathrm{SW} / 7^{\circ}\right)$ are consistent with a syncline hingeline of $192 / 5^{\circ}$. This is sub-parallel with hingelines that define folding of the Gwoira Conglomerate, which plunge S-SSW (Fig. 30).

Deposited directly atop the Biman Sandstone are several generations of fluvial terraces (Fig. 23). Terraces were delineated based on aerial photography (Gwoira Range Series, C.A.J.16 5046-5048, 24/Jun/1954), a 4.5 m FUGRO DEM, and photographs acquired from a helicopter fly-over during the 2015 field season. The direction in which these terraces slope is shown in Fig. 37, and a relative chronology of these terraces is shown in Fig. 38a. A more detailed DEM has since been generated from additional photography acquired in 2016 - however, integration of this dataset was outside the scope of this study. 
It is possible to extract terrace surface slope information from the $4.5 \mathrm{~m}$ FUGRO DEM. In this way it is possible to ascertain whether terraces have been deformed. In ArcGIS I calculated surface slope and aspect. I plot slope as a raster with contours of slope overlain; aspect is represented as vectors (Fig. 38). While aspect is calculated every $4.5 \mathrm{~m}$, I down-sample $6 x$ such that average aspect is plotted every $27 \mathrm{~m}$ in order to aid visualisation (slope calculations incorporate $4.5 \mathrm{~m}$ data). I calculate a weighted average slope for three terrace surfaces that are well represented in the FUGRO DEM - T7, T9, and T11 (Fig. 38b, c, d). Visual inspection evidences that terraces are to some extent incised by young drainages. Therefore I consider parts of the terrace that have the lowest slopes best represent the terrace surface. First I exclude slope aspect data (A) for which the local slope value $\left(S_{\text {local }}\right)$ exceeds some maximum value $\left(S_{\max }\right)$. I then assign each aspect data a weight value $(W)$, that is linearly proportional to the ratio between the $S_{\text {local }}$ and $S_{\max }(W=1-$ $\left.\mathrm{S}_{\text {local }} / \mathrm{S}_{\max }\right)$. In order to calculate averages of radial aspect data, I convert aspect azimuths into $\mathrm{x}$ and y Cartesian coordinates $\left(A_{x}, A_{y}\right)$ for each aspect measurement $\left(A_{X}=\cos (A) ; A_{y}=\sin (A)\right.$; where $A$ is in radians). I then calculate a weighted average based on the sum of the weighted slope values $\left(A_{\text {weighted }} x=A x / \Sigma(W) ; A_{\text {weighted }} y=A_{Y} / \Sigma(W)\right)$. Finally I convert the weighted $x$ and $y$ Cartesian coordinates back into radial coordinates $\left(A_{\text {weighted }}=\operatorname{atan} 2\left(A_{x}, A_{Y}\right)\right.$. I find that $A_{\text {weighted }}$ varies with the choice of $S_{\max }$ (Fig. 37). The sign of the slopes relates to the dominant aspect of steep areas within the terrace boundary. I prefer a low value of $S_{\max }$ as this restricts the analysis to well-preserved, flat areas. Therefore I select $S_{\max }$ as the lowest value where the value of $A_{\text {weighted }}$ stabilises (Fig. 37). Terrace slopes were measured in ArcGIS in the direction parallel to $A_{\text {weighted. }}$ By measuring slope across the full terrace length it is possible to measure slope to the decimal degree.
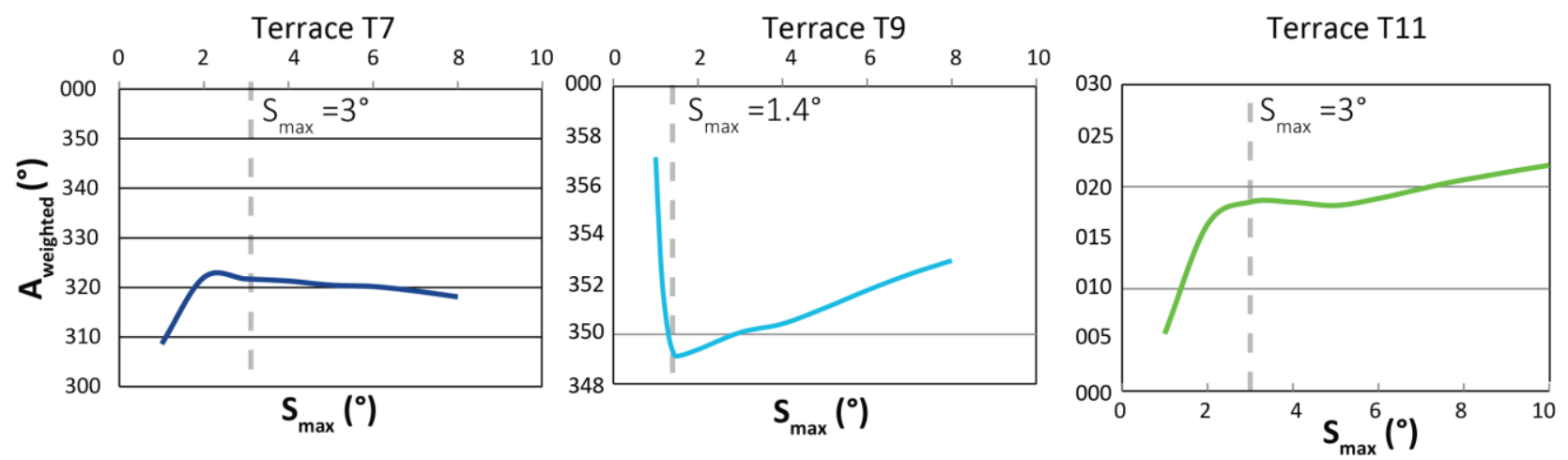

Fig. 37 - Plots illustrating the variability in $A_{\text {weighted }}$ with the choice of $S_{\max }$, for selected fluvial terraces north of Biman. The sign of the slopes relates to the dominant aspect of steep areas within the terrace boundary. I select $S_{\max }$ as the lowest value where the value of $A_{\text {weighted }}$ stabilises (see text for details). 
Based on this analysis, while there is no measurable change in the dip of the terraces analysed (T7, T9, T11), it can be seen that older terraces have been rotated to the east (Fig. 38a, b, c, d). The youngest terrace above the modern floodplain, T11 (Fig. 38b), is located due-north of Biman and immediately west of Duap River, and dips $3.4^{\circ}$ at an azimuth (dip direction) of $016^{\circ}$. The older T9 terrace (Fig. 38c) is located immediately to the west of T11, and dips (dip direction) $1.9^{\circ}$ at an azimuth of $349^{\circ}$. The still older T7 terrace (Fig. 38d) is located to the east of Duap River, and dips (dip direction) $3.0^{\circ}$ at an azimuth of $322^{\circ}$. This records a history of progressive tilting within the area north of Biman during the Late Quaternary (?). Terraces are located on the eastern limb of synclinal fold that deforms the Gwoira Conglomerate (Fig. 24), on which westward-tilting of strata is expected. Therefore the simplest and most probable explanation for the progressive folding of fluvial terraces is that they were folded by the same on-going tectonic event as that which folded the Gwoira Conglomerate.

This analysis was confounded only slightly by the identification of terrace sub-boundaries, with terrace risers $\sim 2 \mathrm{~m}$ in elevation, from photography acquired in 2016. While the aspect of terrace T11 appears to change across this terrace sub-boundary (Fig. 38b), the aspect of terrace T7 does not (Fig. 38d). Therefore the bulk of terrace T11 likely slopes in a more northerly direction than is currently reflected. Future analyses will incorporate this new data, and new terrace correlations will be made accordingly. 


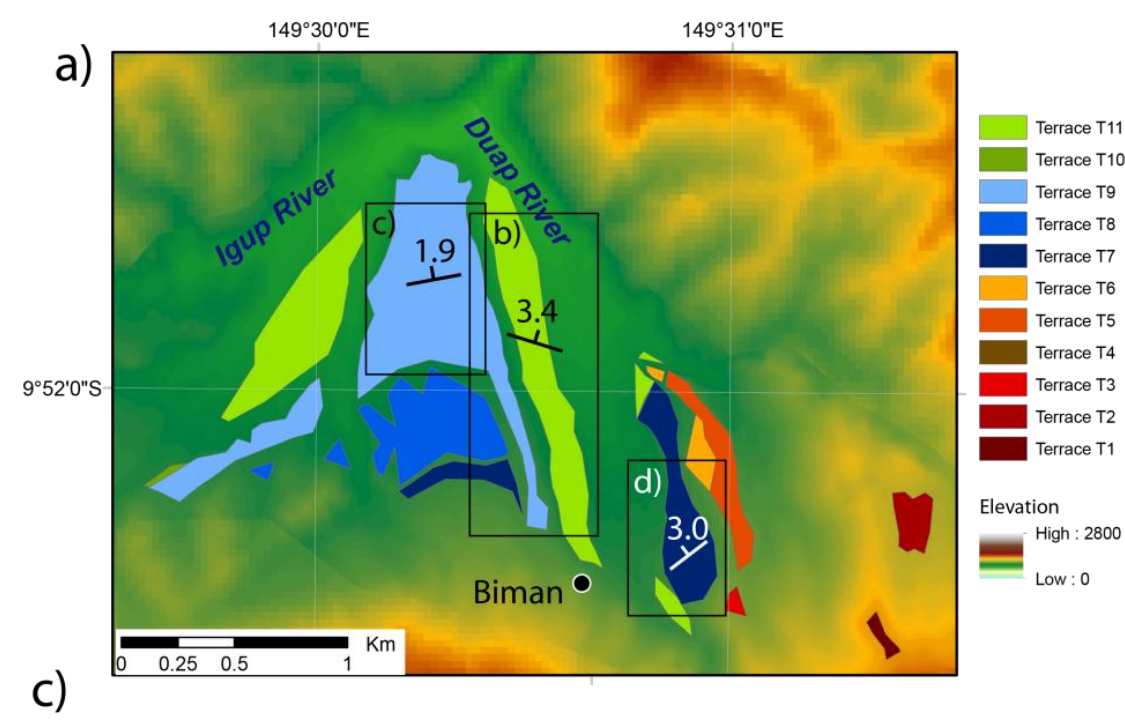

b)
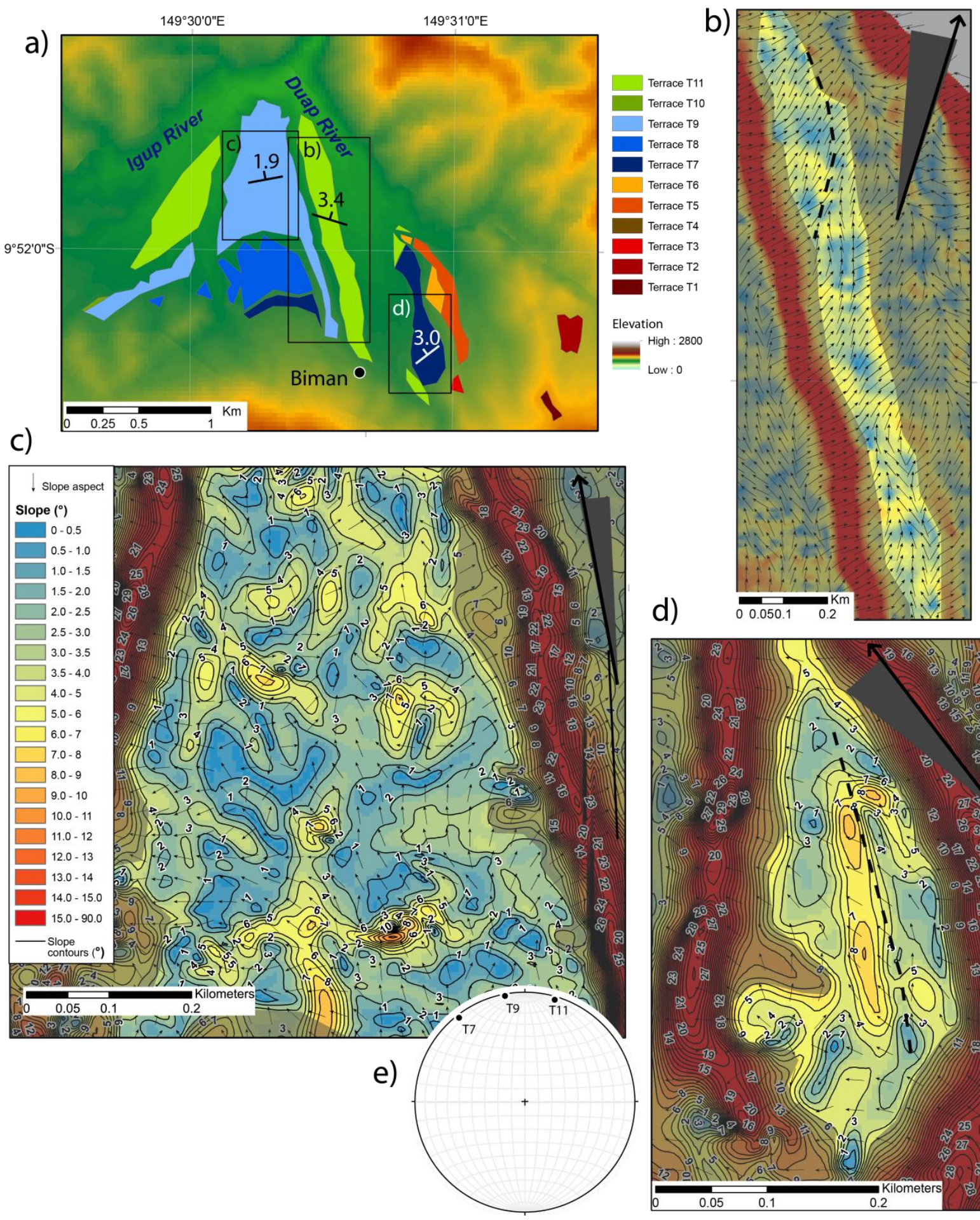

d)

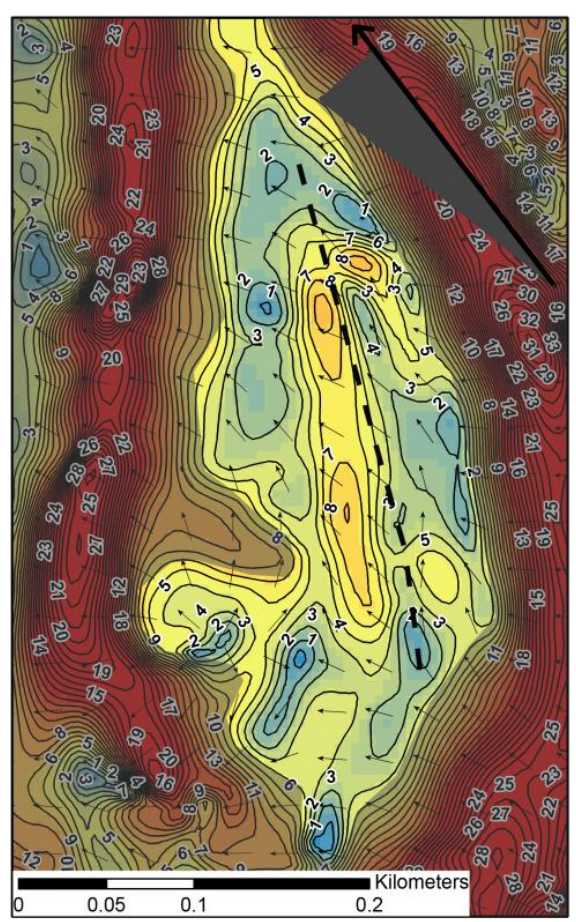

Fig. 38 - Maps depicting Late Quaternary (?) terraces located near Biman at the southern extremity of the Gwoira rider block, based on the analysis of aerial photography and the $4.5 \mathrm{~m}$ FUGRO DEM. See text for details. a) Distribution of identified terraces, showing terrace correlations and relative age relationships. Locations of images b), c) and d) are indicated. Note strike and dip symbols, which indicate the mean terrace orientation (see text for details). b), c), d): Maps showing surface slope (shaded surface, contours) and slope aspect direction (black arrows) of the T11, T9, and T7 terraces, respectively. Uneroded portions of terrace surfaces are generally confined to slopes of $\leq 3^{\circ}$. Weighted average slope aspect (dip direction) is shown at the upper right of each image (black arrow): the black arrow indicates the weighted average slope aspect for a maximum slope of $\leq 2^{\circ}$; and the grey triangle indicates the range of weighted average slope aspects for maximum slopes between $1-3^{\circ}$. The youngest terraces dip NE, whole older terraces are rotated to the NW. See text for details. Dashed lines indicate terrace subdivisions (see text for explanation) e) Stereonet projection showing terrace dip directions. 


\subsubsection{Fluvial Geomorphology of the Gwoira Embayment and Inactive Mai'iu Fault Footwall}

In this section, I investigate the origin of concave-up stream profiles that dissect the Mai'iu Fault footwall. I then model uplift through modelling of two streams that drain north through the Gwoira embayment. Finally, within this section, I present evidence for a stream-capture event that may potentially be related to the recent structural evolution of the Gwoira embayment.

\subsubsection{Convex-Up Stream Profiles}

Many streams draining the SDM, including the Yau-Ruaba and Duap Rivers that drain north through the Gwoira embayment (Fig. 24), have conspicuous convex-up morphologies immediately upstream of the Mai'iu Fault trace (Miller et al., 2012). Such stream morphologies differ from conventional stream profiles, the slope of which constantly decreases with decreasing elevation (Crosby and Whipple, 2006). The origin of such stream morphologies may potentially be related to the structural evolution of the Mai'iu Fault.

Analysis of stream profiles and knickpoints on the SDM has been previously undertaken by Miller et al. (2012). As part of their analysis, these authors estimate erosion (incision) downstream of knickpoints identified within streams draining the SDM massif to the north. In this analysis, the authors assume that the Mai'iu Fault is planar, with a footwall that is undergoing spatially homogeneous uplift. The fault footwall is assumed to be initially drained (at time $t_{1}$; Fig. 39a) by an initial equilibrium (concave-up) stream (Fig. 39a, $t_{1}$ ). Miller et al. (2012) suggest that at some time (at time $t_{2}$; Fig. 39a), this original stream profile has been disturbed due to either: accelerated uplift (Kirby et al., 2007; Stock et al., 2005), presumably due to slip on the Mai'iu Fault; or baselevel fall (Densmore et al., 1997; Snyder et al., 2002), presumably associated with Eustatic sealevel fall. The authors prefer the former possibility, and suggest that this incision event occurred during the Pleistocene, as streams containing $\mathrm{k}_{1}$ knickpoints have incised through by the PlioPleistocene Uga Sandstone (Smith and Davies, 1976), and through an interpreted Plio-Pleistocene erosion surface that extends across much of the Papuan Peninsula (Smith, 1970). The downstream portion of the stream responds to this change in uplift rate by incising the footwall (Fig. 39a, $t_{2}$ ), (Crosby and Whipple, 2006; Whipple, 2004). This signal of relative base-level fall is propagated upstream as a migrating knickpoint (termed $k_{1}$ ). $k_{1}$ knickpoints separate the older, relict stream in the headwaters from a younger stream below. Miller et al. (2012) estimate the amount of vertical incision accommodated by this migrating knickpoint through comparison of the original stream profile with the offset part of the same stream profile in the hanging wall of the Mai'iu Fault (Fig. 
$\left.39 a, t_{2}\right)$. Incision is calculated as the vertical separation of these features. The authors assume that the Mai'iu Fault footwall has been relatively uplifted by the same magnitude as the calculated incision at the range-front ( $780 \mathrm{~m}$ in the case of the SDM).

However, this approach is erroneous. The assumption of Miller et al. (2012) of a planar Mai'iu Fault implies that the Mai'iu Fault footwall is undergoing block uplift (spatially homogeneous uplift rate); however, this is not the case, as the Mai'iu Fault footwall is undergoing flexure, and is thus being progressively back-rotated (Fig. 39b). Additionally, points of inflection ( $k_{1}$ ) between two convex-up stream segments are not discrete knickpoints, and likely represent part of a continuous convex-up stream segment (Fig. 39b) that has developed as a consequence of progressive exhumation and incision of the Mai'iu Fault footwall. Thus the Mai'iu Fault has not undergone a discrete incision event, and has rather evolved in a continuous fashion. Additionally, while the Mai'iu Fault footwall has certainly been incised by streams, the direction of down-cutting is also being progressively back-rotated, such that the paleo-incision vector is curved and non-vertical (Fig. 39b).

While in some settings it is possible for convex-up stream geometries to develop as a consequence of spatial-inhomogeneity in bedrock erodibility (K), (Tucker and Whipple, 2002), there is no evidence for a smooth, systematic change in erodibility of the Mai'iu Fault footwall. Furthermore, Miller et al. (2012) argue that $\mathrm{K}$ is largely spatially invariant on the Papuan Peninsula. Therefore variability in $\mathrm{K}$ alone cannot explain such convex-up stream geometries.

I suggest that streams draining the Mai'iu Fault footwall develop as a consequence of on-going slip on the Mai'iu Fault, consequent back-rotation and incision of the footwall (Fig. 39b). Stream geometry is controlled by spatial inhomogeneity in uplift rate. Streams mimic the domal geometry of the footwall because stream segments in the lowermost fault footwall have been at the surface for a short period of time, and so have had less time to be incised than stream segments in the headwaters. This model is consistent with spatially inhomogeneous uplift rates, and does not require a discrete incision event. It is unclear whether such a stream profile may be in steady state, given on-going slip on the Mai'iu Fault. This interpretation implies that $k_{1}$ knickpoints interpreted by Miller et al. (2012) represent points of inflection at the apex of a convex-up stream segment; this apex is similar in morphology and curvature to the overall domal geometry of the SDM (Fig. 39b), though it is displaced to the north. In this interpretation, these $k_{1}$ apices develop as a consequence of incision concurrent with slip on the Mai'iu Fault. Their distance from the Mai'iu Fault trace in map view is controlled by fault slip rate, local uplift rate, and the dip of the fault. 
Because uplift rate is likely a function of distance from the Mai'iu Fault (Fitz and Mann, 2013b), and because the Mai'iu Fault dip does not change significantly along strike, the width of the area downstream (down-dip) of $k_{1}$ apices is proportional to local slip rate on the fault (Fig. 40). Because $\mathrm{k}_{1}$ apices decrease in distance from the Mai'iu Fault to the west (Miller et al., 2012), the slip rate on the Mai'iu Fault decreases to the west (Fig. 40). This suggestion is supported by the observation that, in the case of the Suckling and Dayman Domes, $k_{1}$ apex positions lies at the up-dip limit of the smooth, well preserved dip-slopes.

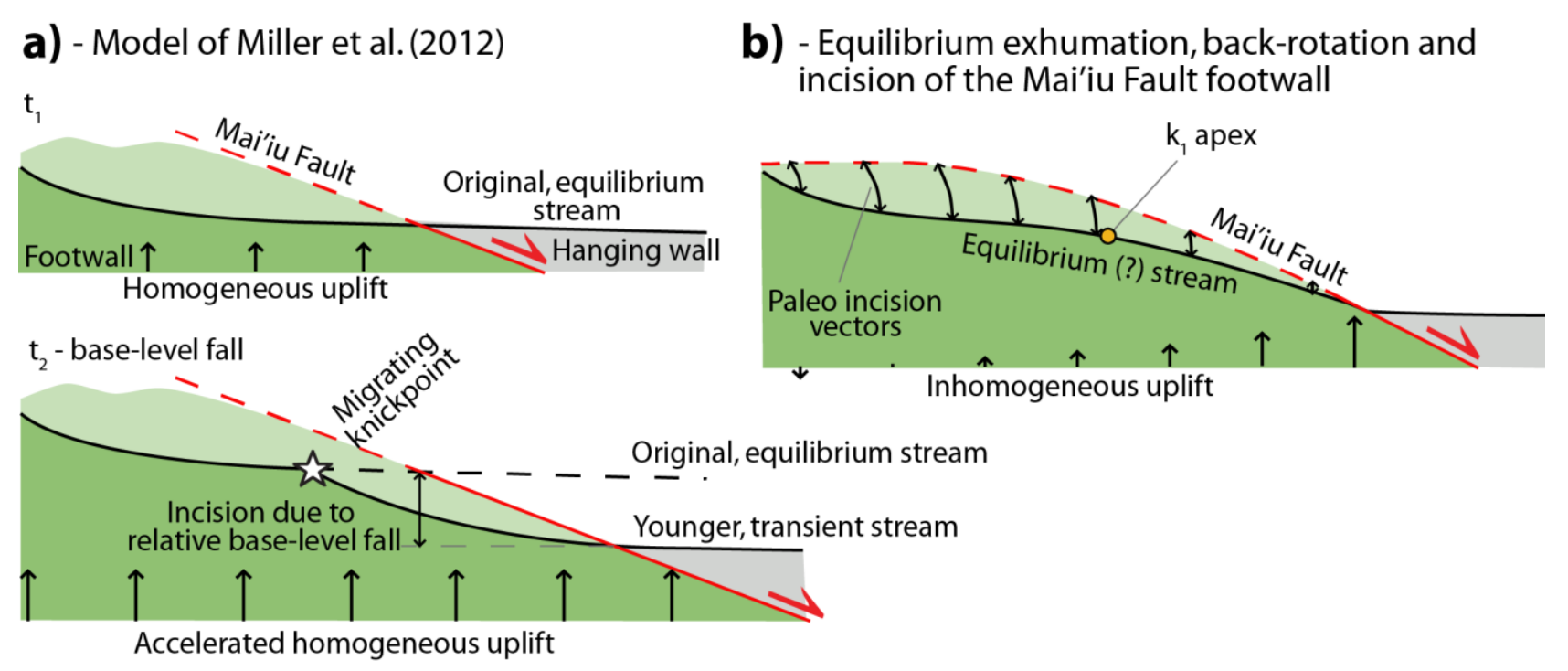

Fig. 39 - Comparison of models of the development of drainages in the footwall of the Mai'iu Fault. a) At time $t_{1}$, an original equilibrium stream drains across the Mai'iu Fault trace. At time $t_{2}$ a relative base-level fall (driven by footwall block uplift) results in offset of the original stream. The lower reaches of the stream responds by incising into the footwall; this incision migrates upstream as a migrating knickpoint (star). This model implies spatially uniform uplift rate, with a greater rate of uplift at time $t_{2}$. Modified after Miller et al. (2012). b) Streams draining the Mai'iu Fault footwall develop as a consequence of on-going slip on the Mai'iu Fault, consequent back-rotation and incision of the footwall. It is unclear whether such a stream would be in steady state. This model assumes spatially inhomogeneous uplift rates that do not vary over time. Note that paleo-incision vectors are also progressively back-rotated. 


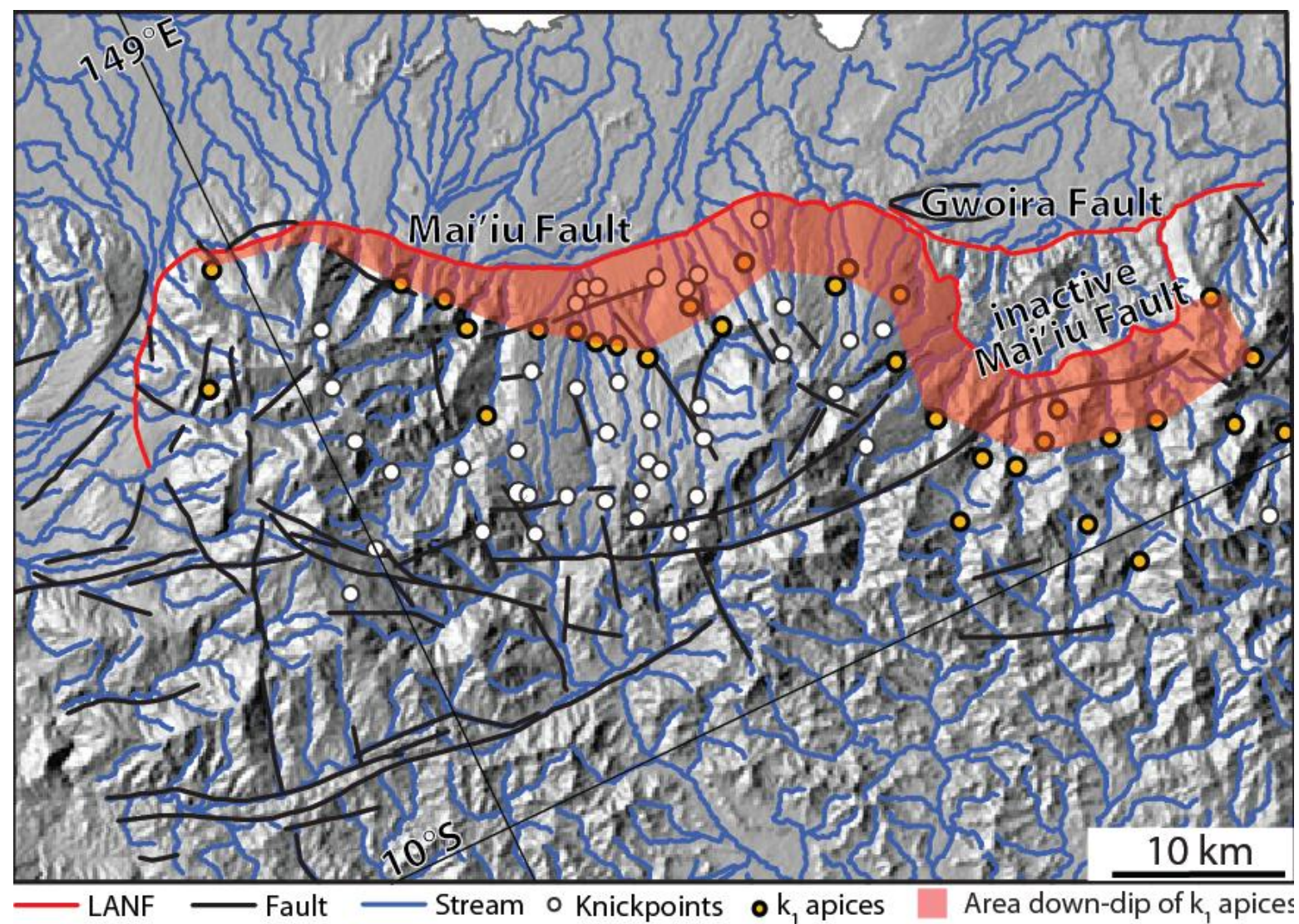

Fig. 40 - Map illustrating the location of $k_{1}$ apices (orange circles) identified by Miller et al. (2012). The distance of $k_{1}$ apices from the Mai'iu Fault trace in map view is controlled by fault slip rate, local uplift rate, and the dip of the fault. Because uplift rate is likely a function of distance from the Mai'iu Fault, and because the Mai'iu Fault dip does not change significantly along strike, the width of the area downstream (down-dip) of $k_{1}$ apices is proportional to local slip rate on the fault. Based on this it appears that the slip rate on the Mai'iu Fault wanes to the west. This suggestion is supported by the observation that, in the case of the Suckling and Dayman Domes, $\mathrm{k}_{1}$ apex positions lies at the up-dip limit of the smooth, well preserved dip-slopes. Map modified after Miller et al. (2012).

\subsubsection{Modelling of Uplift Rates}

In order to understand the process by which convex-up streams develop in the footwall of the inactive Mai'iu Fault south of the Gwoira embayment, I model long-term uplift rates along the Ruaba and Duap Rivers, using stream profiles calculated for the $30 \mathrm{~m}$ SRTM DEM in ArcGIS. I first calculate flow direction raster, from which I calculate a flow accumulation raster. I then threshold this raster to display only high flow areas, and convert the resultant raster to produce a stream polyline. I then use the stack profile utility to project the $30 \mathrm{~m}$ SRTM DEM onto the calculated stream polylines - I do this for the Yau-Ruaba and Duap Rivers, from their headwaters to the flood plain north of the Gwoira Fault. I also export upstream drainage area (A) for each position.

Uplift rates derived from uplifted coral reefs along the coast of Goodenough Bay (Fitz and Mann, 2013b; Mann and Taylor, 2002) suggest that the Gwoira Fault footwall is been characterised by 
uplift rates that increase to the north. Uplift rate distributions within can be modelled along a stream section using the detachment limited stream profile equation (Equation 2). Although the equation is not usually employed in this fashion, $U$ may in theory be allowed to vary with distance downstream, provided the resultant stream profile is in steady state. This is because the detachment limited stream profile equation inherently assumes a steady state condition, where stream profile geometry reflects rates of uplift (U) and erosion of stream bedrock (E) which themselves do not vary with time. For this modelling exercise I assume $\theta_{d}=0.5$ (theoretical intrinsic concavity), approximately equal to the mean value for the Papuan Peninsula (Miller et al., 2012), although results are not very sensitive to the choice of $\theta_{d}$ (Schoenbohm et al., 2004). I also assume $m=1$, and $n=2$ (dimensionless coefficients), (Whipple et al., 2000) based on preliminary modelling of nearby streams with normal drainage morphology (and constant uplift rates), with uplift rates defined as those specified by Mann and Taylor (2002) and Fitz and Mann (2013b). K (erosional efficiency factor) is poorly constrained, and so is a free variable, although it must be constant for a given lithology.

$$
S=\left(\frac{U}{K}\right)^{\frac{1}{n}} A^{-\theta_{d}}, \quad \theta_{d}=\frac{m}{n} \quad k_{s}=\left(\frac{U}{K}\right)^{\frac{1}{n}}
$$

Equation 2 - The equation for detachment-limited streams. See text for details. From Tucker and Whipple (2002).

By varying $U$ with distance upstream, I attempt to match the stream profiles for the Yau-Ruaba and Duap Rivers. I do this in slope-upstream drainage area space. I allow $U$ to vary with alongstream distance for an assumed range of $K$ values; assuming values of $\theta_{d}, m$, and $n$ (described above), and imposing values of upstream-drainage area exported from ArcGIS, I iteratively match the model with data extracted from the $30 \mathrm{~m}$ SRTM DEM by imposing linear and exponentially varying $U$ distributions. Uplift rate varies with position $\left(U_{x}\right)$, is assumed to increase towards the north (based on the uplift-rate pattern shown in Fitz and Mann (2013a), and varies in an exponential fashion within discrete exponential functions bounded by each lithological unit (Gorupu Metabasalt, Gwoira Conglomerate, alluvium), according to the following relationships (Equation 3):

$$
\begin{array}{cc}
U_{x}(n+1)=U_{x}(n)+A \cdot \exp \left(a_{x}\right) ; & U_{x 1}=U_{x 0} ; \\
a_{x}(n+1)=a_{x}(n)+\partial a_{x} ; & a_{x 1}=a_{x 0}
\end{array}
$$

Equation 3 - Equations that describe the exponential downstream variation in $U_{x}$ within a particular lithology. See text for details. 
Within a particular lithology: $U_{x 0}$ is the rate of uplift at the upstream lithologic boundary; $A$ is the exponential coefficient; $a_{x 0}$ is some distance-varying value at the upstream lithologic boundary; and $\delta \mathrm{a}_{\mathrm{x}}$ is the variation in $\mathrm{a}_{\mathrm{x}}$ with distance downstream. However, because both $\mathrm{K}$ and $\mathrm{U}_{\mathrm{x}}$ are unknown, the result is therefore non-unique - that is, it is possible to 'trade-off' an increase in $U$ with a corresponding increase in $\mathrm{K}$. Therefore I impose values of $\mathrm{K}_{\mathrm{sn}}$ (Equation 2) of 10-209, as calculated for nearby streams $(n=16)$ in the Mt Simpson area, south of the Gwoira embayment (Miller et al., 2012). Therefore, while I input random values of $\mathrm{K}$, I only consider model runs in which $\mathrm{K}_{\mathrm{sn}}$ is between $10-209$.

I run a preliminary model in which $\mathrm{I}$ arbitrarily define $\mathrm{K}_{\text {Gorupu }}, \mathrm{K}_{\text {Gwoira, }}$ and $\mathrm{K}_{\text {alluvium }}$ (because $\mathrm{K}$ and $\mathrm{U}$ vary proportionately (Equation 2), results are qualitative only). Assuming steady state, it is possible to fit DEM-derived stream profiles (Fig. 41) with modelled profiles in with uplift rates increase towards the north towards the Gwoira Fault trace (although it should be noted that streams are not everywhere north-draining). This is consistent with uplift and back-rotation of the Gwoira Fault footwall. Modelled values of $U$ are not entirely consistent between the Yau-Ruaba and Duap Rivers, although both show an increase in $U$ to the north, and an abrupt decrease in uplift rates (U 0 mm/yr) north of the Gwoira Fault (Fig. 41b).

Preliminary model results also suggest a strongly exponential increase in uplift rate with downstream distance for the part of the Yau-Ruaba and Duap Rivers that incise the inactive Mai'iu Fault footwall. However this pattern of uplift rates is unlikely in this region, because this model does not take account of the fact that the Mai'iu Fault footwall accommodated mostly horizontal motion (rather than vertical uplift), and that the Mai'iu Fault footwall has undergone flexural backrotation. Because streams have likely incised into the Mai'iu Fault footwall concurrent with LANF slip, the assumption of steady state may be inappropriate. This is because the lowermost parts of the scarp have been fluvially eroded for a shorter period of time. A simple linear increase in uplift rates may be more reasonable for the inactive Mai'iu Fault footwall.

Stacking of profiles parallel to longitudinal stream profiles allows for the visualisation of the maximum elevation of surrounding topography. Two such stacked profiles have been constructed for the Duap and Yau Rivers (Fig. 41c), comprised of five and four parallel profiles, respectively these indicate the geometry of the uneroded inactive Mai'iu Fault footwall. A line connecting points of maximum elevation suggests a domal morphology for the footwall of the inactive Mai'iu Fault, with a maximum elevation of $\sim 2300 \mathrm{~m}$. This evidences that the area south of the Gwoira embayment also expresses a domal morphology, of lower elevation than Dayman Dome ( 2900 
$\mathrm{m})$, but equal to the elevation of Mt Masasoru to the east ( $2300 \mathrm{~m})$. This supports the idea that Mt Masasoru comprises part of the same MCC as the SDM. This also suggests that the southern bound of the SDM extends at least as far south as the headwaters of the Duap and Yau-Ruaba Rivers, which is more than $4 \mathrm{~km}$ further south than the spatial distribution of Gorupu Metabasalt would suggest (Fig. 18). This may indicate that the mapped distribution of Gorupu Metabasalt (Davies and Smith, 1974) ought to extend further south.

\section{a)}

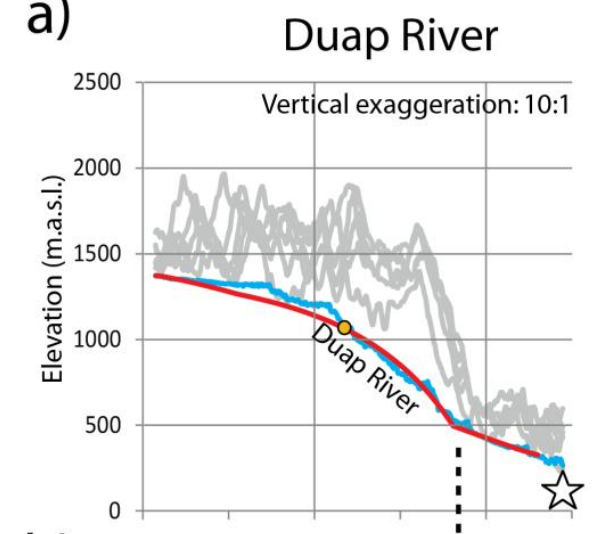

b)
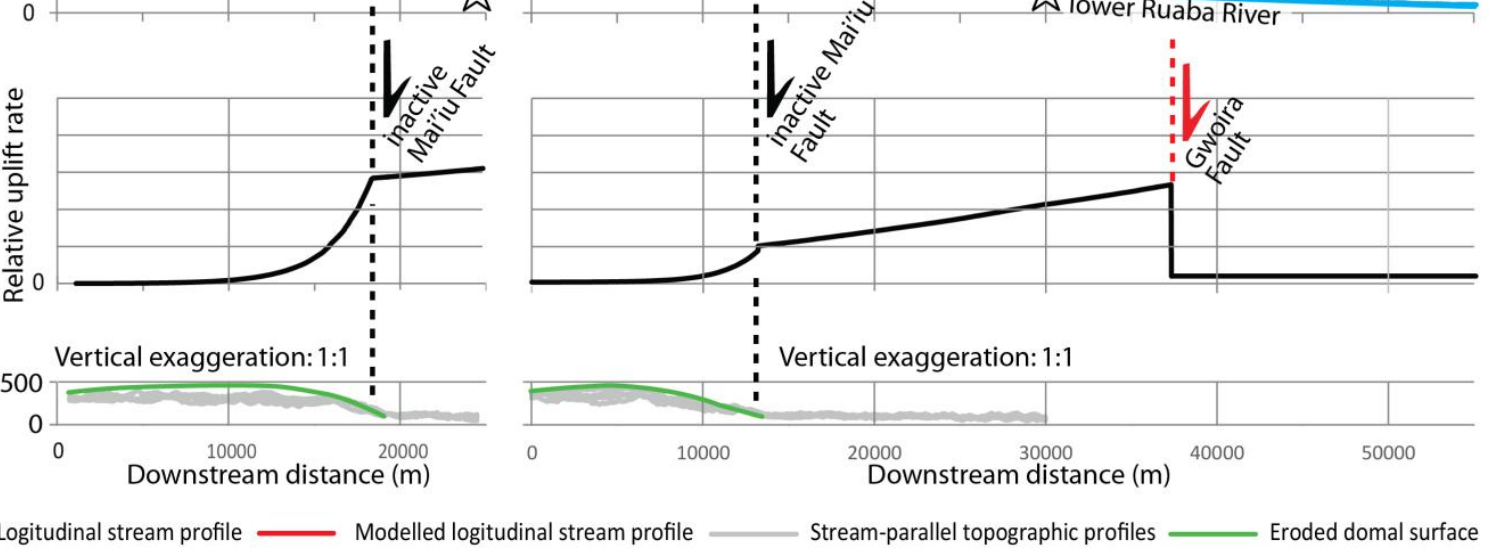

Fig. 41 - a) Stream profiles drawn through the Yau-Bonenau and Ruaba Rivers, compared with best-fit modelled stream profiles. Grey lines represent profiles drawn through topography parallel to the stream, which illustrate the geometry of the uneroded inactive Mai'iu Fault footwall (see text for details). Note the positions of knick points (star; also in map inset), $\mathrm{k}_{1}$ apex (orange circle), and the inactive Mai'iu and Gwoira Faults. b) Relative (non-quantitative) uplift rate distribution used to generate modelled longitudinal stream profiles. Note the exponential part is an artefact of incision concurrent with slip on the now inactive Mai'iu Fault. c) Unexaggerated profiles illustrating the original, uneroded domal geometry of the inactive Mai'iu Fault footwall south of the Gwoira embayment.

In order to quantify long-term uplift rates at the Gwoira Fault trace, I model long-term uplift rates within the Gwoira embayment through modelling of stream profiles, assuming the same detachment-limited stream profile geometry as described in the previous section (Tucker and Whipple, 2002). I run a simple Monte-Carlo simulation based on the same model configuration in 
which I randomly generate values for $\mathrm{K}$, and for parameters governing uplift rate distributions within a particular structural block $\left(\mathrm{U}_{\mathrm{x} 0}, \mathrm{~A}, \mathrm{a}_{\mathrm{x} 0}, \delta \mathrm{a}_{\mathrm{x}}\right)$. The quality of model runs is graded using the absolute value of residuals between modelled slope, and the slope derived from the $30 \mathrm{~m}$ SRTM DEM, at each position. In this way it is possible to quantify uplift rates at a particular position based on the comparison of many model configurations with topographic data extracted from the DEM. I investigate uplift rate at the range-front (at the Gwoira Fault trace; Fig. 24); once again I assume that $U_{x}$ increases to the north (i.e., Fig. 41b). I plot modelled values of $U$ at the Gwoira Fault trace against their residual anomalies (Fig. 42). Because no error bounds exist for the DEMcalculated slopes values, it is not possible to estimate uplift rates based on calculated residual anomalies. Therefore uplift rates are calculated at the $1 \sigma$ and $2 \sigma$ confidence intervals, based on the variance of the entire dataset. $1 \sigma(2 \sigma)$ fits are calculated as those values within $1 \sigma(2 \sigma)$ of the total mean. $1 \sigma(2 \sigma)$ mean and standard deviations are calculated based on $1 \sigma(2 \sigma)$ fits.

Results are consistent with uplift rates of $3.7 \pm 2.6 \mathrm{~mm} / \mathrm{yr}(1 \sigma)$, and $4.2 \pm 3.6 \mathrm{~mm} / \mathrm{yr}(2 \sigma$; Table 3$)$. Model results overlap with uplift rates of $4.9 \pm 0.3 \mathrm{~mm} \mathrm{yr}^{-1}$ calculated for uplifted Late Quaternary coral reefs located $\sim 20 \mathrm{~km}$ east of the Ruaba River on the southwest coast of Goodenough Bay (Mann and Taylor personal communication, 2016). The large uncertainties exhibited by model results (Table 3 ) are largely a function of noise inherent in the spread of measured slope data for the Yau-Ruaba River; thus this study would benefit from a more refined method of quantifying stream slope and its error. The range of model outputs is also confined by the requirement that $U$ increases exponentially towards the north. Model results are equivalent to a dip-slip rate of 1.6$8.9 \mathrm{~mm} / \mathrm{yr}(1 \sigma)$, and $0.9-11.0 \mathrm{~mm} / \mathrm{yr}(2 \sigma)$, assuming a $45^{\circ}$ dip for the Gwoira Fault. This supports the idea that the Gwoira Fault has been active and rapidly slipping during the Late Quaternary.

\begin{tabular}{ccccccc}
\hline & \multicolumn{3}{c|}{$1 \sigma$} & \multicolumn{2}{c}{$2 \sigma$} \\
\cline { 2 - 7 } $\mathrm{N}$ & Mean & Mode & Standard deviation & Mean & Mode & Standard deviation \\
& $(\mathrm{mm} / \mathrm{yr})$ & $(\mathrm{mm} / \mathrm{yr})$ & $(\mathrm{mm} / \mathrm{yr})$ & $(\mathrm{mm} / \mathrm{yr})$ & $(\mathrm{mm} / \mathrm{yr})$ & $\begin{array}{c}\mathrm{mm} / \mathrm{r}) \\
223\end{array}$ \\
3.70 & 4.09 & 2.58 & 4.20 & 4.09 & 3.57 \\
\hline
\end{tabular}

Table 3 - Summary of results of modelling of uplift rates at the Gwoira Fault trace, based on modelling of the Yau-Ruaba River stream profile. $1 \sigma(2 \sigma)$ mean uplift rate only includes those values within $1 \sigma(2 \sigma)$ of the raw calculated mean. 


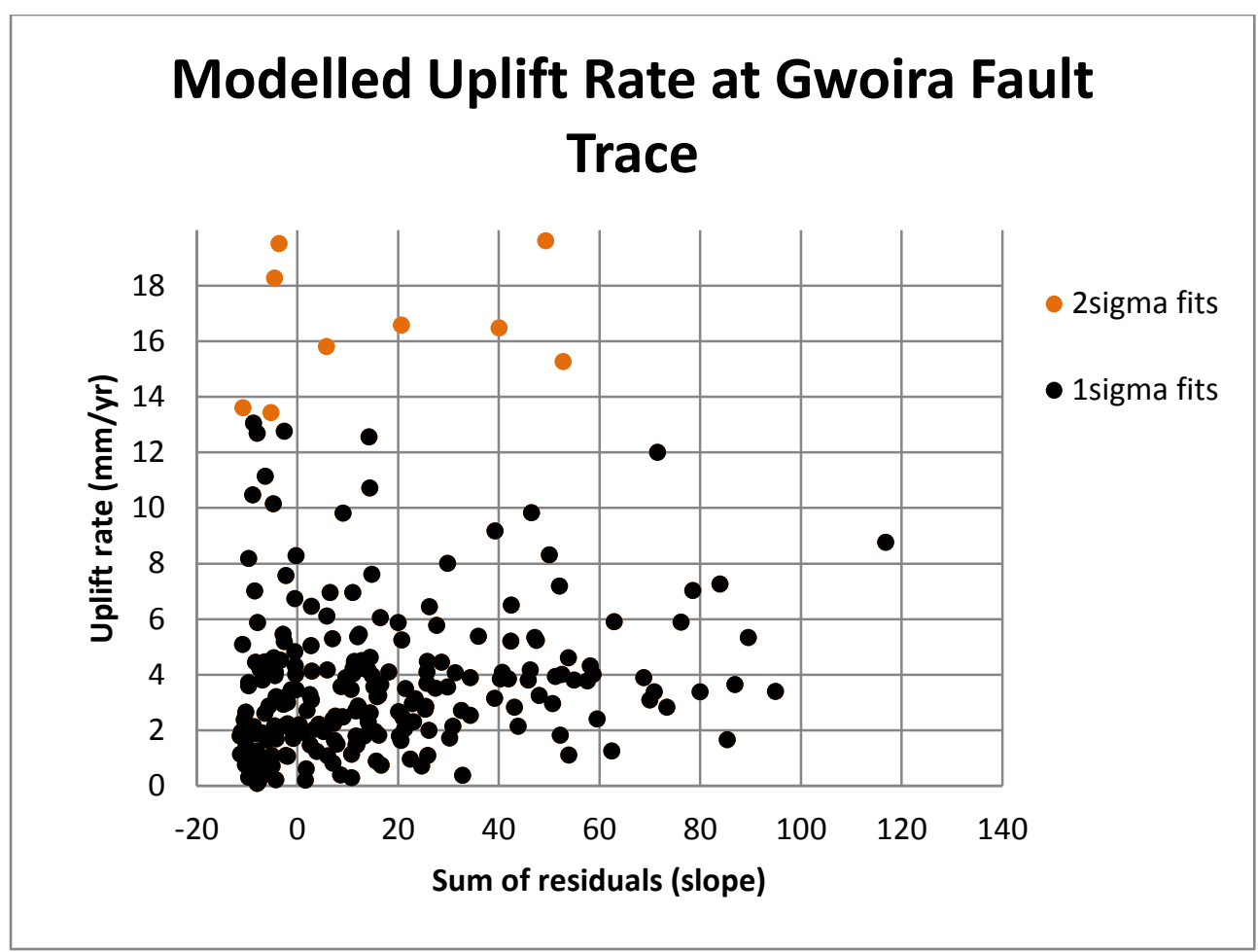

Fig. 42 - Modelled long-term uplift rates for the Yau-Ruaba River at the Gwoira Fault trace. Modelled uplift rates are plotted against the corresponding sum of the absolute values of slope residuals with respect to stream slope extracted from the $30 \mathrm{~m}$ SRTM DEM (see text for details). Results are consistent with uplift rates of $3.7 \pm 2.6 \mathrm{~mm} / \mathrm{yr}(1 \sigma)$, and $4.2 \pm 3.6 \mathrm{~mm} / \mathrm{yr}(2 \sigma)$.

\subsubsection{Stream-Capture Event}

There is a large discontinuity in the Ruaba River, which is identifiable in profile view (Fig. 41a) as an abrupt downstream increase in stream curvature. Below this discontinuity the lower Ruaba River is much more deeply incised and forms a $\sim 30 \mathrm{~m}$ deep gully identified from helicopter flyovers. This discontinuity is marked by a $30 \mathrm{~m}$ high waterfall, and is coincident with the confluence of the Duap River, and is inferred to be coincident with the angular unconformity between SP1 and SP2 (Fig. 24). This represents a fluvial knickpoint that was not previously identified by Miller et al. (2012).

Fluvial knickpoints may develop due to a range of factors, including up-stream propagating signals of stream base-level lowering (due to either tectonic or climatic effects), (Densmore et al., 1997; Snyder et al., 2002), an increase in uplift rate (Kirby et al., 2007; Stock et al., 2005), discontinuities in bedrock erodibility, and stream capture events (Prince et al., 2011). They may also represent static features that arise due to contrasts in bedrock erodibility (Crosby and Whipple, 2006). In this instance knickpoints are unlikely to have developed as a result of an increase in precipitation, because while this would increase the rate of erosion, it would lead to systematic shallowing of stream gradients (Miller et al., 2012; Whipple and Tucker, 1999), which is not the case. This knickpoint is also unlikely to represent an up-stream propagating knickpoint, because the Duap 
River does not contain a knickpoint where it joins the Ruaba River (rather it presents a smooth, continuous surface). While this knickpoint is approximately coincident with the unconformity separating SP1 and lower SP2 strata, field observations suggest no significant contrast in erodibility of those lithofacies. Therefore it is likely that this knickpoint has developed due to a stream capture event (Prince et al., 2011). Stream capture would be expected to result in dramatic readjustment of downstream fluvial profiles, and of adjacent hillslopes (Prince et al., 2011).

This would have involved the capture of Duap River by the Ruaba River (Fig. 43). This interpretation implies a considerable reorganisation of drainages within the Gwoira embayment. It is possible that the headwaters of Igup River once drained into Bime Stream, as run are parallel. Similarly, the headwaters of Duap River may once have drained into the Domora River. This evolution scenario is illustrated in Fig. 43. Flights of Late Quaternary (?) fluvial terraces near Biman (Fig. 38, Fig. 43) are confined to a broad, triangular area; 'step out' from the current active drainages (Fig. 38); and generally slope NNE to NNW; therefore these terraces must have developed subsequent to the development of the Igup-Duap drainage system. The Biman Sandstone which immediately underlies these terraces may represent a lacustrine deposit that formed prior to this stream capture event. Therefore this formation may potentially date the stream capture event.

This reorganisation of drainages could potentially be a consequence of the structural evolution of the Gwoira embayment, although this relationship is unclear. It is possible that on-going synclinal folding of the Gwoira embayment has favoured the development of NNE-draining streams within the syncline core. The role of back-tilting of the Gwoira embayment is also unclear, for this would be expected to inhibit the development of NNE-draining streams, and favour the development of $\mathrm{E}-\mathrm{W}$ draining streams such as the central section of the Ruaba River. 


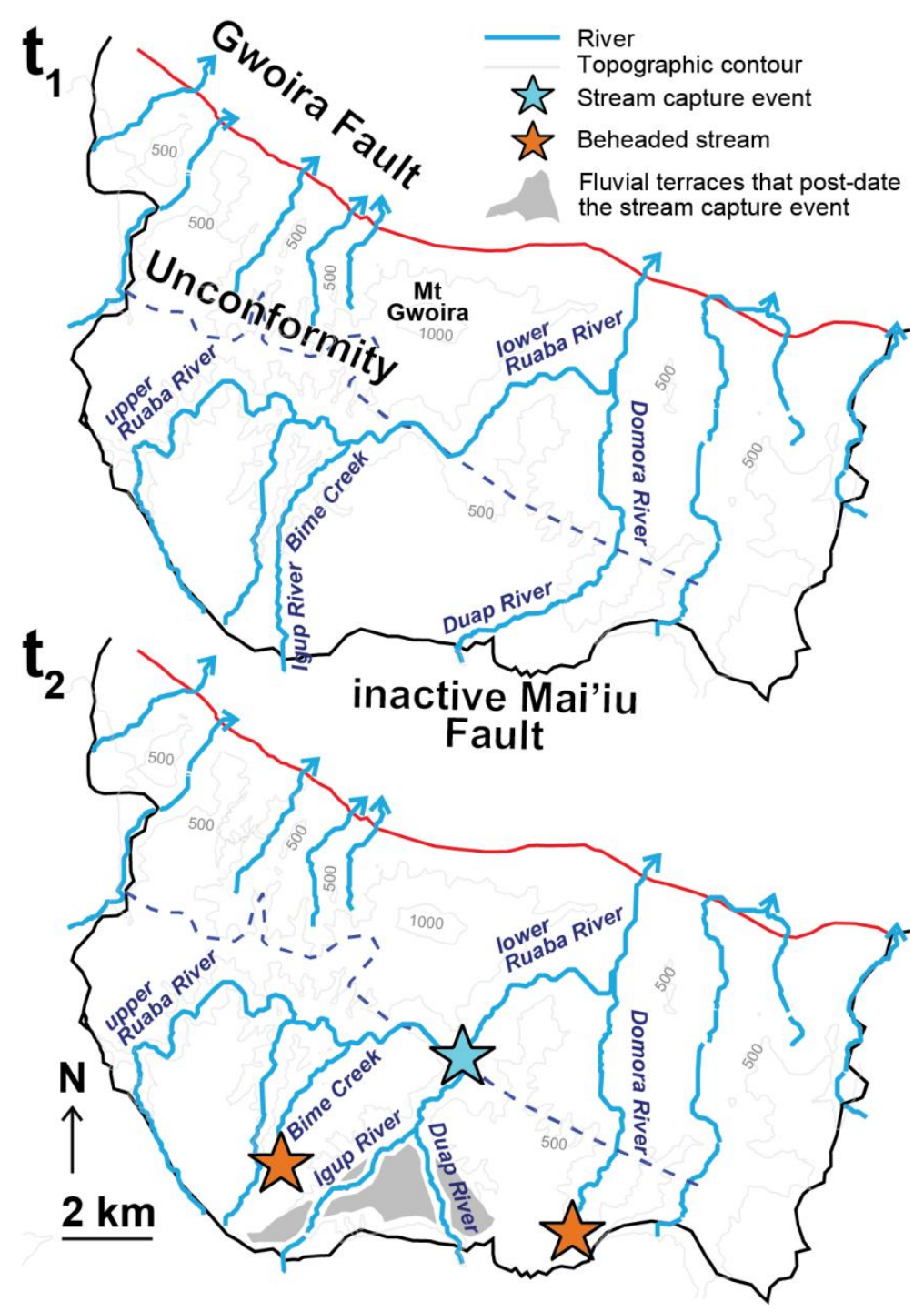

Fig. 43 - Conceptual model illustrating the possible evolution of a stream capture event within the Gwoira embayment. $\mathbf{t}_{\mathbf{1}}$ - The central-southern part of the Gwoira embayment is drained by Igup River-Bime Creek, and by Duap River-Domara River. $\mathbf{t}_{\mathbf{2}}$ - The Igup and Duap Rivers incise into the central-southern part of the Gwoira embayment, and eventually join the Ruaba River, resulting in stream capture of these drainages (blue star). This also results in the beheading of the headwaters of Bime Creek and Domara River (orange stars). Flights of fluvial terraces (grey areas) then develop within the Igup-Duap catchment as these rivers continue to incise.

\subsection{Conclusions}

- The Gwoira rider block represents the sole rider block adorning the Mai'iu LANF. It is located within the Gwoira embayment, a $20 \mathrm{~km}$ wide synformal megamullion in the inactive Mai'iu Fault surface.

- This chapter has described a revised stratigraphy and structure of the Gwoira rider block and the Gwoira Fault hanging wall. Unfortunately the depositional age of the Gwoira Conglomerate is not yet known. The Gwoira Conglomerate can be divided into two distinct 
stratigraphic packages separated by a south-dipping angular unconformity, and differentiated by variable degrees of $\mathrm{N}$-S trending synclinal folding.

- SP1 strata exhibit E-W oriented dip fanning, suggesting deposition concurrent with folding about south-plunging hingelines.

- Upper SP2 strata exhibit N-S oriented dip fanning, which implies that deposition of this unit occurred concurrent with back-rotation of the Gwoira embayment. It is interpreted that Upper SP2 was deposited subsequent to the onset of motion on the Gwoira Fault.

- The inactive Mai'iu Fault, Gwoira Conglomerate, overlying recent Late Quaternary (?) lacustrine and alluvial deposits, and possibly the Gwoira Fault, have all been folded into N-S trending synclines within the Gwoira embayment. Structurally deeper Gwoira Conglomerate strata are more folded than structurally shallower strata; this evidences that folding was concurrent with deposition, which was itself concurrent with extension on the Mai'iu Fault (Smith and Davies, 1976).

- SP1 strata (which was deposited prior to the onset of motion on the Gwoira Fault) steepen in orientation with distance southward within the Gwoira Embayment, which suggests rolling-hinge style back-rotation of the Gwoira Fault footwall.

- Upper SP2 strata, which were deposited following the onset on motion on the Gwoira Fault, shallow in dip (fan) with distance southward.

- From analysis of cut-off angles between down-dip projected Gwoira Conglomerate strata and the inactive Mai'iu Fault, it is shown that SP1 strata south of Mt Gwoira have been back-tilted by $14-30^{\circ}$, and lower SP2 has been back-rotated $6-11^{\circ}$. Subsequent to the deposition of upper SP2 strata, SP1 strata south of Mt Gwoira have been back-rotated 9$25^{\circ}$, and lower SP2 strata have been back-rotated $18-20^{\circ}$. This later back-rotation is presumed to be due to slip on the Gwoira Fault, concurrent with on-going flexure of the Mai'iu Fault footwall. Upper SP2 strata have undergone $\sim 10^{\circ}$ of back-tilting since their deposition.

- Slickenline orientations within the Gwoira Fault footwall indicate NNE-SSW oriented extension on $\sim 60^{\circ}$ dipping Andersonian faults, while restoration of fault and slickenline orientations based on local bedding attitudes indicates a component of dextral and sinistral strike-slip faulting.

- Through consideration of the structure of the Gwoira rider block, it can be shown that the Gwoira Fault has accommodated $\sim 3.5 \mathrm{~km}$ of dip slip in Kwan River, and $>2.8 \mathrm{~km}$ of dip-slip north of Mt Gwoira. Based on this amount of slip, and the horizontal rate of extension 
indicated by regional campaign GPS of Wallace et al. (2014), motion on the Gwoira Fault initiated at $248(+80-69) \mathrm{ka}$.

- The geometry of the Mai'iu Fault suggests that the inactive Mai'iu Fault has been shortened E-W more than the Mai'iu Fault as a whole. The magnitude of E-W shortening accrued by SP1 Gwoira Conglomerate strata (2.51\%) is comparable to that of the inactive Mai'iu Fault (1.15\%), suggesting that the two were folded together in response to the same tectonic event.

- Modelling of vitrinite reflectance data from a single coal sample suggest that exposed parts of the Gwoira Conglomerate were buried to a maximum depth of $1.34 \pm 0.33 \mathrm{~km}(1 \sigma)$, and $0.97 \pm 0.61 \mathrm{~km}(2 \sigma)$.

- Late Quaternary (?) terraces deposited within the Gwoira embayment, on the eastern limb of the syncline that affects underlying Gwoira Conglomerate strata, have been tilted to the west, and older terraces have been tilted more than younger terraces. This is attributed to on-going synclinal folding within the Gwoira embayment.

- The $k_{1}$ knickpoints of Miller et al. (2012) have been reinterpreted as culminations of convex-up parts of streams that drain the SDM to the north, which are here termed $k_{1}$ apices; the distribution of $k_{1}$ apices is consistent with an approximately constant slip rate on the Mai'iu and Gwoira Faults, that reduces to approximately zero to the west at Gorupu Crater.

- Modelled uplift rates, derived from modelling of stream profiles for rivers that drain N-S through the Gwoira embayment, are consistent with on-going back-rotation of the Gwoira rider block, and Monte-Carlo modelling of uplift at the Gwoira Fault trace indicates an uplift rate of $3.7 \pm 2.6 \mathrm{~mm} / \mathrm{yr}(1 \sigma)$, and $4.2 \pm 3.6 \mathrm{~mm} / \mathrm{yr}(2 \sigma)$.

Chapter 4 presents an interpretation of the evolution of the Gwoira rider block, and of the processes responsible for LANF corrugation amplification. 


\section{Chapter 4: The Pliocene to Recent Tectonic Evolution of the Gwoira Embayment}

\subsection{Introduction}

This chapter synthesises the structural evolution of the Gwoira embayment. Structural observations presented in chapter 3 evidence progressive N-S trending synclinal folding of the Gwoira Conglomerate within the near-surface, and of overlying fluvial terraces. Synclinal folding was concurrent with the deposition of the Gwoira Conglomerate and overlying strata, and has continued to the present day. In addition to this chronology of progressive synclinal folding is process of rider block formation; the Gwoira Fault has replaced the inactive Mai'iu Fault as the main splay within the Gwoira embayment. The initiation of slip on the Gwoira Fault and consequent formation of the Gwoira rider block at 243 (+99 -82) ka has resulted in uplift and backtilting of the Gwoira rider block. It is necessary to explain the concurrent occurrence of synclinal folding, and rider block abandonment; it is possible that these two processes are related.

While the processes governing rider block formation are relatively well understood (Choi and Buck, 2012; Choi et al., 2013; Reston and Ranero, 2011), the processes governing MCC megamullion formation and amplification are strongly contended. These processes were briefly introduced in Chapter 3. Although extension-perpendicular constrictive folding has in recent years emerged as a possible impetus for the origin and amplification of MCC megamullions (Singleton, 2013), this process has not so far been unequivocally proven for an active MCC-bounding LANF. It also remains unclear whether MCC megamullions continue to amplify within the upper crust.

Extension-perpendicular constriction ought to be recorded by the folding of the LANF hanging wall, which would result in true horizontal shortening of hanging wall strata (in contrast to bending folding, which would result in layer parallel extension). Several previous studies of MCCs have documented horizontal shortening of the lower and upper plates (e.g., Bradley, 2011; Chauvet and Séranne, 1994; Fletcher and Bartley, 1994; Holm et al., 1994; Mancktelow and Pavlis, 1994; Seiler et al., 2010; Singleton, 2013; Yin, 1991; Yin and Dunn, 1992). Additionally, synextensional folding of syn-tectonically deposited hanging wall strata has previously been described in the case of now inactive LANFs (e.g., Angelier, 1977; Holm et al., 1994; Oldow et al., 2009; Singleton, 2013; Yin and Dunn, 1992). However such interpretations of structures associated with now inactive LANFs are complicated by overprinting deformation and erosion (Reynolds and Spencer, 1989; Singleton, 2011; Singleton, 2013; Whitney et al., 2013). As such, while extensionperpendicular folding of LANF hanging wall sedimentary rocks is compatible with syn-tectonic 
folding due to horizontal constriction, it is difficult to rule out the possibility of drag folding of upper plate strata adjacent to an already corrugated LANF (Singleton, 2013), or bending of the LANF in response to along-strike variability in the magnitude of $\sigma_{v}$ (Fletcher et al., 1995; Tucholke et al., 1998). Various models of MCC megamullion formation and amplification are discussed in the following section.

\subsection{Theories of MCC Megamullion Formation and Amplification}

\subsubsection{Inheritance of Fault Roughness}

MCC megamullions and mullions may represent inherited fault roughness of some older inherited or reactivated fault (Fletcher et al., 1995; e.g., Navarro and Manapla, 2002; Tucholke et al., 1998; Woodward and Osborne, 1980), or inherited scalloped/cuspate features that developed due to the initial linkage of shorter faults (Ferrill et al., 1999). Similarly, the inheritance of a folded foliation may potentially lead to the development of a corrugated fault geometry (Davies and Warren, 1988; John, 1987). Megamullions may develop as a natural consequence of initial extension within a rift; Lévy and Jaupart (2011) predict extension-parallel folds to form as a natural consequence of progressive strain in an extended elastic sheet, prior to the initiation of faulting. However, the inheritance of fault roughness contradicts observations of LANF hanging wall folding that is synchronous with LANF slip (e.g., Bradley, 2011; Holm et al., 1994; Mancktelow and Pavlis, 1994; Oldow et al., 2009; Seiler et al., 2010; Yin, 1991; Yin and Dunn, 1992). Additionally, footwall fabrics of many MCCs are demonstrably folded - this requires some alternative explanation (e.g., Chauvet and Séranne, 1994; Fletcher and Bartley, 1994; Mancktelow and Pavlis, 1994; Singleton, 2013). However, various theories of inherited fault roughness may potentially be reconciled with such observations by the suggestion that MCC megamullions may amplify inherited fault sinuosity (Seiler et al., 2010). The caveat to this is that many OCCs, which are unlikely to reactivate faults, are frequently corrugated (Reston and Ranero, 2011).

\subsubsection{Variable Melt Production}

Alternatively, MCC megamullions may arise due to along-strike variability in melt production. Such a scenario would in theory result in BDT depths that vary along strike. This would lead to 'forceful doming' or 'moulding' of the LANF surface in the lower crust as the footwall is exhumed, resulting in corrugation formation (Lin et al., 1990; Whitney et al., 2013; Yin, 1991). This theory has mostly been proposed in the context of OCCs. However, magmatism may instead be a passive consequence of decompression melting, as the LANF footwall is exhumed with progressive slip 
(Whitney et al., 2013). Fletcher et al. (1995) observe a weak relationship between MCC geometry and location, and the location of igneous intrusions, and so suggest that intrusions merely form in response to decompression melting. Furthermore, modelling of Rey et al. (2009) suggests that megamullions may develop in the absence of melt. Variable melt production cannot account for LANF hanging wall folding, or the amplification of corrugations within the upper brittle crust where intrusions would have cooled considerably (Fletcher et al., 1995; Tucholke et al., 1998). At any rate, variable melt production is less relevant for continental MCCs because melt production is generally far lower.

\subsubsection{Footwall and Hanging Wall Bending}

It may be that megamullions develop within a heterogeneous vertical stress field, which would promote bend folding of both the LANF footwall and hanging wall (Fletcher et al., 1995; Tucholke et al., 1998). In this model $\sigma_{H \max }$ remains equal to $\sigma_{2}$ over time, and differential tectonic unroofing, perhaps due to along-strike variability in LANF slip rate (Janecke et al., 1998; Schlische, 1995), results in the local reduction of $\sigma_{1}$ above nascent antiformal megamullions (Singleton, 2013). This would result in broad bending of the lower and upper plates (Kapp et al., 2008), with the wavelength of folding controlled by the along-strike slip rate variability. This would explain the observation that LANF extension-parallel folding may be exaggerated during the late stages of MCC evolution (Singleton, 2013). However this model fails to account for the wide range of superimposed corrugation wavelengths observed on many MCCs (e.g., Daczko et al., 2011).

\subsubsection{Buckle Folding and Amplification within a Constrictive Stress Regime}

Recently it has become more widely accepted that megamullions may form due to horizontal shortening that acts perpendicular to the extension direction (e.g., Avigad et al., 2001; Chauvet and Séranne, 1994; Fletcher and Bartley, 1994; Fletcher et al., 1995; Holm et al., 1994; Lévy and Jaupart, 2011; Mancktelow and Pavlis, 1994; Singleton, 2013; Yin, 1991). Horizontal buckle folding may be driven by a constrictive stress field (Fig. 44); this is defined as a stress regime in which the magnitude of $\sigma_{v}$ is approximately equal to $\sigma_{H \max }$ (uniaxial stress), where $\sigma_{H \max }$ is oriented perpendicular to the extension direction, and where $\sigma_{\mathrm{v}}=\sigma_{1}$ and $\sigma_{\mathrm{Hmax}}=\sigma_{2}$. Such a stress field may develop due to a reduction in $\sigma_{v}$ (Fletcher et al., 1995; Tucholke et al., 1998), or due to a relative increase in the magnitude of $\sigma_{H \max }$ with respect to $\sigma_{v}$, although it is unclear why this might occur. Horizontal shortening would be accommodated primarily by buckle folding, with possible subordinate strike-slip faulting and flexural slip along foliation planes (Fletcher and Bartley, 1994). 
Along-strike variability in the magnitude of tectonic erosion may also potentially result in the superimposition of a component of fault bending (described above), as certain parts of the LANF are unroofed more quickly than others.
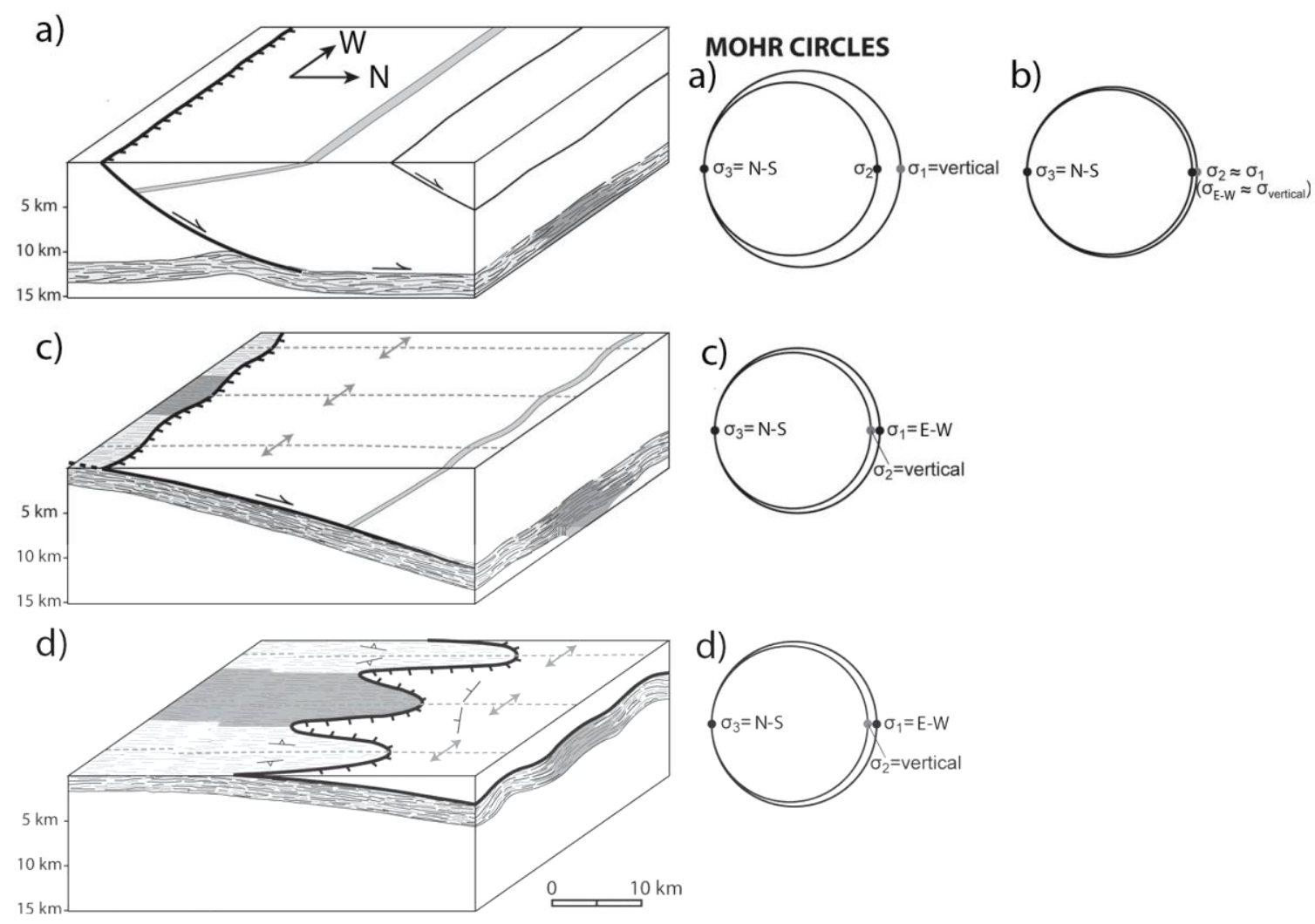

Fig. 44 - Conceptual model illustrating the development of LANF corrugations due to a constrictional stress field. This particular model assumes that constrictional stresses arises due to tectonic denudation driven by detachment slip (a) and consequent reduction of $\sigma_{v}$, such that the magnitude of $\sigma_{v} \sim \sigma_{H \max }(\mathbf{b})$. Eventually $\sigma_{H \max }>\sigma_{v}(\mathbf{c}, \mathbf{d})$, which drives horizontal shortening and corrugation formation. Minor modifications after Singleton (2013).

The development of a constrictional stress field in an extensional tectonic setting may not require a significant departure from an isotropic stress condition. McGarr (1988) suggests that hydrostatic stress $\left(\sigma_{1}=\sigma_{2}=\sigma_{3}\right)$ is the most stable crustal stress configuration in the absence of tectonic stresses, and Andersonian theory (Anderson, 1905) suggests that crustal extension generally initiates due to the reduction of one horizontal stress $\left(\sigma_{3}\right)$, such that $\sigma_{1}=\sigma_{2}>\sigma_{3}$. Therefore $\sigma_{1}$ may only marginally exceed $\sigma_{2}$ in many extensional settings, and thus a modest tectonic unloading may be sufficient to rotate $\sigma_{1}$ to a horizontal orientation (Chauvet and Séranne, 1994). Furthermore, constrictive folding may be possible even if $\sigma_{H \max }$ only equals $\sigma_{v}$, due to the thin elastic thickness of the crust within continental rifts (Lévy and Jaupart, 2011; Singleton, 2013). Therefore a constrictive stress field may not require special conditions, and may rather emerge as a natural consequence of typical stresses characterised by extensional tectonic settings. 
Constrictive stresses may be encouraged during the late stages of LANF evolution due to footwall unloading and consequent reduction in $\sigma_{v}$ (Chauvet and Séranne, 1994; Fletcher and Bartley, 1994; Fletcher et al., 1995). Horizontal buckle folding may also be assisted in the later stages of MCC exhumation by the ascent of warm lower crustal and mantle rocks, and the consequent reduction of the footwall elastic thickness such that a small constrictional strain can induce buckling (Yin, 1991). A constrictive stress regime may instead be induced by a transtensional stress regime (Mancktelow and Pavlis, 1994), or by 'lateral extrusion' of the lower plate, in which a pair of listric strike-slip faults, trending oblique to the LANF, allow for the tectonic escape of the footwall, concurrent with horizontal compression perpendicular to extension (Ratschbacher et al., 1991). Such models successfully explain the regional scale that a constrictive stress regime is necessarily characterised by (Chauvet and Séranne, 1994), i.e., the large spatial distribution and scale of synextensional compressional features.

Several processes could potentially enable the development of a constrictive stress regime. The magnitude of horizontal compressive stresses may be increased within the upper crust as a consequence of the presence of a weak discontinuity within the crust. Below such a discontinuity horizontal stresses could not be sustained, perhaps due to horizontal flow within the middle crust (Block and Royden, 1990; Fletcher et al., 1995; Wernicke, 1990). This 'detachment' of the crust beneath the discontinuity would result in whatever compressive horizontal stresses present being resolved on a smaller vertical cross-sectional area (i.e., limited to the upper crust). Horizontal stresses may also be elevated within the upper crust if tectonic denudation results in isostatically uncompensated crust adjacent to an exhuming MCC (Yin, 1991). However, geological evidence for uncompensated topography or Moho relief is lacking (Lévy and Jaupart, 2011; Tirel et al., 2004). One explanation that attempts to resolve this discrepancy is that extension-perpendicular shortening may balance extension-parallel crustal thinning due to extension, resulting in zero net change in Moho depth (Avigad et al., 2001). Alternatively, crustal thinning may be balanced by lateral middle and lower crustal flow, driven by lateral gradients in $\sigma_{\mathrm{v}}$ (Bird, 1991; Block and Royden, 1990; Fletcher et al., 1995; Wernicke, 1992; Whitney et al., 2013).

It is possible that extension-perpendicular shortening is accommodated intermittently, between periods of extension. $\sigma_{H \max }$ may periodically exceed $\sigma_{\mathrm{v}}$ as extension-parallel slip transiently increases the magnitude of $\sigma_{3}$ (Avigad et al., 2001; Singleton, 2013). Such temporal variability in $\sigma_{H \max }$ has been suggested by Zoback (1989) within the Basin and Range province, based on earthquake focal mechanisms and observed fault slip sense, which the author speculates may 
fluctuate at the timescale of individual seismic ruptures. Conversely, paleostress calculations of Seiler et al. (2010) suggest a stable uniaxial stress regime that does not vary with time.

\subsection{Discussion}

\subsubsection{Synclinal Folding of the Gwoira Embayment}

The mechanism responsible for synclinal folding of the Gwoira Conglomerate must also account for folding and tilting of: overlying fluvial and lacustrine deposits; the inactive Mai'iu Fault; and possibly the Gwoira Fault. It is unlikely that the Mai'iu Fault has inherited roughness from the OSF, because the amount of shortening recorded by Gwoira Conglomerate SP1 strata $(2.51 \%)$ is more similar to the total shortening accommodated by the inactive Mai'iu Fault (1.15\%), than the total shortening minus the apparent shortening (roughness) of the OSF (0.65\%). From these estimates I suggest that the Mai'iu Fault and Gwoira Conglomerate, with similar values of apparent shortening, were shortened E-W together during the same tectonic event. I also suggest that the apparent shortening of the OSF represents original roughness of the fault; however, this roughness is unlikely to have been inherited by the Mai'iu Fault, because that would imply a smaller amount of true shortening accommodated by the Mai'iu Fault compared with that of the Gwoira Conglomerate. This implies either that the Mai'iu Fault did not occupy the entire OSF surface and rather formed an original planar surface, or that the roughness of the deeper portion of the OSF was 'smoothed' at depth. Therefore some alternative mechanism is required for the development of corrugations in the Mai'iu Fault surface.

Along-strike variability in magma production cannot account for synclinal folding of the Gwoira Embayment. While the Suckling Granite (emplaced at 3.3 Ma; Daczko et al., 2011) and the Mai'iu Monzonite (emplaced at $12 \mathrm{~km}$ depth, cutting the mylonitic fabric; Davies and Smith, 1974) outcrop a short distance south ( 3 and $5 \mathrm{~km}$ respectively) of Mt Suckling, there is no evidence for the existence of large igneous bodies beneath Dayman Dome and Mt Masasoru. Even should such bodies exist beneath the surface, along-strike variability in BDT depth cannot account for synclinal folding of the Gwoira Conglomerate, of Late Quaternary (?) fluvial terraces, and of the Biman Sandstone in the near surface, where such intrusions would certainly have cooled.

Bending of the Mai'iu Fault footwall and hanging wall in response to along-strike variability in $\sigma_{v}$ can account for synclinal folding the Mai'iu Fault footwall and hanging wall. In fact a component of fault bending is expected given local deposition of up to $2950 \mathrm{~m}$ of Gwoira Conglomerate within the Gwoira embayment, which would have locally increased the magnitude of $\sigma_{\mathrm{v}}$, leading to 
subsidence of the Gwoira embayment. However, such bending would have manifested as layerparallel extension of the Gwoira Conglomerate; this is inconsistent with observations of oblique strike-slip faulting within the Gwoira Fault footwall, as these faults would have accommodated EW shortening. Therefore, bending alone cannot account for synclinal folding within the Gwoira embayment.

Synclinal folding within the Gwoira embayment is consistent with extension-perpendicular constriction. Synclinal folding of the Gwoira embayment was therefore accommodated by horizontal buckle folding. Because a constrictive stress field is characterised by $\sigma_{H \max } \sim \sigma_{\mathrm{v}}$ (such that $\sigma_{2}-\sigma_{3} \sim \sigma_{1}-\sigma_{3}$, such a stress regime is expected to result in a component of conjugate strike slip faulting, which accommodate extension-perpendicular shortening (Fletcher and Bartley, 1994; Singleton, 2013; Yin, 1991). As such this model is consistent with numerous observations of outcrop-scale conjugate strike-slip faults in the footwall of the Mai'iu Fault near Biniguni Falls (Little et al., 2015). This model is also consistent with observations of strike-slip faulting within the Gwoira Fault footwall; however, because shear-sense indicators were largely not present, it is impossible to ascertain whether these strike-slip faults accommodate E-W shortening.

The origin of this constrictive stress field is unclear. As discussed in section 4.2.4, constriction may arise as a natural consequence of long-lived extension. In this model, an extensional tectonic regime initially develops solely due to the reduction of $\sigma_{3}$, which diverges from an isotropic stress condition; therefore $\sigma_{1}$ may be roughly equal to $\sigma_{2}$ in many extensional tectonic regimes. Largemagnitude extension could promote the development of constrictional stresses, as crustal thinning results in the progressive reduction of $\sigma_{1}$ within the crust (Singleton, 2013). Preferential tectonic denudation of the MCC relative to adjacent crust along-strike of the LANF could also potentially render $\sigma_{v}$ resolved on the LANF less than $\sigma_{v}$ within along-strike adjacent crust; this would favour the development of a constrictional stress field (Fletcher et al., 1995). Folding of the Mai'iu Fault may have been assisted by a low footwall elastic thickness, possibly due to the upward advection of heat, or the inheritance of a thrust surface between the Gorupu Metabasalt and underlying Kagi Metamorphics. Alternatively, constriction may instead be a consequence of tectonic unroofing of the MCC (Fletcher et al., 1995; Singleton, 2013). This would result in a progressive reduction in $\sigma_{1}$ resolved on the LANF footwall. In the case of the Mai'iu Fault there is no significant E-W variation in surface topography that could feasibly give rise to $E-W$ constriction of the entire Suckling-Dayman massif (SDM). However Abers et al. (2012) model considerable ( 6 $\mathrm{km}$ ) differences in Moho relief between the SDM and the eastern-most extremity of Cape Vogel Peninsula. This implies a greater thickness of dense mantle peridotite $\left(\rho \sim 3325 \mathrm{~kg} \mathrm{~m}^{-3}\right)$ to the east 
of the SDM, which could potentially elevate E-W compressive stresses. However the Moho is not resolved west of the SDM.

It is possible that constriction of the SDM is instead promoted by proximity to regional-scale strikeslip structures. Two large faults, the Keveri and Onuam Faults, cut the Mai'iu Fault footwall south of the SDM. The Keveri Fault is a major active structure that has been inferred to be strike-slip based on the presence of horizontal slickenlines described by Lindley (2014). It is inferred by Lindley (2014) to be sub-vertical based on low-level aeromagnetic data, although these data are equivocal. Similarly, right-stepping stream offsets identified by Tim Little (2016, personal communication) using the $30 \mathrm{~m}$ SRTM DEM suggest that the Onuam Fault accommodates dextral strike-slip motion. The Onuam Fault also probably accommodates down-to-the-south motion, as indicated by a marked decrease in the slopes of south-draining streams to the south of the fault. However the geometry and kinematics of both faults are poorly constrained. Furthermore, this interpretation conflicts with regional GPS observations, which suggest only a small component of sinistral transtension in the vicinity of the SDM (Wallace et al., 2014).

\subsubsection{The Timing of Onset of Motion on the Mai'iu Fault}

The timing of the onset of motion on the Mai'iu Fault must pre-date the age of the oldest Gwoira Conglomerate strata, because they are derived from the erosion of the Mai'iu Fault footwall (Smith and Davies, 1976). Unfortunately ${ }^{26} \mathrm{Al} /{ }^{10} \mathrm{Be}$ cosmogenic burial age data were not yet available at the time of thesis presentation.

However the timing of onset of motion is likely constrained by the age of the Mai'iu Monzonite, and of the Suckling Granite (3.3 $\pm 0.1 \mathrm{Ma}$; Caffi, 2008). This is because, as discussed in detail in Chapter 2, these intrusives cut the mylonitic fabric (Davies and Smith, 1974), and are inferred to have been intruded at depths of $12 \mathrm{~km}$ (4 kbar), (Daczko et al., 2009). This age for the Suckling Granite is consistent with my estimated age of 2.8-3.6 Ma (Chapter 2), based on simple 1D kinematics $(t=d / v)$. This calculation assumes that: the rate of horizontal extension accommodated by the Mai'iu Fault has been constant and equal to the modern regional rate of horizontal extension indicated by campaign GPS measurements (7-9 mm/yr; Wallace et al., 2014); and that the Mai'iu Fault has accommodated $\sim 25 \mathrm{~km}$ of extension, as indicated by the width of the slipparallel horizontal length of the smooth, corrugated surface of Dayman Dome. 


\subsubsection{Evolution of the Gwoira Embayment}

Progressive folding of the inactive Mai'iu Fault, Gwoira Conglomerate, and Late Quaternary (?) sediments within the Gwoira embayment has acted simultaneously with progressive back-tilting of the Gwoira embayment, and consequent rider block formation. The Pliocene to recent tectonic evolution of the Gwoira rider block is interpreted as follows.

The Owen Stanley Fault was partially extensionally reactivated by the Mai'iu Fault during the Pliocene, as indicated by the age Suckling Granite (Caffi, 2008). Sustained slip on the Mai'iu Fault resulted in the formation of a domed footwall MCC. A greater magnitude of slip was accommodated in the west of the SDM, as indicated by the wider $\sim \mathrm{N}-\mathrm{S}$ extent of Gorupu Metabasalt in that region, compared with further east near Mt Masasoru (Fig. 11), (Davies and Smith, 1974), although the greater map-distance between the Mai'iu Fault trace and $k_{1}$ apices along the eastern part of the fault indicates that a greater magnitude of slip has occurred in the east within the geomorphically recent past (ca. Late Pleistocene-present). On-going slip on the Mai'iu Fault resulted in the creation of accommodation space north of the Mai'iu Fault, in which the Gwoira Conglomerate was deposited during the Pliocene (Fig. 45a), (Smith and Davies, 1976). The Gwoira Conglomerate was formed from clasts eroded from the SDM as the exhumed scarp of the Mai'iu Fault was sub-aerially eroded (Smith and Davies, 1976). SP1 and lower SP2 were deposited against the Mai'iu Fault concurrent with slip on the LANF, and some component of their present south-dipping orientation was acquired as a consequence of progressive slip on the fault. Bedding-fault cut-off angles suggest that at the time of the deposition of SP1, the Mai'iu Fault locally dipped $40-49^{\circ} / \mathrm{N}$; this orientation shallowed to a dip of $30^{\circ} / \mathrm{N}$ at the time of the deposition of lower SP2. The differences between these cut-off angles implies that in response to this shallowing of the Mai'iu Fault, SP1 strata were back-rotated $14-30^{\circ}$, and lower SP2 was backrotated by $6-11^{\circ}$. Rolling-hinge style deformation of the Mai'iu Fault footwall resulted in more rapid steepening of SP1 strata that outcrop south of Mt Gwoira compared with those that outcrop north of Mt Gwoira; this process is presumed to have been on-going throughout the development of the Gwoira embayment.

The development of a constrictional stress field, (the cause of which is ambiguous), is supported by numerous observations of conjugate strike-slip faulting $20 \mathrm{~km}$ ENE within the Mai'iu Fault footwall at Biniguni Falls (Little et al., 2015). Strike-slip faults observed within the Gwoira Fault footwall may have accommodated similar E-W shortening, although my data do not constrain this. This constrictive stress regime promoted N-S trending synclinal folding of the Mai'iu Fault from at least as early as the age of the deepest exposed Gwoira Conglomerate strata; this is evidenced by 
progressive synclinal folding of all Gwoira Conglomerate strata. Folding was accommodated by a synclinal box fold, with shortening being accommodated largely by inward dipping monoclines; the reason for this is unclear. The superposition of synclinal folding within the Gwoira embayment and on-going rolling-hinge style back-rotation of the LANF footwall resulted in 3D buckling of the Mai'iu Fault, and shallowing of the LANF within the Gwoira embayment. Preferential shortening of the Mai'iu Fault occurred within the Gwoira embayment (evidenced by the greater amount of E-W shortening accommodated by the inactive Mai'iu Fault, as compared with the Mai'iu Fault as a whole. The Gwoira Conglomerate was preferentially deposited within this embayment (Fig. 45b). Deposition of the Gwoira Conglomerate may have itself contributed to corrugation formation, because the weight of $\sim 2.5 \mathrm{~km}$ (Fig. 25B, C, C2) of overlying rock within the Gwoira embayment would have increased the magnitude of vertical stress resolved on the Mai'iu Fault surface. This may have resulted in the application of a component of bending of the fault footwall and hanging wall. Constriction resulted in on-going syn-depositional folding of the Gwoira Conglomerate, as evidenced by a decrease in the amplitude of synclinal folds with structural height within the Gwoira Conglomerate (Fig. 45b). Progressive synclinal folding has also manifested as subtle E-W dip-fanning within SP1, as evidenced by direct field measurements. A period of erosion resulted in the formation of the angular unconformity that has been inferred to divide SP1 and SP2 (Fig. 45b); the cause of this erosion event is unknown. The hingelines for the synclines that deform SP1 and SP2 may have been oriented approximately horizontally prior to the formation of the Gwoira Fault, assuming that SP2 beds were approximately horizontal prior to the onset of uplift along the Gwoira Fault. SP1 and lower SP2 strata may have fanned towards the Mai'iu Fault as part of a rollover anticline (Fig. 32); however this dip-fanning, if present, has been obscured by subsequent folding of the Gwoira Conglomerate. The Gwoira Conglomerate was buried to a depth of $1.34 \pm 0.33 \mathrm{~km}(1 \sigma)$, and $0.74 \pm 0.64 \mathrm{~km}(2 \sigma)$, as indicated by vitrinite reflectance data. Structural analysis of cross-section C (Fig. 25) suggests burial to $2.3 \mathrm{~km}$ (Fig. 45b). Therefore constriction must have been active at least within the upper $\sim 2 \mathrm{~km}$.

Progressive synclinal folding of the now inactive Mai'iu Fault footwall, combined with LANF 'rolling-hinge' type back-rotation (indicated by steepening of Gwoira Conglomerate strata towards the south from the Gwoira Fault trace), resulted in shallowing of the Mai'iu Fault within the Gwoira embayment (Fig. 45b). Amplification of the megamullion that forms the Gwoira embayment and resultant shallowing of the Mai'iu Fault ultimately rendered the inactive Mai'iu Fault unviable for slip, resulting in its abandonment and replacement by the Gwoira Fault (Fig. 45c). This resulted in the formation of the Gwoira rider block at 248 (+80 -69) ka, as estimated 
from fault heaves and regional extension rates based on modelling of campaign GPS of Wallace et al. (2014).

Sediments and sedimentary rocks within the Gwoira embayment were progressively tilted to the south as a consequence of slip on the Gwoira Fault, and on-going rolling-hinge style flexure of the LANF footwall (Fig. 45c). Based on the difference between the amount of tilting due to back-tilting of the Mai'iu Fault, and the present dips of Gwoira Conglomerate strata, I calculate that SP1 strata have been back-tilted by an additional $9-25^{\circ}$, and lower SP2 strata by $18-20^{\circ}$, subsequent to the deposition of upper SP2. This is consistent with my interpretation that the Gwoira Fault has been back-rotated by $13-23^{\circ}$, from an ideal initial dip of $60^{\circ}$. Progressive back-tilting of the Gwoira embayment led to the development of N-S dip fanning within upper SP2 strata (Fig. 45c). Based on their fanned geometries and the location of upper SP2 onlap termination south of Mt Gwoira, I infer that upper SP2 strata were deposited against the southern flank of Mt Gwoira, concurrent with uplift on the Gwoira Fault. That the shallowest upper SP2 strata dip 094/SW/10 indicates that $10^{\circ}$ of southward back-tilting has occurred subsequent to their deposition (Fig. 45c).

Constriction has affected rocks in the near-surface within the Gwoira embayment, as evidenced by: progressive synclinal folding of the Gwoira Conglomerate, which has not been buried more deeply than $2.5 \mathrm{~km}$; inferred folding of the Gwoira Fault surface; progressive eastward tilting of Late Quaternary (?) fluvial terraces located on the eastern limb of the syncline that folds the Gwoira Conglomerate; and NE-SW folding of the Biman Sandstone. On-going southward backtilting of the Gwoira rider block is indicated by modelling of longitudinal stream profiles through the Yau-Ruaba and Duap Rivers; these results also suggest uplift rates of $3.6 \pm 2.9 \mathrm{~mm} / \mathrm{yr}(1 \sigma)$, and $4.3 \pm 3.9 \mathrm{~mm} / \mathrm{yr}(2 \sigma)$ at the Gwoira Fault trace in lower Ruaba River. This result is consistent with uplift rates calculated from dating of emergent coral reefs exposed along the southern coast of Goodenough Bay (Mann et al., 2009; Mann and Taylor, 2002). Progressive synclinal folding may have favoured the development of $\mathrm{N}$-draining streams within the syncline core; I infer this to be the cause of the stream capture event evidenced by stream concavities for the Duap River and Ruaba River, in which the former was captured by the latter (Fig. 43). This event is recorded by a large, stationary fluvial knickpoint at the confluence of the Ruaba and Duap Rivers (Fig. 41). This event may also be pre-dated by the deposition of the lacustrine, Late Quaternary (?) Biman Sandstone. 


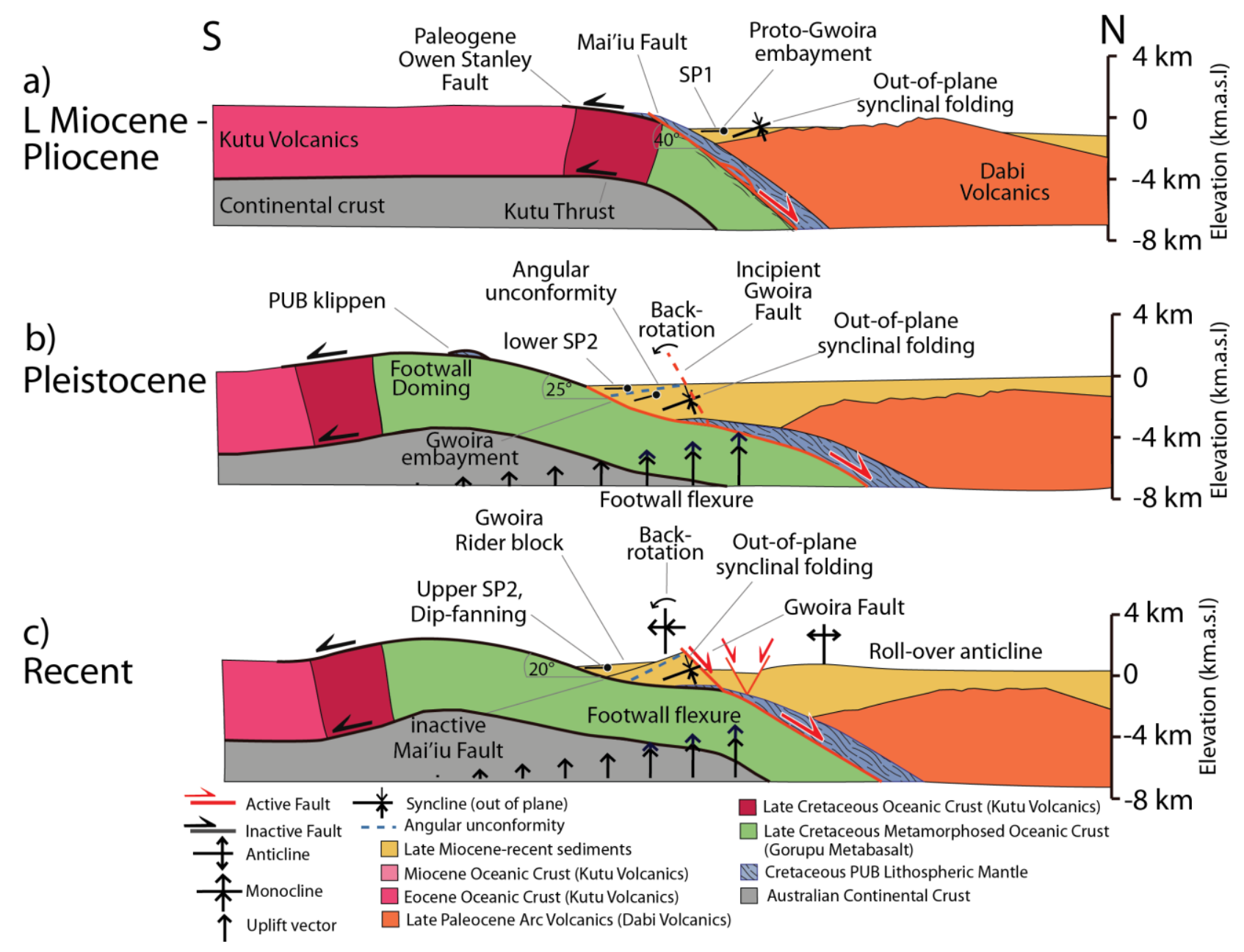

Fig. 45 - Schematic N-S cross-sections drawn through the Gwoira rider block, illustrating the Pliocene to recent evolution of the Gwoira embayment. a) The Owen Stanley Fault is extensionally reactivated as the Mai'iu Fault; a constrictive stress field leads to N-S trending buckle folding of the Mai'iu Fault footwall. Syn-rift sediments, including the Gwoira Conglomerate, derived from the erosion of the Mai'iu Fault footwall are deposited on the Mai'iu Fault hanging wall. b) E-W shortening localises within the Gwoira depression, and preferential deposition of the Gwoira Conglomerate within this accommodation space leads to a component of bending of the Mai'iu Fault, which augments the amplification of the Gwoira embayment. Shallowing of the Mai'iu Fault within the Gwoira embayment leads to its abandonment in favour of the Gwoira Fault. c) The Gwoira rider block has been captured by the Mai'iu Fault footwall, and is being uplifted by the Gwoira Fault. The deposition of upper SP2 strata post-dates the age of the Gwoira Fault. The Gwoira embayment has been folded about an E-W trending monocline that has tilted strata to the south, with strata further south being more rotated. This is a consequence of on-going rollinghinge style flexure of the LANF footwall. 


\subsection{Conclusions}

- N-S oriented extensional accommodated by the Mai'iu Fault from the Pliocene was accompanied by extension-perpendicular folding of the Gwoira embayment. Both the hanging wall and footwall of the Mai'iu Fault have been folded. That folding has affected the youngest strata within the Gwoira embayment evidences that constrictional stresses have characterised the shallow crust until the present day.

- Synclinal folding is interpreted as having been motivated by a constrictional stress regime; this is consistent with numerous observations of conjugate strike-slip faulting in the footwall of the Mai'iu Fault near Biniguni Falls, which accommodates a component of E-W shortening (Little et al., 2015). However the cause of this constrictional stress regime is unclear.

- The juxtaposition of N-S and E-W trending folding of the Mai'iu Fault resulted in 3D buckling of the LANF, resulting in shallowing of the now inactive Mai'iu Fault beneath the Gwoira embayment. This resulted in severe misorientation of the LANF, ultimately leading to local fault abandonment within the Gwoira embayment. The consequent initiation of slip on the Gwoira Fault resulted in the formation of the Gwoira rider block, which has been transferred to the footwall of the active detachment. Therefore in the case of the Gwoira embayment the processes of extension-perpendicular constrictional folding and rider block formation are causally related.

- Absolute dating of the Gwoira Conglomerate would allow the timing of this evolution to be better constrained. 


\section{Chapter 5 - Slip Rate and Style of the Active Mai'iu Fault West of Pumani}

\subsection{Introduction}

Fault slip rate may be constrained through TCN exposure dating of the exhumed fault scarp (Benedetti et al., 2003; Benedetti et al., 2002; Hoeft and Frankel, 2010; McNeill et al., in prep; Mitchell et al., 2001; Palumbo et al., 2004; Schlagenhauf et al., 2010; Schlagenhauf et al., 2011). As discussed in chapter 1, TCN exposure dating is founded upon the idea that TCN accumulate in situ at a constant rate within rocks exposed at Earth's surface. As such TCN exposure dating provides a powerful tool with which to investigate fault slip rate. However, one factor which must be accounted for in the analysis is local erosion rate. Erosion results in the removal of the uppermost part of the fault scarp that hosts the highest TCN concentrations. Therefore erosion, if unaccounted for, would result in artificially low sample TCN concentrations, and thus erroneously low exposure ages and rapid slip rates. Erosion also places a limit on the timescale of analysis, because for long exposure periods TCN accumulation will be balanced by TCN loss due to erosion. This loss of temporal resolution is known as 'secular equilibrium'.

The slip rate of the Mai'iu Fault has not previously been independently determined. However the Mai'iu Fault is presumed to be active and rapidly slipping west of Pumani (Fig. 11). This assumption is based on several strands of evidence. The lowermost scarp of the Mai'iu Fault is smooth and relatively uneroded. Additionally, the Mai'iu Fault hanging wall is cut by active synthetic and antithetic normal faults that strike sub-parallel to the Mai'iu Fault (discussed in section 5.3), and that are presumably related to active slip on the LANF. The Pleistocene (?) Kwagira Beds (Davies and Smith, 1974) in the immediate hanging wall of the Mai'iu Fault near Biniguni Falls have been tilted $10^{\circ}$ to the south (discussed in section 5.3). Finally, campaign GPS velocities of Wallace et al. (2014) suggest 7-9 mm/yr N-S extension between the southern coast of the Papuan Peninsula and the southern coast of Collingwood Bay (Fig. 11). Assuming all horizontal extension is accommodated by slip on the Mai'iu Fault, this would make it one of the fastest slipping LANFs known.

This chapter presents the findings from a slope-parallel TCN transect of the lowermost Mai'iu Fault scarp at Biniguni Falls, in order to directly measure the rate of slip on the Mai'iu Fault during the Holocene. I use ${ }^{10} \mathrm{Be}$ in quartz veins exposed in the lowermost Mai'iu Fault footwall at Biniguni Falls to produce an exposure age transect for the Mai'iu Fault, in order to determine whether the fault is active, and if so determine a modern slip velocity. Fault slip rate and local erosion rates are 
modelled using a Monte-Carlo simulation, similar to the approach of Schlagenhauf et al. (2011). I then place these results in the context of structures observed in the hanging wall of the active Mai'iu Fault between Gorupu Crater and Wapon.

In this chapter, I also investigate the nature of deformation in the hanging wall of the Mai'iu Fault west of Pumani (Fig. 11). While the Gwoira rider block records a history of LANF partial abandonment in the near-surface, further west the Mai'iu Fault appears, based on the smooth surface of Dayman Dome, to be actively slipping. This has important mechanical implications for the LANF, and may represent an along-strike variation in LANF viability. At face value this might suggest that the Mai'iu Fault is better oriented for slip, or mechanically weaker, west of Pumani. It is also important to validate whether the Mai'iu Fault is in fact actively slipping, so that we may know if structures currently exposed in the LANF hanging wall are related to active slip on the fault.

In this chapter, I continually reference the geological map (Fig. 52), which demarcates various geographical locations; this figure will be referred to out of sequence. Also, in the interests of efficiency and readability, the TCN sample processing methodology has been relegated to Appendix A. All field data used within this chapter are supplied within Appendix D (attached CDROM).

\subsection{TCN Analysis of the Mai'iu Fault Scarp}

The lowermost Mai'iu Fault scarp at Biniguni Falls is a large, 80x130 m expanse of unvegetated, exposed bedrock, comprising Gorupu Metabasalt exposed due to slip along the Mai'iu Fault. Rare quartz veins cross-cut the dominant foliation on the exposed fault surface (scarp). By means of

${ }^{10} \mathrm{Be}$ exposure dating, these quartz veins may be used to date the progressive exposure of the scarp due to slip along the fault, and thereby estimate the rate of fault dip-slip. Fifteen quartz vein samples were collected from the lowermost Mai'iu Fault scarp at Biniguni Falls (Fig. 46; location given in Fig. 52). These were spaced at $\sim 5 \mathrm{~m}$ intervals over a $\sim 130 \mathrm{~m}$ long scarp-parallel down-dip transect. We targeted the ${ }^{10} \mathrm{Be}$ in quartz veins, as mixed quartz-calcite veins are relatively abundant, if not particularly voluminous, in the Gorupu Metabasalt footwall. Samples localities were clear of vegetation cover and located at local high points (culminations) on the exhumed fault surface, which is corrugated on the 1-10 $\mathrm{m}$ scale; this targeted sampling of high points minimises the effect of erosion. Only the upper $\sim 3-5 \mathrm{~cm}$ of rock was sampled at each locality, and samples were extracted in several pieces using a petrol powered rock saw, hammer and chisel. 
Local topographic shielding was measured at each sample locality, and the GPS position taken. A series of photographs $(n=64)$, were taken from a range of orientations during a helicopter fly-over of the Mai'iu Fault scarp at Biniguni Falls. From these, and sample GPS localities, a $0.1 \mathrm{~m}$ DEM (vertical resolution of $\sim 1 \mathrm{~m}$ ) of the fault scarp was generated using Structure-From-Motion (SFM) analysis (Fig. 46; Norton, unpublished data, 2016). This DEM was constructed by Kevin Norton. This DEM allows for the accurate quantification of fault geometry; however the accuracy of this DEM is limited to the precision of GPS locations of TCN samples (Table 4).

\begin{tabular}{|c|c|c|c|c|c|c|c|}
\hline Sample & $\begin{array}{l}\text { Latitude } \\
\text { (decimal } \\
\text { degrees) }\end{array}$ & $\begin{array}{c}\text { Longitude } \\
\text { (decimal } \\
\text { degrees) } \\
\end{array}$ & $\begin{array}{c}\text { Elevation (m; } \\
\text { from SFM } \\
\text { model) }\end{array}$ & $\begin{array}{l}\text { Thickness } \\
(\mathrm{cm})\end{array}$ & $\begin{array}{c}\text { Sample } \\
\text { weight } \\
\text { (g) }\end{array}$ & $\begin{array}{l}\text { Density } \\
\left(\mathrm{g} / \mathrm{cm}^{\wedge} 2\right)\end{array}$ & $\begin{array}{c}\text { Shielding } \\
\text { correction }\end{array}$ \\
\hline PNG15-2 & -9.67735 & 149.26855 & 157.8 & 1.9 & 43.64 & 2.75 & 0.9865 \\
\hline PNG15-3 & -9.6772 & 149.26855 & 153.3 & 3.3 & 43.95 & 2.75 & 0.9916 \\
\hline PNG15-4 & -9.67704 & 149.26858 & 146.9 & 3.0 & 30.31 & 2.75 & 0.9923 \\
\hline PNG15-5 & -9.67698 & 149.2688 & 140.5 & 1.6 & 44.20 & 2.75 & 0.9959 \\
\hline PNG15-6 & -9.67684 & 149.26854 & 141.7 & 5.2 & 23.48 & 2.75 & 0.9910 \\
\hline PNG15-8 & -9.67675 & 149.26864 & 136.2 & 2.0 & 14.76 & 2.75 & 0.9921 \\
\hline PNG15-9 & -9.67673 & 149.26878 & 132.5 & 4.0 & 33.75 & 2.75 & 0.9941 \\
\hline PNG15-11 & -9.67658 & 149.2688 & 127.6 & 2.6 & 24.29 & 2.75 & 0.9935 \\
\hline PNG15-17 & -9.67637 & 149.26906 & 117.4 & 2.8 & 11.68 & 2.75 & 0.9939 \\
\hline PNG15-18 & -9.67631 & 149.26896 & 115.7 & 2.7 & 28.78 & 2.75 & 0.9938 \\
\hline
\end{tabular}

Table 4 - Summary of samples described within this chapter. The density of metabasalt is taken from Daly et al. (1966), (2.704-2.851); and from Finlayson et al. (1977), (2.68-2.78).

The Mai'iu Fault scarp at Biniguni Falls was reportedly used as a pineapple plantation which was in operation until a major flood in 2007, which indicates the presence of a soil mantle prior to this time. Thus, while the bedrock is currently exposed, prior to 2007 the scarp was probably draped with soil of a similar thickness $(\sim 50 \mathrm{~cm})$ to that currently present in adjacent areas not affected by the flood waters. The apparent lack of significant erosion of the smooth and striated scarp (Fig. 46), (Little et al., 2015), and its concordance with the morphology of the surrounding Dayman Dome (Fig. 52) suggests that local erosion rates are relatively low. However some degree of fluvial erosion has occurred, as indicated by the stripping of soil cover during the 2007 flood. 


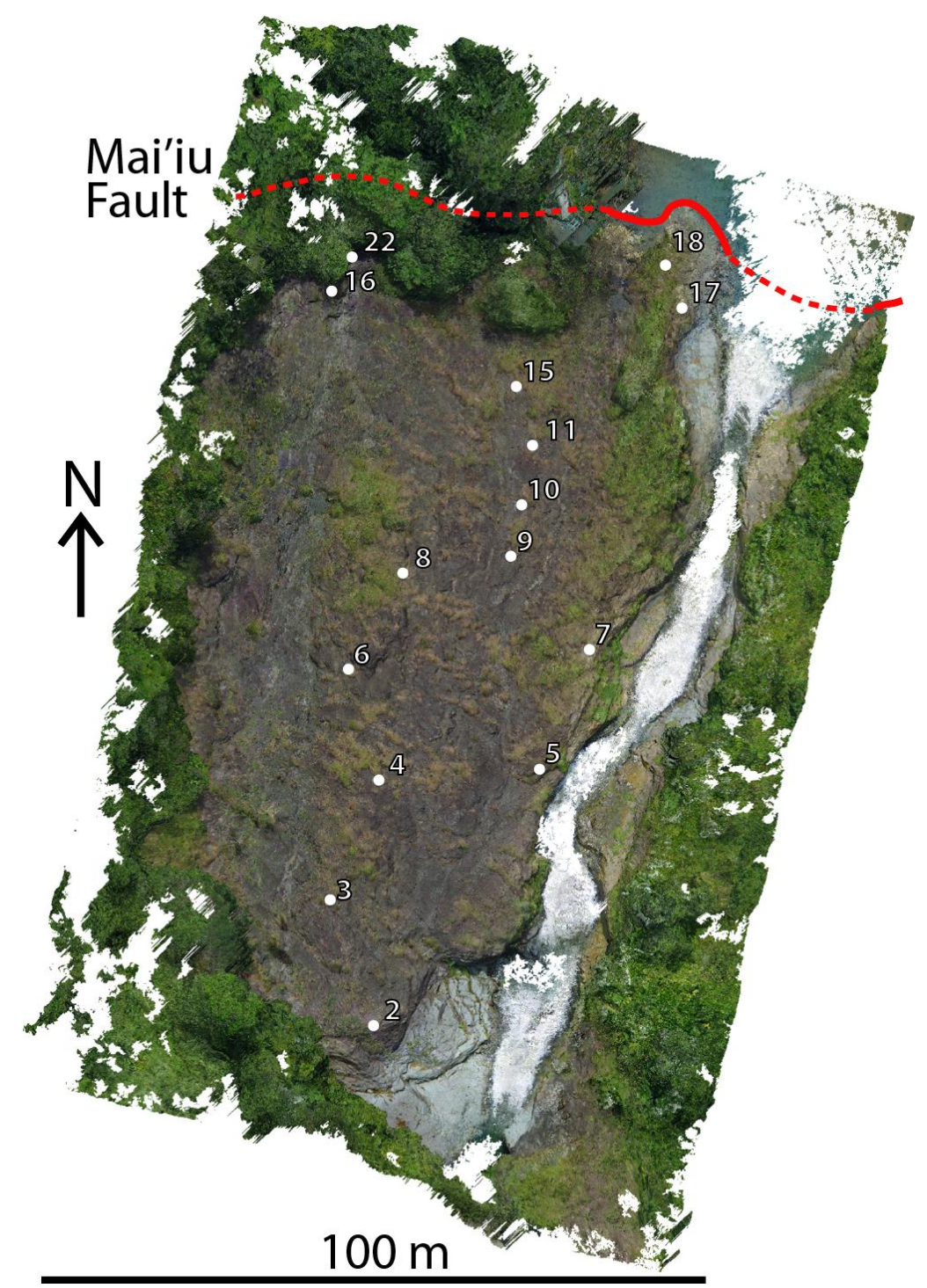

Fig. 46 - Orthorectified $0.1 \mathrm{~m}$ horizontal resolution Structure-From-Motion model of the lowermost Mai'iu Fault scarp at Biniguni Falls, generated from photographs $(n=64)$ taken from a helicopter fly-over. Note the position of the Mai'iu Fault trace (red line); at the range-front the Mai'iu Fault dips $21^{\circ} / \mathrm{N}$. TCN sample localities are labelled; note that only ten of these samples were selected for processing (Table 5).

Of the fifteen samples collected, ten were selected for analysis (Table 5) based on their quartz content; these were distributed over the full extent of the exposed fault scarp (Fig. 46). Samples were processed after the method based on that of Von Blanckenburg et al. (2004) and Norton et al. (2008); this methodology is given in Appendix A. Processed samples were submitted to The University of Cologne for AMS analysis, in order to determine ${ }^{10} \mathrm{Be} /{ }^{9} \mathrm{Be}$ ratios. ${ }^{10} \mathrm{Be}$ concentrations ( $\mathrm{N}_{\text {sample; }}$ Fig. 47) were then calculated based on these ratios; from these it is possible to calculate sample exposure ages, given some knowledge of local erosion rate; this is discussed below.

Within my dataset, there are three samples that I treat as outliers (Fig. 47, red squares) that are identified based on the magnitude of $\mathrm{N}_{\text {sample }}$ with respect to the concentrations of surrounding 
samples. Based on the smoothly increasing concentration of most samples (Fig. 47, black squares), I interpret that these data represent the main data distribution. Reversals in TCN concentration up-scarp are not physically possible; therefore reversals in the TCN concentration profile (Fig. 47) require either locally higher erosion rates, or sample contamination during processing (probably because ${ }^{9} \mathrm{Be}$ was lost relative to ${ }^{10} \mathrm{Be}$ during sample dissolution, while the sample is not yet fully mixed; see Appendix A). Sample PNG-15-17 lies outside (to the right of) the main data distribution (Fig. 47), and exhibits TCN concentrations 4x that of nearby PNG-15-18, and 1.3-3.9x that of all other samples. This sample may be contaminated; the alternative, that all other samples have been vertically incised by $\sim 10-20 \mathrm{~m}$, is not geologically plausible. The relatively smooth surface of the lowermost Mai'iu Fault scarp, and its concordance with the overall $21^{\circ} / \mathrm{N}$ dip of the Mai'iu Fault, suggests that the scarp be eroded no more than $\sim 4 \mathrm{~m}$, and more likely $<2 \mathrm{~m}$, at any of our sample localities. Additionally, samples PNG-15-2 and PNG-15-4 both fall outside of (to the left of) the main data distribution (Fig. 47), and each imply age reversals. I interpret these samples as having been more deeply eroded, by $<2.1 \mathrm{~m}$ and $<1.8 \mathrm{~m}$ respectively, compared to the rest of the scarp (0.8 $\pm 0.8 \mathrm{~m} ; 1 \sigma$; see section 5.2.1.1). This is consistent with a moderately higher magnitude of erosion at these sample localities, with erosion generally less than $2 \mathrm{~m}$ at all points on the fault scarp for all model simulations. Alternatively, the low TCN concentrations of PNG-15-2 may be explained by shielding beneath now eroded rock. PNG-15-2 was located $\sim 10 \mathrm{~cm}$ below the local maximum scarp relief, which might suggest that it was shielded by rock at depth. In either case, I discard PNG-15-2 and PNG-15-4 as eroded or shielded outliers.

\begin{tabular}{|c|c|c|c|c|}
\hline $\begin{array}{l}\text { Sample } \\
\text { number }\end{array}$ & $\begin{array}{l}\text { Slope-parallel distance } \\
\text { from fault trace }(\mathrm{m} ; d)\end{array}$ & $\begin{array}{c}\text { Sample }{ }^{10} \mathrm{Be} \\
\text { concentration } \\
\text { (atoms/g; } \mathrm{N}_{\text {sample }} \text { ) }\end{array}$ & 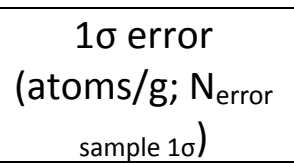 & Relative \% error \\
\hline PNG15-2 & 131.58 & 11584.82 & 1780.64 & 15.4 \\
\hline PNG15-3 & 112.78 & 15755.57 & 1898.86 & 12.1 \\
\hline PNG15-4 & 93.88 & 7411.96 & 1296.80 & 17.5 \\
\hline PNG15-5 & 85.22 & 15374.12 & 1745.01 & 11.4 \\
\hline PNG15-6 & 76.76 & 14628.90 & 2131.56 & 14.6 \\
\hline PNG15-8 & 61.02 & 10035.55 & 2453.00 & 24.4 \\
\hline PNG15-9 & 55.18 & 12669.98 & 1772.06 & 14.0 \\
\hline PNG15-11 & 38.49 & 8547.11 & 1580.66 & 18.5 \\
\hline PNG15-17 & 15.77 & 20781.95 & 3732.46 & 18.0 \\
\hline PNG15-18 & 10.32 & 5291.91 & 1254.46 & 23.7 \\
\hline
\end{tabular}

Table 5 - Summary of sample TCN concentrations ( $\left.\mathrm{N}_{\text {sample }}\right)$. 


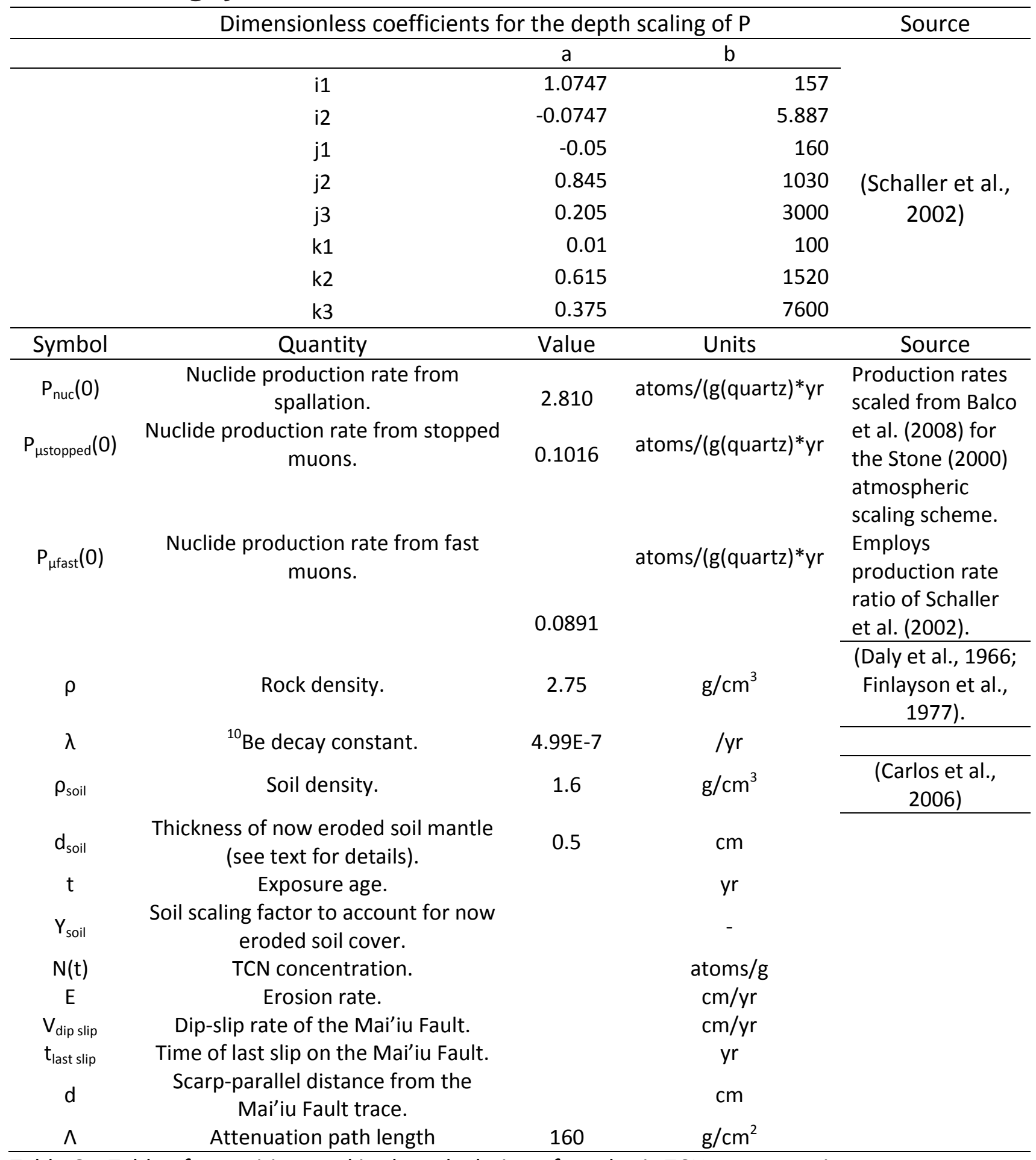

Table 6 - Table of quantities used in the calculation of synthetic TCN concentrations. 


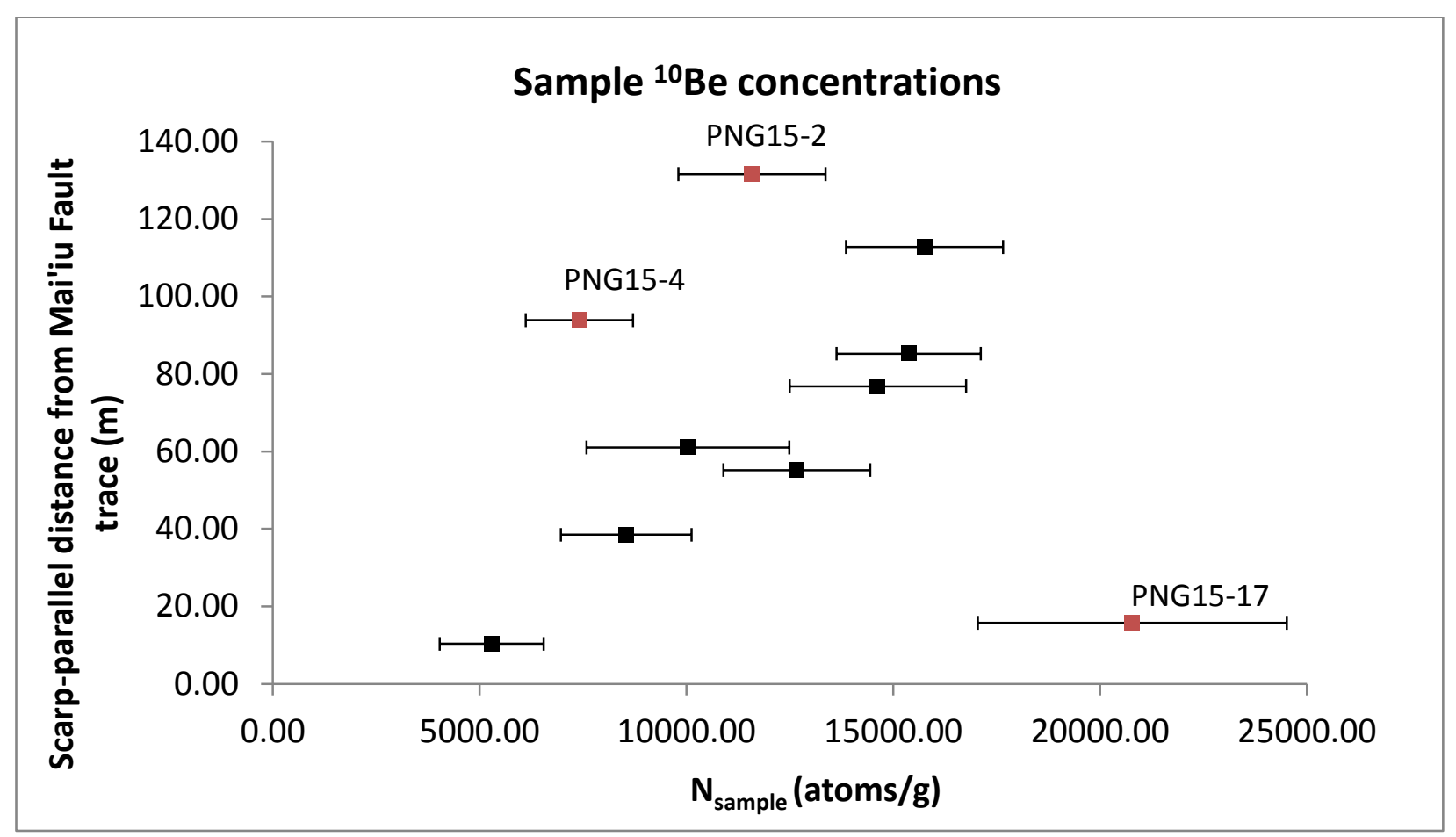

Fig. 47 - Sample ${ }^{10}$ Be concentrations, plotted against scarp-parallel distance Mai'iu Fault trace. The central, coherent portion of data (black squares) and inferred sample outliers (red squares) are labelled. See text for details.

It is not sufficient to simply determine fault slip rate for an assumed erosion rate, because no independent constraints on local erosion rate exist. Therefore I model slip rates and erosion rates using a simple Monte-Carlo simulation, in order to reproduce my measured scarp TCN concentration profile. I generate synthetic TCN concentration-scarp-parallel distance plots, in which I compare modelled TCN concentrations with sample TCN concentrations; this modelling methodology was largely developed by Kevin Norton (personal communication, 2016), after the approach of Schlagenhauf et al. (2011). I first calculate a synthetic exposure age at $2 \mathrm{~m}$ along-scarp intervals along the Mai'iu Fault scarp based on linear 1D kinematics (note that calculations are made in terms of non-SI units $\mathrm{cm}$ and $\mathrm{g}$ ):

$$
t=\frac{d}{V_{\text {dip slip }}}+t_{\text {last slip }}
$$

Equation 4 - Calculation of scarp exposure age at each scarp-parallel position (d). Quantities listed in Table 6.

For these points I then calculate TCN concentrations using the equation for post-exposure TCN concentration from Schaller et al. (2002), (Equation 5). Note once more that calculations are made 
in terms of non-SI units $\mathrm{cm}$ and g. Quantities are listed in Table 6. The model is reiterated for random values of erosion rate $(E)$, slip rate $\left(V_{\text {dip slip }}\right)$, and the time of potential fault abandonment ( $\left.t_{\text {last slip }}\right)$. The model outputs a synthetic nuclide concentration, $\mathrm{N}_{\text {sample }}(t)$, which is then compared with sample TCN concentrations ( $\mathrm{N}_{\text {sample; }}$ Fig. 48 ; note that model outputs are presented in metres).

$$
\begin{aligned}
N_{\text {sample }}(t)= & Y_{\text {soil }}\left[P_{\text {Nuc }}(0) \times \sum_{i=1}^{2} \frac{a_{i}}{\left(\lambda+\frac{\rho \times E}{b_{i}}\right)}\right. \\
& +P_{\text {нstopped }}(0) \times \sum_{j=1}^{3} \frac{a_{j}}{\left(\lambda+\frac{\rho \times E}{b_{j}}\right)} \\
& \left.+P_{\text {ffast }}(0) \times \sum_{k=1}^{3} \frac{a_{k}}{\left(\lambda+\frac{\rho \times E}{b_{k}}\right)}\right] \times \mathrm{e}^{-\lambda \times t} \\
Y_{\text {soil }} & =\times \operatorname{Exp}\left(-\frac{\rho_{\text {soil }} \times d_{\text {soil }}}{\Lambda}\right)
\end{aligned}
$$

Equation 5 - Calculation of post-exposure TCN accumulation (above), and soil scaling factor (below). Quantities listed in Table 6. Modified from Schaller et al. (2002).

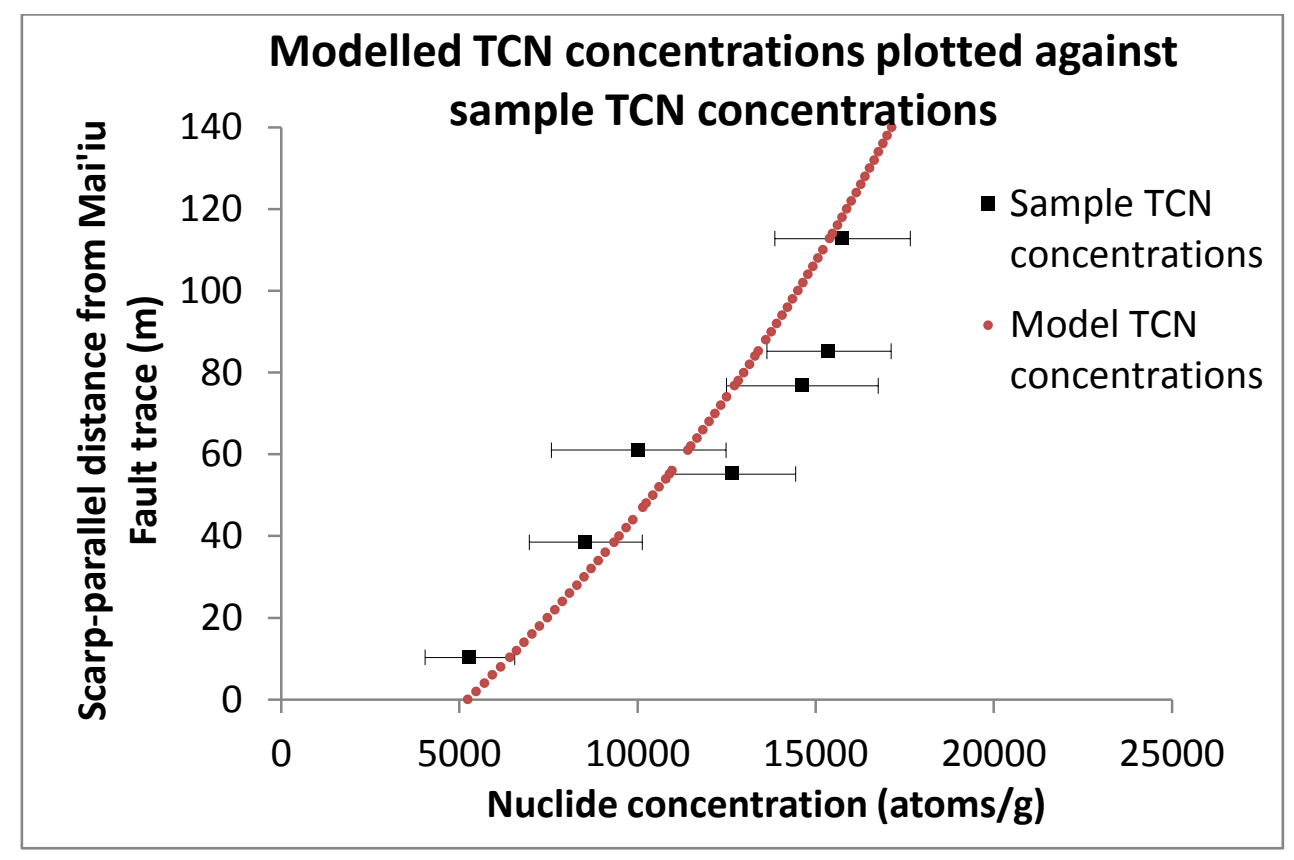

Fig. 48 - Example of modelled TCN concentrations ( $\left.N_{\text {model }}\right)$, in which I randomly vary erosion rate,

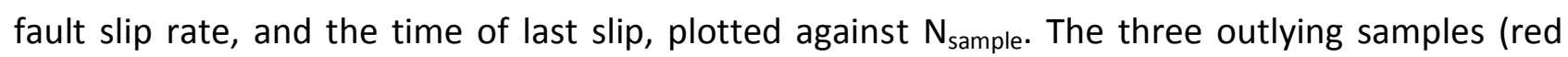
squares of Fig. 47) are excluded. This model is run for mean model output parameters (discussed below), i.e., an erosion rate of $0.043 \mathrm{~mm} / \mathrm{yr}$, a fault dip-slip rate of $13.9 \mathrm{~mm} / \mathrm{yr}$, and a time of last slip on the Mai'iu Fault of $2.9 \mathrm{ka}$. The sum of residuals $(A)$ is equal to -10866 atoms/g (i.e., the model on average underestimates sample TCN concentrations). 
In order to compare model outputs, I calculate the sum of residual anomalies $(A)$ between measured TCN concentrations $\left(\mathrm{N}_{\text {sample}}\right)$ and the modelled TCN concentrations $\left(\mathrm{N}_{\text {model }}\right)$. Positive values of $A$ for a particular sample $\left(\mathrm{N}_{\text {model }}>\mathrm{N}_{\text {sample}}\right)$ implies that that the model under predicts the

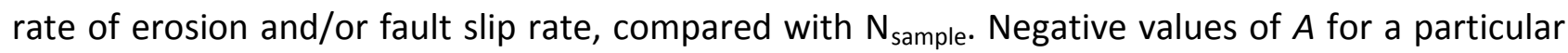
sample $\left(\mathrm{N}_{\text {model }}<\mathrm{N}_{\text {sample}}\right.$ ) implies that the model over predicts the rate of erosion and/or fault slip

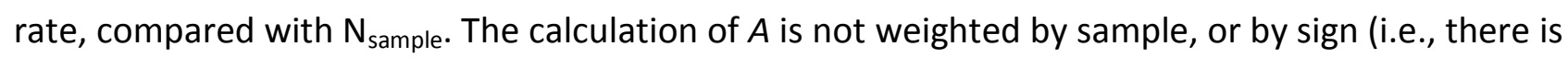
no preference as to whether the model over-fits or under-fits). I then calculate the absolute value of the difference between $A$ and the magnitude of error of measured TCN concentrations $\left(N_{\text {error }}\right.$ sample); this is a measure of how well a particular model run predicts $\mathrm{N}_{\text {sample. }}$. The sum of $\mid A_{\text {sample }}-$ $N_{\text {error sample } 1 \sigma} \mid$ for all samples is termed $1 \sigma_{\text {sum; }}$ model runs with $1 \sigma_{\text {sum }}<0$ are within $1 \sigma$ error of

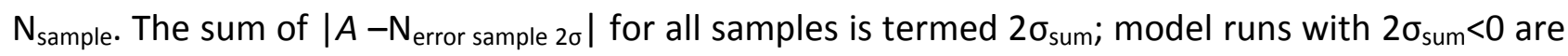
within $2 \sigma$ error of $\mathrm{N}_{\text {sample. }}$

While in theory a scarp-TCN dataset may be used to identify periods of seismic slip (as opposed to aseismic creep) through the identification of periods of active slip and periods of relative quiescence (TCN concentrations increase less rapidly with scarp height during slip events), in general the temporal resolution of our data is not sufficient to make these distinctions (Schlagenhauf et al., 2011).

I conduct initial modelling in order to constrain the erosion rate and time of last slip on the Mai'iu Fault. The model assumes that the fault dip-slip rate and the local erosion rate do not vary over time. I assume a uniform soil thickness of $50 \mathrm{~cm}$, of a density of $1.6 \mathrm{~kg} \mathrm{~m}^{-3}$ (Carlos et al., 2006). Initial modelling suggests that at the $1 \sigma$ level, erosion rates do not exceed $0.12 \mathrm{~mm} / \mathrm{yr}$; these low erosion rates are consistent with observations of minimal erosion of the scarp, and are broadly consistent with erosion rates reported for Papua New Guinea by Korup et al. (2007). At the $1 \sigma$ level, the time of last slip on the Mai'iu Fault does not exceed $5.5 \mathrm{ka}$. At the $1 \sigma$ level, fault dip-slip rate does not exceed $30 \mathrm{~mm} / \mathrm{yr}$; this encompasses regional rates of extension suggested by campaign GPS data of Wallace et al. (2014).

\subsubsection{Modelled Erosion Rates for the Mai'iu Fault at Biniguni Falls}

This model outputs erosion rates that are normally distributed at the $1 \sigma$ level; $2 \sigma$ results are artificially truncated by my upper limit on modelled erosion rates. Modelled erosion rates are $0.043 \pm 0.025 \mathrm{~mm} / \mathrm{yr}(1 \sigma)$, (Table 7; Fig. 49). These values are at the low end of documented erosion rates reported from Papua New Guinea (Herman et al., 2013; Korup et al., 2007; Pain and Bowler, 1973; Simonett, 1967). This subject is further discussed below. From inspection of results 
it is clear that my imposed constraints on modelled erosion rates did not limit the range of model outputs for fits within $1 \sigma$ (Fig. 49, black dots). Modelled erosion rates require $0.8 \pm 0.8 \mathrm{~m}(1 \sigma)$ of erosion at the top of the Biniguni Falls scarp (located $132 \mathrm{~m}$ up-dip from the Mai'iu Fault trace), which is consistent evidence for low levels of local erosion. For comparison, total erosion at each TCN sample locality may also be independently estimated through comparison of sample elevations with a projected, ideal planar fault surface, dipping $21^{\circ} / \mathrm{N}$. This approach yields similar total erosion magnitude to the model results, generally $\leq 2 \mathrm{~m}$, with some few exceptions (e.g., 3.9 m, PNG-15-2).

\begin{tabular}{crrr}
\hline & \multicolumn{3}{c|}{$1 \sigma$} \\
\cline { 2 - 4 } $\mathrm{N}$ & $\begin{array}{c}\text { Mean } \\
\mathrm{mm} / \mathrm{yr})\end{array}$ & Standard deviation $(\mathrm{mm} / \mathrm{yr})$ & Mode $(4 \mathrm{dp} ; \mathrm{mm} / \mathrm{yr})$ \\
501 & 0.043 & 0.025 & 0.038
\end{tabular}

Table 7 - Summary of modelled erosion rates for the Mai'iu Fault scarp at Biniguni Falls. The calculated mean erosion rate is calculated from $1 \sigma$ fits (see text). Results indicate that erosion rate is $0.043 \pm 0.025 \mathrm{~mm} / \mathrm{yr}(1 \sigma)$.

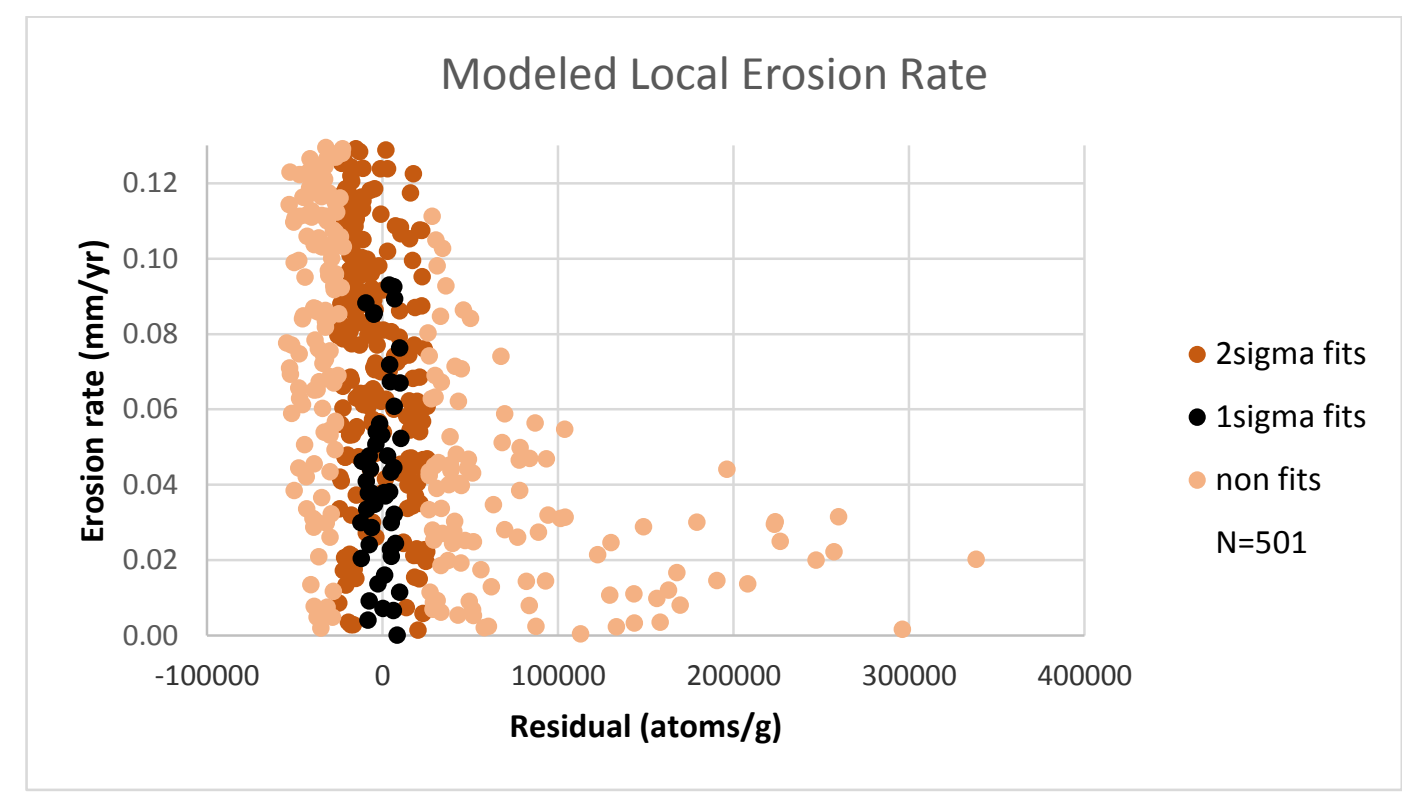

Fig. 49 - Plot of modelled erosion rates. Black points represent $1 \sigma$ fits; dark orange points represent $2 \sigma$ fits; and light orange points represent non-fits. $1 \sigma$ fits are approximately normally distributed, and are not truncated.

\subsubsection{Modelled Time of Last Slip on the Mai'iu Fault at Biniguni Falls}

This model outputs the time of last slip. Modelling (Table 8, Fig. 50) suggests the period of last slip on the Mai'iu Fault occurred at $2.9 \pm 1.4 \mathrm{ka}(1 \sigma)$; this implies that the Mai'iu Fault last slipped within the last $1.5-4.4$ ka (68\% confidence). While $1 \sigma$ results are not truncated by the imposed 7 ka upper 
limit (Fig. 50, black dots), $2 \sigma$ results are truncated (Fig. 50, dark orange dots). It is unlikely that final wholesale abandonment of the Mai'iu Fault has fortuitously occurred only within the last several thousand years; it is more likely that the time of last slip represents the time at which the most recent seismic slip event occurred on the Mai'iu Fault. It should be noted that the model simulates slip as occurring at a constant rate (i.e., aseismically); this is because the low sampling resolution and relatively large magnitudes of $\mathrm{N}_{\text {sample error }}$ preclude the identification of seismic slip events within most of the TCN profile. Thus the time of last slip represents an anomaly that cannot be explained by a scenario of constant (aseismic) slip. This interpretation is consistent with the idea that earthquakes on LANF may have long return times (Wernicke, 1995) - modelled earthquake recurrence intervals of 0.4-2.5 ka are consistent with global LANF earthquakes modelled by Styron and Hetland (2014) with modelled return times of $M \geq 7.0$ events, and potentially $M \geq 7.5$ events.

\begin{tabular}{crrr|}
\hline & \multicolumn{3}{c|}{$1 \sigma$} \\
\cline { 2 - 4 } N & Mean (ka) & Standard deviation (ka) & Mode (2 s.f.; ka) \\
501 & 2.93 & 1.44 & 3.2
\end{tabular}

Table 8 - Summary of results of modelling of the time of last slip on the Mai'iu Fault at Biniguni Falls. The calculated fault abandonment age only includes those values within $2 \sigma$ of the raw calculated mean. Note that modelled fault abandonment age was limited to 0-7 ka. Results indicate that the Mai'iu Fault last slipped within the last 1.5-4.4 ka (68\% confidence).

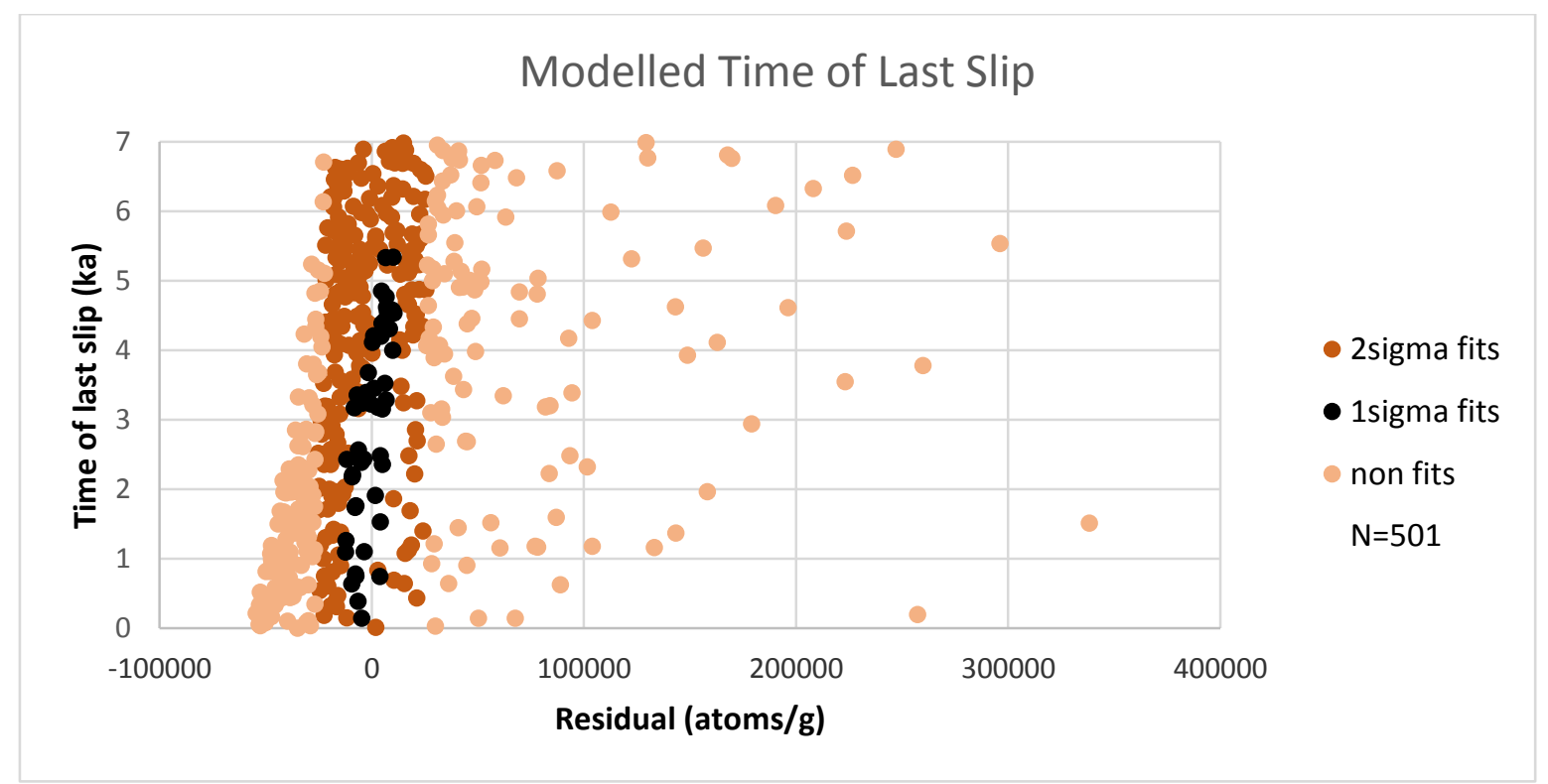

Fig. 50 - Plot showing modelled time of last slip on the Mai'iu Fault. $1 \sigma$ fits are not truncated. Results indicate that the Mai'iu Fault last slipped within the last 1.5-4.4 ka (68\% confidence). 


\subsubsection{Modelled Recent Dip-Slip Velocity for the Mai'iu Fault at Biniguni Falls}

A second model run uses modelled erosion rates $(0.018-0.068 \mathrm{~mm} / \mathrm{yr})$ and the time of last slip $(1.49-4.37 \mathrm{ka})$ from the first model run, in order to further refine the Holocene time-averaged dipslip rate of the Mai'iu Fault. I allow fault slip rate to vary freely between 0-35 mm/yr - this ensures that the range of modelled fault slip-rates is not truncated at the $1 \sigma$ level. Modelling (Table 9; Fig. 51) suggests that the Mai'iu Fault at Biniguni Falls slipped on average at a rate of $13.9 \pm 4.0 \mathrm{~mm} / \mathrm{yr}$ $(1 \sigma)$, which implies a minimum slip rate of $10.0 \mathrm{~mm} / \mathrm{yr}(1 \sigma)$. Dividing the scarp length by this dipslip rate, accounting for the period of last slip, suggests that this slip rate is resolved over the last $13.2 \pm 2.7 \mathrm{ka}(1 \sigma)$. This suggests rapid dip-slip on the $21^{\circ} / \mathrm{N}$ dipping Mai'iu Fault, at rates that slightly exceed rates of regional horizontal extension (7-9 mm/yr) suggested by campaign GPS data of Wallace et al. (2014); these horizontal GPS velocities equate to a dip-slip rate of 7.5-9.6 mm/yr if all slip is resolved on the Mai'iu Fault.

\begin{tabular}{ccrr}
\hline & \multicolumn{3}{c}{$1 \sigma$} \\
\cline { 2 - 4 } $\mathrm{N}$ & Mean & Standard deviation $(\mathrm{mm} / \mathrm{yr})$ & Mode (3 s.f.; mm/yr) \\
500 & $(\mathrm{~mm} / \mathrm{yr})$ & 3.96 & 12.10 \\
\hline
\end{tabular}

Table 9 - Summary of results of modelling of dip-slip rate for the Mai'iu Fault scarp at Biniguni Falls. The calculated mean slip rate only includes those values within $1 \sigma$ of the raw calculated mean. Results indicate that the Mai'iu Fault is slipping $13.9 \pm 4.0 \mathrm{~mm} / \mathrm{yr}(1 \sigma)$. This rate is artificially high, as a consequence of the way in which I calculate residual anomalies. See text for details.

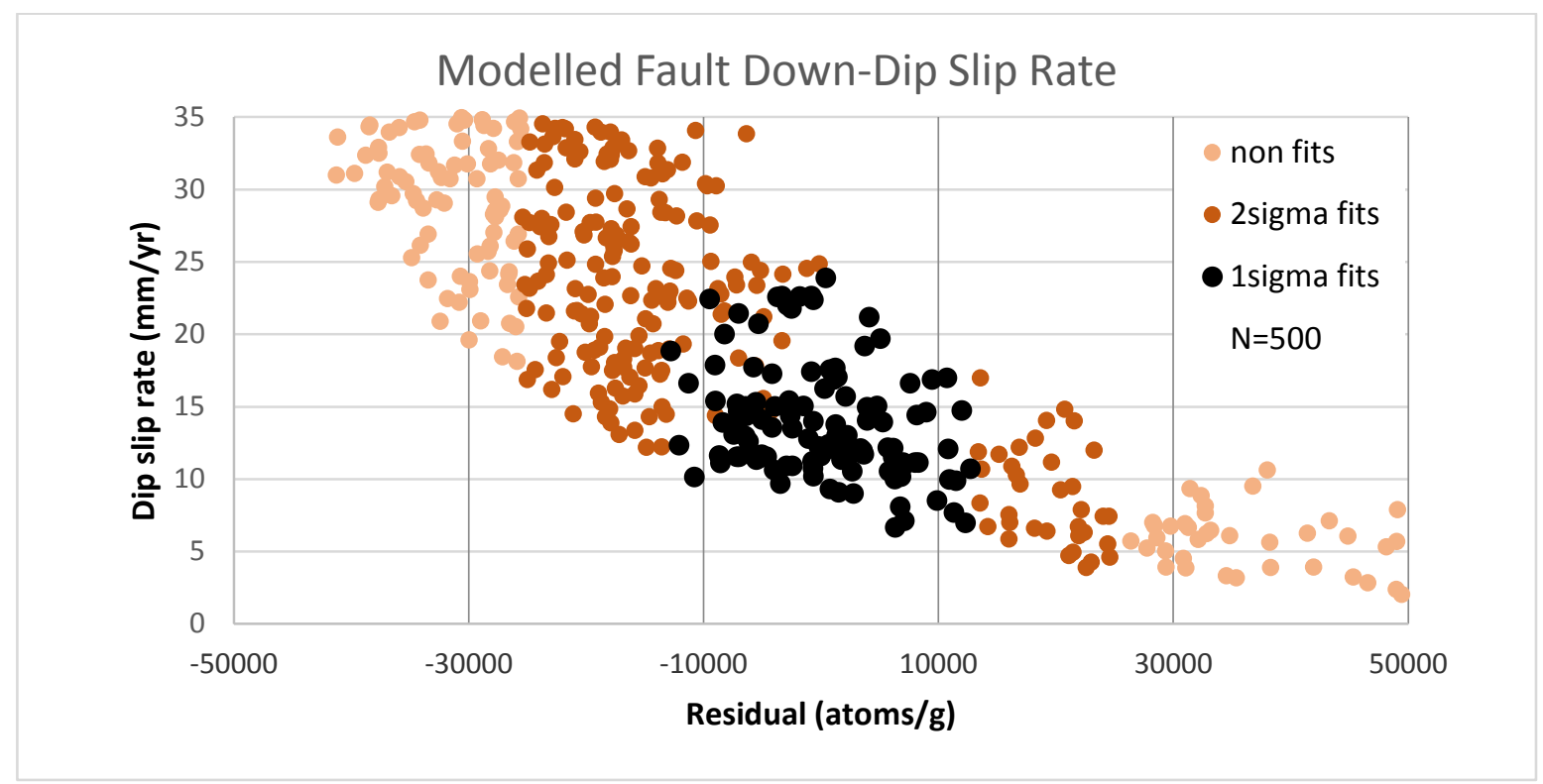

Fig. 51 - Plot of modelled fault slip rates. Model runs with a positive residual imply erosion of sample locations $\left(\mathrm{N}_{\text {sample }}<\mathrm{N}_{\text {model }}\right)$; model runs with negative residuals imply contamination of samples $\left(\mathrm{N}_{\text {sample }}>\mathrm{N}_{\text {model }}\right)$. Modelling suggests a dip-slip rate of $13.9 \pm 4.0 \mathrm{~mm} / \mathrm{yr}(1 \sigma)$, and a minimum dip-slip rate of $10.0 \mathrm{~mm} / \mathrm{yr}(1 \sigma)$. 


\subsection{Structure of the Mai'iu Fault Hanging Wall}

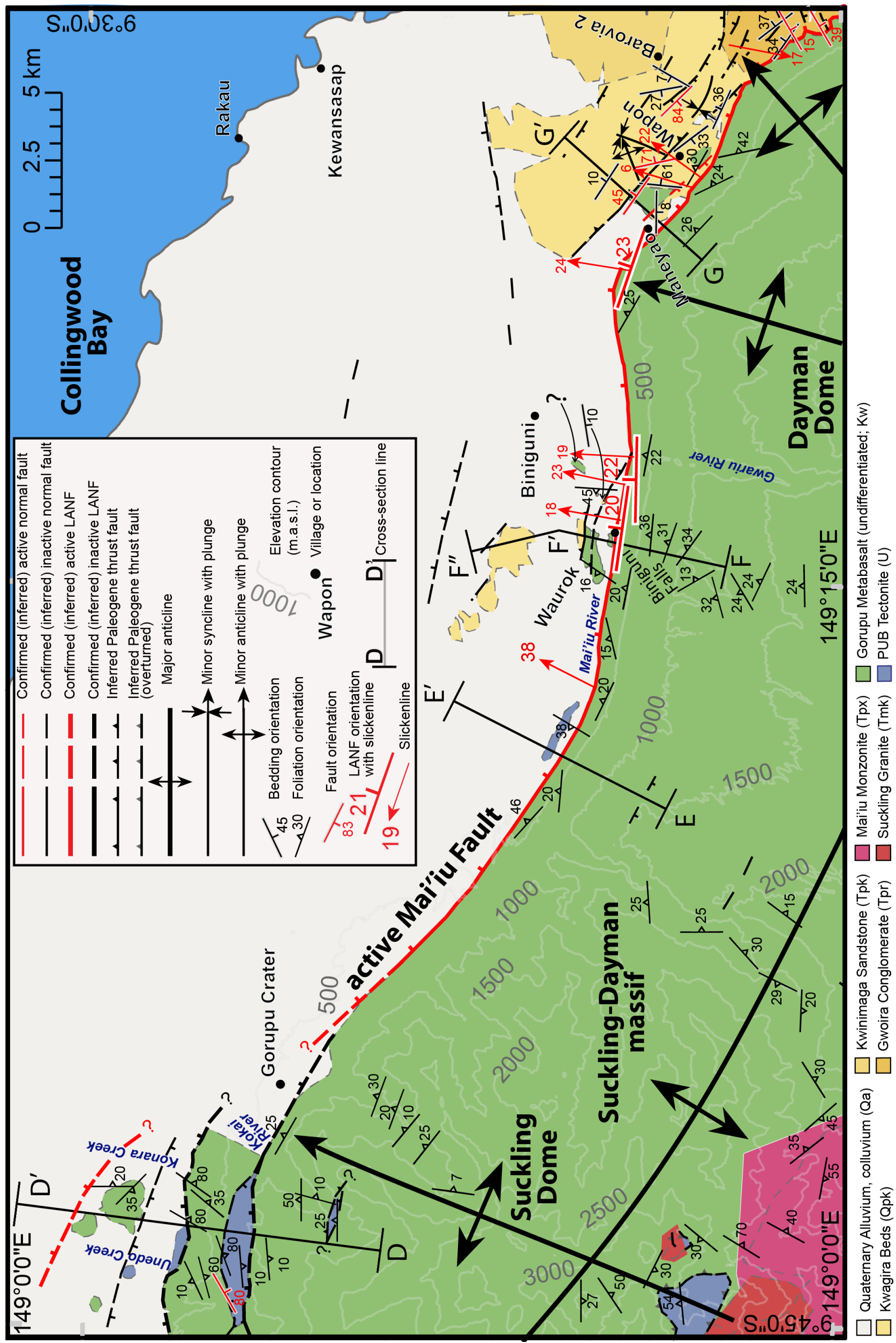


Fig. 52 - Geological map detailing the Mai'iu Fault between Gorupu Crater and Wapon. The Mai'iu Fault bounds the Suckling-Dayman massif to the north, and is active between Pumani (Fig. 11) and Gorupu Crater; however, the Mai'iu Fault has been offset by high-angle antithetic faults west of Gorupu Crater. Near Biniguni Falls and Wapon, the active Mai'iu Fault hanging wall locally comprises inferred inherited Paleogene thrust sheets, comprising Gorupu Metabasalt. Note the positions of cross-sections D, E, F and G. Includes data from Davies and Smith (1974), Davies et al. (unpublished field notes, 1965-1972), Smith and Green (1961).

The Mai'iu Fault represents an inherited Paleogene thrust fault (the Owen Stanley Fault) that has been extensionally reactivated during the Pliocene as a LANF. The present understanding is that the Gorupu Metabasalt comprises the bulk of the Suckling-Dayman massif, forms the footwall of the Mai'iu Fault (Fig. 52), and is in fault contact with the overlying PUB ophiolite (Smith and Davies, 1976). However field exposures of Gorupu Metabasalt north of the Mai'iu Fault (Fig. 52) do not conform to this model. These observations of Gorupu Metabasalt in the hanging wall of the Mai'iu Fault require either: through-going normal faulting that cross-cuts the Mai'iu Fault at depth, such that footwall Gorupu Metabasalt is uplifted and exposed north of the Mai'iu Fault; or Paleogene thrust imbrication of the Gorupu Metabasalt into the otherwise ultramafic upper plate of the Owen Stanley Fault, resulting in tectonic stacking of the Gorupu Metabasalt into the Papuan Ultramafic Belt (PUB) tectonites (i.e., Davies, 1980a). Both interpretations would have major mechanical implications for the activity and deformational style of the Mai'iu Fault, because the former interpretation would require that the Mai'iu Fault be abandoned within the near-surface. I discuss these two possibilities below.

One interpretation that would explain the presence of Gorupu Metabasalt in the hanging wall of the Mai'iu Fault is that young, deeply-biting high-angle normal faults have cut and offset the older Mai'iu LANF by hundreds of metres. Such high-angle faults could either be active only within the upper crust, or at all structural depths (this subject is discussed further in sections 6.3.3 and 6.4.2). This interpretation would require that the Mai'iu Fault be locally abandoned at least within the near-surface, for reoccupation of such a highly disjointed (i.e., by 100's of metres) LANF surface would not be possible. Extensional strain would be accommodated by high-angle normal faults in the near-surface. Such dismemberment of a LANF by high-angle normal faults in the near-surface has been documented in the case of LANFs in the Panamint, Inyo, and Slate ranges, California, by (Cichanski, 2000). This style of through-going normal faulting may be rationalised in terms of the conceptual model of Tucholke et al. (1998), who attempt to provide a mechanical framework for MCC back-rotation. Brittle deformation of the footwall is essential within any LANF evolution model where the footwall back-rotates, because back-rotation occurs principally within the upper 
crust (Bartley et al., 1990). Tucholke et al. (1998) speculate that faulting of the LANF footwall may occur as a consequence of bending stresses associated with back-rotation.

An alternative explanation for the local occurrence of Gorupu Metabasalt exposures to the north of the main trace of the Mai'iu Fault is that the hanging wall of the Mai'iu Fault constitutes an inherited Paleogene thrust duplex. This model would imply that the Neogene Mai'iu LANF has not been cross-cut, and remains active at all depths. Instead, this model implies that the Owen Stanley thrust fault imbricated parts of its immediate footwall (the Gorupu Metabasalt) during Paleogene obduction of the PUB. It is thought that the Gorupu Metabasalt was thrust beneath the PUB during the Paleogene along the Owen Stanley Fault, which is assumed to represent a single suture (Davies and Jaques, 1984); however, it has been suggested by Davies (1980a) that convergence may have been distributed across a duplex system of related thrust faults. Such faults have not been identified, but Davies (1980a) refers to some limited qualitative evidence for contraction within the Gorupu Metabasalt. It is possible that one such thrust fault developed as a duplex, which cut the Gorupu Metabasalt in the footwall of the original fault.

In the following sections I weigh evidence supporting each of these two hypotheses.

\subsubsection{Gorupu Crater - Mai'iu River Area}

I have prepared two cross-sections (Fig. 53) that illustrate my interpretation of the Mai'iu Fault surface and hanging wall in the Gorupu Crater-Mai'iu River area. The repetition of the PUB in cross-section D (Fig. 53D) has previously been interpreted as representing splaying of the Owen Stanley Fault, which led to structural repetition of the PUB during Paleogene obduction (Davies, 1980a). However, it is very challenging to test this hypothesis based on field data alone, as lowangle faults could potentially represent either thrust faults or back-rotated high-angle normal faults, and shear sense indicators were not observed during the mapping of Smith and Green (1961) and Davies et al. (1965-1972). A PUB lens in cross-section D is here interpreted as having been emplaced by thrusting. However the attitude of a single $80^{\circ} / \mathrm{SE}$ dipping shear zone measured at the PUB-Gorupu Metabasalt contact east of Gorupu Crater (unpublished data, Davies 19651967; Fig. 52) is consistent with through-going high-angle antithetic faulting, as is evidence for drag folding against this structure within the PUB, as mapped by Smith and Green (1961).

Thus I interpret that the Mai'iu Fault at Gorupu Crater is abandoned in the near-surface in favour of high-angle normal faulting. This interpretation implies that the Mai'iu Fault is inactive at the range-front west of Gorupu Crater (Fig. 53D). This is supported by the fact that the clear trace of 
the Mai'iu Fault further east becomes more diffuse west of Gorupu Crater, which suggests that the Mai'iu Fault is not active at the range-front. It is possible to use modelled slip rates to qualitatively assess the rate of fault slip along strike of Biniguni Falls, using the distribution of $k_{1}$ apices discussed in Chapter 3 (Fig. 39). $k_{1}$ apices represent convex-up portions of stream channels that drain the SDM to the north; these were previously mapped as fluvial knick points by Miller et al. (2012), (see chapter 3 for details). I interpret $k_{1}$ apices as having formed as consequence of fluvial incision concurrent with on-going slip on the Mai'iu Fault (they are advected up the Mai'iu Fault footwall). Their position is a function of long-term fault slip rate, erosion rate, and erodibility. Since the distance between $\mathrm{k}_{1}$ apices and the Mai'iu Fault is approximately constant (within error) between Biniguni Falls and the east of the Gwoira rider block (Fig. 40), it is probably that long-term fault slip rate is approximately constant over this distance. However, the distance between $k_{1}$ apices and the Mai'iu Fault decreases to the west towards Gorupu Crater (Fig. 40); this is consistent with a decrease in long-term fault slip rate towards the west, approaching a slip rate of zero at the northernmost point of the SDM. Note that this is only indicative of the slip rate resolved on the part of the Mai'iu Fault that lies at the immediate range-front. This zone of LANF abandonment in the near-surface west of Gorupu Crater, and consequent 'stepping-out' of the active LANF surface, may have developed due to interference of the western extremity of the Mai'iu Fault with the Musa Valley Graben, located to the west of Mt Suckling (Fig. 11).

However, on-going uplift of Mt Suckling is not kinematically consistent with slip dominantly along antithetic normal faults. On-going uplift of Suckling Dome is suggested by the presence of a windgap at Wowo Gap immediately to the west of Mt Suckling (Fig. 11), which has formed as a consequence of uplift of a north-draining stream channel, ultimately resulting in beheading of the original channel headwaters. Since the original stream that drained through Wowo Gap to the north incises through the Pleistocene Silimidi Conglomerate and Sivai Breccia Member (Davies and Smith, 1974), this wind-gap must have formed as least as recently as the Pleistocene. Thus I propose that on-going uplift of Suckling Dome is accommodated by on-going slip along the Mai'iu Fault at depth, or by slip on concealed synthetic high-angle normal faults.

Cross-section E (Fig. 53E) does not particularly constrain the structure of the Mai'iu Fault hanging wall, although it is consistent with LANF slip within the near-surface. The PUB in cross-section E was undeformed and massive in outcrop. I interpret the PUB here as representing a paleotopographic high, which rises above the bulk of the PUB as it becomes progressively structurally deep with increasing distance east (Fig. 11). 


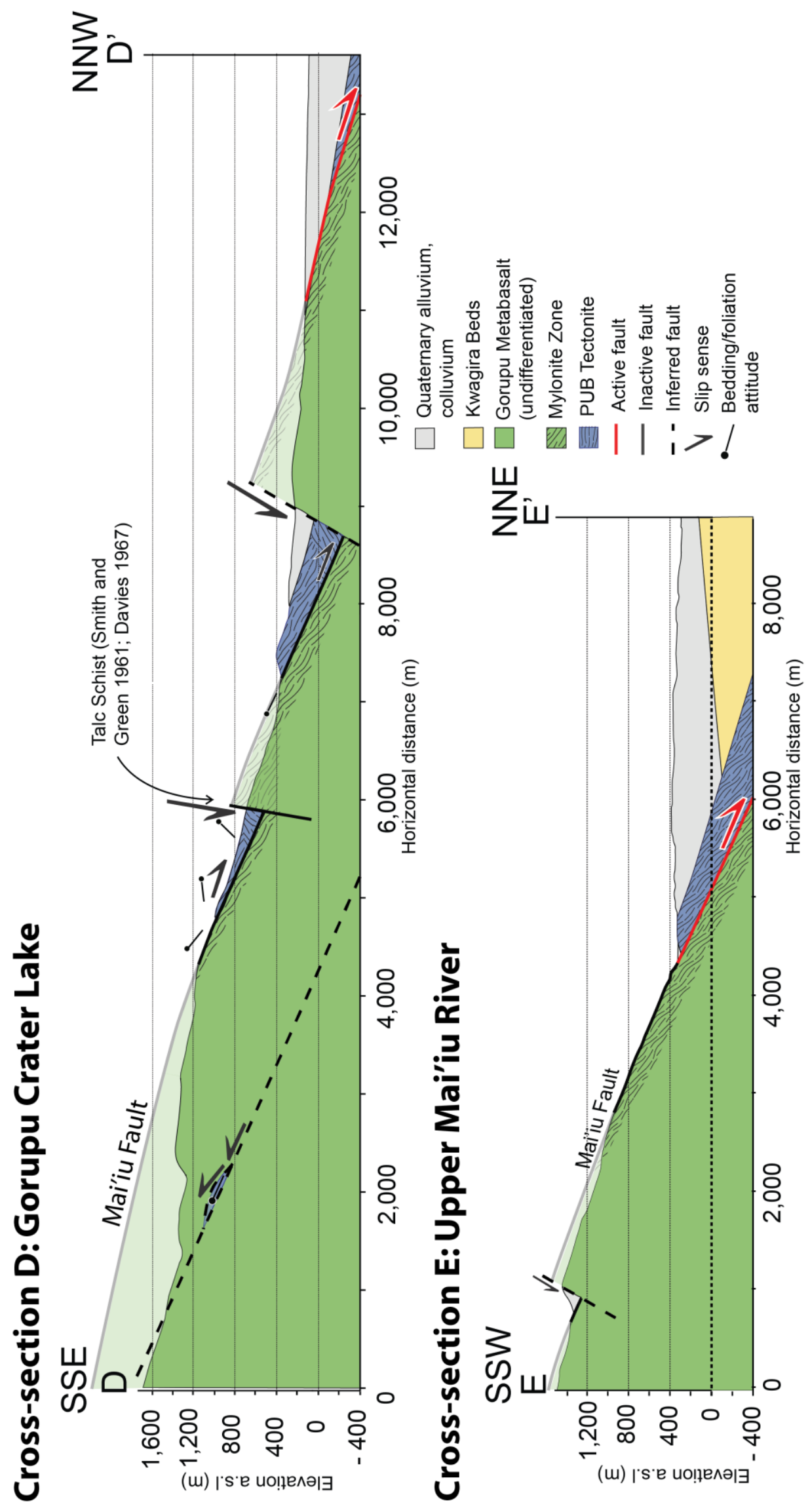

Fig. 53 - Geologic cross-sections west of Gorupu Crater Lake (D), and through the upper Mai'iu River (E). The interpretation of these cross-sections is equivocal - see text for details. D) The Mai'iu Fault is dissected by high-angle normal faulting. The significance of the PUB lens at $x=2000 \mathrm{~m}$ is unknown, and is here interpreted as a fault inlier. E) The Mai'iu Fault is active at all structural depths. Includes data from Davies and Smith (1974), Davies et al. (unpublished field notes, 1965-1972), Smith and Green (1961). 
For cross-section E (Fig. 53), antithetic faulting of the Mai'iu Fault footwall, rather than synthetic faulting of the hanging wall resulting in rider block formation, implies that the hanging wall is stronger than the footwall at the depth of LANF abandonment. This is because for a hanging wall and footwall of equal strength, it is kinematically more favourable to cut intact hanging wall rock with a synthetic fault that it is to cut intact footwall rock with an antithetic fault. Preferential faulting of the footwall may be explained by the presence of a strong wedge of ultramafic PUB in the immediate hanging wall (Fig. 54). Such a scenario is reasonable, given substantial outcropping of PUB in the Mai'iu Fault hanging wall northwest of Suckling Dome (Fig. 11), (Davies and Smith, 1974), and the lack of observed brittle deformation observed within the PUB along the Mai'iu River (Fig. 52). However, the strengths of the PUB and Gorupu Metabasalt are not independently known.

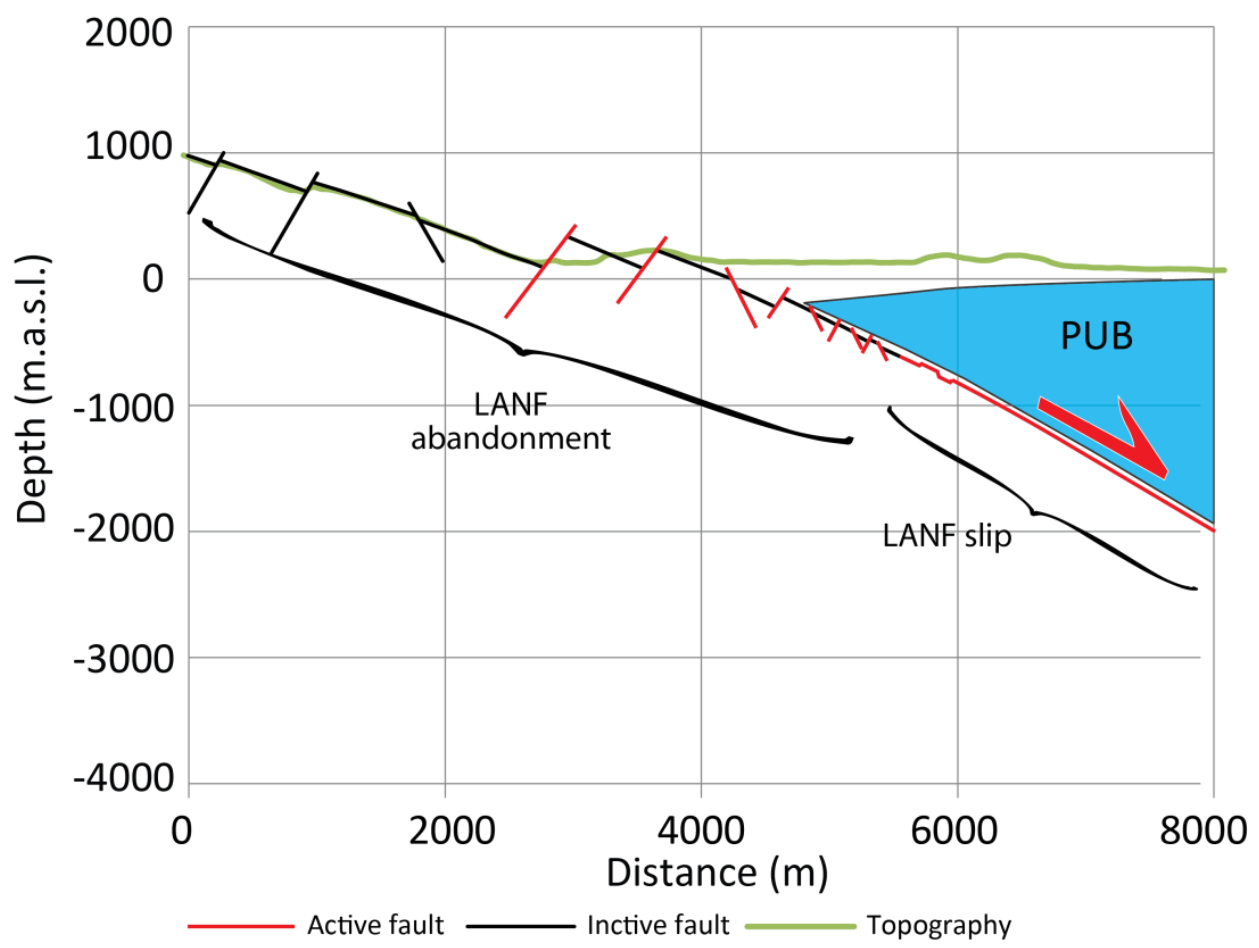

Fig. 54 - Cartoon illustrating LANF abandonment in the near-surface in favour of high-angle normal faulting. LANF abandonment, in response to excessive LANF strength of misorientation, occurs within the near-surface, with cross-cutting faults first initiating beneath a wedge of strong PUB (blue), which prevents fault propagation into the hanging wall.

\subsubsection{Biniguni Falls - Wapon Area}

I have prepared two cross-sections (Fig. 55F, G) that illustrate my interpretation of the Mai'iu Fault surface and hanging wall further east, between Biniguni Falls and Wapon (Fig. 52). Cross-section $F$ passes through the Mai'iu Fault scarp at Biniguni Falls, the study area for section 5.2. It also passes through Waurok, a hill comprising Gorupu Metabasalt elevated a 110 m above the surrounding floodplain. In order to explain evidence for active slip on the Mai'iu Fault at Biniguni Falls, I 
interpret that Waurok represents the elevated nose of an inherited Paleogene thrust fault. The more southern of these two thrust faults is marked by an E-W trending cuspate notch that divides Waurok in two (Fig. 52). An indurated conglomerate/breccia exposed on the northern flank of Waurok (Fig. 55F) may potentially have formed in association with this inferred thrust surface, although fabric orientations were not observed within this unit.

Cross-section G (Fig. 55G) is interpreted in a similar fashion. A fault that was observed in the field to $\operatorname{dip} 45^{\circ} / \mathrm{NE}$ is inferred to represent an inherited Paleogene thrust fault; however the slip sense is on thus structure is not known. An active antithetic high-angle normal fault is inferred to cut the hanging wall of the Mai'iu Fault further south (Fig. 55G); this fault is marked by a NW-SE trending, SW-facing escarpment. The footwall of this normal fault comprises indurated Gorupu Metabasalt breccia, itself composed of angular blocks up to $\sim 1 \mathrm{~m}$ in diameter; this breccia is too indurated to have formed in association with slip on the nearby antithetic normal fault in the near-surface. This unit (Fig. 55G) was also previously described by Davies et al. (unpublished field data 1968), who describe a weakly developed shear foliation, oriented $304 / \mathrm{NE} / 25^{\circ}$; this interpretation is maintained by Davies (1980a). I interpret that this foliation within the Gorupu Metabasalt breccia represents an inherited Paleogene thrust; this is consistent with its north-dipping geometry, and degree of induration. 


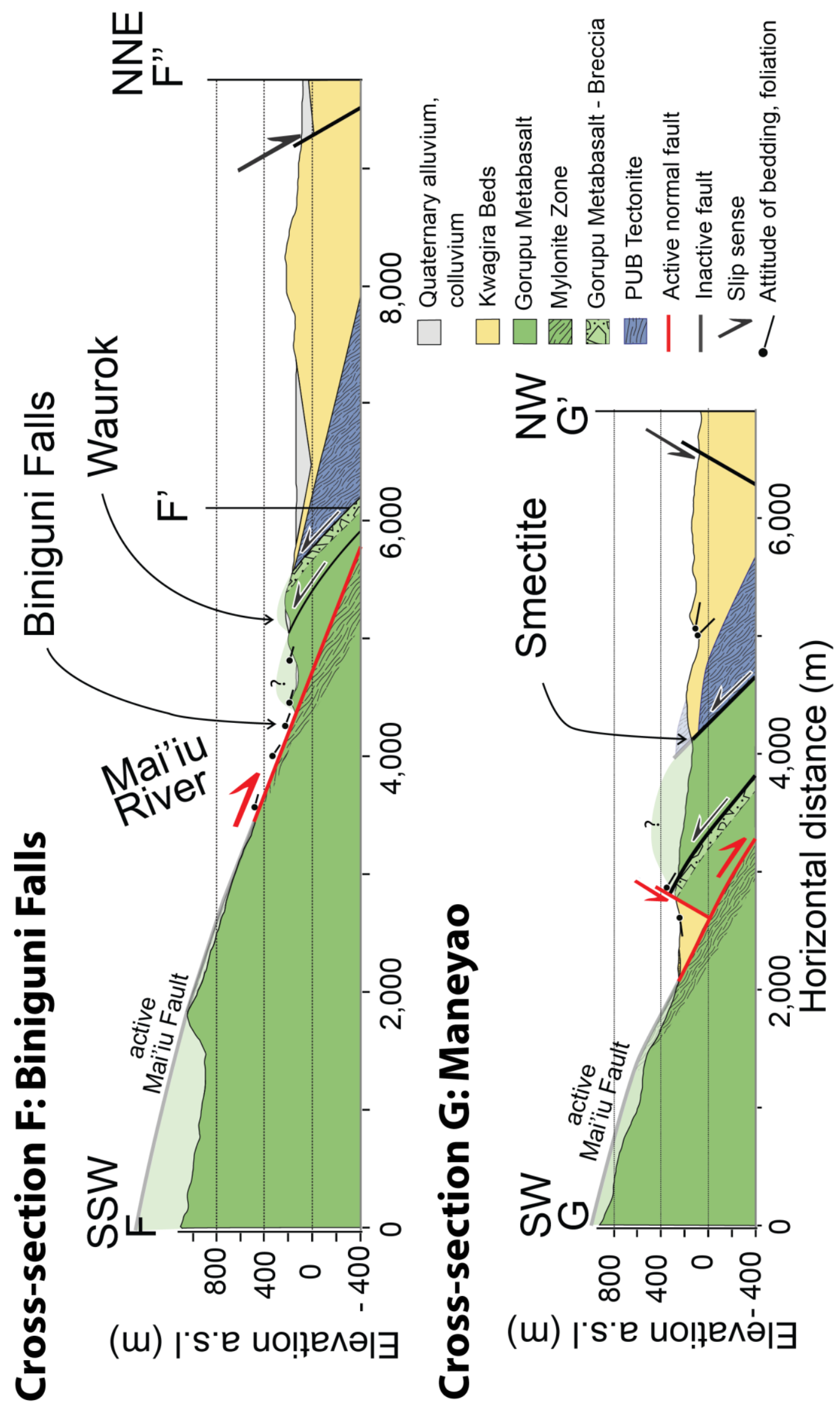

Fig. 55 - Geologic cross-sections through Biniguni Falls (F), and Maneyao (G). Section G passes through the sample locality at Biniguni Falls of section 5.2. In both sections, topographically elevated exposures of Gorupu Metabasalt in the hanging wall are interpreted as forming thrust duplexes that developed during Paleogene thrusting. See text for details. Includes data from Davies and Smith (1974), and Davies et al. (unpublished field notes, 1965-1972). 


\subsection{Discussion}

\subsubsection{Slip Rate of the Mai'iu Fault at Biniguni Falls}

Modelling results confirm that the Mai'iu Fault is active and rapidly slipping. Modelling suggests that the time of last slip of the Mai'iu Fault occurred at $2.9 \pm 1.4 \mathrm{ka}(1 \sigma)$. The scarp TCN concentration profile is modelled in terms of a constant dip-slip rate prior to this time of last slip. Resultant fault slip rates are equal to $13.9 \pm 4.0 \mathrm{~mm} / \mathrm{yr}(1 \sigma)$, resolved over the last $13.2 \pm 2.7 \mathrm{ka}(1 \sigma)$. This implies a minimum slip rate of $10.0 \mathrm{~mm} / \mathrm{yr}(1 \sigma)$.

It should be noted that modelled slip rates assume an original soil thickness of $50 \mathrm{~cm}$; I consider this to represent an upper limit on soil thickness, based on observations of soil on adjacent hillslopes. Thinner soil thicknesses would result in higher $\mathrm{N}_{\text {model }}$ for the same input parameters (less soil shielding), which would require a combination of higher slip rates and higher erosion

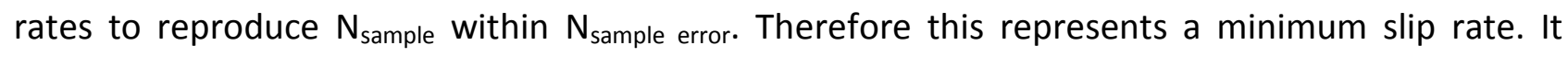
should also be noted that model results assume a homogeneous erosion rate. However, much like samples PNG15-2 and PNG15-4, which were deemed to have experienced additional erosion that resulted in lowering $\mathrm{N}_{\text {sample, }}$ other samples may have also been additionally eroded. If this were the case, $\mathrm{N}_{\text {sample }}$ would be lowered, which would require a combination of higher slip rates and higher erosion rates. Therefore, this represents a minimum slip rate.

Modelled slip rates are at the upper end of slip rates estimated for LANFs globally, e.g., 0.21-0.35 $\mathrm{mm} / \mathrm{yr}$ (Numelin et al., 2007a), $<1 \mathrm{~mm} / \mathrm{yr}$ (Collettini and Holdsworth, 2004), $<1 \mathrm{~mm} / \mathrm{yr}$ (Hayman et al., 2003), 2.4 $\pm 0.3 \mathrm{~mm} / \mathrm{yr}$ (Hreinsdóttir and Bennett, 2009), 2-3.2 mm/yr (Burchfiel et al., 1987), 1.30-1.75 mm/yr (SCHWEIG, 1989), $18 \mathrm{~mm} / \mathrm{yr}$ (Abbott et al., 2001), 20-30 mm/yr (Ring and Reischmann, 2002). Modelled dip-slip rates are slightly faster (statistically distinct at $1 \sigma$ error) than regional GPS velocities, which suggest 7.5-9.6 $\mathrm{mm} / \mathrm{yr}$ of dip-slip if all horizontal extension is resolved onto the $21^{\circ} / \mathrm{N}$ dipping Mai'iu Fault (Wallace et al., 2014). The difference between the slip rate predicted by regional GPS, and the modelled slip rate for the fault based on TCN concentrations, is equal to $0.4-11.5 \mathrm{~mm} / \mathrm{yr}$. However these datasets are almost certainly consistent for $2 \sigma$ errors (which have not been calculated in this thesis due to limits on computational time). The difference in modelled mean slip rates between these two studies may potentially be explained by poorly constrained locking coefficients in the modelling of Wallace et al. (2014), due to the configuration of the campaign GPS network.

While the slip-rate on the Mai'iu Fault may vary along-strike, it is useful to compare the slip rate modelled in this chapter with other estimates obtained from further east. Modelled slip rates are

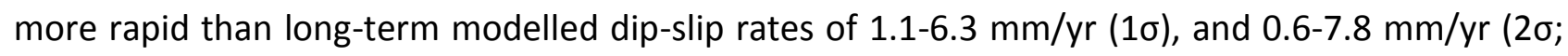


Chapter 3), derived from Monte-Carlo modelling of uplift rates resolved on the Ruaba River (see section 3.5.8.2). However modelled slip rates are consistent with the Quaternary (resolved over the last 8.6-11.0 ka) rate of dip-slip implied by uplift rates $(4.64-5.18 \mathrm{~mm} / \mathrm{yr}$ ) calculated for coral reefs exposed $\sim 50 \mathrm{~km}$ southeast near Siri Siri (Fig. 11) at the western extremity of Goodenough Bay; these unpublished data suggest 9.3-10.4 mm/yr of dip-slip assuming all uplift is accommodated by a $30^{\circ} / \mathrm{N}$ dipping fault (Fitz and Mann, personal communication 2016). These data suggest that the Mai'iu and Gwoira Faults are actively and rapidly slipping between the Gwoira rider block and Siri Siri, with slip rate increasing modestly to the east.

My results may be qualitatively extrapolated to the west, based on patterns of stream geometry (Chapter 3). Active slip on the Mai'iu and Gwoira Faults between Biniguni Falls and the Gwoira rider block is supported by the large map-distance $(\sim 5.5 \mathrm{~km})$ between $\mathrm{k}_{1}$ apices (which represent convex-up parts of streams that drain the SDM to the north; discussed in Chapter 3). This mapdistance decreases in an approximately linear fashion (Fig. 40) to the west from Biniguni Falls ( 5.5 $\mathrm{km}$ ) towards Gorupu Crater ( $1 \mathrm{~km}$ ). Because $k_{1}$ apices are advected to the south with progressive slip on the Mai'iu Fault, shortening of the map-distance between $k_{1}$ apices and the Mai'iu Fault suggests a much slower long-term slip rate on the Mai'iu Fault at Gorupu Crater (this will be discussed further in section 5.4.1). This is consistent with modelling of regional GPS velocities (Wallace et al., 2014), which suggests a westward decrease in the amount of horizontal extension accommodated by the Mai'iu Fault

Due to our low sampling density on the Mai'iu Fault scarp at Biniguni Falls, it is not possible to analyse seismic events based on discontinuities in TCN concentration with down-scarp distance (e.g., Schlagenhauf et al., 2011). It is also not possible to model the magnitude of slip events, due to the low resolution of data. However, the time of last slip on the Mai'iu Fault scarp at Biniguni Falls of at $2.9 \pm 1.4 \mathrm{ka}(1 \sigma)$; slip prior to this time, followed by non-slip is consistent with a seismic event at $2.9 \pm 1.4 \mathrm{ka}(1 \sigma)$. It is also possible that my TCN concentration profile describes another seismic event at $d=39-55 \mathrm{~m}$, which would have occurred at $6.7 \pm 1.0 \mathrm{ka}(1 \sigma)$; however this discontinuity is not statistically distinct given the wide errors in sample TCN concentrations (Fig. 47). The presence of discontinuities in the TCN profile, due to discrete seismic slip events, would be consistent with modelling of seismic coupling by Wallace et al. (2014), which suggest strong seismic coupling on the Mai'iu Fault within the upper $\sim 3-4 \mathrm{~km}$ (although their modelling also showed that it was not particularly sensitive to fault locking coefficients). My modelling results also corroborate other evidence of seismic slip: seismic slip on the inactive Mai'iu Fault is evidenced by pseudotachylite veins that were observed in the immediate fault footwall at Bibitan 
(Fig. 11), which yield ${ }^{40} \mathrm{Ar} /{ }^{39} \mathrm{Ar}$ ages of $1.85 \pm 0.17 \mathrm{Ma}, 2.24 \pm 0.29 \mathrm{Ma}$ (Little et al., 2016); and faulted alluvium that lies against the Gwoira Fault in Nowandowan River, both of which are unconformably overlain by unfaulted alluvium, evidence a discrete seismic event (Fig. 29).

\subsubsection{Modelled Erosion Rates}

Modelled erosion rates of $0.043 \pm 0.025 \mathrm{~mm} / \mathrm{yr}(1 \sigma)$, are at the low end of published erosion rates reported for Papua New Guinea. Simonett (1967) has estimated long-term erosion rates for the Torricelli Mountains, Northwest Papua New Guinea, of 1-1.43 mm/yr for areas of high seismicity, and of $0.230 \mathrm{~mm} / \mathrm{yr}$ for areas of low seismicity. Pain and Bowler (1973) estimate lower long term erosion rates of $0.580-2.200 \mathrm{~mm} / \mathrm{yr}$ for seismically active areas in the Torricelli Mountains and Adelbert Range, Northern Papua New Guinea. Herman et al. (2013) have modelled global erosion rates, based on bedrock thermochronometric ages, for the last $2 \mathrm{Myr}$, and suggest long-term erosion rates of 0.25-3.5 mm/yr for Papua New Guinea. Korup et al. (2007) derive still lower erosion rates from incision of landslides in Central-Northern Papua New Guinea, of 0.06-0.155 $\mathrm{mm} / \mathrm{yr}$. However, it is difficult to compare erosion rates between areas of varying lithology; relatively rapid erosion rates tend to be derived from soft rock, which would be expected to erode more rapidly than the indurated Gorupu Metabasalt.

\subsubsection{Mai'iu Fault Deformation Style}

In order to explain the local presence of Gorupu Metabasalt in the hanging wall of the Mai'iu Fault (Fig. 52), I suggest that a thrust duplex, formed during the Paleogene, has locally resulted in the structural repetition of those units. The evolution of such a thrust duplex is shown in Fig. 56 . Exposure of such thrust imbricates has resulted in the local exposure of Gorupu Metabasalt north of the Mai'iu Fault near Biniguni Falls and Wapon. However, this model does not preclude the possibility that high-angle normal faults also cut the Mai'iu Fault. In fact, structural data at Gorupu Crater are consistent with high-angle antithetic normal faulting. The suggestion that the Owen Stanley Fault does not represent a single thrust suture has been previously suggested by Davies (1980a), who infers that the entire Suckling-Dayman massif represents a thrust sheet that has been emplaced over continental crust of the Papuan Peninsula. 


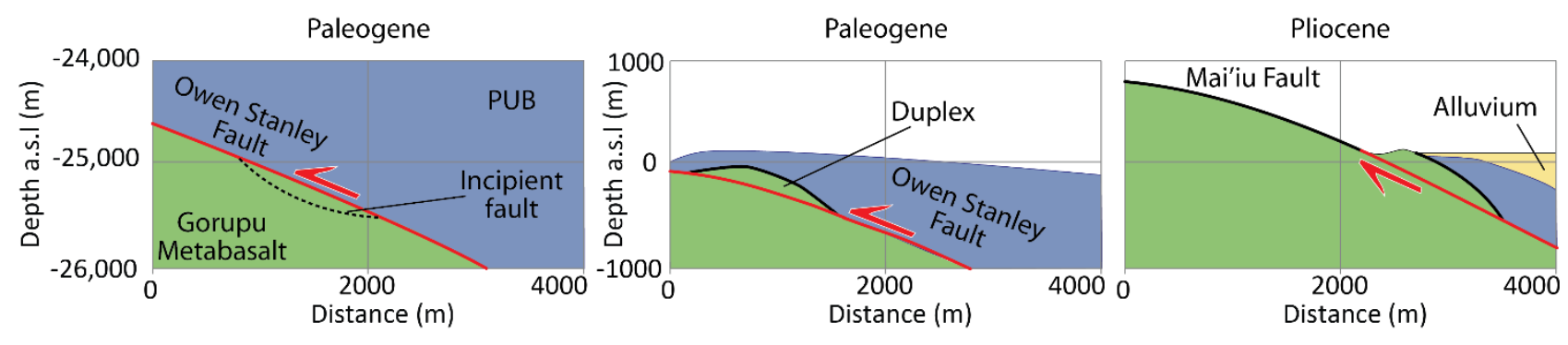

Fig. 56 - Interpretive evolution of the Mai'iu Fault, illustrating the formation of a thrust duplex in the hanging wall of the OSF during the Paleogene. Thrust surfaces are now situated at sea-level in the hanging wall of the Mai'iu Fault near Biniguni Falls and Wapon.

\subsection{Conclusions}

- This chapter has presented modelling of ${ }^{10} \mathrm{Be}$ concentrations from quartz samples obtained from the lowermost scarp of the Mai'iu Fault at Biniguni Falls.

- An up-dip gradient in TCN concentrations indicates that this part of the Mai'iu Fault is actively slipping. Modelling of the scarp TCN concentration profile suggests a rate of dipslip of $13.9 \pm 4.0 \mathrm{~mm} / \mathrm{yr}(1 \sigma)$, (minimum dip-slip rate of $10.0 \mathrm{~mm} / \mathrm{yr} ; 1 \sigma)$, resolved over the last $13.2 \pm 2.7 \mathrm{ka}(1 \sigma)$. Modelled dip-slip rates are slightly more rapid (statistically distinct at $1 \sigma$ error) than slip rates indicated by regional GPS velocities of Wallace et al. (2014), although they almost certainly overlap at $2 \sigma$ (additional model run time would be require to substantiate this).

- Modelling also suggests that the time of last slip on the Mai'iu Fault occurred at $2.9 \pm 1.4 \mathrm{ka}$

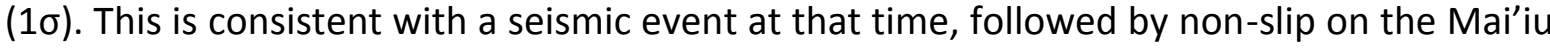
Fault until the present day.

- Modelled erosion rates are $0.043 \pm 0.025 \mathrm{~mm} / \mathrm{yr}(1 \sigma)$; these rates are comparable to the lower end of the range of rates previously reported for Papua New Guinea.

- Exposures of Gorupu Metabasalt north of the Mai'iu Fault do not conform to the present stratigraphic framework for the (extensionally inverted) Owen Stanley Fault. Excepting a revision of the regional stratigraphy of Smith and Davies (1976), these observations require either that high-angle antithetic faults cut the Mai'iu Fault, or that Paleogene thrust duplexes have caused structural stacking of the Gorupu Metabasalt - or both - such that a fault-bounded slice of it now lies above the active LANF. The latter interpretation is more probable in the vicinity of Biniguni Falls and Maneyao, for it accounts for active slip on the Mai'iu Fault. However, structural data at Gorupu Grater are instead consistent with highangle antithetic normal faulting that cross-cuts the Mai'iu Fault. 


\section{Chapter 6: Mohr-Coulomb Modelling of the Mai'iu and Gwoira Faults}

\subsection{Introduction}

In this Chapter, simple Mohr-Coulomb mechanics are used to model the Mai'iu Fault, in order to constrain its frictional strength and explore the processes responsible for LANF abandonment in the near-surface. The frictional and cohesive strength of most LANFs are poorly known, and experimentally determined values of fault friction for individual LANFs are generally derived from a small number of $\mathrm{cm}$-sized gouge samples, with results that are often widely varying (e.g., Niemeijer and Collettini, 2014). Because the frictional properties of LANFs may potentially vary along strike and with structural depth, it is difficult to confidently establish a representative value of LANF frictional strength. Sustained LANF slip requires some combination of: fluid overpressure, a non-Andersonian stress regime, or low fault friction $\left(\mu_{\mathrm{f}}<0.4\right)$; however each of these possible explanations is problematic for various reasons, as discussed below (Collettini, 2011). First, fluid overpressures are improbable in extensional tectonic regimes dominated by a vertical $\sigma_{1}$ orientation (Sibson, 2001), and studies of inactive LANFs suggests that fluid overpressures are unlikely within the near-surface (e.g., Reynolds and Lister, 1987). Second, despite modelling efforts that propose the rotation of $\sigma_{1}$ in response to lower crustal flow (e.g., Westaway, 2002, 2005), there is virtually no geological evidence for a non-vertical regional $\sigma_{1}$ proximal to LANFs (Collettini, 2011). Third, weak minerals, such as talc or smectite, generally do not seem to constitute a major fraction of fault gouges within exposed LANFs (Collettini, 2011); however, it has been suggested that weak minerals may only need to be present in small quantities in order to significantly reduce fault friction (Cannat et al., 2009).

In the case of the Mai'iu Fault, there exist some geological constraints on on-fault fluid pressure and $\sigma_{1}$ orientation. The abundance of long-lived hot and cold water springs along the fault trace (Davies and Smith, 1974; Latter, 1964) is suggestive of hydrostatic fluid pressures. Quartz-calcite mineralisation within faults that cut the Mai'iu Fault footwall may be explained by intermittent attainment of lithostatic stress and hydrofracturing between seismic events. Moreover, outcropscale faulting in the footwall of the Mai'iu Fault (Little et al., 2015) is consistent with a vertical $\sigma_{1}$ orientation - this, coupled with an estimated back-rotation of the Mai'iu Fault of $\sim 10^{\circ}$ based on the microseismicity pattern of Eilon et al. (2015), requires that $\sigma_{1}$ be inclined no more than $10^{\circ}$. This is supported by preliminary results of Merjamo et al. (unpublished data, 2016), who have derived a horizontal-axis paleomagnetic rotation of $\sim 10^{\circ}$ from a suite of oriented Gorupu 
Metabasalt samples. Additionally, preliminary numerical model runs of Ellis (unpublished data, 2016) suggest that $\sigma_{1}$ may be inclined for a weak LANF surface. Thus, given these constraints it is likely that slip on the Mai'iu Fault is enabled by low fault frictional strength. In support of this deduction, the frictional strength of the inactive strand of the Mai'iu Fault has recently been determined to be $0.13 \leq \mu \leq 0.28$ through experimental deformation of gouge obtained from near Bibitan (Little et al., 2015). However there are inherent limitations in interpreting friction values obtained from experimentally deformed fault rocks from LANFs, and extrapolating those findings to the LANF as a whole. Mohr-Coulomb modelling of the LANF surfaces allows frictional strength to be independently constrained; in this way it will be possible to assess whether the findings of Little et al. (2015) are applicable for the inactive Mai'iu Fault as a whole, for the active Mai'iu Fault, and for the Gwoira Fault. This will aid interpretation of the mechanism by which the Mai'iu Fault continues to slip.

Choi and Buck (2012) have produced a framework for assessing the strength characteristics of a LANF in terms of simple Mohr-Coulomb mechanics, given the presence of a rider block. It is generally assumed that LANF abandonment in the near-surface ('partial abandonment') results in rider block formation (Choi and Buck, 2012). Rider blocks (discussed in previous Chapters) form when a LANF locks up in the near surface above some abandonment depth in response to LANF back-rotation. The presence of a rider block imposes a lower limit on LANF strength, because an extremely weak LANF will remain active despite severe misorientation. Thus the geometry of the Gwoira rider block may be used to place constraints of the strength of the Mai'iu Fault (Choi and Buck, 2012; Choi et al., 2013). It may be that the absence of rider blocks elsewhere on the Suckling-Dayman massif is a consequence of lower fault friction, or a more steeply-dipping welloriented fault geometry (Reston and Ranero, 2011).

In the interests of efficiency and readability, detailed methodologies detailing modelling of the active Mai'iu Fault geometry, and LANF abandonment in terms of Mohr-Coulomb mechanics, have been relegated to Appendices $B$ and $C$. 


\begin{tabular}{|c|c|c|}
\hline Symbol & Quantity & Units \\
\hline$z$ & Depth. & $\mathrm{m}$ \\
\hline$\sigma_{1}$ & Greatest principle stress. & $\mathrm{MPa}$ \\
\hline$\sigma_{\mathrm{V}}$ & Vertical stress. & $\mathrm{MPa}$ \\
\hline$\sigma_{n}^{\prime}$ & Effective normal stress. & $\mathrm{MPa}$ \\
\hline$\theta$ & Angle between fault plane and the $\sigma_{1}$ direction. & degrees \\
\hline$\lambda$ & Pore fluid factor. & - \\
\hline$P_{f}$ & Fluid pressure. & $\mathrm{MPa}$ \\
\hline$\mu$ & Coefficient of internal friction. & none \\
\hline$\mu_{\mathrm{f}}$ & Coefficient of friction (fault). & none \\
\hline$\mu_{\mathrm{c}}$ & Coefficient of friction (crust). & none \\
\hline$C_{f}$ & Fault cohesive strength. & $\mathrm{MPa}$ \\
\hline $\mathrm{Cc}$ & Crustal cohesive strength. & $\mathrm{MPa}$ \\
\hline$\sigma_{\text {diff }}$ & Differential stress. & $\mathrm{MPa}$ \\
\hline$\sigma_{\text {diff LANF }}$ & Differential stress required to reactivate a LANF. & $\mathrm{MPa}$ \\
\hline$\sigma_{\text {diff crust }}$ & Differential stress required to cut intact crust. & $\mathrm{MPa}$ \\
\hline $\int \sigma_{\text {diff }}$ & $\begin{array}{l}\text { The area between } \sigma_{\text {diff LANF }}(\mathrm{z}) \text {, and } \sigma_{\text {diff crust }}(\mathrm{z}) \text {, where } \sigma_{\text {diff LANF }}-\sigma \text { diff } \\
\text { crust } \\
\text { defined as positive. } \int \sigma d i f f>0 \text { results in LANF partial abandonment. }\end{array}$ & $\mathrm{MPa}$ \\
\hline$d_{c}$ & The cross-over depth. This is the greatest depth for which $\sigma_{\text {diff LANF }}=\sigma_{\text {diff crust }}$. & $\mathrm{m}$ \\
\hline$\theta_{\mathrm{i}}$ & Fault $\theta$, at a particular depth, at the time of LANF abandonment. & degrees \\
\hline$\theta_{f}$ & Fault $\theta$, at a particular depth, at the present day. & degrees \\
\hline$f(z)$ & $\begin{array}{l}\text { Fault rotation coefficient, which varies linearly between some maximum value at } \\
\text { the surface, and } f(z)=0 \text { at depth } d_{0} \text {. This quantity controls the magnitude of fault } \\
\text { rotation at each depth. } f(z)=0 \text { implies zero fault rotation at all depths, while } f(z)>0 \\
\text { results in some finite amount of fault rotation at depths shallower than } d_{0}\end{array}$ & - \\
\hline$\theta_{\text {ideal }}$ & Optimum $\theta$ for a fault with the same frictional properties as the LANF. & degrees \\
\hline$\theta_{\text {scale }}$ & An arbitrary constant (here set to $45^{\circ}$, equal to the dip of Gwoira Fault). & degrees \\
\hline $\mathrm{d}_{0}$ & The depth at which $f(z)$ approaches zero. & $\mathrm{m}$ \\
\hline
\end{tabular}

Table $10-$ Table of quantities used in this chapter. See text for further explanation.

\subsubsection{The Frictional Strength of LANFs}

Globally, fault friction has been experimentally determined for very few LANFs, and reported friction values vary widely even for individual LANFs. Numelin et al. (2007b) have determined through experimental deformation of fault gouge obtained from a LANF located in Panamint Valley, California, that LANF friction is generally confined to $0.6 \leq \mu \leq 0.7$ for most samples tested, although samples with $\geq 50 \%$ clay content were $0.2 \leq \mu \leq 0.4$. Additionally, Smith and Faulkner (2010), and Niemeijer and Collettini (2014) have produced a broad range of fault friction values $(0.25 \leq \mu \leq 0.8)$ from experimental deformation of fault gouges obtained from the Zuccale LANF, Italy, although fluid-saturated gouge and talc and chlorite phyllonites (up to $70 \%$ talc) were characterised by $\mu \leq 0.40$. Smith and Faulkner (2010) speculate that weaker, clay-bearing fault 
gouges may enable LANF slip at depths shallower than $2 \mathrm{~km}$, and Niemeijer and Collettini (2014) ascribe the variability in LANF friction to the presence of strong, quartz-calcite dominate clasts within the talc-calcite dominated matrix.

The frictional strength of the inactive strand of the Mai'iu Fault has recently been determined through experimental deformation of gouge obtained from near Bibitan (Little et al., 2015). Gouge samples comprise $50-65 \%$ corrensite/saponite, and were experimentally deformed at $\sigma_{n}{ }_{n}=30-120$ $\mathrm{MPa}$ and $50-200^{\circ} \mathrm{C}$. The results constrain fault friction for the samples to $0.13 \leq \mu \leq 0.28$ (Little et al., 2015), which falls within the range of experimentally determined friction values for other global LANFs described above. However, this experimental data are reflective only of the inactive Mai'iu Fault beneath the Gwoira rider block - it is not known whether this range of values is representative of other positions on the Mai'iu Fault, or what friction value might be representative of the fault as a whole. It is possible that the remainder of the Mai'iu Fault (that does not form rider blocks) has different strength characteristics.

The frictional strength of the Mai'iu Fault has also been previously modelled using extensional wedge theory (Spencer, 2011), who finds that this particular LANF is best described by $0.13 \leq \mu \leq 0.27$ (Fig. 57). Extensional wedge modelling is based on Mohr-Coulomb mechanics, but in contrast to the more thorough approach of Choi and Buck (2012), this methodology represents a LANF as a simple planar surface that dips at a uniform angle equal to the dip at the fault trace. This modelled planar fault is overlain by a modelled equilibrium extensional wedge, the surface taper of which is estimated from local topography (Xiao et al., 1991). Spencer (2011) also assumes that the Mai'iu Fault is everywhere active at the surface and that dips observed at the lower-most fault scarp $\left(16-24^{\circ} / N\right)$ are also representative of the entire LANF surface at depth. The latter assumption is inconsistent with the microseismicity pattern described by Eilon et al. (2015). Moreover, this model arbitrarily assumes a weak hanging wall friction angle of $10^{\circ}$ more than the fault friction angle. The lower frictional values reported are certainly spurious, because the shallower dip measurements incorporated are derived from the inactive Mai'iu Fault, which has a complex geometry, and is inactive and so cannot be modelled as an equilibrium wedge. Excluding fault dip angles for the inactive Mai'iu Fault from the analysis of Spencer (2011) yields a narrower range of $0.19 \leq \mu \leq 0.27$ for the Mai'iu Fault based on critical wedge theory; however, it is necessary to advance this model by better accounting for fault LANF geometry at depth, and by differentiating between active and inactive LANF strands. 


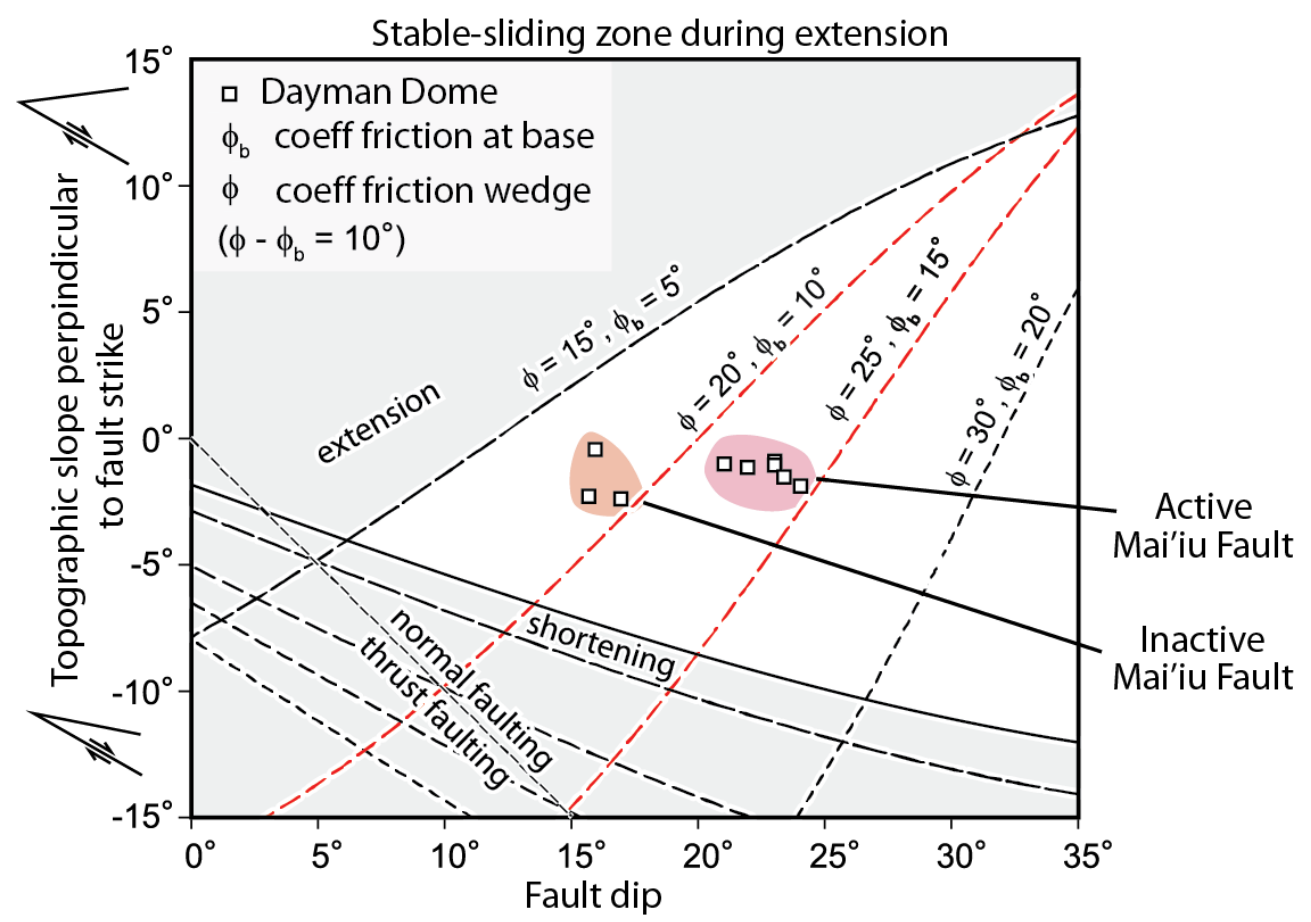

Fig. 57 - The results of extensional wedge modelling of Mai'iu Fault, simplified after Spencer (2011). Fault dips for the inactive Mai'iu Fault fall are $16-17^{\circ} / \mathrm{N}$, while those for the active Mai'iu Fault are $21-24^{\circ} / \mathrm{N}$. Topographic slopes for both faults are $2.5-1 \% \mathrm{~N}$ - note illustrations clarifying the slope direction for positive and negative topographic slopes. Modelled fault friction for the active Mai'iu Fault is bounded by $0.19 \leq \mu \leq 0.27$.

\subsection{Methodology}

I assess the strength of the Mai'iu Fault according to the framework of Choi and Buck (2012). The numerical details of Mohr-Coulomb modelling are explained in Appendix C. As discussed in Chapter 1, calculations are made in terms of Mohr-Coulomb mechanics, such that fault lock-up orientation at any particular position on the fault is a function of fault friction $\left(\mu_{f}\right)$ and crustal friction $\left(\mu_{c}\right)$, fault cohesion $\left(C_{f}\right)$, crustal cohesion $\left(C_{c}\right)$. It is also a function of $\theta, P_{f}$, depth, and $\sigma_{1}$ orientation (see Table 1 for explanation of quantities; Choi and Buck, 2012; Choi et al., 2013). Abandonment of part of a LANF is controlled by the sign of $\int \sigma_{\text {diff }}-$ this quantity is the difference between the depth-integrated differential stress $\left(\sigma_{\text {diff }}\right)$ required for continued slip on the curved LANF ( $\sigma_{\text {diff LANF }}$ ) of varying local orientation $\theta$, and the depth-integrated differential stress ( $\left.\sigma_{\text {diff crust }}\right)$ required to abandon part of the LANF by initiating a new planar fault that cuts through previously intact, homogeneous crust (Table 10, Fig. 58), (Choi and Buck, 2012). This new fault is generally assumed to cut the hanging wall as a synthetic fault, and to form a rider block (Choi and Buck, 2012; Reston and Ranero, 2011). $\int \sigma_{\text {diff }}$ is computed above some cross-over depth ( $d_{c} ;$ Table 10; Fig. 58 ) - this is the shallowest point on the LANF at which $\sigma_{\text {diff crust }}$ equals $\sigma_{\text {diff LANF }}$ (Choi and Buck, 2012; Nur et al., 1986) - that is, the difference between $\sigma_{\text {diff crust }}$ and $\sigma_{\text {diff LANF }}$ is integrated over the depth interval above their lowermost intersection, or 'intersection point'. If $\int \sigma_{\text {diff }}$ is positive, then 
LANF abandonment (rider block abandonment) occurs upward of depth $d_{c}$, and a new ideally oriented fault forms at depth $d_{c}$, potentially forming a rider block. This defines the condition for abandonment of the shallowest portion of the LANF, and resultant rider block formation.

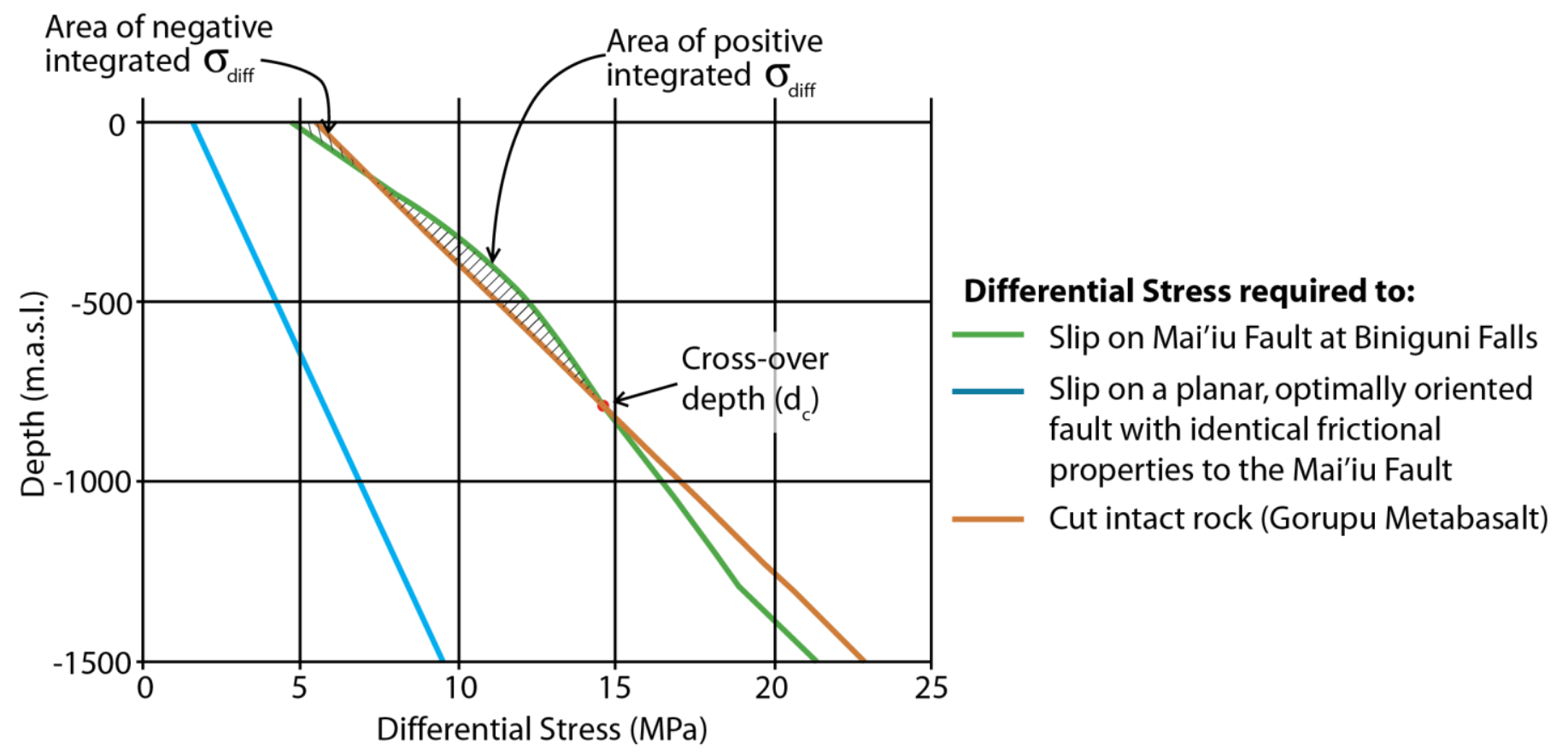

Fig. 58 - Cartoon illustrating the $\sigma_{\text {diff }}$ resolved on a LANF at the time of near-surface abandonment. I compare the $\sigma_{\text {diff }}$ required for slip on the Mai'iu Fault (green line) with $\sigma_{\text {diff }}$ required to fracture intact rock (orange line). If these two curves cross (i.e. there is some depth for which it is easier to cut a new fault than to continue slipping on the LANF), I integrate the area enclosed between the curves up-dip of the intersection point. Parts of the LANF surface may only abandoned if the integral $\left(\int \sigma_{\text {diff }}\right)$ is positive over some depth range; if this condition is met, then the LANF is abandoned above depth $d_{c}$, resulting in LANF 'partial abandonment'. Note that $\int \sigma_{\text {diff }}$ sums to zero for the special case where the fault abandonment criteria has been precisely attained. Also note the magnitude of $\sigma_{\text {diff }}$ required for slip on a planar, optimally oriented fault with $\mu_{\mathrm{f}}$ identical to the Mai'iu Fault (blue line).

Because $C_{c}$ for both the hanging wall and footwall lithologies is not well known, I treat $C_{c}$ as a free variable, and plot results in terms of $\mu_{f}$ and $C_{f}$ for a range of $C_{c}$ inputs. Because $\mu_{f}$ and $C_{f}$ are both unknown, $\mu_{f}$ may only be constrained by making an assumption regarding the magnitude of $C_{f} . I$ infer a maximum permissible fault cohesion value of $C_{f} \leq 1.8 \mathrm{MPa}$, based on the upper limit of gouge cohesive strength as described by Jeanne et al. (2012). The strengths of the active Mai'iu Fault, inactive Mai'iu Fault, and Gwoira Fault are assumed to be identical, and $\mu_{f}, \mu_{c}, C_{f}$, and $C_{c}$ in general are not allowed to vary with depth. In general I assume that $\sigma_{1}=\sigma_{V}, \lambda=0.4 P_{f}$, and $\mu_{c}=0.65$ (see Table 10). In order to determine whether the LANF continues to slip, or whether it locks up over some depth interval, I compute $\sigma_{\text {diff LANF }}$ at $50 \mathrm{~m}$ depth intervals, to a maximum depth of $4 \mathrm{~km}$ - thus I do not consider scenarios where $d_{c}>4 \mathrm{~km}$. I resolve stresses onto a modelled fault 
geometry. The modelled active Mai'iu Fault surface is convex-up in shape, and with surface dips $\left(21^{\circ} / \mathrm{N}\right)$ equal to those observed in the field, and dips at depth calculated after the method of Choi and Buck (2012) based on an assumption of maximum curvature (see Appendix B). The inactive Mai'iu Fault surface was modelled using LeapFrog Geo, based on the preserved fault dip-slope surfaces (see Chapter 3). The Gwoira Fault was set at a planar dip of $45^{\circ} / \mathrm{N}$, as is constrained by field observations made north of Mt Gwoira.

For simplicity, I ignore the component of $\sigma_{v}$ due to surface topography above sea level. In general this component of overburden is very small, because only the topography of the LANF hanging wall will be resolved on the fault. As such, the significant topography of the Mai'iu and Gwoira Fault footwalls does not influence the mechanics of the active LANF. Hanging wall overburden is equivalent to $\sim 1 \mathrm{MPa}$ at the Mai'iu Fault trace, and tapering to zero at sea-level. Because paleotopography at the time of the abandonment of the inactive Mai'iu Fault is unknown, an assumption of zero topography is probably fair. Additionally, based on our limited knowledge of LANF geometry at depth, I only model the fault to a maximum depth of $4 \mathrm{~km}$, unless otherwise stated - therefore I do not capture possible fault abandonment processes at greater depth. However this is not problematic, because, due to the curved geometry of the Mai'iu Fault, model runs where the LANF is viable at depth generally result in LANF abandonment in the upper $2 \mathrm{~km}$.

\subsection{Results}

\subsubsection{Strength of the Active Gwoira-Mai'iu Fault Surface}

I model the strength of the active Gwoira-Mai'iu Fault surface. In this modelling exercise, acceptable model outputs are those that successfully predict active and continuing LANF slip (nonabandonment) at all depths on the currently active fault. The modelled section passes $\sim \mathrm{N}-\mathrm{S}$ through Mt Gwoira, through the deepest part of the Gwoira embayment. I plot lines of critical stability, which represent the maximum fault strength conditions $\left(\mu_{f}, C_{f}\right)$ at which the LANF may remain active for the modelled fault geometry (Fig. 59). I assume an upper limit of plausible hanging wall cohesion for the Gwoira Conglomerate of $\mathrm{C}_{\mathrm{c}}=5 \mathrm{MPa}$, based on in situ block shear tests of two Jurassic-Cretaceous sandy conglomerates (Cai et al., 2004; Maejima et al., 2003). Fault frictional strength on the active fault must be $0.128 \leq \mu_{\mathrm{f}} \leq 0.265$ for $\mathrm{C}_{\mathrm{f}}<1.8 \mathrm{MPa}$. The lower bound of this range may be increased if $C_{f}$ is less than $1.8 \mathrm{MPa}$; although $C_{f}$ of fault gouge may be up to 1.8 MPa (Jeanne et al., 2012), it is generally less than 0.5 MPa (e.g., Bos et al., 2000; Niemeijer and Spiers, 2005; Yasuhara et al., 2005). $\mathrm{C}_{\mathrm{f}} \leq 0.5 \mathrm{MPa}$ would imply $\mu_{\mathrm{f}} \geq 0.2$. 
However for a more complex model, in which $C_{c}$ is allowed to increase linearly with depth at a rate of $0.6 \mathrm{MPa} / \mathrm{km}$, a moderately stronger LANF $\left(\mu_{\mathrm{f}} \leq 0.277\right)$ is predicted. If one allows stresses to be slightly non-Andersonian, with a $\sigma_{1}$ that plunges $5^{\circ} / \mathrm{S}$, then a stronger fault friction of $\mu_{\mathrm{f}} \leq 0.372$ is predicted.
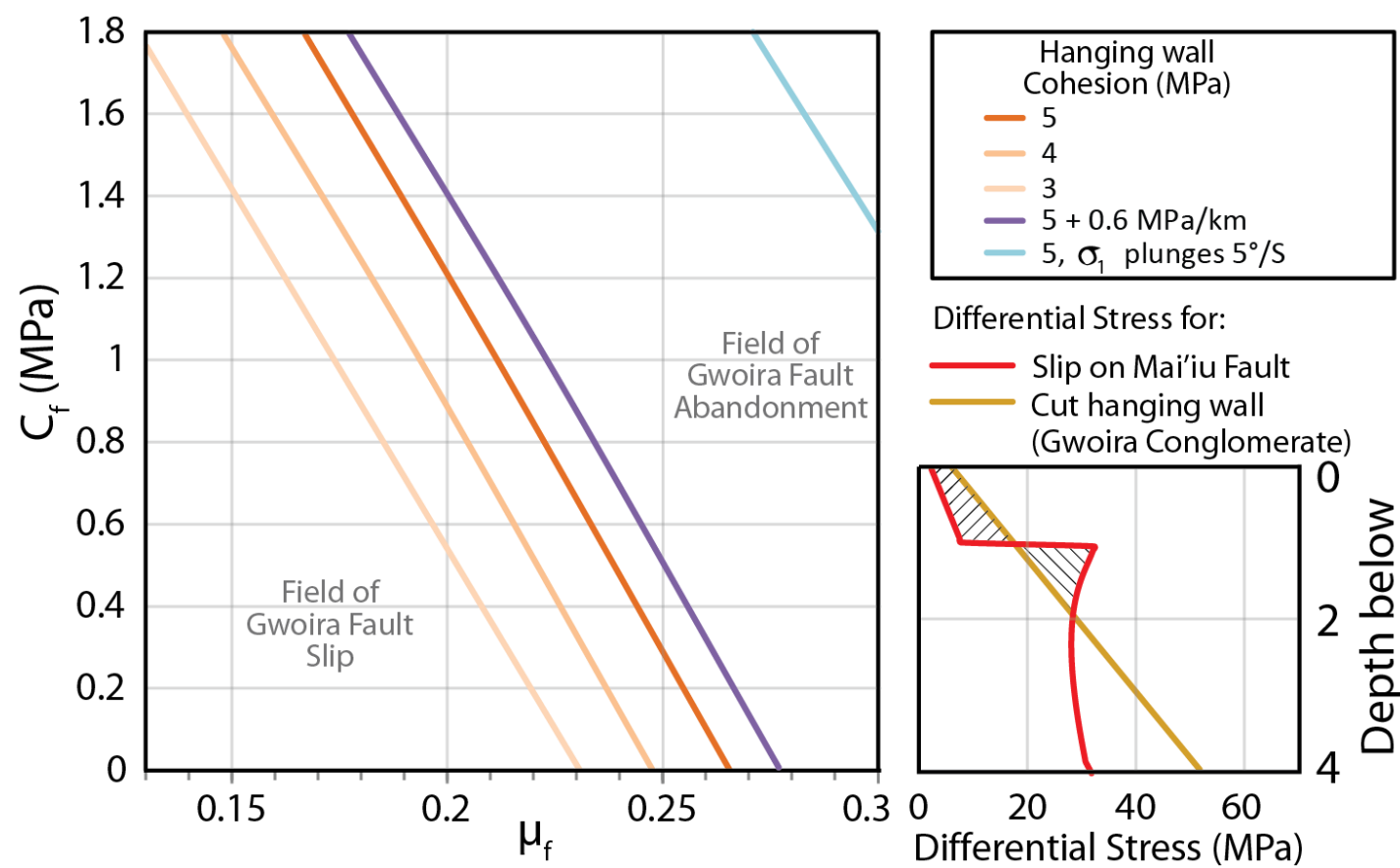

Differential Stress for:
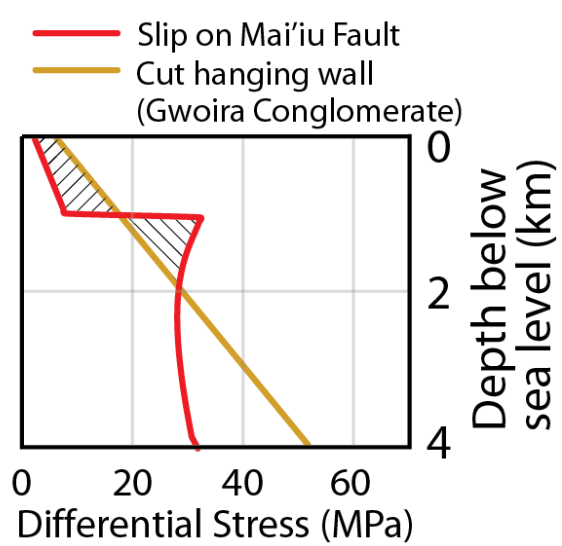

Fig. 59 - Plot of modelled fault cohesion $\left(C_{f}\right)$ and fault friction $\left(\mu_{f}\right)$ for the active Gwoira-Mai'iu Fault surface. Main plot: coloured lines divide fields of Gwoira-Mai'iu Fault slip to the left, from fields of Gwoira-Mai'iu Fault abandonment to the right, for a certain set of conditions (see legend). Because field observations indicate that the Gwoira Fault is active, the strength of the LANF must lie to the left of the line for a particular value of hanging wall cohesion $\left(\mathrm{C}_{c}\right)$. For an Andersonian stress field $\left(\sigma_{\mathrm{v}}=\sigma_{1}\right)$ and vertically invariant hanging wall cohesion of $\leq 5 \mathrm{MPa}$, the Mai'iu Fault must have a friction coefficient that is between $0.128-0.265$. The lower bound of this range may be increased if $C_{f}$ is less than $1.8 \mathrm{MPa}$ (see text for details).

\subsubsection{Strength of the Inactive Mai'iu Fault Surface}

I also apply this model to an experiment in which the currently inactive part of the Mai'iu Fault surface is retro-deformed, assuming a chronology of progressive shallowing of the inactive Mai'iu Fault, which ultimately led to its abandonment in favour of the more northern, planar, steeply dipping, and active Gwoira Fault (this chronology is described in Chapter 4). In this way it is possible to estimate of strength of the inactive LANF strand, given an acceptable range of possible LANF geometries at the time of abandonment. The spatial distribution of back-tilting within the Gwoira embayment is only broadly constrained (Chapter 3); therefore I approximate back-rotation of the inactive Mai'iu Fault using a simple model in which back-rotation varies linearly as a function of depth (Fig. 60), above some depth on non-rotation. The inferred amount of fault rotation $\left(\theta_{f}-\theta_{i}\right)$ decreases with increasing depth, above a depth of zero rotation $\left(d_{0}\right)$ at the depth 
at which the Mai'iu Fault is thought to become planar (Fig. 60b), dipping $31^{\circ} / \mathrm{N}$ in accordance with the observed microseismicity alignment of Eilon et al. (2015). The amount of fault rotation is calculated in $50 \mathrm{~m}$ depth increments. The modelled retro-deformed fault geometry is calculated in terms of the fault orientation at the time of abandonment $\left(\theta_{i}\right)$, where $\theta_{i}=\theta_{f}+f(z) \cdot\left(-\theta_{\text {scale }}\right)$. $\theta_{f}$ represents the present fault geometry with respect to the $\sigma_{1}$ direction. The decreasing fault rotation with increased depth is parameterised as the coefficient $f(z)$, which varies linearly between some maximum value at $d_{0}$. The quantity $\theta_{\text {scale }}$ is an arbitrary value, here set to $45^{\circ}$ (equal to the dip of Gwoira Fault). Values of $f(z)>0.6$ are unlikely, as these result in a surface fault dip of $>65^{\circ}$. Furthermore, I constrain a range of possible $f(z)$ values based on the back-tilting of the Gwoira Conglomerate - this is discussed below. While none of these retro-deformed geometries likely correspond to the true shape of the Mai'iu Fault at abandonment, they are reasonable, and allow some broad constraints to be placed on fault strength at the time of abandonment.

Models simulate an additional overburden for the now inactive Mai'iu Fault at the time of abandonment. This is based on projection of lower SP2 beds up-dip, towards the Gwoira Fault; this indicates a paleo-overburden of $\sim 3400 \mathrm{~m}$ at the point where the Gwoira Fault splays upwards from the Mai'iu Fault, assuming lower SP2 strata were oriented horizontally at the time of initiation of slip on the Gwoira Fault. In these experiments I model the fault to a maximum depth of $5.55 \mathrm{~km}$; this greater depth ensures that $\int \sigma_{\text {diff }}$ is not positive at the base of the modelled fault for fault abandonment condition. 


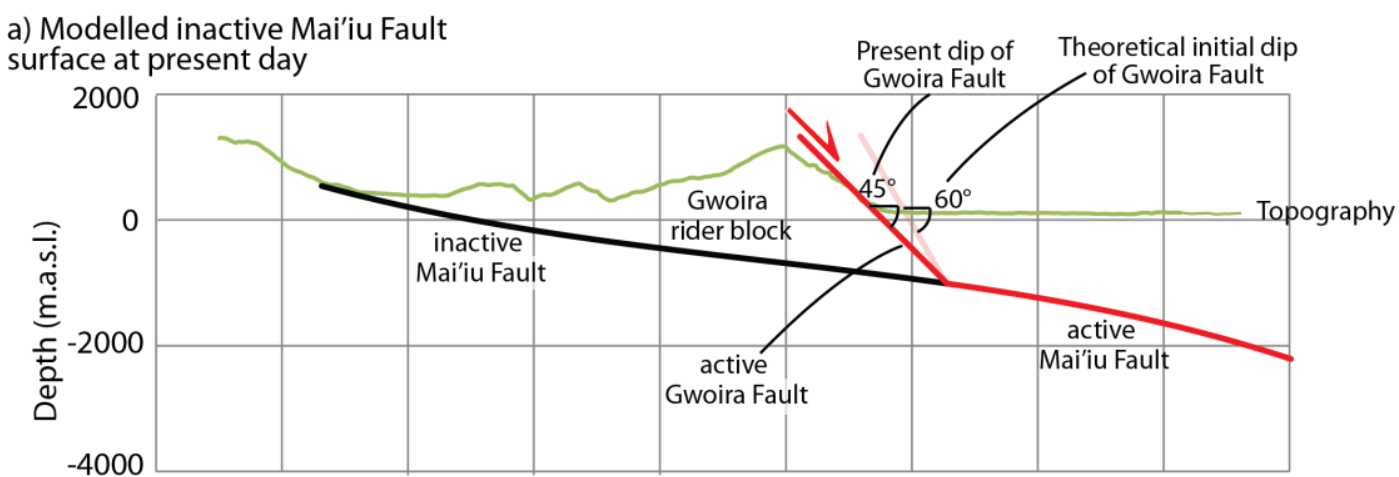

b) Modelled inactive Mai'iu and Gwoira Fault profiles immeditely prior to abandonment of the former, in favour of slip on the latter

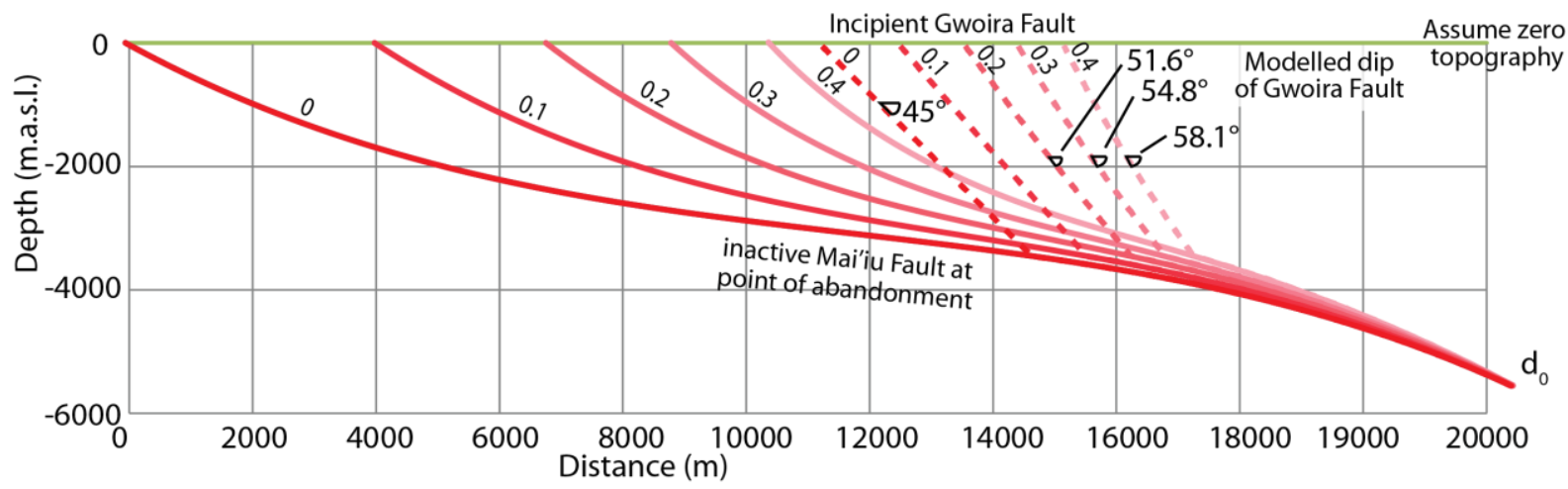

Fig. 60 - a) Modelled geometry of the inactive Mai'iu Fault at the present day. The LANF surface, modelled using Leapfrog Geo in Chapter 3, is approximated by a cubic polynomial. b) A range of possible modelled retro-deformed fault geometries for the inactive Mai'iu Fault at the time of abandonment - labels indicate the magnitude of the scaling coefficient $f(z)$. Over time the Mai'iu Fault profile is assumed to shallow in dip linearly as a function of depth (parameterised by the coefficient $f(z)$ - see text for details). Note the dip angle of the modelled Gwoira Fault, measured at the same point now exposed at the surface. Models run with $f(z)=0.4$ are preferred, because they produce a dip angle for the Gwoira Fault that is approximately equal to that of an ideally dipping normal fault (discussed in text). Models were not run for $f(z)>0.4$, because they produce dips for the Gwoira Fault that exceed $60^{\circ}$.

Results of this modelling exercise (Fig. 61) suggest that for $C_{c} \leq 5 \mathrm{MPa}$ (Cai et al., 2004), LANF frictional strength is limited to $\mu_{\mathrm{f}} \leq 0.309$. However a stronger LANF is permissible $\left(\mu_{\mathrm{f}} 0.389\right)$ for the case of a non-Andersonian stress field in which $\sigma_{v}$ dips $5 \%$. Additionally, it is possible to further constrain these results through assessment of how well each model run reproduces the geometry of the Gwoira Fault at the time of abandonment of the inactive Mai'iu Fault. I assume that the Gwoira Fault initiated at an ideal dip angle of $60^{\circ}$, and has since been back-rotated by between 13$23^{\circ}$ (Chapter 3 ). Therefore the preferred retro-deformed model runs are those run for $f(z)=0.4$, yield an initial dip angle for the Gwoira Fault of $58.1^{\circ}$, measured at the same point now exposed at the surface. I discard model runs with $f(z)>0.4$, because they produce unrealistic dips for the Gwoira Fault of $>60^{\circ}$. Models run for $f(z)=0.4$ suggest that $\mu_{f}$ is between $0.26-0.309$ (Fig. 61). This bound is narrowed to $0.3 \leq \mu_{\mathrm{f}} \leq 0.309$ for $\mathrm{C}_{\mathrm{f}} \leq 0.5 \mathrm{MPa}$. Further refinement of values based on the overlap of the results of experimental deformation of fault gouge $(0.13 \leq \mu \leq 0.28)$ obtained from the 
inactive Mai'iu Fault (Little et al., 2015) suggests that fault friction for the inactive Mai'iu Fault are $0.26 \leq \mu_{\mathrm{f}} \leq 0.28$.

Models do not correctly predict the abandonment depth $d_{c}$ of the inactive Mai'iu Fault, which I estimate to be equal to $3400 \mathrm{~m}$. This may be because the model is highly sensitive to the choice of $d_{0}$ (i.e., a shallower choice of $d_{0}$ yields weaker fault friction estimates). I presently assume that $d_{0}$ is located at the projected top of the planar seismicity zone of Eilon et al. (2015); however, microseismicity does not constrain the shape of the Mai'iu Fault above 11 km depth (Fig. 12). This has not been explored fully.

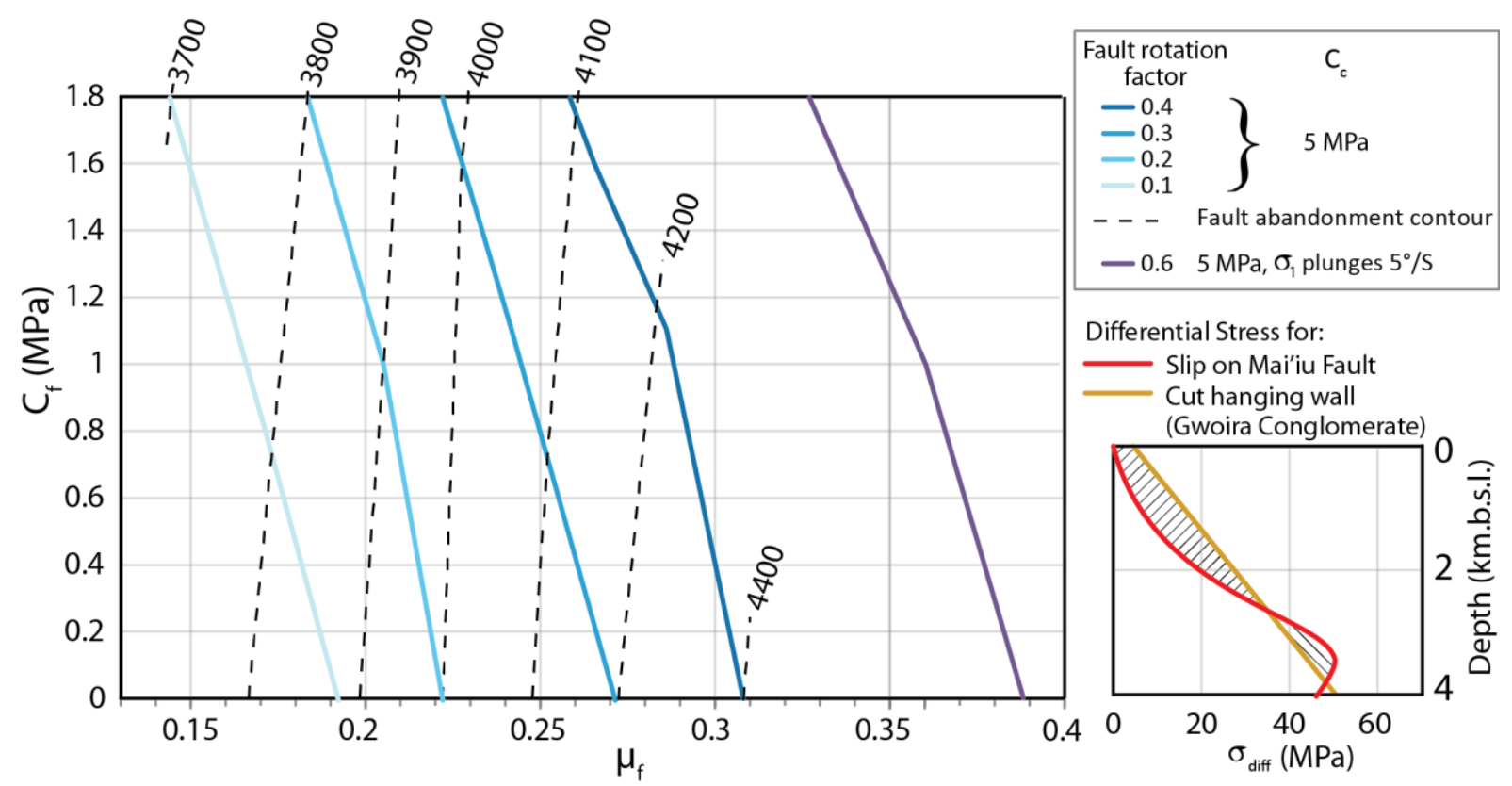

Fig. 61 - Plot of critical fault abandonment conditions. In this model I retro-deform the inactive Mai'iu Fault by an amount stipulated by a fault rotation coefficient $f(z)$, (see text for details). Each line separates a field of LANF abandonment (and consequent rider block formation) on the right, from continued LANF slip on the left. Lines therefore represent critical conditions at which the modelled retro-deformed fault locks up, and the strength of the inactive Mai'iu Fault lies on a line for a given $\mathrm{f}(\mathrm{z})$. Modelled fault friction is $\mu_{\mathrm{f}} \leq 0.309$ for $\mathrm{C}_{\mathrm{c}}=5 \mathrm{MPa}$ and Andersonian stresses. $\mu_{\mathrm{f}}$ is $\leq 0.39$ for $\mathrm{C}_{\mathrm{c}}=5 \mathrm{MPa}$ and a $5^{\circ} / \mathrm{S}$ dipping $\sigma_{\mathrm{v}}$. Note fault abandonment contours, which indicate that the fault is abandoned at greater depth for higher $\mu_{\mathrm{f}}$. For my preferred model run of $f(z)=0.4$ (see text), $\mu_{f}$ must be between $0.26-0.309$ for $C_{f} \leq 1.8 \mathrm{MPa}$. This bound is reduced to $0.3 \leq \mu_{\mathrm{f}} \leq 0.309$ for $\mathrm{C}_{\mathrm{f}} \leq 0.5 \mathrm{MPa}$. Model are run for Andersonian stresses unless otherwise specified; I assume hydrostatic $P_{f}$; and $\mu_{c}=0.65$.

\subsubsection{Strength of the Active Mai'iu Fault at Biniguni Falls}

In this section I describe modelling of the strength of the active Mai'iu Fault at Biniguni Falls (Fig. 52) based on its observed geometry and known continued activity. Based on TCN exposure dating (Chapter 5), the active Mai'iu Fault must be slipping in the near-surface. However, widespread outcrop scale faulting of this fault's footwall requires some explanation. I model the geometry of 
the active Mai'iu Fault based on an assumption of constant fault curvature, after Choi and Buck (2012), and constrained at depth by the $31^{\circ} / \mathrm{N}$ dipping alignment of microseismicity described by Eilon et al. (2015). This suggests that rocks exposed at the active Mai'iu Fault trace at Biniguni Falls, which are currently dipping $21-23^{\circ} / \mathrm{N}$ at the surface, have been back-rotated $\sim 10^{\circ}$ through flexural footwall back-rotation as they were exhumed.
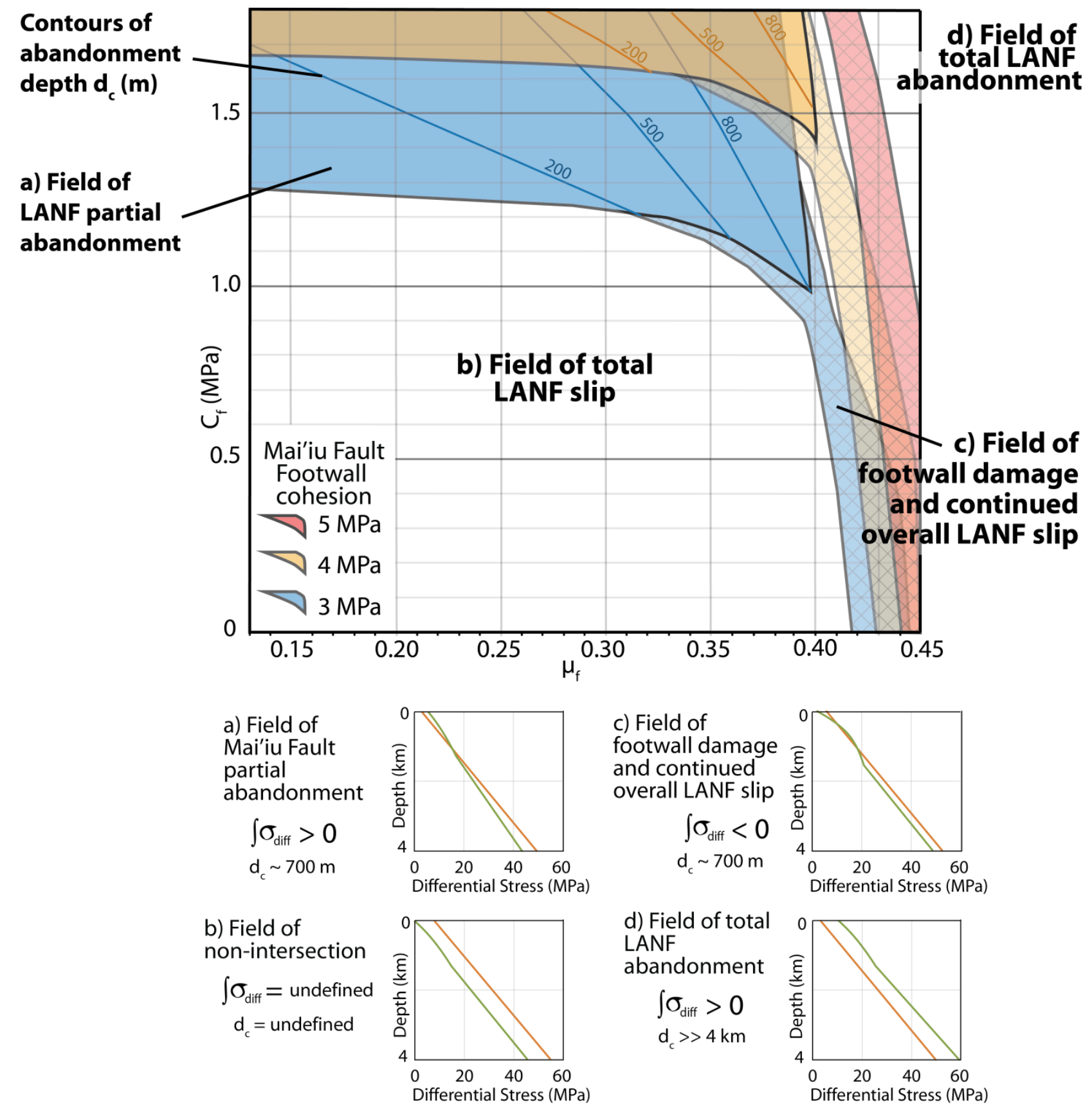

Fig. 62 - The results of Mohr-Coulomb modelling of the active Mai'iu Fault at Biniguni Falls. Shaded areas (field $a$ ) define, for a particular $C_{c}$, stability fields of LANF partial abandonment, where sustained LANF slip (non-abandonment) at depth is accompanied by abandonment at some depth. Contours represent LANF partial abandonment depth in metres. Field $b$ represents the field of LANF slip at all depths. Cross-hatched areas (field $c$ ) define stability fields for overall LANF slip at all depths, with local LANF misorientation ('footwall damage'; discussed below). Field $d$ represents the field of LANF abandonment at all depths. Plots a)-d) - illustration of $\sigma_{\text {diff LANF }}$ (green) and $\sigma_{\text {diff crust }}$ (orange) conditions for fields a)-d). Plots represent $\sigma_{\text {diff }}$ conditions for each scenario, plotted for an example where $d_{c} \sim 700 \mathrm{~m}$. Only field $\mathrm{c}$ is permissible for $\mathrm{C}_{\mathrm{f}}<0.5$ $\mathrm{MPa}$, which would imply $\mu_{\mathrm{f}} \geq 0.409$. 
Modelling results (Fig. 62) suggest that there are four possible conditions that may characterise any particular LANF: the LANF may be partially abandoned in the near-surface (field $a$ ); it may be slipping at all depths (field $b$ ); it may be slipping at the scale of the entire fault, but with the wall rocks locally being at yield in some places above $d_{c}$ (field $c$ ); or the entire LANF may be non-viable and abandoned (field $d$ ). The physical manifestations of these four scenarios are illustrated in Fig. 63. The modelled strength of the active Mai'iu Fault depends on which field is interpreted to best describe the active Mai'iu Fault at Biniguni Falls.

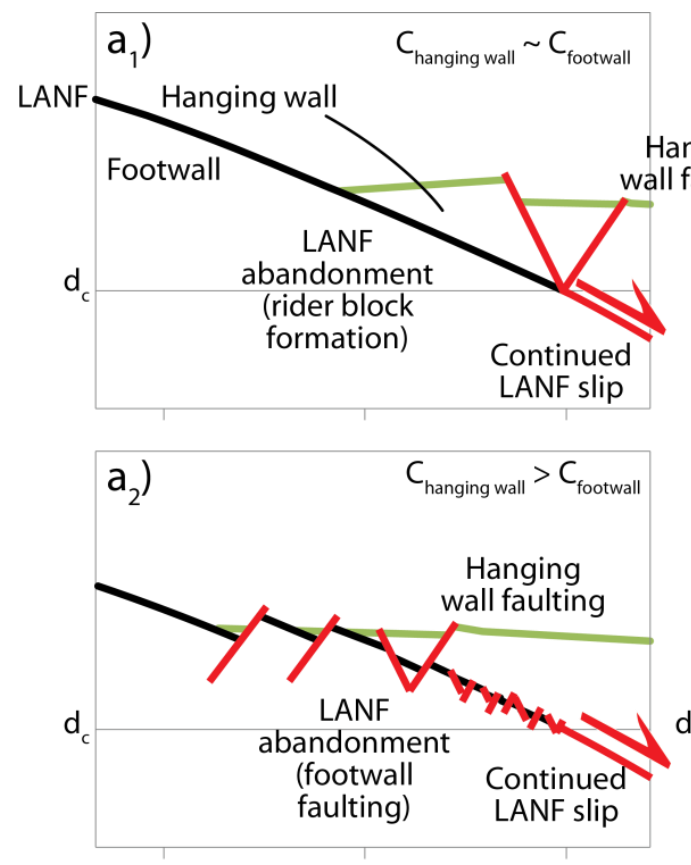

b)
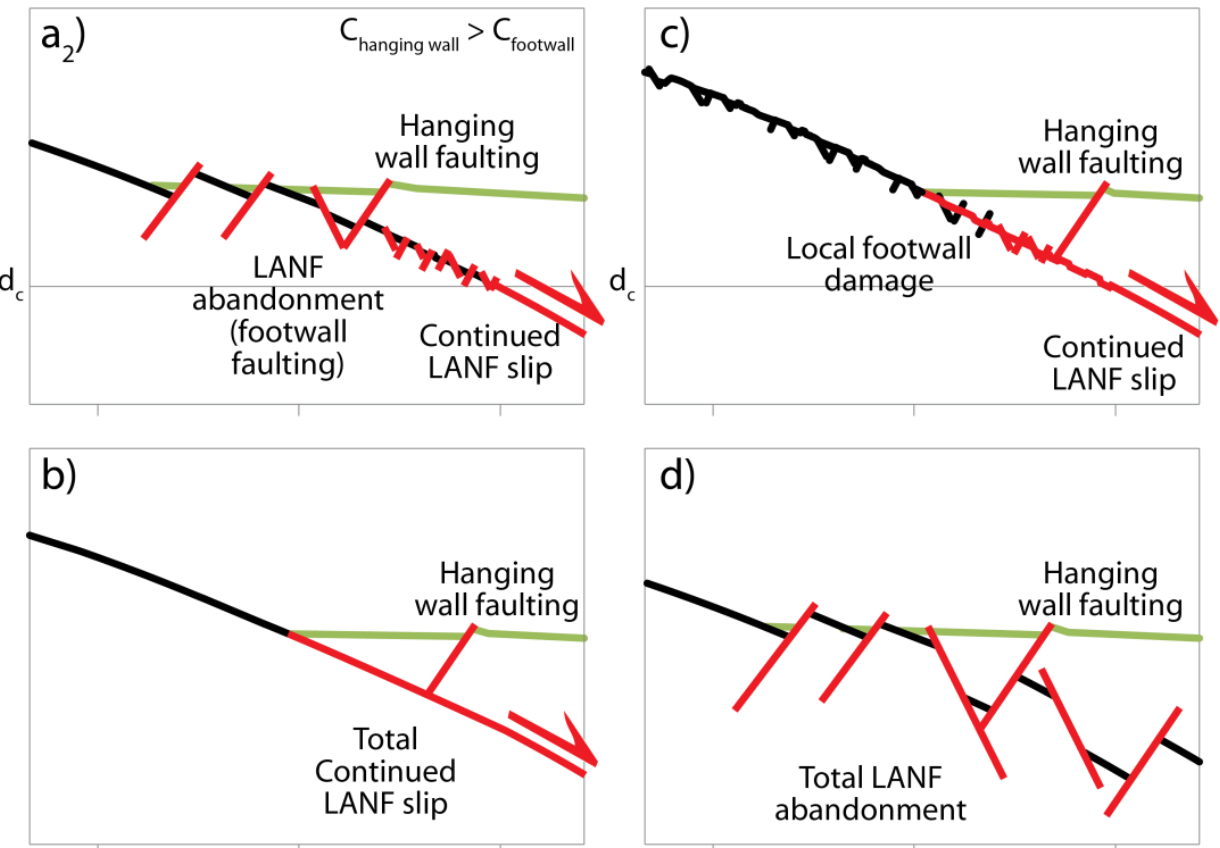

d)

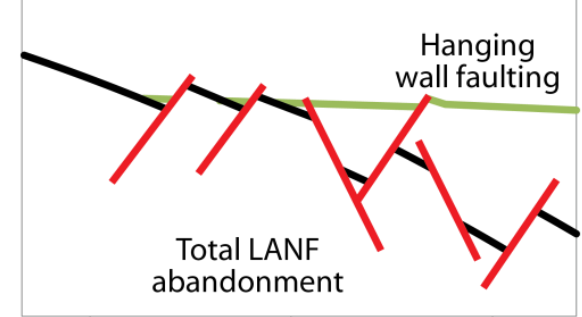

Fig. 63 - Illustrations showing the physical manifestation of the mechanical conditions stipulated in Fig. 62. a) LANF 'partial abandonment', where the LANF is abandoned above $d_{c}$. This category is divided into two sub-categories: $a_{1}$ ) LANF partial abandonment results in synthetic hanging wall faulting. $a_{2}$ ) Because hanging wall strength $>$ footwall strength, LANF partial abandonment results in footwall faulting. b) Continued LANF slip at all depths. c) Local footwall damage occurs above depth $d_{c}$. Due to the small offset on footwall damage faults, the LANF remains active at all depths. d) LANF abandonment at all depths. The All four scenarios may include hanging wall faulting. 


\subsection{Discussion}

\subsubsection{Constraints on LANF Strength}

Modelling of the Gwoira-Mai'iu Fault suggests that the LANF is weak $\left(\mu_{\mathrm{f}} \leq 0.265\right.$; Fig. 59). This result overlaps with the results of modelling of the inactive Mai'iu Fault, which suggests that $\mu_{f}$ is between 0.26-0.309 (Fig. 60) for the preferred model run of $f(z)=0.4$ (this run best reproduces an ideal initial $60^{\circ}$ dip for the Gwoira Fault). While the results of these two modelling exercises overlap, it may be that $\mu_{f}$ for the active Gwoira-Mai'iu Fault is different than that of the inactive Mai'iu Fault. It should be noted that the latter model run is subject to uncertainty associated with our lack of knowledge regarding the paleo-geometry of the inactive Mai'iu Fault at the time of abandonment, and uncertainty regarding the precise manor in which the LANF footwall has been back-rotated. Constraints on fault friction from modelling of the Mai'iu Fault at Biniguni Falls depend on the interpretation of the significance of outcrop-scale faults that cut the LANF footwall, and of the reason for why there are elevated exposures of Gorupu Metabasalt to the north of the Mai'iu Fault trace. These issues will be addressed in section 6.4.2.

Modelled LANF friction values for the Mai'iu Fault in general overlap with the results of extensional wedge modelling for the Mai'iu Fault of Spencer (2011). Excluding fault dip angles taken from the inactive Mai'iu Fault, fault friction values modelled by Spencer (2011) fall within $0.19 \leq \mu \leq 0.27$. However, I argue that the overlap with my results is largely fortuitous. Even excluding the inclusion of LANF attitudes taken from the inactive Mai'iu Fault, Spencer (2011) models the Mai'iu Fault as a planar slab dipping north at dips far shallower than its dip at depth (Eilon et al., 2015). Furthermore, he arbitrarily assumes that the Mai'iu Fault hanging wall friction angle (wedge internal friction) is always $10^{\circ}$ greater than the fault friction angle (basal friction); however, this suggests an unrealistically weak hanging wall, and there is no justification for why hanging wall strength ought to be a function of $\mu_{\mathrm{f}}$.

My modelled results from Biniguni Falls are consistent with the findings of Spencer (2011) only for the interpretation where the active Mai'iu Fault is actively slipping with no footwall damage (scenario b; Fig. 62; Fig. 63), or for the interpretation that the Mai'iu Fault is abandoned in the near-surface with $C_{\mathrm{f}}>1 \mathrm{MPa}$ with $\mathrm{C}_{\mathrm{c}}=3 \mathrm{MPa}$ (scenarios $\mathrm{a}_{1}$, $\mathrm{a}_{2}$; Fig. 62; Fig. 63).

The model results are subject to several uncertainties. While $P_{f}$ was only a minor control, the effect of a non-vertical $\sigma_{1}$ is to expand the range of allowable fault friction values. Auxiliary models, instead run with $\sigma_{1}$ dipping $5^{\circ} / \mathrm{S}$, predict significantly greater fault friction. As discussed above, a rotated stress field is not precluded by our field observations. Therefore, the Mai'iu Fault 
may be stronger than our models suggest if $\sigma_{1}$ is indeed non-vertical. Better constraints on the stress field from paleopiezometry would allow more accurate modelling of LANF strength.

\subsubsection{Deformational Style of the Active Mai'iu Fault at Biniguni Falls}

The modelled strength of the active Mai'iu Fault depends on which field is interpreted to best describe the active Mai'iu Fault at Biniguni Falls. Based on fault slip rates derived from the lowermost Mai'iu Fault scarp (see Chapter 5), the Mai'iu Fault cannot be abandoned at all depths (scenario $d$ ). Additionally, based on observations of pervasive development of outcrop-scale extensional footwall faulting in the LANF footwall, we know that the LANF cannot be viable and continuing to slip at all depths (scenario $b$ ). The interpretation of LANF partial abandonment, whether this results in synthetic hanging wall faulting and rider block formation (scenario $a_{1}$ ), or through-going footwall faulting (scenario $a_{2}$ ), contradicts evidence for active slip on the Mai'iu Fault at the Earth's surface. Therefore, I prefer the interpretation that the Mai'iu Fault occupies domain $c$, and that the fault is characterised by $\mu_{f} \geq 0.32$, with low values of $C_{c}$ owing to the inheritance of older faults that cross-cut the footwall. This implies that outcrop-scale faulting of the footwall is due to local footwall damage above $d_{c}$, concurrent with on-going LANF slip at all depths. This interpretation explains both active slip on the LANF, and observations of outcropscale faulting of the LANF footwall.

To my knowledge, scenario $c$ (i.e., LANF 'footwall damage'; Fig. 62) has not been previously described. I clarify the mechanics of this condition as follows: if the LANF as a whole is still able to slip, but there is some depth range for which $\sigma_{\text {diff LANF }}$ exceeds $\sigma_{\text {diff crust, }}$ (i.e. where locally $\int \sigma_{\text {diff }}<0$ ), then local, small-scale faulting (here termed 'damage') may cross-cut the LANF above $d_{c}$ (Fig. 62, Fig. 63). 'Footwall damage' represents new optimally oriented faults that cut the footwall. Such faults cut the least viable parts of the LANF. Shallower than $d_{c}$, abandonment of the LANF is preferred, and small-scale faulting occurs, even if the LANF is still capable of slip at longer timescales. Because footwall damage faults are subject to local stresses, and because shallow and potentially locked portions of the LANF may only slip during earthquake events, footwall damage faults may continue to accrue slip despite continued slip on the LANF. Lack of exposure in the Mai'iu Fault hanging wall precludes assessment of whether such damage affects the hanging wall to a similar extent. This model for the formation of footwall damage fault may potentially be tested through paleopiezometry of mineralisation within footwall faults, as this would elucidate the depth-range over which footwall damage occurred. 
LANF footwall damage occurs for a relatively narrow range of $\mu_{f}$, for a given assumed $C_{c}\left(\mu_{f} \geq 0.32\right.$ for $\mathrm{C}_{\mathrm{c}}=3 \mathrm{MPa}, \mu_{\mathrm{f}} \geq 0.335$ for $\mathrm{C}_{\mathrm{c}}=4 \mathrm{MPa}$ and $\mathrm{C}_{\mathrm{f}}<1.8 \mathrm{MPa}$ ). This lower bound on fault friction is increased to $\mu_{\mathrm{f}} \geq 0.409$ if $\mathrm{C}_{\mathrm{f}}<0.5 \mathrm{MPa}$; in fact, field $\mathrm{c}$ is the only permissible result for $\mathrm{C}_{\mathrm{f}}<0.5 \mathrm{MPa}$ (Fig. 62). However, these values of modelled LANF friction do not overlap with the upper bounds of values modelled in previous sections $\left(0.128 \leq \mu_{\mathrm{f}} \leq 0.265\right.$ for the Gwoira-Mai'iu Fault for $\mathrm{C}_{\mathrm{f}}<1.8$ $\mathrm{MPa} ; 0.26 \leq \mu_{\mathrm{f}} \leq 0.309$ for the inactive Mai'iu Fault for $\mathrm{C}_{\mathrm{f}}<1.8 \mathrm{MPa}$ ). This inconsistency requires some explanation. It is unlikely that the geometry of the Mai'iu Fault diverges significantly from that modelled here, so that is unlikely to be a major source of error. One potential source of error is that my assumption of depth-invariant $C_{c}$ may be unrealistic - models run where $C_{c}$ is allowed to increase linearly with depth predict higher $\mu_{\mathrm{f}}$. Therefore, it may be that $\mathrm{C}_{\mathrm{c}}$ for the Gwoira Conglomerate increases more rapidly with depth than $\mathrm{C}_{c}$ in the vicinity of Biniguni Falls. This would lead to a stronger fault friction for the Gwoira-Mai'iu Fault, such that it overlaps with the modelled strength of the Mai'iu Fault at Biniguni Falls. Alternatively, it may be that footwall damage at Biniguni Falls developed due to the presence of an asperity on the Mai'iu Fault surface. This would lead to local, temporary abandonment of the LANF surface, between large earthquake events that are capable of propagating past the jammed asperity and reoccupying the entire LANF surface. Footwall damage could accrue between such earthquake events. However, there is no geological evidence for such an asperity. The simplest explanation, and my preferred interpretation, is that the strength of the active Mai'iu Fault varies along strike.

The condition of LANF footwall damage requires that $C_{c}$ be significantly weaker than reported values of metabasalt cohesive strength of 15-32 MPa (Karaman et al., 2013). For the active Mai'iu Fault footwall (Gorupu Metabasalt) to have $\mathrm{C}_{\mathrm{c}}>5 \mathrm{MPa}$ requires that the active Mai'iu Fault have $\mu>0.44$, which is highly inconsistent with modelling results from the Gwoira rider block, which suggest a weaker LANF. Alternatively, low footwall cohesion may be consistent with observations of low flexural rigidity for most MCCs - this observation has previously been explained as being a consequence of either elevated temperatures, or footwall weakening (Cannat et al., 2009). While the former mechanism is unlikely in the case of the Mai'iu Fault, given the prevalence of microseismicity with the mid-lower crust beneath the Suckling-Dayman massif (Eilon et al., 2015), the potential inheritance and reactivation of older footwall faults might explain the Mai'iu Fault footwall's apparently low cohesive strength. As such footwall bulk cohesion would be a reflection of the cohesive strength of partially annealed footwall faults. A weak footwall might also be due to the presence of frictionally weak phyllosilicate-rich horizons (Cannat et al., 2009), although this has not been confirmed by field observations of the Gorupu Metabasalt. 


\subsection{Conclusions}

- The geometries of LANFs that have been partially abandoned have the potential to constrain LANF strength. The results of Mohr-Coulomb modelling provide new constraints on LANF strength and slip behaviour.

- Theoretically, LANF misorientation may potentially result in synthetic splay faulting (rider block formation), cross-cutting antithetic faulting, or footwall damage, depending on the relative strength of the LANF.

- Model results suggest that for $3 \leq \mathrm{C}_{c} \leq 5 \mathrm{MPa}$, fault friction for the active Gwoira-Mai'iu Fault surface is $0.128 \leq \mu_{\mathrm{f}} \leq 0.265$ for $\mathrm{C}_{\mathrm{f}}<1.8 \mathrm{MPa}$, and $0.2 \leq \mu_{\mathrm{f}} \leq 0.265$ for $\mathrm{C}_{\mathrm{f}} \leq 0.5 \mathrm{MPa}$.

- Modelling of abandonment conditions of the inactive Mai'iu Fault suggests that $0.26 \leq \mu_{\mathrm{f}} \leq 0.309$ for $\mathrm{C}_{\mathrm{f}}<1.8 \mathrm{MPa}$, and $0.3 \leq \mu_{\mathrm{f}} \leq 0.309$ for $\mathrm{C}_{\mathrm{f}} \leq 0.5 \mathrm{MPa}$, for the most plausible model run of $f(z)=0.4$. For higher values of $C_{f}$, both of these results overlap with the results of experimental deformation of gouge $(0.13 \leq \mu \leq 0.28)$ obtained from the inactive Mai'iu Fault (Little et al., 2015); further refinement of values based on this overlap suggest that fault friction for the inactive Mai'iu Fault are $0.26 \leq \mu_{\mathrm{f}} \leq 0.28$. This suggests that past slip on the inactive Mai'iu Fault, and continued slip on the active Gwoira-Mai'iu Fault, were enabled by low fault frictional strength.

- The process responsible for continued slip on the active Mai'iu Fault $\sim 30 \mathrm{~km}$ to the northwest at Biniguni Falls, concurrent with widespread field observations of outcrop-scale faulting of the LANF footwall, requires some along-strike change in fault strength (assuming homogeneous Andersonian stress conditions). This chapter proposes a process whereby overall the LANF remains active, but locally stress conditions exceed the LANF abandonment criteria. This results in highly localised, small-scale 'footwall damage' where the LANF footwall is locally dissected by outcrop-scale faulting.

- Model results suggest a weak footwall cohesion of $C_{c} \leq 5$ for the Mai'iu Fault at Biniguni Falls. For crustal cohesion to exceed $5 \mathrm{MPa}$ requires that the Mai'iu Fault have $\mu>0.44$ at Biniguni Falls, which would be highly discordant with modelled fault friction from further east.

- Modelling results are consistent with independent evidence for the overall viability and continued slip on the Mai'iu Fault at Biniguni Falls, although they suggest greater LANF friction $\left(\mu_{\mathrm{f}} \geq 0.32\right)$ on this part of the LANF compared with values of LANF strength determined further east. Modelling suggests that for $C_{f} \leq 0.5 \mathrm{MPa}$, fault friction must be significantly stronger $\left(\mu_{\mathrm{f}} \geq 0.409\right)$ than the LANF east of Pumani. 
- An inherent limitation of the modelling methodology is that differential stresses are not considered in three dimensions (Yin, 1991). 3D numerical models are required to fully understand the phenomenon of simultaneous LANF corrugation amplification and rider block abandonment (see Chapters 3,4), because constriction acts out-of-plane with the extension direction. 


\section{Overall Conclusions}

This chapter briefly summarises the findings presented in this thesis. Conclusions are subdivided according to chapter.

\subsection{Structure of the Gwoira Embayment}

- The Gwoira embayment represents a broad synformal megamullion in the Mai'iu Fault surface. The part of the Mai'iu Fault beneath the Gwoira embayment is inactive, and is separated from the active Mai'iu Fault to the north by the younger, active and more steeply dipping Gwoira Fault. The Gwoira embayment contains a large fault-bounded slice of Gwoira Conglomerate, called the Gwoira rider block; this is an actively uplifting rider block which has formed a consequence of the abandonment of the inactive Mai'iu Fault in favour of the Gwoira Fault.

- The Gwoira Conglomerate has been progressively folded into broad, south-plunging, nested synclines; this folding occurred concurrently with deposition of the Gwoira Conglomerate. Structurally deeper strata are more folded, and are separated from overlying strata by an angular unconformity. The structurally deepest exposed Gwoira Conglomerate strata have been shortened E-W by $2.51 \%$ as a consequence of synclinal folding. In detail, south-plunging synclines are box folds, possessing compound axial traces, with shortening largely concentrated into inward-dipping monoclines; the reason for this partitioning of deformation is unclear. Cosmogenic ${ }^{26} \mathrm{Al} /{ }^{10} \mathrm{Be}$ burial age data that may potentially date this sequence of progressive folding were not yet available at the time of thesis presentation.

- Deeper Gwoira Conglomerate strata steepen to the south with increasing structural height; this is interpreted as being due to flexure of the underlying Mai'iu Fault.

- Structurally higher Gwoira Conglomerate strata shallow to the south (dip-fanning); this is interpreted as being due to deposition of these strata concurrent with uplift and backrotation of the Gwoira rider block.

- Based on analysis of bedding-fault cut-off angles, a component of back-tilting of the Mai'iu Fault and the Gwoira Conglomerate must have occurred concurrent with deposition of the Gwoira Conglomerate. This component of back-tilting is inferred to be due to progressive flexure of the Mai'iu Fault. Back-tilting within the Gwoira embayment continued subsequent to the deposition of the uppermost Gwoira Conglomerate strata. This component of back-tilting is inferred to be due to slip on the Gwoira Fault accompanied by on-going flexure of the Mai'iu Fault. 
- Normal faulting associated with slip on the Gwoira Fault is accompanied by strike-slip faulting within the Gwoira Fault footwall; unfortunately, because observations of stratal offset are largely unavailable, it is not possible to identify whether these strike-slip faults accommodate E-W shortening, or extension.

- Late Quaternary (?) terraces deposited within the Gwoira embayment, upon the eastern limb of the syncline that affects underlying Gwoira Conglomerate strata, have been tilted to the west, and older terraces have been tilted more than younger terraces. This is attributed to on-going synclinal folding within the Gwoira embayment.

- The apparent amount of E-W shortening accommodated since the initiation of the Mai'iu Fault has been estimated for the Gwoira Conglomerate (2.51\%), the inactive Mai'iu Fault (1.15\%), the Mai'iu Fault as a whole $(0.79 \%)$, and OSF $(0.62 \%)$; these estimates assume shortening of an originally planar fault. From these estimates it is interpreted that the Mai'iu Fault and Gwoira Conglomerate, possessing similar values of apparent shortening, were shortened $\mathrm{E}-\mathrm{W}$ together during the same tectonic event. It is also interpreted that the apparent shortening of the OSF represents original roughness of the fault; however, this roughness is unlikely to have been inherited by the Mai'iu Fault, because that would imply a smaller amount of true shortening accommodated by the Mai'iu Fault compared with that of the Gwoira Conglomerate. This implies either that the Mai'iu Fault did not occupy the entire OSF surface and rather formed an original planar surface, or that the roughness of the deeper portion of the OSF was 'smoothed' at depth.

- The $k_{1}$ knickpoints of Miller et al. (2012) have been reinterpreted as culminations of convex-up parts of streams that drain the SDM to the north, which are here termed $k_{1}$ apices. The distribution of $k_{1}$ apices is consistent with an approximately constant slip rate on the Mai'iu Fault between Biniguni and the Gwoira embayment, that linearly declines west of Biniguni to approximately zero at Gorupu Crater.

- Uplift rates within the Gwoira embayment have been constrained through modelling of stream profiles; results are consistent with a northward increase in uplift rates towards the Gwoira Fault, with uplift at the Gwoira Fault trace of $3.7 \pm 2.6 \mathrm{~mm} / \mathrm{yr}(1 \sigma)$, and $4.2 \pm 3.6$ $\mathrm{mm} / \mathrm{yr}$.

- The maximum burial depth of the Gwoira Conglomerate has been modelled from vitrinite reflectance data; results suggest burial to $1.34 \pm 0.33 \mathrm{~km}(1 \sigma)$, and $0.97 \pm 0.61 \mathrm{~km}(2 \sigma)$. However the single lignite coal sample analysed may been hydrothermally altered; this would lead to an underestimation of maximum burial depth. 
- Based on an assumption of constant slip rate, the onset of motion on the Gwoira Fault is calculated to be $248(+80-69) \mathrm{ka}$. This age assumes constant slip at the rate indicated by regional campaign GPS of Wallace et al. (2014), a dip of $37-47^{\circ} / \mathrm{N}$ of the Gwoira Fault, and uplift of $\sim 1300 \mathrm{~m}$ of now partially eroded relief of Mt Gwoira from a depth of at least $\sim 400$ m. This original topography of Mt Gwoira assumes my preferred interpretation that SP1 and lower SP2 strata have been folded about an E-W trending monocline, such that they shallow in dip towards the north. However this age is likely over-estimated, given that the Gwoira Fault has likely been back-rotated from an ideal initial dip of $60^{\circ}$.

\subsection{Pliocene-Recent Evolution of the Gwoira Embayment}

- E-W shortening of the Gwoira Conglomerate and of the Gwoira and Mai'iu faults has been motivated by extension-perpendicular constriction. This is consistent with numerous observations of conjugate strike-slip faulting of the Mai'iu Fault footwall at Biniguni Falls (Little et al., 2015). However the origin of this constrictive stress field is uncertain.

- This thesis argues for a causal relationship between the amplification of the Gwoira embayment megamullion, and the formation of the Gwoira rider block. Megamullion amplification, superimposed by 'rolling-hinge' style LANF back-rotation, resulted in 3D buckling of the LANF and progressive shallowing of the Mai'iu Fault within the Gwoira embayment, which ultimately resulted in local LANF abandonment. This is indicated by the progressive reduction of the cut-off angle between Gwoira Conglomerate bedding and the now inactive Mai'iu Fault with increasing structural height. The Mai'iu Fault was locally abandoned in favour of the Gwoira Fault, which may itself have been shortened E-W by $0.51 \%$ (although this may instead represent original roughness of the Gwoira Fault).

\subsection{Slip Rate and Deformational Style of the Active Mai'iu Fault at Biniguni Falls}

- Modelling of TCN concentrations from quartz vein samples obtained from the lowermost Mai'iu Fault scarp evidences that Mai'iu Fault is actively slipping at Biniguni Falls. Modelling suggests that Mai'iu Fault is on average slipping at a rate of: $13.9 \pm 4.0 \mathrm{~mm} / \mathrm{yr}(1 \sigma)$, over the last $13.2 \pm 2.7 \mathrm{ka}(1 \sigma)$.

- Modelling suggests that the time of last slip on the Mai'iu Fault occurred at $2.9 \pm 1.4$ ka (1б); this is interpreted as representing a seismic slip event at that time, followed by non-slip until the present day. 
- Modelling also suggests that the local rate of erosion is $0.043 \pm 0.025 \mathrm{~mm} / \mathrm{yr} \mathrm{mm} / \mathrm{yr}(1 \sigma)$, which is consistent with observations of minimal erosion of the Mai'iu Fault scarp at Biniguni Falls.

- The hanging wall of the Mai'iu Fault is interpreted as a Paleogene thrust imbricate, associated with Paleogene obduction of the PUB. However, near Gorupu Crater abandonment of the Mai'iu Fault has occurred within the near-surface. There the LANF has been cross-cut by high-angle normal faults.

\subsection{Frictional Strength of the Mai'iu Fault}

- Limits have been placed on LANF strength through Mohr-Coulomb modelling of LANF abandonment criteria.

- Modelling of the Gwoira-Mai'iu Fault suggests that LANF friction is $0.128 \leq \mu_{\mathrm{f}} \leq 0.265$ for a liberal upper limit on fault cohesion of $\mathrm{C}_{\mathrm{f}}<1.8 \mathrm{MPa}$.

- Modelling of a retro-deformed geometry for the inactive Mai'iu Fault suggests that LANF friction at the time of its abandonment was $0.26 \leq \mu_{\mathrm{f}} \leq 0.309$ for $\mathrm{C}_{\mathrm{f}}<1.8 \mathrm{MPa}$, for the preferred model run in which the modelled initial dip of the Gwoira Fault is approximately $60^{\circ}$.

- Results are consistent with experimentally determined values of fault friction for the fault $(0.13 \leq \mu \leq 0.28)$ described by Little et al. (2015). These results confirm that slip on the Mai'iu Fault and Gwoira Fault is enabled by low frictional strength in the vicinity of the Gwoira rider block.

- Mohr-Coulomb modelling of the Mai'iu Fault at Biniguni Falls suggests stronger values of fault friction. For the preferred interpretation that the Mai'iu Fault has undergone footwall damage, fault friction is $\geq 0.32$ for crustal cohesion of $C_{c} \geq 3 \mathrm{MPa}$, and for $C_{f}<1.8 \mathrm{MPa}$. This implies along-strike variability in the frictional strength of the Mai'iu Fault.

- Modelling of the Mai'iu Fault at Biniguni Falls also suggests low values of footwall cohesion; this is rationalised in terms of low footwall flexural rigidity, which implies either the inheritance of faults within the Mai'iu Fault footwall, or significant heat advection from the lower crust.

- While LANF partial abandonment has previously been interpreted as exclusively leading to synthetic faulting of the LANF hanging wall, resulting in rider block formation, it is here shown that alternative modes of abandonment are possible. It is possible for the LANF footwall to be cross-cut by faulting concurrent with continued slip on the LANF, what is here termed footwall 'damage'; this occurs as a consequence of the LANF locally being 
misoriented for slip, but the LANF as a whole still being suitably oriented for slip. This is the case at Biniguni Falls. Alternatively, high-angle normal faulting of the LANF footwall may result in LANF abandonment; this is the case near Gorupu Crater. This is in contrast to the mode of LANF abandonment in the near surface due to synthetic splay faulting, which is generally assumed in the literature (e.g., Choi et al., 2012; Choi and Buck, 2012; Choi et al., 2013; Reston and Ranero, 2011).

\subsection{Unanswered Questions and Directions for Future Research}

- The age of the Gwoira Conglomerate has not yet been ascertained, although ten TCN burial samples have already been submitted for AMS analysis. The age of the oldest Gwoira Conglomerate strata will place a minimum age for the onset of motion on the Mai'iu Fault.

- The ages of Late Quaternary (?) fluvial terraces deposited within the Gwoira embayment are unknown. Such ages would provide an absolute chronology for progressive folding in the near-surface in response to a constrictive stress field.

- The sense of strike-slip motion accommodated by faults within the Gwoira Fault footwall is poorly constrained.

- The stratigraphy and structure of the eastern-most Gwoira embayment, and of the Papuan Peninsula north of Pumani, are poorly known.

- The clast petrology of the Gwoira Conglomerate as a whole is not well known. A systematic study of clast composition over the full thickness of the Gwoira Conglomerate could potentially produce a record of the progressive exhumation of the Mai'iu Fault footwall.

- 3D numerical modelling may inform the origin of the constrictive stress field, which remains unknown.

- Very little is known about the magnitude and recurrence intervals of seismic events on the Mai'iu and Gwoira faults.

- The geometry of the Mai'iu Fault at depth, while modelled in this thesis, is poorly constrained. It would be valuable to independently confirm the geometry of the Mai'iu Fault in the near-surface through some combination of seismic refraction/reflection, and gravity surveying.

- The cause of the apparent low cohesive strength of the Mai'iu Fault footwall at Biniguni Falls is equivocal.

- It would be beneficial to test the Mohr-Coulomb models presented in this thesis with 3D modelling. Such models will be necessary to further investigate the origin of constriction in the evolution of the LANF. 


\section{References}

Abbott, R. E., Louie, J. N., Pullammanappallil, S., and Caskey, S. J., 2001, Geophysical confirmation of lowangle normal slip on the historically active Dixie Valley fault, Nevada: Journal of Geophysical Research, v. 106, no. B3, p. 4169-4181.

Abers, G., Eilon, Z., Gaherty, J., Jin, G., Kim, Y., Obrebski, M., and Dieck, C., 2016, Southeast Papuan crustal tectonics: imaging extension and buoyancy of an active rift: Journal of Geophysical Research: Solid Earth, v. 121, no. 2, p. 951-971.

Abers, G., Kim, Y., Gaherty, J., Eilon, Z., Jin, G., and Verave, R., Imaging to understand exhumation of UHP rocks during rifting: the 2010-2011 CDPapua seismic experiment, in Proceedings AGU Fall Meeting Abstracts2012, Volume 1, p. 06.

Abers, G. A., 1991, Possible seismogenic shallow-dipping normal faults in the Woodlark-D'Entrecasteaux extensional province, Papua New Guinea: Geology, v. 19, no. 12, p. 1205-1208.

Abers, G. A., Ferris, A., Craig, M., Davies, H., Lerner-Lam, A. L., Mutter, J. C., and Taylor, B., 2002, Mantle compensation of active metamorphic core complexes at Woodlark rift in Papua New Guinea: Nature, v. 418 , no. 6900 , p. 862-865.

Abers, G. A., Mutter, C. Z., and Fang, J., 1997, Shallow dips of normal faults during rapid extension: Earthquakes in the Woodlark-D'Entrecasteaux rift system, Papua New Guinea: Journal of Geophysical Research, v. 102, no. B7, p. 15301.

Allmendinger, R. W., Cardozo, N., and Fisher, D. M., 2011, Structural geology algorithms: Vectors and tensors, Cambridge University Press.

Altmann, J. B., 2010, Poroelastic effects in reservoir modelling [Dipl.-Geophys: Karlsruhe Institute of Technology.

Anders, M. H., and Schlische, R. W., 1994, Overlapping faults, intrabasin highs, and the growth of normal faults: The Journal of Geology, p. 165-179.

Anderson, E., 1905, The dynamics of faulting: Transactions of the Edinburgh Geological Society, v. 8, no. 3, p. 387-402.

Angelier, J., 1977, Essai sur la néotectonique et les derniers stades tarditectoniques de l'arc Egéen et de l'Egée méridionale: Bulletin de la Société géologique de France, no. 3, p. 651-662.

Avigad, D., Ziv, A., and Garfunkel, Z., 2001, Ductile and brittle shortening, extension-parallel folds and maintenance of crustal thickness in the central Aegean (Cyclades, Greece): Tectonics, v. 20, no. 2, p. 277-287.

Axen, G. J., 1992, Pore pressure, stress increase, and fault weakening in low-angle normal faulting: Journal of Geophysical Research: Solid Earth (1978-2012), v. 97, no. B6, p. 8979-8991.

Axen, G. J., 2004, Low-angle normal fault mechanics and crustal strength, in Karner, G., ed., Rheology and Deformation of the Lithosphere, Columbia University Press, p. 46 - 91.

Balco, G., and Shuster, D. L., 2009, 26 Al-10 Be-21 Ne burial dating: Earth and Planetary Science Letters, v. 286, no. 3, p. 570-575.

Balco, G., Stone, J. O., Lifton, N. A., and Dunai, T. J., 2008, A complete and easily accessible means of calculating surface exposure ages or erosion rates from 10Be and 26Al measurements: Quaternary Geochronology, v. 3, no. 3, p. 174-195.

Baldwin, S., Fitzgerald, P., Bermudez, M., Webb, L., Moucha, R., Miller, S., Catalano, J., and Zirakparvar, N., Linking deep earth to surface processes in the Woodlark Rift of Papua New Guinea; a framework for understanding (U) HP exhumation globally, in Proceedings AGU Fall Meeting Abstracts2012, Volume 1, p. 04.

Baldwin, S. L., and Ireland, T. R., 1995, A tale of two eras: Pliocene-Pleistocene unroofing of Cenozoic and late Archean zircons from active metamorphic core complexes, Solomon Sea, Papua New Guinea: Geology, v. 23, no. 11, p. 1023-1026.

Baldwin, S. L., Lister, G. S., Hill, E., Foster, D. A., and McDougall, I., 1993, Thermochronologic constraints on the tectonic evolution of active metamorphic core complexes, D'Entrecasteaux Islands, Papua New Guinea: Tectonics, v. 12, no. 3, p. 611-628.

Baldwin, S. L., Monteleone, B. D., Webb, L. E., Fitzgerald, P. G., Grove, M., and Hill, E. J., 2004, Pliocene eclogite exhumation at plate tectonic rates in eastern Papua New Guinea: Nature, v. 431, no. 7006, p. 263-267. 
Baldwin, S. L., Webb, L. E., and Monteleone, B. D., 2008, Late Miocene coesite-eclogite exhumed in the Woodlark Rift: Geology, v. 36, no. 9, p. 735-738.

Bartley, J. M., Fletcher, J. M., and Glazne, A. F., 1990, Tertiary extension and contraction of lower plate rocks in the central Mojave metamorphic core complex, southern Californi: Tectonics, v. 9, p. 521-534.

Behr, W. M., and Platt, J. P., 2011, A naturally constrained stress profile through the middle crust in an extensional terrane: Earth and Planetary Science Letters, v. 303, no. 3-4, p. 181-192.

Benedetti, L., Finkel, R., King, G., Armijo, R., Papanastassiou, D., Ryerson, F., Flerit, F., Farber, D., and Stavrakakis, G., 2003, Motion on the Kaparelli fault (Greece) prior to the 1981 earthquake sequence determined from $36 \mathrm{Cl}$ cosmogenic dating: Terra Nova, v. 15, no. 2, p. 118-124.

Benedetti, L., Finkel, R., Papanastassiou, D., King, G., Armijo, R., Ryerson, F., Farber, D., and Flerit, F., 2002, Post-glacial slip history of the Sparta fault (Greece) determined by $36 \mathrm{Cl}$ cosmogenic dating: Evidence for non-periodic earthquakes: Geophysical Research Letters, v. 29, no. 8, p. 87-81-87-84.

Bickel, R. S., 1969, Geology of the Cape Vogel Basin, Territory of Papua New Guinea: General Exploration Company Australasia Pty Ltd.

Bickel, R. S., 1974, Reconnaissance Geology of Cape Vogel Basin, Papua New Guinea: AAPG Bulletin, v. 58, no. 12, p. $2477-2489$.

Bierman, P. R., 1994, Using in situ produced cosmogenic isotopes to estimate rates of landscape evolution: A review from the geomorphic perspective: Journal of Geophysical Research: Solid Earth (19782012), v. 99, p. $13,885-813,885$.

Bird, P., 1991, Lateral extrusion of lower crust from under high topography in the isostatic limit: Journal of Geophysical Research: Solid Earth, v. 96, no. B6, p. 10275-10286.

Biswas, S., 1982, Rift basins in western margin of India and their hydrocarbon prospects with special reference to Kutch basin: AAPG Bulletin, v. 66, no. 10, p. 1497-1513.

Block, L., and Royden, L. H., 1990, Core complex geometries and regional scale flow in the lower crust: Tectonics, v. 9, no. 4, p. 557-567.

Bos, B., Peach, C., and Spiers, C., 2000, Frictional-viscous flow of simulated fault gouge caused by the combined effects of phyllosilicates and pressure solution: Tectonophysics, v. 327, no. 3, p. 173-194.

Bradley, K. E., The Role of Extension-Parallel Folding in the Tectono-Sedimentary Development of the Early to Middle Miocene Kymi-Aliveri Basin, Evia, Greece, in Proceedings 2011 GSA Annual Meeting in Minneapolis2011.

Buchan, F. D., 1985, Petroleum potential of the Cape Vogel, Bougainville and New Island Basins (unpublished): Robertson Research.

Buck, W. R., 1988, Flexural rotation of normal faults: Tectonics, v. 7, no. 5, p. 959-973.

Burchfiel, B., Hodges, K., and Royden, L., 1987, Geology of Panamint Valley-Saline Valley Pull-Apart System, California: Palinspastic evidence for low-angle geometry of a Neogene Range-Bounding Fault: Journal of Geophysical Research: Solid Earth, v. 92, no. B10, p. 10422-10426.

Byerlee, J., 1978, Friction of rocks: Pure and applied Geophysics, v. 116, no. 4-5, p. 615-626.

Caffi, P., 2008, Evolution of an Active Metamorphic Core Complex [BS Honours: Macquarie University.

Cai, M., Kaiser, P., Uno, H., Tasaka, Y., and Minami, M., 2004, Estimation of rock mass deformation modulus and strength of jointed hard rock masses using the GSI system: International Journal of Rock Mechanics and Mining Sciences, v. 41, no. 1, p. 3-19.

Cairns, E. A., Little, T. A., Turner, G. M., Wallace, L. M., and Ellis, S., 2015, Paleomagnetic evidence for vertical-axis rotations of crustal blocks in the Woodlark Rift, SE Papua New Guinea: Miocene to Present-Day kinematics in one of the world's most rapidly extending plate boundary zones: Geochemistry, Geophysics, Geosystems.

Cannat, M., Sauter, D., Escartín, J., Lavier, L., and Picazo, S., 2009, Oceanic corrugated surfaces and the strength of the axial lithosphere at slow spreading ridges: Earth and Planetary Science Letters, $v$. 288 , no. 1 , p. $174-183$.

Cardozo, N., and Allmendinger, R. W., 2013, Spherical projections with OSXStereonet: Computers \& Geosciences, v. 51, p. 193-205.

Carlos, T. L., Fernando, P. L., Renato, R., Jacques, A. R. C., Klaus, R., and Santos, B. O. O., 2006, Field spatial and temporal patterns of soil water content and bulk density changes: Scientia Agricola.

Célérier, B., 1988, How much does slip on a reactivated fault plane constrain the stress tensor?: Tectonics, v. 7 , no. 6, p. 1257. 
Cerling, T., and Craig, H., 1994, Geomorphology and in-situ cosmogenic isotopes: Annual Review of Earth and Planetary Sciences, v. 22, p. 273-317.

Chaproniere, G. C. H., 2009, Foraminiferal Biostratigraphy of Samples from the Adau Limestone, Ada'u River area, Mt Suckling, Papua New Guinea: A Report to Papuan Precious Metals Ltd.

Chauvet, A., and Séranne, M., 1994, Extension-parallel folding in the Scandinavian Caledonides: implications for late-orogenic processes: Tectonophysics, v. 238, no. 1-4, p. 31-54.

Chéry, J., 2001, Core complex mechanics: From the Gulf of Corinth to the Snake Range: Geology, v. 29, no. 5, p. 439-442.

Choi, E., Buck, R., Laiver, L., and Petersen, K. D., 2012, Bounds on Fault Strength Based on Geometry of Rider Blocks, AGU 2012: San Francisco.

Choi, E., and Buck, W. R., 2012, Constraints on the strength of faults from the geometry of rider blocks in continental and oceanic core complexes: Journal of Geophysical Research: Solid Earth, v. 117, no. B4, p. 1-14.

Choi, E., Buck, W. R., Lavier, L. L., and Petersen, K. D., 2013, Using core complex geometry to constrain fault strength: Geophysical Research Letters, v. 40, no. 15, p. 3863-3867.

Cichanski, M., 2000, Low-angle, range-flank faults in the Panamint, Inyo, and Slate ranges, California: Implications for recent tectonics of the Death Valley region: Geological Society of America Bulletin, v. 112 , no. 6 , p. $871-883$.

Çiftçi, N. B., 2013, In-situ stress field and mechanics of fault reactivation in the Gediz Graben, Western Turkey: Journal of Geodynamics, v. 65, p. 136-147.

Collettini, C., 2011, The mechanical paradox of low-angle normal faults: Current understanding and open questions: Tectonophysics, v. 510, no. 3-4, p. 253-268.

Collettini, C., and Holdsworth, R., 2004, Fault zone weakening and character of slip along low-angle normal faults: insights from the Zuccale fault, Elba, Italy: Journal of the Geological Society, v. 161, no. 6, p. 1039-1051.

Crosby, B. T., and Whipple, K. X., 2006, Knickpoint initiation and distribution within fluvial networks: 236 waterfalls in the Waipaoa River, North Island, New Zealand: Geomorphology, v. 82, no. 1-2, p. 1638.

Cuadros, J., Caballero, E., Huertas, F. J., de Cisneros, C. J., Huertas, F., and Linares, J., 1999, Experimental Alteration of Volcanic Tuff: Smectite Formation and Effect on $^{\wedge} 1^{\wedge} 80$ Isotope Composition: Clays and clay minerals, v. 47, no. 6, p. 769-776.

Daczko, N., Caffi, P., Halpin, J., and Mann, P., 2009, Exhumation of the Dayman dome metamorphic core complex, eastern Papua New Guinea: Journal of Metamorphic Geology, v. 27, no. 6, p. 405-422.

Daczko, N. R., Caffi, P., and Mann, P., 2011, Structural evolution of the Dayman dome metamorphic core complex, eastern Papua New Guinea: Geological Society of America Bulletin, v. 123, no. 11-12, p. 2335-2351.

Daly, R., Manger, G. E., and Clark, S. P., 1966, Section 4: Density of rocks: Geological Society of America Memoirs, v. 97, p. 19-26.

Davies, H., 1971, Peridotite-gabbro-basalt complex in eastern Papua: an overthrust plate of oceanic mantle and crust, Department of National Development, Bureau of Mineral Resources, Geology and Geophysics.

-, 1980a, Folded thrust fault and associated metamorphism in the Suckling-Dayman massif, Papua New Guinea, Geological Survey of Papua New Guinea.

Davies, H., and Jaques, A., 1984, Emplacement of ophiolite in Papua New Guinea: Geological Society, London, Special Publications, v. 13, no. 1, p. 341-349.

Davies, H., Perembo, R., Winn, R., and KenGemar, P., Terranes of the New Guinea orogen, in Proceedings Proceedings of the Geology Exploration and Mining Conference. Madang. Australasian Institute of Mining and Metallurgy, Melbourne, Australia1997, p. 61-66.

Davies, H., Smith, I., Cifali, G., and Belford, D., 1968, Eastern Papua geological reconnaissance: Bur. Miner. Resour. Aust. Rec, v. 66.

Davies, H., Symonds, P., and Ripper, I., 1984, Structure and evolution of the southern Solomon Sea region: BMR Journal of Australian Geology \& Geophysics, v. 9, no. 1, p. 49-68.

Davies, H. L., Crustal structure and emplacement of ophiolite in south-eastern Papua New Guinea, in Proceedings Proceedings in Mafic-Ultramafic Rocks in Orogenic Belt, International Colloquim, Paris, 1980b, Volume 272, National Center for Scientific Researches, p. 17-33. 
Davies, H. L., and Smith, I. E., 1971, Geology of eastern Papua: Geological Society of America Bulletin, v. 82, no. 12 , p. 3299-3312.

Davies, H. L., and Smith, I. E., 1974, Tufi-Cape Nelson, Papua New Guinea, Sheets SC/55-8 and SC55-4, Geological Series and Explanatory Notes: Bureau of Mineral Resources, Geology and Geophysics, Department of Minerals and Energy in co-operation with the Geological Survey of Papua New Guinea, scale 1:250,000.

Davies, H. L., SWIFT, M., and JONDA, L., 2014, Puzzling Juxtaposition of Extensional and Contractional Tectonics in Southeastern Papua New Guinea.

Davies, H. L., and Warren, R., 1988, Origin of eclogite-bearing, domed, layered metamorphic complexes ("core complexes") in the D'entrecasteaux Islands, Papua New Guinea: Tectonics, v. 7, no. 1, p. 121.

Davies, H. L. a. W., A.N., 2001, Buna - 1:250,000 Geological Series. Explanatory notes to accompany Buna 1:250,000 geological map: Geological Survey of Papua New Guinea, Explanatory Notes SC/55-7.

Densmore, A. L., Anderson, R. S., McAdoo, B. G., and Ellis, M. A., 1997, Hillslope evolution by bedrock landslides: Science, v. 275, no. 5298, p. 369-372.

Dow, D. B., 1977, A geological synthesis of Papua New Guinea, Australian Government Publishing Service.

Drummond, B., Collins, C., and Gibson, G., 1979, The crustal structure of the Gulf of Papua and northwest Coral Sea: BMR Journal of Australian Geology and Geophysics, v. 4, p. 341-351.

Dula Jr, W. F., 1991, Geometric Models of Listric Normal Faults and Rollover Folds: AAPG Bulletin, v. 75, no. 10, p. 1609-1625.

Dunai, T. J., 2010, Cosmogenic Nuclides: Principles, concepts and applications in the Earth surface sciences, Cambridge University Press.

Dunai, T. J., and Lifton, N. A., 2014, The nuts and bolts of cosmogenic nuclide production: Elements, v. 10, no. 5, p. 347-350.

Dunne, J., Elmore, D., and Muzikar, P., 1999, Scaling factors for the rates of production of cosmogenic nuclides for geometric shielding and attenuation at depth on sloped surfaces: Geomorphology, v. 27, no. 1, p. 3-11.

Eilon, Z., Abers, G. A., and Gaherty, J. B., 2016, A Joint Inversion for Shear Velocity and Anisotropy: The Woodlark Rift, Papua New Guinea: Geophysical Journal International.

Eilon, Z., Abers, G. A., Gaherty, J. B., and Jin, G., 2015, Imaging continental breakup using teleseismic body waves: The Woodlark Rift, Papua New Guinea: Geochemistry, Geophysics, Geosystems, v. 16, no. 8, p. 2529-2548.

Eilon, Z., Abers, G. A., Jin, G., and Gaherty, J. B., 2014, Anisotropy beneath a highly extended continental rift: Geochemistry, Geophysics, Geosystems, v. 15, no. 3, p. 545-564.

Ekström, G., Nettles, M., and Dziewoński, A., 2012, The global CMT project 2004-2010: Centroid-moment tensors for 13,017 earthquakes: Physics of the Earth and Planetary Interiors, v. 200, p. 1-9.

Ellis, S., Little, T., Wallace, L., Hacker, B., and Buiter, S., 2011, Feedback between rifting and diapirism can exhume ultrahigh-pressure rocks: Earth and Planetary Science Letters, v. 311, no. 3, p. 427-438.

Fang, J., 2000, Styles and distribution of continental extension derived from the rift basins of eastern Papua New Guinea.

Ferrill, D. A., Stamatakos, J. A., and Sims, D., 1999, Normal fault corrugation: implications for growth and seismicity of active normal faults: Journal of Structural Geology, v. 21, no. 8, p. 1027-1038.

Ferris, A., Abers, G. A., Zelt, B., Taylor, B., and Roecker, S., 2006, Crustal structure across the transition from rifting to spreading: the Woodlark rift system of Papua New Guinea: Geophysical Journal International, v. 166, no. 2, p. 622-634.

Finlayson, D., Drummond, B., Collins, C., and Connelly, J., 1977, Crustal structures in the region of the Papuan Ultramafic Belt: Physics of the Earth and Planetary Interiors, v. 14, no. 1, p. 13-29.

Fitz, G., and Mann, P., 2013a, Tectonic uplift mechanism of the Goodenough and Fergusson Island gneiss domes, eastern Papua New Guinea: Constraints from seismic reflection and well data:

Geochemistry, Geophysics, Geosystems, v. 14, no. 10, p. 3969-3995.

,- 2013b, Evaluating upper versus lower crustal extension through structural reconstructions and subsidence analysis of basins adjacent to the D'Entrecasteaux Islands, eastern Papua New Guinea: Geochemistry, Geophysics, Geosystems, v. 14, no. 6, p. 1800-1818. 
Fitz, G. G., 2011, Offshore mapping and modeling of Miocene-Recent extensional basins adjacent to metamorphic gneiss domes of the D'Entrecasteaux Islands, eastern Papua New Guinea [MSc: Univ. of Texas at Austin, $183 \mathrm{p}$.

Fletcher, J. M., and Bartley, J. M., 1994, Constrictional strain in a non-coaxial shear zone: implications for fold and rock fabric development, central Mojave metamorphic core complex, California: Journal of Structural Geology, v. 16, no. 4, p. 555-570.

Fletcher, J. M., Bartley, J. M., Martin, M. W., Glazner, A. F., and Walker, J. D., 1995, Large-magnitude continental extension: An example from the central Mojave metamorphic core complex: Geological Society of America Bulletin, v. 107, no. 12, p. 1468-1483.

Francis, G., Lock, J., and Okuda, Y., 1987, Seismic stratigraphy and structure of the area to the southeast of the Trobriand Platform: Geo-marine letters, v. 7, no. 3, p. 121-128.

Gaina, C., Müller, R. D., Royer, J. Y., and Symonds, P., 1999, Evolution of the Louisiade triple junction: Journal of Geophysical Research: Solid Earth (1978-2012), v. 104, no. B6, p. 12927-12939.

Garcés, M., and Gee, J. S., 2007, Paleomagnetic evidence of large footwall rotations associated with lowangle faults at the Mid-Atlantic Ridge: Geology, v. 35, no. 3, p. 279-282.

Garside I.E., S. J. D., 1973, Goodenough No. 1 well completion report: Amoco Australia Exploration Company.

Goodliffe, A. M., Taylor, B., Martinez, F., Hey, R., Maeda, K., and Ohno, K., 1997, Synchronous reorientation of the Woodlark Basin spreading center: Earth and Planetary Science Letters, v. 146, no. 1, p. 233242.

Gordon, S., Little, T., Hacker, B., Bowring, S., Korchinski, M., Baldwin, S., and Kylander-Clark, A., 2012, Multistage exhumation of young UHP-HP rocks: Timescales of melt crystallization in the D'Entrecasteaux Islands, southeastern Papua New Guinea: Earth and Planetary Science Letters, v. 351, p. 237-246.

Gosse, J. C., and Phillips, F. M., 2001, Terrestrial in situ cosmogenic nuclides: theory and application: Quaternary Science Reviews, v. 20, no. 14, p. 1475-1560.

Granger, D. E., 2006, A review of burial dating methods using 26Al and 10Be: Geological Society of America Special Papers, v. 415, p. 1-16.

Granger, D. E., and Muzikar, P. F., 2001, Dating sediment burial with in situ-produced cosmogenic nuclides: theory, techniques, and limitations: Earth and Planetary Science Letters, v. 188, no. 1, p. 269-281.

GSPNG \& BGS, 2004, Gravity map of Papua New Guinea. 1:2500000 scale: Geological Survey of Papua New Guinea \& British Geological Survey.

Hall, R., 2001, Cenozoic reconstructions of SE Asia and the SW Pacific: changing patterns of land and sea: Faunal and floral migrations and evolution in SE Asia-Australasia, p. 35-56.

Hall, R., and Spakman, W., 2002, Subducted slabs beneath the eastern Indonesia-Tonga region: insights from tomography: Earth and Planetary Science Letters, v. 201, no. 2, p. 321-336.

Haq, B. U., 1988, Mesozoic and Cenozoic chronostratigraphy and cycles of sea-level change.

Hayman, N. W., Knott, J. R., Cowan, D. S., Nemser, E., and Sarna-Wojcicki, A. M., 2003, Quaternary lowangle slip on detachment faults in Death Valley, California: Geology, v. 31, no. 4, p. 343-346.

Heine, C., Müller, R. D., Steinberger, B., and DiCaprio, L., 2010, Integrating deep Earth dynamics in paleogeographic reconstructions of Australia: Tectonophysics, v. 483, no. 1, p. 135-150.

Herman, F., Seward, D., Valla, P. G., Carter, A., Kohn, B., Willett, S. D., and Ehlers, T. A., 2013, Worldwide acceleration of mountain erosion under a cooling climate: Nature, v. 504, no. 7480, p. 423-426.

Hill, E., Baldwin, S. L., and Lister, G. S., 1995, Magmatism as an essential driving force for formation of active metamorphic core complexes in eastern Papua New Guinea: Journal of Geophysical Research: Solid Earth (1978-2012), v. 100, no. B6, p. 10441-10451.

Hill, K. C., and Hall, R., 2003, Mesozoic-Cenozoic evolution of Australia's New Guinea margin in a west Pacific context: Geological Society of America Special Papers, v. 372, p. 265-290.

Hoeft, J. S., and Frankel, K. L., 2010, Temporal variations in extension rate on the Lone Mountain fault and strain distribution in the eastern California shear zone-Walker Lane: Geosphere, v. 6, no. 6, p. 917936.

Holm, D. K., Fleck, R. J., and Lux, D. R., 1994, The Death Valley turtlebacks reinterpreted as MiocenePliocene folds of a major detachment surface: The Journal of Geology, p. 718-727.

Holm, R. J., Rosenbaum, G., and Richards, S. W., 2016, Post 8Ma reconstruction of Papua New Guinea and Solomon Islands: Microplate tectonics in a convergent plate boundary setting: Earth-Science Reviews, v. 156, p. 66-81. 
Holm, R. J., Spandler, C., and Richards, S. W., 2013, Melanesian arc far-field response to collision of the Ontong Java Plateau: geochronology and petrogenesis of the Simuku Igneous Complex, New Britain, Papua New Guinea: Tectonophysics, v. 603, p. 189-212.

,- 2015 , Continental collision, orogenesis and arc magmatism of the Miocene Maramuni arc, Papua New Guinea: Gondwana Research, v. 28, no. 3, p. 1117-1136.

Hreinsdóttir, S., and Bennett, R. A., 2009, Active aseismic creep on the Alto Tiberina low-angle normal fault, Italy: Geology, v. 37, no. 8, p. 683-686.

Ikari, M. J., Saffer, D. M., and Marone, C., 2007, Effect of hydration state on the frictional properties of montmorillonite-based fault gouge: Journal of Geophysical Research: Solid Earth, v. 112, no. B6.

Jackson, J. A., and White, N. J., 1989, Normal faulting in the upper continental crust: observations from regions of active extension: Journal of Structural Geology, v. 11, no. 1/2, p. 15 - 36.

Janecke, S. U., Vandenburg, C. J., and Blankenau, J. J., 1998, Geometry, mechanisms and significance of extensional folds from examples in the Rocky Mountain Basin and Range province, USA: Journal of Structural Geology, v. 20, no. 7, p. 841-856.

Jeanne, P., Guglielmi, Y., and Cappa, F., 2012, Multiscale seismic signature of a small fault zone in a carbonate reservoir: Relationships between $v p$ imaging, fault zone architecture and cohesion: Tectonophysics, v. 554, p. 185-201.

Jin, G., Gaherty, J., Abers, G., Kim, Y., Eilon, Z., Buck, W., and Verave, R., Surface wave tomography of D'Entrecasteaux Islands, Papua New Guinea, implication of mantle control on localization of extension and exhumation, in Proceedings AGU Fall Meeting Abstracts2013, Volume 1, p. 2554.

Jin, G., Gaherty, J. B., Abers, G., Kim, Y., Eilon, Z., and Roger Buck, W., 2015, Crust and upper mantle structure associated with extension in the Woodlark Rift, Papua New Guinea from Rayleigh-wave tomography: Geochemistry, Geophysics, Geosystems, v. 16.

John, B. E., 1987, Geometry and evolution of a mid-crustal extensional fault system: Chemehuevi Mountains, southeastern California: Continental extensional tectonics: Geological Society [London] Special Publication, v. 28, p. 313-335.

Jolivet, L., Labrousse, L., Agard, P., Lacombe, O., Bailly, V., Lecomte, E., Mouthereau, F., and Mehl, C., 2010, Rifting and shallow-dipping detachments, clues from the Corinth Rift and the Aegean: Tectonophysics, v. 483, no. 3, p. 287-304.

Kapp, P., Taylor, M., Stockli, D., and Ding, L., 2008, Development of active low-angle normal fault systems during orogenic collapse: Insight from Tibet: Geology, v. 36, no. 1, p. 7-10.

Karaman, K., Cihangir, F., and Kesimal, A., 2013, Kaya Malzemesinin Kohezyon ve İçsel Sürtünme Açısının Dolaylı Yöntemlerle İrdelenmesi: Mehmet Akif Ersoy Üniversitesi Fen Bilimleri Enstitüsü Dergisi, v. 4, no. 2, p. 13-19.

King, P. R., New Zealand's changing configuration in the last 100 million years: plate tectonics, basin development, and depositional setting, in Proceedings New Zealand Petroleum Conference 2000.

Kirby, E., Johnson, C., Furlong, K., and Heimsath, A., 2007, Transient channel incision along Bolinas Ridge, California: Evidence for differential rock uplift adjacent to the San Andreas fault: Journal of Geophysical Research: Earth Surface, v. 112, no. F3.

Knesel, K. M., Cohen, B. E., Vasconcelos, P. M., and Thiede, D. S., 2008, Rapid change in drift of the Australian plate records collision with Ontong Java plateau: Nature, v. 454, no. 7205, p. 754-757.

Korschinek, G., Bergmaier, A., Faestermann, T., Gerstmann, U., Knie, K., Rugel, G., Wallner, A., Dillmann, I., Dollinger, G., and Von Gostomski, C. L., 2010, A new value for the half-life of 10 Be by heavy-ion elastic recoil detection and liquid scintillation counting: Nuclear Instruments and Methods in Physics Research Section B: Beam Interactions with Materials and Atoms, v. 268, no. 2, p. 187-191.

Korup, O., Clague, J. J., Hermanns, R. L., Hewitt, K., Strom, A. L., and Weidinger, J. T., 2007, Giant landslides, topography, and erosion: Earth and Planetary Science Letters, v. 261, no. 3, p. 578-589.

Lal, D., 1988, In situ-produced cosmogenic isotopes in terrestrial rocks: Annual Review of Earth and Planetary Sciences, v. 16, p. 355-388.

Lal, D., and Peters, B., 1967, Cosmic ray produced radioactivity on the earth, Kosmische Strahlung II/Cosmic Rays II, Springer, p. 551-612.

Lambotte, S., Lyon-Caen, H., Bernard, P., Deschamps, A., Patau, G., Nercessian, A., Pacchiani, F., Bourouis, S., Drilleau, M., and Adamova, P., 2014, Reassessment of the rifting process in the Western Corinth Rift from relocated seismicity: Geophysical Journal International, v. 197, no. 3, p. 1822-1844. 
Latter, J., 1964, Explanatory notes to accompany a geological sketch map of part of the western Daga Ranges, Papua: Bur. Miner. Resour Aust. Rec, v. 113.

Lavier, L. L., Buck, W. R., and Poliakov, A., 2000, Factors controlling normal fault offset in an ideal brittle layer: Journal of Geophysical Research, v. 105, p. 23431 - 23442.

Lavier, L. L., Buck, W. R., and Poliakov, A. N. B., 1999, Self-consistent rolling-hinge model for the evolution of large-offset low-angle normal faults: Geology, v. 27, no. 12, p. $1127-1130$.

Lecomte, E., Huet, B., Le Pourhiet, L., Labrousse, L., and Jolivet, L., Extension in the Aegean nappe-stacks: Numerical Model and their Geological Validation, in Proceedings AGU Fall Meeting Abstracts2010, Volume 1, p. 2299.

Lévy, F., and Jaupart, C., 2011, Folding in regions of extension: Geophysical Journal International, v. 185, no. 3, p. 1120-1134.

Lin, J., Purdy, G., Schouten, H., Sempere, J., and Zervas, C., 1990, Evidence from gravity data for focused magmatic accretion along the Mid-Atlantic Ridge: Nature, v. 344, no. 6267, p. 627-632.

Lindley, I. D., 2014, Suckling Dome and the Australian-Woodlark plate boundary in eastern Papua: the geology of the Keveri and Ada'u Valleys: Australian Journal of Earth Sciences, v. 61, no. 8, p. 11251147.

-, 2016, Epithermal and arc-related layered mafic platinum-group element mineralisation in the maficultramafic rocks of eastern Papua: Australian Journal of Earth Sciences, p. 1-19.

Lindley, I. D., Kirakar, J., and Moore, R., 2010, Annual report for the period ending 31 May 2010, EL 1424 Mt Suckling, Northern \& Central Provinces: Report for Papuan Precious Metals Ltd. Open file, Geological Survey of Papua New Guinea.

Lingenfelter, R., and Flamm, E., 1964, Solar Neutrons and the Earth's Radiation Belts: Science, v. 144, no. 3616, p. 292-294.

Lister, G. S., and Davis, G. A., 1989, The origin of metamorphic core complexes and detachment faults formed during Tertiary continental extension in the northern Colorado River region, USA: Journal of Structural Geology, v. 11, no. 1, p. 65-94.

Little, T., Hacker, B., Brownlee, S., and Seward, G., 2013, Microstructures and quartz lattice-preferred orientations in the eclogite-bearing migmatitic gneisses of the D'Entrecasteaux Islands, Papua New Guinea: Geochemistry, Geophysics, Geosystems, v. 14, no. 6, p. 2030-2062.

Little, T., Hacker, B., Gordon, S., Baldwin, S., Fitzgerald, P., Ellis, S., and Korchinski, M., 2011, Diapiric exhumation of Earth's youngest (UHP) eclogites in the gneiss domes of the D'Entrecasteaux Islands, Papua New Guinea: Tectonophysics, v. 510, no. 1, p. 39-68.

Little, T. A., Baldwin, S., Fitzgerald, P., and Monteleone, B., 2007, Continental rifting and metamorphic core complex formation ahead of the Woodlark spreading ridge, D'Entrecasteaux Islands, Papua New Guinea: Tectonics, v. 26, no. 1.

Little, T. A., Boulton, C., Webber, S., Mizra, M., Oesterle, J., Ellis, S., Norton, K., Wallace, L., Biemiller, J., Seward, D., and Boles, A., 2016, Overview of the Mechanics of the Active Mai'iu Low Angle Normal Fault (Dayman Dome), Southeastern Papua New Guinea, AGU 2016: San Francisco.

Little, T. A., Boulton C., Mizera M., Webber S., Oesterle J., Ellis S., Norton K., Wallace L., Biemiller J., and D., S., 2015, Preliminary Results ont he Mechanics of the Active Mai'iu Low Angle Normal Fault (Dayman Dome), Woodlark Rift, SE Papua New Guinea, AGU 2015: San Francisco.

Lock, J., Davies, H., Tiffin, D., Murakami, F., and Kisimoto, K., 1987, The Trobriand subduction system in the western Solomon Sea: Geo-marine letters, v. 7, no. 3, p. 129-134.

Lus, W. Y., McDougall, I., and Davies, H. L., 2004, Age of the metamorphic sole of the Papuan Ultramafic Belt ophiolite, Papua New Guinea: Tectonophysics, v. 392, no. 1, p. 85-101.

Macnab, R., 1967, Geology of the Keveri area, eastern Papua: Bureau of Mineral Resources, Geology \& Geophysics, Record, v. 98.

Maejima, T., Morioka, H., Mori, T., and Aoki, K., 2003, Evaluation of the loosened zone on excavation of the large underground rock cavern: Modern Tunnel Science and Technology. Rotterdam, AA Balkema, v. 10331038.

Malusà, M. G., Faccenna, C., Baldwin, S. L., Fitzgerald, P. G., Rossetti, F., Laura Balestrieri, M., Danišík, M., Ellero, A., Ottria, G., and Piromallo, C., 2015, Contrasting styles of (U) HP rock exhumation along the Cenozoic Adria-Europe plate boundary (Western Alps, Calabria, Corsica): Geochemistry, Geophysics, Geosystems. 
Mancktelow, N. S., and Pavlis, T. L., 1994, Fold-fault relationships in low-angle detachment systems: Tectonics, v. 13, no. 3, p. 668-685.

Mann, P., Horton, B., Taylor, F., Shen, C., Lin, K., and Renema, W., Uplift patterns of reef terraces and sedimentary rocks constrain tectonic models for metamorphic core complexes in eastern Papua New Guinea, in Proceedings AGU Fall Meeting Abstracts2009, Volume 1, p. 0642.

Mann, P., and Taira, A., 2004, Global tectonic significance of the Solomon Islands and Ontong Java Plateau convergent zone: Tectonophysics, v. 389, no. 3, p. 137-190.

Mann, P., and Taylor, F., Emergent late Quaternary coral reefs of eastern Papua New Guinea constrain the regional pattern of oceanic ridge propagation, in Proceedings AGU Fall Meeting Abstracts2002, Volume 1, p. 1206.

Martinez, F., Goodliffe, A. M., and Taylor, B., 2001, Metamorphic core complex formation by density inversion and lower-crust extrusion: Nature, v. 411, no. 6840, p. 930-934.

Masarik, J., and Reedy, R. C., 1995, Terrestrial cosmogenic-nuclide production systematics calculated from numerical simulations: Earth and Planetary Science Letters, v. 136, no. 3, p. 381-395.

Mattioni, L., Le Pourhiet, L., and Moretti, I., 2006, Rifting through a heterogeneous crust: insights from analogue models and application to the Gulf of Corinth: Geological Society, London, Special Publications, v. 253, p. 213-231.

McClay, K., 1989, Analogue models of inversion tectonics: Geological Society, London, Special Publications, v. 44 , no. 1 , p. 41-59.

McGarr, A., 1988, On the state of lithospheric stress in the absence of applied tectonic forces: Journal of Geophysical Research: Solid Earth, v. 93, no. B11, p. 13609-13617.

McNeill, L. C., Collier, R. E. L., and Stone, J., in prep, Slip rates of the Eastern Gulf of Corinth (Greece) Skinos and Pisia normal faults from $36 \mathrm{Cl}$ cosmogenic surface exposure dating: Implications for Fault Displacement and Rift Models.

Middleton, M., 1982, Tectonic history from vitrinite reflectance: Geophysical Journal International, v. 68, no. 1 , p. 121-132.

Middleton, R., Klein, J., Kutschera, W., Paul, M., and Margaritz, H., 1987, 26Al: Measurement and Applications [and Discussion]: Philosophical Transactions of the Royal Society of London A: Mathematical, Physical and Engineering Sciences, v. 323, no. 1569, p. 121-143.

Miller, S. R., Baldwin, S. L., and Fitzgerald, P. G., 2012, Transient fluvial incision and active surface uplift in the Woodlark Rift of eastern Papua New Guinea: Lithosphere, v. 4, no. 2, p. 131-149.

Mitchell, S. G., Matmon, A., Bierman, P. R., Enzel, Y., Caffee, M., and Rizzo, D., 2001, Displacement history of a limestone normal fault scarp, northern Israel, from cosmogenic $36 \mathrm{Cl}$ : Journal of Geophysical Research: Solid Earth (1978-2012), v. 106, no. B3, p. 4247-4264.

Monteleone, B., Baldwin, S., Webb, L., Fitzgerald, P., Grove, M., and Schmitt, A., 2007, Late MiocenePliocene eclogite facies metamorphism, D'Entrecasteaux Islands, SE Papua New Guinea: Journal of Metamorphic Geology, v. 25, no. 2, p. 245-265.

Monteleone, B. D., Baldwin, S. L., Ireland, T. R., and Fitzgerald, P. G., Thermochronologic constraints for the tectonic evolution of the Moresby seamount, Woodlark Basin, Papua New Guinea, in Proceedings Proc. ODP, Sci. Results2001, Volume 180, p. 35.

Morris, A., Gee, J., Pressling, N., John, B., MacLeod, C. J., Grimes, C., and Searle, R., 2009, Footwall rotation in an oceanic core complex quantified using reoriented Integrated Ocean Drilling Program core samples: Earth and Planetary Science Letters, v. 287, no. 1, p. 217-228.

Navarro, M., and Manapla, P., 2002, Fault Roughness and Fault Complexity: PhD Thesis, University of Bonn, $96 \mathrm{pp}$.

Neumann, T., Ostermaier, M., Kramar, U., and Simon, R., Formation of framboidal pyrite in estuarine sediments of the Achterwasser lagoon, SW Baltic Sea, and implications on trace metal mobility, in Proceedings Geophysical Research Abstracts2006, Volume 8, p. 230.

Newman, J., Edman, J., Howe, J., and LeFever, J., The Bakken at Parshall Field: inferences from new data regarding hydrocarbon generation and migration, in Proceedings Unconventional Resources Technology Conference2013, Society of Petroleum Engineers.

Niemeijer, A., and Spiers, C., 2005, Influence of phyllosilicates on fault strength in the brittle-ductile transition: Insights from rock analogue experiments: Geological Society, London, Special Publications, v. 245, no. 1, p. 303-327. 
Niemeijer, A. R., and Collettini, C., 2014, Frictional properties of a low-angle normal fault under in situ conditions: thermally-activated velocity weakening: Pure and Applied Geophysics, v. 171, no. 10, p. 2641-2664.

Norris, T., Gancarz, A., Rokop, D., and Thomas, K., Half-life of Al-26, in Proceedings Lunar and Planetary Science Conference Proceedings1983, Volume 14, p. B331-B333.

Norton, K. P., von Blanckenburg, F., Schlunegger, F., Schwab, M., and Kubik, P. W., 2008, Cosmogenic nuclide-based investigation of spatial erosion and hillslope channel coupling in the transient foreland of the Swiss Alps: Geomorphology, v. 95, no. 3, p. 474-486.

Numelin, T., Kirby, E., Walker, J. D., and Didericksen, B., 2007a, Late Pleistocene slip on a low-angle normal fault, Searles Valley, California: Geosphere, v. 3, no. 3, p. 163-176.

Numelin, T., Marone, C., and Kirby, E., 2007b, Frictional properties of natural fault gouge from a low-angle normal fault, Panamint Valley, California: Tectonics, v. 26, no. 2.

Nur, A., Ron, H., and Scotti, O., 1986, Fault mechanics and the kinematics of block rotations: Geology, v. 14, no. 9, p. 746-749.

Oldow, J. S., Elias, E. A., Ferranti, L., McClelland, W. C., and McIntosh, W. C., 2009, Late Miocene to Pliocene synextensional deposition in fault-bounded basins within the upper plate of the western Silver Peak-Lone Mountain extensional complex, west-central Nevada: Geological Society of America Special Papers, v. 447, p. 275-312.

Ollier, C., and Pain, C., 1980, Actively rising surficial gneiss domes in Papua New Guinea: Journal of the Geological Society of Australia, v. 27, no. 1-2, p. 33-44.

,- 1981 , Active gneiss domes in Papua New Guinea, new tectonic landforms: Zeitschrift für Geomorphologie, v. 25, no. 2, p. 133-145.

Osborn, T., and Jones, P., 2014, The CRUTEM4 land-surface air temperature data set: construction, previous versions and dissemination via Google Earth: Earth System Science Data, v. 6, no. 1, p. 61-68.

Ott, B., and Mann, P., 2015, Late Miocene to Recent formation of the Aure-Moresby fold-thrust belt and foreland basin as a consequence of Woodlark microplate rotation, Papua New Guinea: Geochemistry, Geophysics, Geosystems, v. 16, no. 6, p. 1988-2004.

Pain, C., and Bowler, J., 1973, Denudation following the November 1970 earthquake at Madang, Papua New Guinea: Zeitschrift für Geomorphologie (suppl.), v. 18, p. 92-104.

Palumbo, L., Benedetti, L., Bourlès, D., Cinque, A., and Finkel, R., 2004, Slip history of the Magnola fault (Apennines, Central Italy) from $36 \mathrm{Cl}$ surface exposure dating: evidence for strong earthquakes over the Holocene: Earth and Planetary Science Letters, v. 225, no. 1, p. 163-176.

Papp, S., Nason-Jones, J., 1928, Geology of Part of the Cape Vogel Peninsula, North-East Papua.

Perry, E. R., 2005, Field and Petrographic Analysis of Mylonitic Fabrics: Implications for Tectonic Corrugation Development, Tanque Verde Ridge, Arizona, USA [MS thesis]: Austin [M.S. Geo. Sci.: The University of Texas at Austin.

Petersen, K. D., and Buck, W. R., 2015, Eduction, extension, and exhumation of ultrahigh-pressure rocks in metamorphic core complexes due to subduction initiation: Geochemistry, Geophysics, Geosystems, v. 16, no. 8, p. $2564-2581$.

Pieters, P., 1978, Sheets SC/55-6,-7 and-11 Port Moresby, Kalo, Aroa,1:250,000 Geological Map and Explanatory Notes: Bur. Miner. Resour. Aust., Canberra.

Pigram, C., and Symonds, P., Eastern Papuan Basin-A new model for the tectonic development, and implications for petroleum prospectivity, in Proceedings Petroleum Exploration in Papua New Guinea, Proceedings of the Second Petroleum Convention1993, p. 213-231.

Prince, P. S., Spotila, J. A., and Henika, W. S., 2011, Stream capture as driver of transient landscape evolution in a tectonically quiescent setting: Geology, v. 39, no. 9, p. 823-826.

Proffett, J. M., 1977, Cenozoic geology of the Yerington district, Nevada, and implications for the nature and origin of Basin and Range faulting: Geol. Soc. Am. Bull., v. 88, p. $247-266$.

Ratschbacher, L., Merle, O., Davy, P., and Cobbold, P., 1991, Lateral Extrusion in the Eastern Alps,. 1. Boundary-Conditions and Experiments Scaled for Gravity: Tectonics, v. 10, no. 2, p. 245-256.

Reston, T., and Ranero, C. R., 2011, The 3-D geometry of detachment faulting at mid-ocean ridges: Geochemistry, Geophysics, Geosystems, v. 12, no. 7.

Rey, P., Teyssier, C., and Whitney, D., 2009, The role of partial melting and extensional strain rates in the development of metamorphic core complexes: Tectonophysics, v. 477, no. 3, p. 135-144. 
Reynolds, S., and Spencer, J., 1989, Pre-Tertiary rocks and structures in the upper plate of the Buckskin detachment fault, west-central Arizona: Geology and mineral resources of the Buckskin and Rawhide mountains, west-central Arizona: Arizona Geological Survey Bulletin, v. 198, p. 67-102.

Reynolds, S. J., and Lister, G. S., 1987, Structural aspects of fluid-rock interactions in detachment zones: Geology, v. 15, no. 4, p. 362-366.

Rigo, A., Lyon-Caen, H., Armijo, R., Deschamps, A., Hatzfeld, D., Makropoulos, K., Papadimitriou, P., and Kassaras, I., 1996, A microseismic study in the western part of the Gulf of Corinth (Greece): Implications for large-scale normal faulting mechanisms: Geophysical Journal International, v. 126, no. 3, p. 663-688.

Ring, U., and Reischmann, T., 2002, The weak and superfast Cretan detachment, Greece: exhumation at subduction rates in extruding wedges: Journal of the Geological Society, v. 159, no. 3, p. 225-228.

Rogerson, R., Williamson, A., and Francis, G., 1984, Recent advances in the knowledge of geology, energy resources and metallogenesis of Papua New Guinea since 1981, Geological Survey of Papua New Guinea.

Rossi, B. R., 1964, Cosmic Rays, New York, McGraw Hill Book Company.

Schaller, M., Von Blanckenburg, F., Veldkamp, A., Tebbens, L., Hovius, N., and Kubik, P., 2002, A 30000 yr record of erosion rates from cosmogenic $10 \mathrm{Be}$ in middle European river terraces: Earth and Planetary Science Letters, v. 204, no. 1, p. 307-320.

Schlagenhauf, A., Gaudemer, Y., Benedetti, L., Manighetti, I., Palumbo, L., Schimmelpfennig, I., Finkel, R., and Pou, K., 2010, Using in situ Chlorine-36 cosmonuclide to recover past earthquake histories on limestone normal fault scarps: a reappraisal of methodology and interpretations: Geophysical Journal International, v. 182, no. 1, p. 36-72.

Schlagenhauf, A., Manighetti, I., Benedetti, L., Gaudemer, Y., Finkel, R., Malavieille, J., and Pou, K., 2011, Earthquake supercycles in Central Italy, inferred from $36 \mathrm{Cl}$ exposure dating: Earth and Planetary Science Letters, v. 307, no. 3-4, p. 487-500.

Schlische, R. W., 1995, Geometry and origin of fault-related folds in extensional settings: AAPG bulletin, v. 79, no. 11 , p. 1661-1678.

Schoenbohm, L., Whipple, K., Burchfiel, B., and Chen, L., 2004, Geomorphic constraints on surface uplift, exhumation, and plateau growth in the Red River region, Yunnan Province, China: Geological Society of America Bulletin, v. 116, no. 7-8, p. 895-909.

SCHWEIG, E. S., 1989, Basin-range tectonics in the Darwin Plateau, southwestern Great Basin, California: Geological Society of America Bulletin, v. 101, no. 5, p. 652-662.

Seiler, C., Fletcher, J. M., Quigley, M. C., Gleadow, A. J., and Kohn, B. P., 2010, Neogene structural evolution of the Sierra San Felipe, Baja California: Evidence for proto-gulf transtension in the Gulf Extensional Province?: Tectonophysics, v. 488, no. 1, p. 87-109.

Shibaoka M., G. K. E., Bennett A.J.R., 1973, Hydrocarbon generation in sediments in Amoco Goodenough No. 1 and Nubiam No. 1 wells, Trobriand Basin, Papua New Guinea: CSIRO Division of Mineralogy (unpublished).

Sibson, R. H., 1985, A note on fault reactivation: Journal of Structural Geology, v. 7, no. 6, p. 751-754.

Sibson, R. H., 2001, Seismogenic Framework for Hydrothermal Transport and Ore Deposition: Reviews in Economic Geology, v. 14, p. 25-50.

Simonett, D. S., 1967, Landslide distribution and earthquakes in the Bewani and Torricelli Mountains, New Guinea: Landform studies from Australia and New Guinea, p. 64-84.

Singleton, J. S., 2011, Kinematic and geometric evolution of the Buckskin-Rawhide metamorphic core complex, west-central Arizona.

Singleton, J. S., 2013, Development of extension-parallel corrugations in the Buckskin-Rawhide metamorphic core complex, west-central Arizona: Geological Society of America Bulletin, v. 125, no. 3-4, p. 453-472.

Smith, I., 1970, Late Cainozoic uplift and geomorphology in southeastern Papua: Search, v. 1, no. 5, p. 222225.

-, 1973, The geology of the Calvados Chain, southeastern Papua: Bur. Miner. Resour. Aust. Bull, v. 139, p. 59-65.

Smith, I., and Milsom, J., 1984, Late Cenozoic volcanism and extension in eastern Papua: Geological Society, London, Special Publications, v. 16, no. 1, p. 163-171. 
Smith I.E., D. H. L., 1970, Abau, Papua New Guinea, Sheet SC 55-12, Geological Series: Bureau of Mineral Resources, Geology and Geophysics, Department of Minerals and Energy in co-operation with the Geological Survey of Papua New Guinea, scale 1:250,000.

Smith, I. E., and Davies, H. L., 1976, Geology of the southeast Papuan mainland, Australian Government Publishing Service for the Bureau of Mineral Resources, Geology and Geophysics, v. 165.

Smith, J. W., and Green, D. H., 1961, The geology of the Musa River area, Papua, Bureau of Mineral Resources, Geology and Geophysics.

Smith, S., and Faulkner, D., 2010, Laboratory measurements of the frictional properties of the Zuccale lowangle normal fault, Elba Island, Italy: Journal of Geophysical Research: Solid Earth, v. 115, no. B2.

Snyder, N. P., Whipple, K. X., Tucker, G., and Merritts, D., 2002, Interactions between onshore bedrockchannel incision and nearshore wave-base erosion forced by eustasy and tectonics: Basin Research, v. 14 , no. 2, p. 105-127.

Soto-Cordero, L., 1998, Crustal processes associated with two slow convergent systems: The Trobriand trough, Papua New Guinea and the northern Panama deformed belt.

Spencer, J. E., 1982, Origin of folds of Tertiary low-angle fault surfaces, southeastern California and western Arizona: Mesozoic-Cenozoic Tectonic Evolution of the Colorado River Region, California, Nevada and Arizona. Cordilleran Publishers, San Diego, CA, p. 123-134.

-, 1999, Geologic continuous casting below continental and deep-sea detachment faults and at the striated extrusion of Sacsayhuaman, Peru: Geology, v. 27, no. 4, p. 327-330.

,- 2000 , Possible origin and significance of extension-parallel drainages in Arizona's metamorphic core complexes: Geological Society of America Bulletin, v. 112, no. 5, p. 727-735.

Spencer, J. E., 2010, Structural analysis of three extensional detachment faults with data from the 2000 Space-Shuttle Radar Topography Mission: GSA Today, v. 20, no. 8, p. 4-10.

Spencer, J. E., 2011, Gently dipping normal faults identified with Space Shuttle radar topography data in central Sulawesi, Indonesia, and some implications for fault mechanics: Earth and Planetary Science Letters, v. 308, no. 3, p. 267-276.

Spencer, J. E., and Chase, C. G., 1989, Role of crustal flexure in initiation of low-angle normal faults and implications for structural evolution of the Basin and Range province: Journal of Geophysical Research: Solid Earth (1978-2012), v. 94, no. B2, p. 1765-1775.

Stanley, E. R., 1923, The geology of Papua, Government Printer, South Africa.

Stock, G. M., Anderson, R. S., and Finkel, R. C., 2005, Rates of erosion and topographic evolution of the Sierra Nevada, California, inferred from cosmogenic 26Al and 10Be concentrations: Earth Surface Processes and Landforms, v. 30, no. 8, p. 985-1006.

Stoen J .D., G. I. E., 1973, Nubiam No. 1 well completion report: Amoco Australia Exploration Company.

Stone, J. O., 2000, Air pressure and cosmogenic isotope production: Journal of Geophysical Research: Solid Earth, v. 105, no. B10, p. 23753-23759.

Styron, R. H., and Hetland, E. A., 2014, Estimated likelihood of observing a large earthquake on a continental low-angle normal fault and implications for low-angle normal fault activity: Geophysical Research Letters, v. 41, no. 7, p. 2342-2350.

Suggate, R., 2000, The Rank (Sr) scale: its basis and its applicability as a maturity index for all coals: New Zealand Journal of Geology and Geophysics, v. 43, no. 4, p. 521-553.

Swift, M., 2012, Torres Basin: A new Mesozoic petroleum system

in Papua New Guinea, Eastern Australian Basin Symposium IV: Brisbane, p. 1-14.

Swift, M., and Davies, H.L., 2015, History of contractional and extensional tectonics in southeastern Papua New Guinea, AAPG-ICE Conference: Melbourne.

Taylor, B., Goodliffe, A., Martinez, F., and Hey, R., 1995, Continental rifting and initial sea-floor spreading in the Woodlark Basin: Nature, v. 374, no. 6522, p. 534-537.

Taylor, B., and Huchon, P., Active continental extension in the western Woodlark Basin: a synthesis of Leg 180 results, in Proceedings Proceedings of the Ocean Drilling Program, Scientific Results2002, Volume 180, US Gov. Print. Off. Washington, DC, p. 1-36.

Taylor, B., Huchon, P., and Klaus, A., 1999, Background and Regional Setting for ODP Leg 180.

Tirel, C., Brun, J.-P., and Burov, E., 2008, Dynamics and structural development of metamorphic core complexes: Journal of Geophysical Research, v. 113, no. B4. 
Tirel, C., Gueydan, F., Tiberi, C., and Brun, J.-P., 2004, Aegean crustal thickness inferred from gravity inversion. Geodynamical implications: Earth and Planetary Science Letters, v. 228, no. 3, p. 267-280.

Tjhin, K., 1976, Trobriand Basin exploration, Papua New Guinea: Aust. Pet. Explor. Assoc. J, v. 16, p. 81-90.

Tomita, K., Yamane, H., and Kawano, M., 1993, Synthesis of smectite from volcanic glass at low temperature: Clays and Clay Minerals, v. 41, p. 655-655.

Tucholke, B. E., Behn, M. D., Buck, W. R., and Lin, J., 2008, Role of melt supply in oceanic detachment faulting and formation of megamullions: Geology, v. 36, no. 6, p. 455-458.

Tucholke, B. E., Lin, J., and Kleinrock, M. C., 1998, Megamullions and mullion structure defining oceanic metamorphic core complexes on the Mid-Atlantic Ridge: Journal of Geophysical Research: Solid Earth (1978-2012), v. 103, no. B5, p. 9857-9866.

Tucker, G., and Whipple, K., 2002, Topographic outcomes predicted by stream erosion models: Sensitivity analysis and intermodel comparison: Journal of Geophysical Research: Solid Earth, v. 107, no. B9.

van Ufford, A. Q., and Cloos, M., 2005, Cenozoic tectonics of New Guinea: AAPG bulletin, v. 89, no. 1, p. 119-140.

Von Blanckenburg, F., Belshaw, N. S., and O'Nions, R. K., 1996, Separation of 9 Be and cosmogenic 10 Be from environmental materials and SIMS isotope dilution analysis: Chemical Geology, v. 129, no. 1, p. 93-99.

Von Blanckenburg, F., Hewawasam, T., and Kubik, P. W., 2004, Cosmogenic nuclide evidence for low weathering and denudation in the wet, tropical highlands of Sri Lanka: Journal of Geophysical Research: Earth Surface, v. 109, no. F3.

Walker, D. A., and McDougall, I., 1982, 40Ar39Ar and K - Ar dating of altered glassy volcanic rocks: the Dabi Volcanics, PNG: Geochimica et Cosmochimica Acta, v. 46, no. 11, p. 2181-2190.

Wallace, L. M., Ellis, S., Little, T., Tregoning, P., Palmer, N., Rosa, R., Stanaway, R., Oa, J., Nidkombu, E., and Kwazi, J., 2014, Continental breakup and UHP rock exhumation in action: GPS results from the Woodlark Rift, Papua New Guinea: Geochemistry, Geophysics, Geosystems, v. 15, no. 11, p. 42674290.

Wallace, L. M., Stevens, C., Silver, E., McCaffrey, R., Loratung, W., Hasiata, S., Stanaway, R., Curley, R., Rosa, R., and Taugaloidi, J., 2004, GPS and seismological constraints on active tectonics and arc-continent collision in Papua New Guinea: Implications for mechanics of microplate rotations in a plate boundary zone: Journal of Geophysical Research: Solid Earth (1978-2012), v. 109, no. B5.

Webb, L. E., Baldwin, S. L., and Fitzgerald, P. G., 2014, The Early-Middle Miocene subduction complex of the Louisiade Archipelago, southern margin of the Woodlark Rift: Geochemistry, Geophysics, Geosystems, v. 15, no. 10, p. 4024-4046.

Webb, L. E., SI, B., Little, T. A., and Fitzgerald, P. G., 2008, Can microplate rotation drive subduction inversion: Geology, v. 36, no. 10, p. 823-826.

Webber S., Little T.A., Norton K., Mizera M., Österle J., and S., E., 2015, The Mai'iu Low-Angle Normal Fault, SE Papua New Guinea: Structure \& Rider Block Abandonment Chronology, AGU 2015: San Francisco.

Weissel, J. K., Taylor, B., and Karner, G. D., 1982, The opening of the Woodlark Basin, subduction of the Woodlark spreading system, and the evolution of northern Melanesia since mid-Pliocene time: Tectonophysics, v. 87, no. 1, p. 253-277.

Weissel, J. K., and Watts, A., 1979, Tectonic evolution of the Coral Sea basin: Journal of Geophysical Research: Solid Earth (1978-2012), v. 84, no. B9, p. 4572-4582.

Wernicke, B., 1981, Low-angle normal faults in the Basin and Range province: Nappe tectonics in an extending orogen: Nature, v. 291, no. 5817, p. 645-648.

-, 1990, The fluid crustal layer and its implications for continental dynamics, Exposed cross-sections of the continental crust, Springer, p. 509-544.

-, 1992, Cenozoic extensional tectonics of the US Cordillera: The Geology of North America, v. 3, p. 553-581.

-, 1995, Low-angle normal faults and seismicity: A review: Journal of Geophysical Research: Solid Earth, v. 100, no. B10, p. 20159-20174.

Wernicke, B., and Axen, G. J., 1988, On the role of isostasy in the evolution of normal fault systems: Geology, v. 16, p. 848 - 851.

Westaway, R., 2002, The Quaternary evolution of the Gulf of Corinth, central Greece: coupling between surface processes and flow in the lower continental crust: Tectonophysics, v. 348, no. 4, p. 269-318. 
-, 2005, Active low-angle normal faulting in the Woodlark extensional province, Papua New Guinea: A physical model: Tectonics, v. 24, no. 6 .

Whipple, K. X., 2004, Bedrock rivers and the geomorphology of active orogens: Annu. Rev. Earth Planet. Sci., v. 32, p. 151-185.

Whipple, K. X., Hancock, G. S., and Anderson, R. S., 2000, River incision into bedrock: Mechanics and relative efficacy of plucking, abrasion, and cavitation: Geological Society of America Bulletin, v. 112, no. 3, p. 490-503.

Whipple, K. X., and Tucker, G. E., 1999, Dynamics of the stream-power river incision model: Implications for height limits of mountain ranges, landscape response timescales, and research needs: Journal of Geophysical Research: Solid Earth, v. 104, no. B8, p. 17661-17674.

White, M., 1970, Plant fossils from the Cape Vogel Basin, eastern Papua: Bur. Miner. Resour. Aust. Rec. 1970/29 (unpubl).

Whitney, D. L., Teyssier, C., Rey, P., and Buck, W. R., 2013, Continental and oceanic core complexes: Geological Society of America Bulletin, v. 125, no. 3-4, p. 273-298.

Williams, D., 2011, Opening up a new Basin in PNG - PPL 326, PNG Gas Developments Conference 15 June 2011, Newport energy Ltd.

Williamson, A., Rogerson, R., and Haig, D. W., 1983, Geology and mineralisation of Misima Island, Geological Survey of Papua New Guinea.

Wiprut, D., and Zoback, M. D., 2002, Fault reactivation, leakage potential, and hydrocarbon column heights in the northern north sea: Norwegian Petroleum Society Special Publications, v. 11, no. C, p. 203219.

Woodward, R., and Osborne, G., 1980, Low-angle detachment faulting and multiple deformation of the central Buckskin Mountains: Yuma County, Arizona: Geological Society of America Abstracts with Programs, v. 12, no. 3, p. 160.

Xiao, H. B., Dahlen, F., and Suppe, J., 1991, Mechanics of extensional wedges: Journal of Geophysical Research: Solid Earth (1978-2012), v. 96, no. B6, p. 10301-10318.

Yasuhara, H., Marone, C., and Elsworth, D., 2005, Fault zone restrengthening and frictional healing: The role of pressure solution: Journal of Geophysical Research: Solid Earth, v. 110, no. B6.

Yin, A., 1991, Mechanisms for the Formation of Domal and Basinal Detachment Faults: A Three-Dimensional Analysis: Journal of Geophysical Research, v. 96, no. B9, p. 14,577-514,594.

Yin, a., and Dunn, J., 1992, Structural and stratigraphic development of the Whipple-Chemehuevi detachment fault system, southeastern California: Implications for the geometrical evolution of domal and basinal low-angle normal faults: Geological Society of America Bulletin, v. 104, no. 6, p. 659-674.

Zirakparvar, N., Baldwin, S., and Vervoort, J., 2013, The origin and geochemical evolution of the Woodlark Rift of Papua New Guinea: Gondwana Research, v. 23, no. 3, p. 931-943.

Zoback, M. L., 1989, State of stress and modern deformation of the northern Basin and Range province: Journal of Geophysical Research: Solid Earth, v. 94, no. B6, p. 7105-7128. 


\section{Appendices}

\subsection{Appendix A - Quartz Preparation and Separation of Cosmogenic Beryllium and Aluminium}

The original Cosmogenic Be separation scheme was developed by Von Blanckenburg et al. (1996) and Von Blanckenburg et al. (2004). Assistance was also provided by Mirjam Schaller, Veerle Vanacker, Hella Wittmann, Kevin Norton, and Jérôme Chmeleff. Suggestions were made by Darryl Granger. This methodology has since been modified by: Friedhelm Von Blanckenburg, University of Hannover, Jan 2008; Kevin P. Norton, University of Bern, May 2011; Richard S. Jones, Victoria University of Wellington, June 2012. The methodology is as follows:

\section{Initial Quartz Separation}

- Samples were crushed, wet sieved, and the 125-1000 $\mu \mathrm{m}$ fraction saved.

- A hand magnet was used to remove iron particle content. Frantz magnetic separation was employed to isolate the quartz (non-magnetic) fraction.

- Samples were then examined with an optical microscope - if a large amount of feldspar grains remained, Frantz magnetic separation was repeated, with the apparatus instead configured in order to separate diamagnetic minerals (quartz, feldspar). This process was repeated until samples were $>95 \%$ quartz.

- Samples were washed with deionised water, and reacted with $10 \% \mathrm{HCl}$ in an open container. They were then agitated at $60^{\circ} \mathrm{C}$ within $1 \mathrm{~L}$ bottles with $250 \mathrm{~mL} 10 \% \mathrm{HCl}$ for one day, and washed with deionised water.

\section{Quartz Cleaning and Etching With HF}

- Samples were agitated with $5 \% \mathrm{HF}$ at $60^{\circ} \mathrm{C}$, until only pure quartz remained. However if samples still had a large fraction of feldspar, $2.5 \%$ HF was used, and agitation repeated until only pure quartz remained.

- Samples were then dried and weighed.

\section{Final Quartz Leach}

- Samples were leached with $7 \mathrm{M} \mathrm{HF}$ for $\leq 1$ hour at $120^{\circ} \mathrm{C}$, and reacted with Aqua Regia for one hour at $120^{\circ} \mathrm{C}$.

- Samples were then washed with water 4-5 times. Samples were then precisely weighed. 


\section{Carrier Addition}

Applicable for both TCN exposure and TCN burial samples to be sent to Cologne:

- $0.4 \mathrm{mg}$ of $369 \mathrm{ppm}{ }^{9} \mathrm{Be}$ carrier solution was added, and the precise weight of carrier determined.

Only applicable for TCN burial samples to be sent to Cologne:

- $1.0 \mathrm{mg}$ of $\sim 1000 \mathrm{pm}{ }^{27} \mathrm{Al}$ carrier was added, and the precise weight of carrier determined.

\section{Sample Dissolution}

- Samples were dissolved in 28M HF.

\section{Sample conversion and Al-chemistry}

Only applicable for TCN burial samples:

- The total Aluminium in each sample was quantified as follows. Aqua Regia was added to samples, which were slowly heated to evaporation.

- $10 \mathrm{~mL} 6 \mathrm{M} \mathrm{HCl}$ was then added, and samples transferred into cleaned $15 \mathrm{~mL}$ centrifuge tubes and centrifuged for 5 minutes at $3000 \mathrm{rpm}$.

- Samples were accurately weighed.

- A $250 \mu \mathrm{l}$ aliquot was taken and, diluted down to $1 \mathrm{M} \mathrm{HNO}_{3}$, and the total Aluminium content measured using ICP-OES.

\section{BeF $_{2}$ Leaching}

Only applicable for TCN exposure samples. If sample dissolution was successful:

- Millipore $\mathrm{H}_{2} \mathrm{O}$ was added, and samples heated.

- $15 \mathrm{~mL}$ of supernate (containing water-soluble $\mathrm{BeF}_{2}, \mathrm{TiF}_{4}, \mathrm{Fe}(\mathrm{II}), \mathrm{F}_{2}$ but no $\mathrm{AlF}_{3}$ ) was pipetted off. This was repeated twice.

- Samples were then evaporated, $6 \mathrm{M} \mathrm{HCl}$ added, and centrifuged.

- Sample purity was confirmed using ICP-OES.

Only applicable for TCN exposure samples. If sample dissolution was unsuccessful:

- If samples formed persistent precipitates (likely due to excessive feldspar), they were then repeatedly reacted with Aqua Regia at $120^{\circ} \mathrm{C}$.

- If TCN exposure samples still failed to dissolve, then the Beryllium content leached using $\mathrm{H}_{2} \mathrm{O}$, and an aliquot taken to be tested using an ICP-OES in order to confirm the uptake of 
Beryllium (this would not be appropriate for TCN burial samples). Sample purity was confirmed using ICP-OES.

\section{Column Fe}

Use 2 mL Biorad AG1-X8 100-200 mesh (anion) resin in 15 mL Eichrom columns.

- Columns were initially conditioned using 6M HCl. Samples were passed through columns, and $6 \mathrm{M} \mathrm{HCl}$ added to elute $\mathrm{Be}$. Be was collected in clean containers, which were heated to evaporation.

- $\quad 0.4 \mathrm{M}$ oxalic acid was then added, and samples slowly heated and centrifuged.

\section{B - $5 \mathrm{~mL}$ Column Be (Dirty Samples: Al > 5mg)}

Use $5 \mathrm{~mL}$ Biorad AG50-X8 200-400 mesh (cation) resin in $15 \mathrm{~mL}$ Eichrom columns.

- Columns were conditioned using 0.4M oxalic acid. Samples were passed through columns, and $0.4 \mathrm{M}$ oxalic acid added to elute $\mathrm{Fe}, \mathrm{Al}$, and $\mathrm{Ti}$ - this fraction was collected in a clean container.

- $0.5 \mathrm{M} \mathrm{HNO}_{3}$ was then added to columns to elute $\mathrm{Na}$, which was collected in another clean container.

- $1 \mathrm{M} \mathrm{HNO}_{3}$ was then added to elute $\mathrm{Be}$, which was collected in another clean container.

- Samples were then heated to evaporation, and dissolved in $1 \mathrm{M} \mathrm{HNO}_{3}$.

\section{Column Al}

Suitable only for TCN burial samples. Use $1 \mathrm{~mL}$ Biorad AG1-X8 100-200 mesh (anion) resin in $7.5 \mathrm{~mL}$ columns:

- Columns were conditioned using 0.4M oxalic acid. The Fe, Al, Ti fraction was added to the columns, and $0.05 \mathrm{M}$ Oxalic acid/0.5M HCl added to elute $\mathrm{Al}$, which was collected in a clean container.

- $0.3 \mathrm{M} \mathrm{HCl}$ was then added to elute $\mathrm{Ti}$, which was collected in another clean container. Samples were then heated to evaporation.

- Aqua Regia was then added and evaporated. $1 \mathrm{~mL} 15 \mathrm{M} \mathrm{HNO}$ and $1 \mathrm{~mL} \mathrm{H}_{2} \mathrm{O}_{2}$ were then added, and evaporated. 


\section{Be precipitation}

- In order to confirm the successful elution of $\mathrm{Be}, \sim 1 \mathrm{ml}$ of concentrated $\mathrm{NH}_{4} \mathrm{OH}$ was added to each sample. Samples were shaken until a $\mathrm{BeOH}$ precipitate forms; this formed for $\mathrm{pH}$ of 8-9.

- Samples were centrifuged, and the supernate decanted. $3 \mathrm{ml}$ of $\mathrm{H}_{2} \mathrm{O}$ was added, and samples shaken in order to dissociate the precipitate.

- Step b was repeated, but samples were instead redissolved in $5 \mathrm{ml} 1 \mathrm{M} \mathrm{HNO}_{3}$, and $\sim 0.5$ $\mathrm{ml}$ concentrated $\mathrm{NH}_{4} \mathrm{OH}$ added.

- Step b was repeated.

- Samples were centrifuged, and the supernate decanted.

\section{Preparation of Be Samples}

Suitable for submitting to Cologne:

- Be fractions were evaporated, and $1 \mathrm{M} \mathrm{HNO}_{3}$ added. Samples were centrifuged, and transferred into $60 \mathrm{~mL}$ bottles.

\section{Al precipitation}

Suitable only for TCN burial samples.

- Samples were dissolved in $2 \mathrm{~mL} 5 \mathrm{M} \mathrm{HNO}_{3}$, and dried to evaporation.

- $2 \mathrm{~mL}$ Aqua Regia was added, and samples dried to evaporation; this step was then repeated.

- $1 \mathrm{~mL} 15 \mathrm{M} \mathrm{HNO}_{3}+1 \mathrm{~mL} \mathrm{H} \mathrm{O}_{2}$ was then added, and samples dried to evaporation; this step was then repeated four times.

- $5 \mathrm{~mL} 1 \mathrm{M} \mathrm{HNO}_{3}$ was then added, and samples transferred to $60 \mathrm{~mL}$ bottles. 


\subsection{Appendix B - Modelling of the Active Mai'iu Fault at Biniguni Falls}

\begin{tabular}{|c|c|c|}
\hline Symbol & Quantity & Units \\
\hline$\Delta \theta_{\max }$ & $\begin{array}{l}\text { Total change in modelled fault dip with depth. Ostensibly } 60^{\circ} \text {, but here over-ridden } \\
\text { such that dips }>31^{\circ} \text { equal } 31^{\circ} .\end{array}$ & degrees \\
\hline$\beta_{0}$ & Optimal normal fault orientation with respect to $\sigma_{1}$ direction. Equal to $\tan ^{-1}\left(1 / \mu_{\mathrm{f}}\right) / 2$. & degrees \\
\hline $\mathrm{z}_{\mathrm{b}}$ & Elevation at bottom of modelled fault. & $\mathrm{m}$ \\
\hline$z_{t}$ & Elevation at top of modelled fault. & $\mathrm{m}$ \\
\hline C & Integration constant (determined by setting z-intercept to equal $z_{b}$ ). & \\
\hline$\Delta \theta$ & Maximum allowable fault rotation before lock-up. & degrees \\
\hline$\phi_{\mathrm{i}}$ & Initial friction angle. & degrees \\
\hline$\phi_{\mathrm{f}}$ & Final friction angle. & degrees \\
\hline$\rho$ & $\begin{array}{l}\text { Effective density }\left(\rho_{\text {crust }}-\rho_{\text {water }}\right) \text {. This quantity serves as a parameterization of } P_{f} \text {, which } \\
\text { can be modified through varying } \rho_{\text {water }} . \rho_{\text {crust }}=2800 \mathrm{~km} / \mathrm{m}^{3} .\end{array}$ & $\mathrm{kg} / \mathrm{m}^{3}$ \\
\hline g & Acceleration due to gravity. & $\mathrm{m} / \mathrm{s}$ \\
\hline y & Depth. & $\mathrm{m}$ \\
\hline $\mathrm{C}_{\mathrm{i}}$ & Initial cohesion. & $\mathrm{MPa}$ \\
\hline$C_{f}$ & Final cohesion. & $\mathrm{MPa}$ \\
\hline $\mathrm{L}$ & Distance between centre of Mohr circle and x-intercept of final failure criterion. & $\mathrm{MPa}$ \\
\hline $\mathrm{R}$ & $\begin{array}{l}\text { Perpendicular distance from the centre of Mohr circle to initial failure } \\
\text { criterion. }\end{array}$ & $\mathrm{MPa}$ \\
\hline $\mathrm{R}^{\prime}$ & Perpendicular distance from the centre of Mohr circle to final failure criterion. & $\mathrm{MPa}$ \\
\hline
\end{tabular}

Table 11 - Table of quantities used within this appendix.

The following methodology is taken from Choi and Buck (2012). The geometry of the active Mai'iu Fault at Biniguni Falls is modelled after the method of Choi and Buck (2012). The LANF is assumed to have a constant curvature, and I model the fault using the following equation (see Table 11). In order to model the fault surface at depth I fit using the topography of Mt Dayman. Fault geometry is constrained at depth by on-fault microseismicity (>12 km depth) of Eilon et al. (2015), which Abers et al. (2016) claims defines the Mai'iu Fault. Therefore, in cross-section, the fault is assumed to form a planar surface below depths where fault dip $=31^{\circ}$. The following plot (Fig. 64) illustrates an example of a LANF of constant curvature (black), over-ridden at depth by an imposed fault dip of $31^{\circ}(\mathrm{red})$. This profile of constant curvature is calculated using Equation 6:

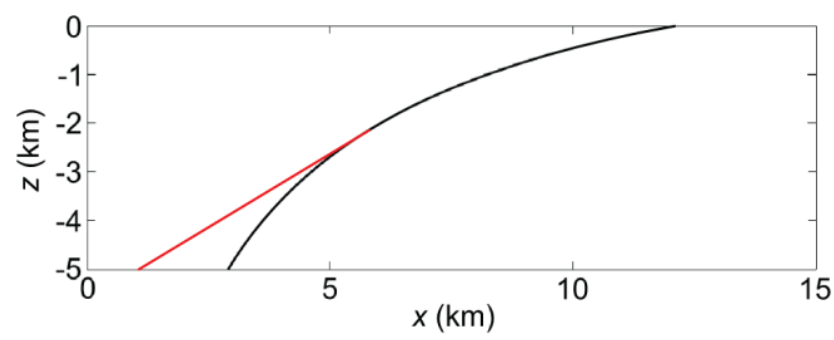

Fig. 64 - Illustration of modelled LANF geometry of constant curvature (black), and planar $31^{\circ}$ dipping LANF for dips $\geq 31^{\circ}$ (red). Choi and Buck (2012). 


$$
x=-\frac{z_{t}-z_{b}}{\Delta \theta_{\max }} \ln \left|\sin \left(\beta_{0}-\Delta \theta_{\max } \frac{z-z_{b}}{z_{t}-z_{b}}\right)\right|+C
$$

Equation 6 - Calculation of a LANF of constant curvature. From Choi and Buck (2012). For quantities see Table 11.

\subsection{Appendix C-Mohr-Coulomb Modelling}

The following methodology is modified after Choi and Buck (2012). I model the strength of the Mai'iu Fault through calculation of $\sigma_{\text {diff }}$ resolved on a modelled fault geometry.

It is instructive to consider $\Delta \theta$, the maximum fault rotation before abandonment, at each point on the fault ( $\Delta \theta$ is illustrated in terms of a Mohr Circle in Fig. 65). There is some maximum amount of rotation that any point on the fault can undergo before it locks up, and is abandoned in favour of a new, ideally oriented fault that cuts the surrounding crust. Because the Mai'iu Fault has reactivated the Owen Stanley Fault, which I presume had an initial fault dip of $31^{\circ}$, based on microseismicity of Eilon et al. (2015), I impose an additional 'synthetic rotation' to the fault. This simulates the fact that the stress field has changed since the Owen Stanley Fault was active. This rotation is equal to $28^{\circ}\left(59-31^{\circ}\right)$. The following Mohr circle illustrates the magnitude of $\Delta \theta$ for a fault - a fault of strength $\phi_{f}, C_{f}$ may be rotated by a maximum angle equal to $\Delta \theta$ before it is abandoned in favour of a new optimally oriented fault that cuts crust of strength $\phi_{i}, C_{i}$. $\Delta \theta$ may be calculated using Equation 7 (see Table 11):

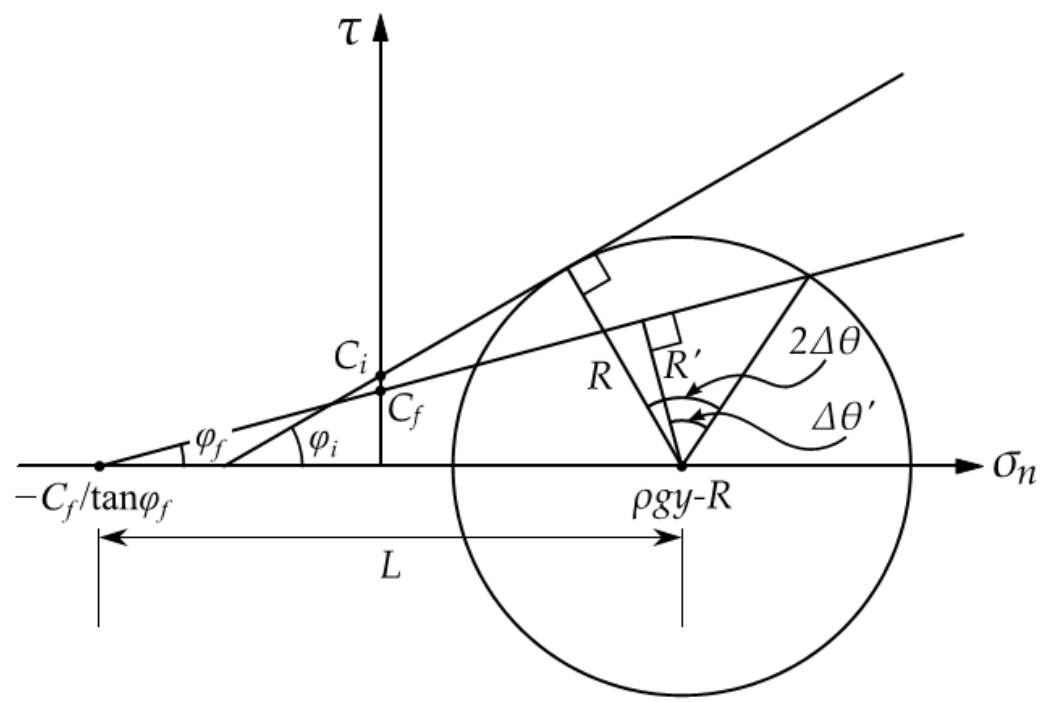

Fig. 65 - Mohr Circle diagram illustrating of the relationship between maximum LANF rotation and other quantities. Choi and Buck (2012). 


$$
\begin{gathered}
\Delta \theta\left(C_{i}, \phi_{i}, C_{f}, \phi_{f}, y\right)=0.5\left[\left(\phi_{i}-\phi_{f}\right)+\cos ^{-1}\left(\frac{\left((\rho g y-R)+\frac{C_{f}}{\tan \phi_{f}}\right) \sin \phi_{f}}{R}\right)\right] \\
R=0.5 \cdot \sigma_{\text {diff crust }}=\frac{\mu_{i} \rho g y+C_{i}}{\sqrt{1+\mu_{i}^{2}}+\mu_{i}}
\end{gathered}
$$

Equation 7 - Above: calculation of maximum LANF rotation prior to abandonment. Below: calculation of R. From Choi and Buck (2012). For quantities see Table 11.

I model fault abandonment in terms of $\sigma_{\text {diff. }} P_{f}$ is parameterised as the quantity $\rho$ (see Table 11$) . P_{f}$ is generally assumed to be hydrostatic. I assume zero topography above sea-level - therefore $\sigma_{\mathrm{V}}=$ pgy is slightly underestimated. The angle $\theta$ is calculated as follows: $\theta=90^{\circ}$ - (fault dip) (divergence of $\sigma_{1}$ from the vertical). I calculate $\sigma_{\text {diff crust }}$ using the following (Equation 8; see Table 11), where $\mu_{\mathrm{i}}=0.65$ :

$$
\sigma_{\text {diff crust }}=\frac{2 \mu_{\mathrm{i}} \rho g y+2 C_{i}}{\sqrt{1+\mu_{\mathrm{i}}^{2}}+\mu_{\mathrm{i}}}
$$

Equation 8 - Calculation of differential stress required to cut intact crust. From Choi and Buck (2012). For quantities see Table 11.

I calculate $\sigma_{\text {diff LANF }}$ using the following (Equation 9):

$$
\left|\sigma_{\text {dif LANF }}\right|=\frac{2 \mu_{f}(\rho g y)+2 C_{f}}{\sin 2 \theta+\mu_{r}(1+\cos 2 \theta)}
$$

Equation 9 - Calculation differential stress required to slip on the LANF. From Choi and Buck (2012). For quantities see Table 11.

The area between the $\sigma_{\text {diff crust }}$ and $\sigma_{\text {diff LANF }}$ curves is integrated with depth $-I$ define that $\sigma_{\text {diff LANF }}$ $\sigma_{\text {diff crust }}>0$. The cross-over depth $d_{c}$ is the deepest position where $\sigma_{\text {diff LANF }}=\sigma_{\text {diff crust. }}$ If $\int \sigma_{\text {diff }}$ is positive above $d_{c}$ then LANF partial abandonment occurs at depth $d_{c}$. If $\int \sigma_{\text {diff }}$ is negative above $d_{c}$ then the LANF is still viable at all depths, but footwall damage occurs above depth $d_{c}$ within the interval where $\sigma_{\text {diff LANF }}>\sigma_{\text {diff crust. }}$ 
9.4 Appendix D - Structural Data and Samples Used within this Thesis - See Attached CD-ROM 